\title{
Basis for Interim Operation for the K-Reactor in Cold Standby
}

by

B. Shedrow

Westinghouse Savannah River Company

Savannah River Site

Aiken, South Carolina 29808

\section{T:ECEIVED \\ NOV 051998 \\ OSTI}

DOE Contract No. DE-AC09-96SR18500

This paper was prepared in connection with work done under the above contract number with the U.S. Department of Energy. By acceptance of this paper, the publisher and/or recipient acknowledges the U. S. Government's right to retain a nonexclusive, royalty-free license in and to any copyright covering this paper, along with the right to reproduce and to authorize others to reproduce all or part of the copyrighted paper. 


\section{DISCLAIMER}

This report was prepared as an account of work sponsored by an agency of the United States Government. Neither the United States Government nor any agency thereof, nor any of their employees, makes any warranty, express or implied, or assumes any legal liability or responsibility for the accuracy, completeness, or usefulness of any information, apparatus, product, or process disclosed, or represents that its use would not infringe privately owned rights. Reference herein to any specific commercial product, process, or service by trade name, trademark, manufacturer, or otherwise does not necessarily constitute or imply its endorsement, recommendation, or favoring by the United States Government or any agency thereof. The views and opinions of authors expressed herein do not necessarily state or reflect those of the United States Government or any agency thereof.

This report has been reproduced directly from the best available copy.

Available to DOE and DOE contractors from the Office of Scientific and Technical Information, P. O. Box 62, Oak Ridge, TN 37831; prices available from (423) 576-8401.

Available to the public from the National Technical Information Service, U. S. Department of Commerce, 5285. Port Royal Road, Springfield, VA 22161. 


\section{DISCLAIMER}

Portions of this document may be illegible in electronic image products. Images are produced from the best available original document. 
Westinghouse

Sayamah River Company

MAR $0 \% 1995$

Mr, Leonard C. Sjostrom

Assistant Manager for Defense Programs

U.S. Department of Energy

P. O. Box A

Aiken, SC 29802

Dear Mr. Sjostrom:
I. B. Now, Jr.

Vico President and Manager

Reactors Division

KEYWORDS:

General Correspondence

K-Reactor

Safety Analysis Report

Basis For Interim Operation

RRD-950026

\section{BASIS FOR INTERMM OPERATION FOR THE K-REACTOR IN COLD STANDBY (U)}

Ref: 1) New to Sjostrom, "Basis for Interim Operation for the K-Reactor in Cold Standby," RRD-940106, dated August 30, 1994

2) New to Sjostrom, "K-Reactor Cold Standby Plan, Revision 2," RRD-940039, dated March 30, 1994

This letter transmits Revision 0 of the Basis For Interim Operation (BIO) For The K-Reactor in Cold Standby, WSRC-TR-94-207, for DOE approval. This revision was approved by WSRC and incorporates the resolution of all DOE comments on Draft C, submitted by Reference 1 .

The BIO examines the hazards associated with K-Reactor in the Cold Standby condition described in the K-Reactor Cold Standby Plan (reference 2). The BIO also examines the L-Reactor and P-Reactor Disassembly Basins to ensure that the storage and handling of irradiated components in those basins and hazardous materials in their Disassembly Areas are bounded by the analyses performed for the K-Reactor Disassembly Basin.

WSRC requests Department of Energy approval of the Basis For Interim Operation (BIO) For The K-Reactor in Cold Standby.

If you have any questions on this matter, please contact T. F. Lentz (557-9558) of my staff.

Sincerely,

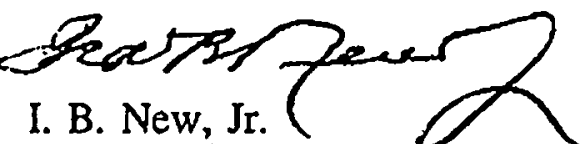

Vice President and Manager, Excess Facilities \& Reactor Fuel Storage Prógram
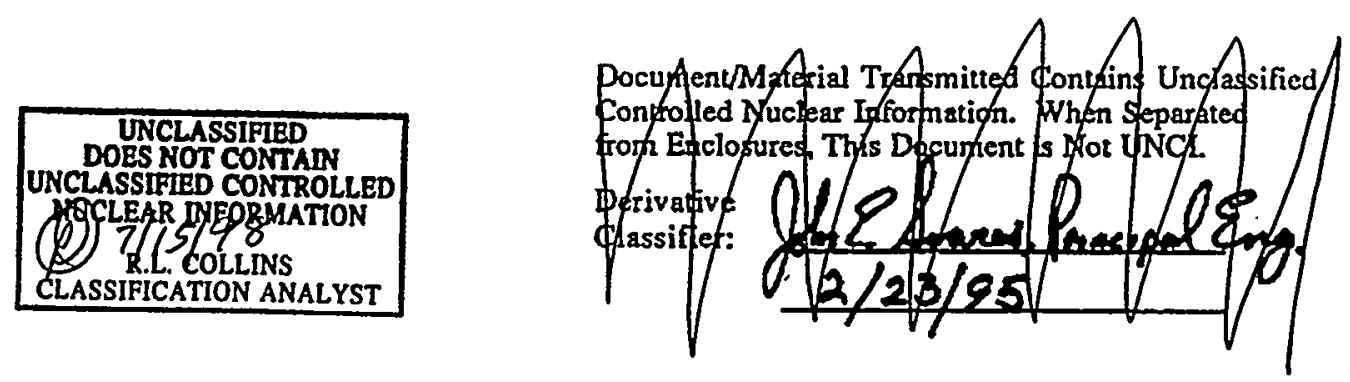
RRD-950026

Page 2 of 2

\section{MAR 071995}

Attachment: Basis For Interim Operation (BIO) For The K-Reactor in Cold Standby, WSRC-TR-94-207, Revision 0.

CC: S. L. Johnson, 703-F*

P. S. Shieh, 703-F

C. A. Everatt, 704-K

M. L. Cowen, 992-1W*

N. K. Savani, 992-1W*

T. C. Easterling, $992-1 W^{*}$

D. B. Rankin, 704-C*

J. N. Dewes, 707-C*

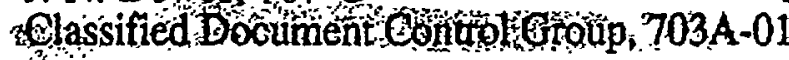

G. H. Clare, 704-C*

C. G. Reynolds, 704-K

T. P. Varallo, 707-C*

D. W. Freeman, 707-C*

J. R. Yanek, 704-C*

J. E. Soares, 707-C*

T. F. Lentz, 707-C*

S. Mobley, 704-C*

*w/o attachment 


\section{BASIS FOR INTERIM OPERATION (BIO) FOR \\ K-REACTOR IN COLD STANDBY(U)}

T. C. EASTERLING

C. E. MORGAN JR.

Patent Status

This internal management report is being transmitted without DOE patent clearance, and no further dissemination or publication shall be made of the report without prior approval of the DOE-SR patent counsel.

Westinghouse Savannah RIver Company Enginearing \& Construction Services Alken, SC 29808

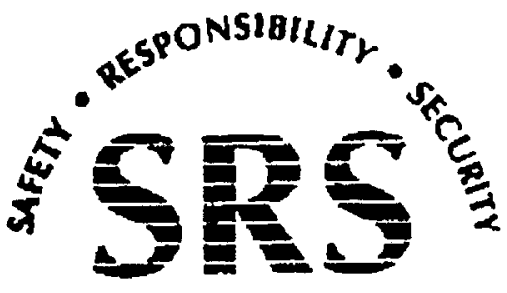
PREPARED FOR THE U.s. DEPARTMENT OF ENEROY UNDER CONTRACT NO. DE-ACOS-89SR18035 


\section{DISCLAIMER}

This report was prepared by the Westinghouse Savannah River Company (Westinghouse) for the United States Department of Energy under Contract DEAC09-89SR18035 and is an account of work performed under that contract. Neither the United States Government, nor Westinghouse, nor any of their employees, makes any warranty, expressed or implied, or assumes any legal liability or responsibility for the accuracy, completeness, or usefulness, of any information, apparatus, product, or process disclosed herein, or represents that its use will not infringe privately owned rights. Reference herein to any specific commercial product, process, or service by trade name, mark, manufacturer, or otherwise does not necessarily constitute or imply endorsement, recommendation, or favoring of same by Westinghouse or by the United States Government or any agency thereof. The views and opinions of authors expressed herein do not necessarily state or reflect those of the United States Government or any agency thereof. 


$\begin{array}{lll}\text { PROJECT: } & - & \text { N/A } \\ \text { DOCUMENT: } & -\quad & \text { WSRC-TR-94-207, Revision } 0 \\ \text { TITLE: } & & \text { BASIS FOR INTERIM OPERATION (BIO) FOR K-REACTOR } \\ & \text { IN COLD STANDBY(U) }\end{array}$

QA TASK NUMBER: SRT-STR-93-8007

REVISION NUMBER: $\quad 0$

APPROVALS:

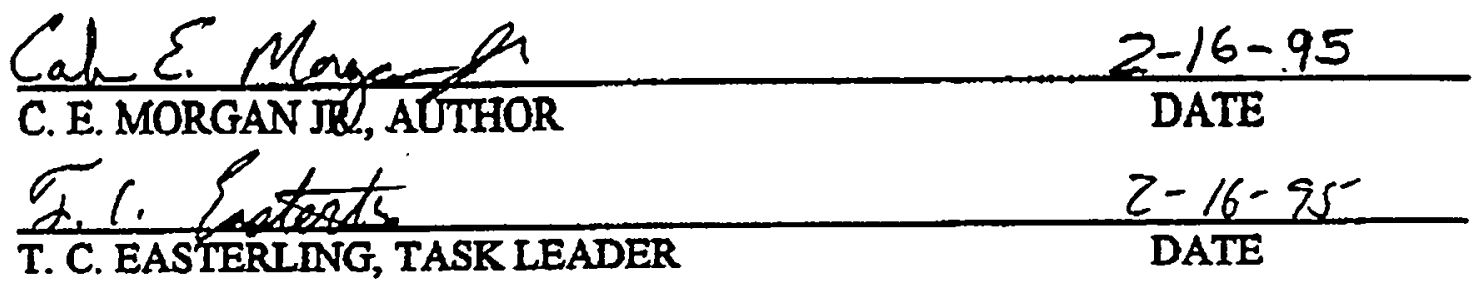


1.0 INTRODUCTION. $1.0-1$

1.1 REASON FOR THE BASIS FOR INTERIM OPERATION........................1.1-1

1.2 BACKGROUND OF K-REACTOR IN COLD STANDBY .........................1.2-1

1.2.1 Current Mission ........................................................................ 1.2-1

1.2.2 Past Relevant Operating Fistory ............................................... 1.2-2

1.3 STATUS OF EXISTING AUTHORIZATION BASIS ................................... 1.3-1

1.4 STATUS OF COMPLIANCE SCHEDULE APPROVALS.............................. 1.4-1

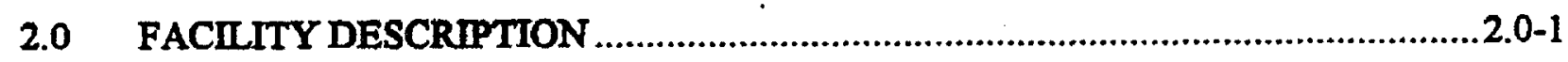

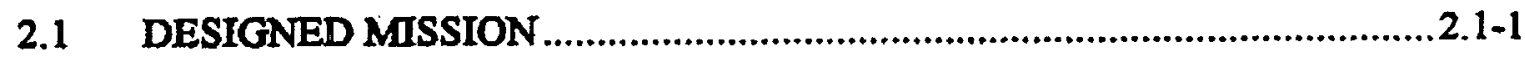

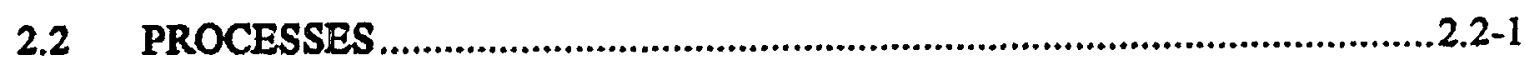

2.2.1 Disassembly Areas ...............................................................2.2-2

2.2.1.1 Disassembly Basins ..................................................2.2.4

2.2.1.2 Disassembly Basin Filtration System ..........................2.2-7

2.2.1.3 Disassembly Bu. Toli. Z System ...........................2.2-8

2.2.1.4 Disassembly Basin Deionizers ....................................2.2.8

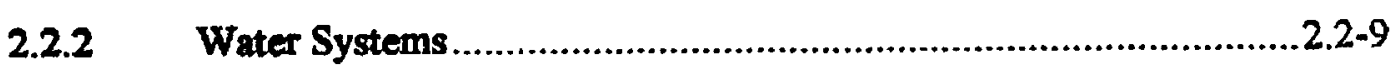

2.2.2.1 Cooling Water System (CWS) …...............................2.2.9

2.2.2.2 Water Removal System (WRS) ................................2.2.9

2.2.2.3 Filtered Water System .............................................2.2.9

2.2.2.4 Service Clarified Water..............................................2.2-9

2.2.2.5 Well Water System .................................................2.2-9 


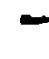

2.2.2.6 Service Raw Water System.

2.2.3 Instrument and Control and Electrical Systems

2.2.3.1 Emergency Lighting System. 2.2-10

2.2.3.2 Safety Alarm System Flashing Lights - Project S-4683 $2.2-10$

2.2.3.3 Miscellaneous Temperature Monitoring System (MTMS)..........................................................2.2-10

2.2.3.4 Remote Monitoring and Control System (REMACS) $2.2-10$

2.2.4 Environmenta/Habitability Monitoring $2.2-12$

2.2.4.1 Miscellaneous Monitors........................................2.2-12

2.2.4.2 Nuclear Incident Monitors (NIMs)..........................2.2.12

2.2.4.3 Kannes ....................................................................

2.2.4.4 Berthold Tritium Monitors (BTMs) .........................2.2-13

2.2.4.5 Groundwater Monitoring Wells ..............................2.2-14

2.2.5 Ventilation System .............................................................2.2-14

2.2.5.1 Airborne Activity Confinement System ....................2.2.14

2.2.5.2 Central Control Room Habitability.........................2.2-16

2.2.5.3 Assembly Area Ventilation System.........................2.2-16

2.2.5.4 Disassembly Area Ventilation System .....................2.2-16

2.2.5.5 Purification Ares Ventilation...................................2.2-16

2.2.5.6 Building 108-K Ventilation System........................2.2-16

2.2.5.7 Miscellaneous Ventilation System..........................2.2-17 


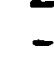

2.2.6 Moderator Processing Facilities 2.2-17

2.2.6.1 High Activity Moderator (HAM) ............................2.2-17

2.2.6.2 Dedeuterization ....................................................2.2.18

2.2.7 Moderator Storage Areas........................................................2.2-18

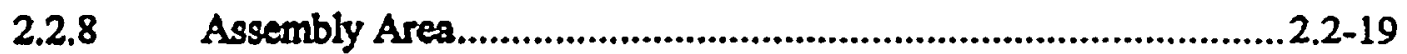

2.2.9 Charge and Discharge Machine/Discharged Assembly Cooling System.

2.2.10 Electrical System in K-Reactor................................................2.2-19

2.2.10.1 Permitted Diesels.....................................................2.2-19

2.2.10.2 Building 151-1K.................................................2.2-20

2.2.10.3 Building Power.....................................................2.2.20

2.2.11 Balance of Plant - K-Reactor ................................................2.2-21

2.2.11.1 Process Steam System ...........................................2.2.2-21

2.2.11.2 Public Address System...........................................2.2-21

2.2.11.3 Outer and Inner Shield Doors ..................................2.2-21

2.2.11.4 Compressed Air System.........................................2.2-21

2.2.11.5 Building Hoists ....................................................2.2-21

2.2.11.6 Structures and Building ...........................................2.2-21

2.2.12 K-Reactor Fire Protection .........................................................2.2-22

2.2.12.1 Fire Water Systems.................................................2.2-22

2.2.13 K-Reactor Emergency Lighting...............................................2.2-22

2.2.14 K-Reactor Emergency Equipment...............................................2.2-22 
2.2.15 Reactor Tank.

2.3 CREDITED STRUCTURES, SYSTEMS, AND COMPONENTS

2.3.1 Building 105-K, 105-L, 105-P Structures.

2.3.2 Disassembly Basin Walls and Floor . 2.3-1

2.3.3 Fuel and Target Assemblies. $.2 .3-1$

2.3.4 K-Reactor Radiation Monitors $.2 .3-1$

2.3.4.1 Kannes. 2.3-I

2.3.4.2 Berthold Tritium Monitors. . 2.3-1

2.3.4.3 VAMPS and GA-6s $.2 .3-2$

2.3.4.4 NIMs. 2.3-2

2.3.5 Disassembly Basin Level Instruments and Alarms. $.2 .3-2$

2.3.6 Instrument Air For Level Instruments.

2.3.7 Disassembly Basin Temperature Instruments and Alarms

2.3.8 Vertical Tube Storage Monorail and Anchor Supports

2.3.9 Basin.Water Makeup System

2.3.10 Disassembly Basin Deionizers $.2 .3-3$

2.3.11 Machine Basin Cutting Saw - Saw Stops........................................2.3-4

2.3.12 Horizontal Bundle and Bucket Storage Racks................................2.3-4

2.3.13 Motor-Operated Carriage on HBBS Monorail with TwinHook Hoist.

2.3.14 Shipping Casks with Blanks and Cadmium Separator Plates . 2.3-5

2.3.15 Fuel Blocking System $2.3-5$

iv 
3.1 SIGNIFICANT ABNORMAL OCCURRENCES AND/OR ACCIDENTS.

3.1.1 Dropped Fuel or Target Assembly 3.1-1

3.1.2 Violation of Handling, Storage, and Criticality Rules 3.1-1

3.1.3 Disassembly Error.

3.1.4 Liquid Radioactive Release to Disassembly Basin or Environment

3.1.5 Improper Shipment of Fuel and Target Material

3.1.6 Disassembly Basin Water Chemistry Out of Specification

3.1.7 Abnormal Disassembly Basin Water Level or Temperature.

3.1.8 Personnel Contamination

3.1.9 Fire $.3 .1-4$

3.1.10 Process Difficulties $.3 .1-4$

3.2 COMPENSATORY MEASURES PLAUVEO/R,LEMENTED

3.3 SAFETY-RELATED CHANGES SINCE LAST SAFETY DOCUMENTATION UPDATE

3.4 SIGNIFICANT SAFETY FINDINGS FROM MOST RECENT OPERATIONAL READINESS REVIEW AND/OR INSPECTION/AUDIT.

4.0 SAFETY DOCUMENTATION..

4.1 K-REACTOR SAFETY EVALUATION DOCUMENTS $4.1-1$ 
4.1.1 K-Reactor Safety Analysis Report

4.1.2 K-Reactor Cold Standby Plan

4.2 K-REACTOR TECHNICAL SPECIFICATIONS

4.3 K-REACTOR SAFETY SYSTEM CLASSIFICATION LIST 4.3-1

4.4 K-REACTOR FIRE HAZARDS ANALYSIS 4.4-1

4.5 K-REACTOR FIRE PROTECTION PROJECT COLD STANDBY STATUS.

4.6 K-REACTOR ASSEMBLY AREA BASIS FOR INTERIM OPERATION

4.7 K-REACTOR MODERATOR STORAGE AREAS BASIS FOR INTERIM OPERATION

4.8 L- AND P-REACTOR TECHNICAL SPECIFICATIONS

4.9 LREACTOR COLD SHUTDOWN PLAN

4.10 P-AREA STANDBY PLAN

4.11 TRANSFER DA GAGES FOR 100-L AND -P AREA FACILITIES

4.12 L AND P-REACTOR SAFETY SYSTEM CLASSIFICATION LIST

5.0 COMPLIANCE STATUS $5.0-1$

5.1 SAFETY-RELATED NONCOMPLIANCES $.5 .1-1$

5.2 COMPENSATORY MEASURES AND SCHEDULES TO COME INTO COMPLIANCE $5.2-1$

5.3 SAFETY IMPACT OF NONCOMPLIANCES AND DEFICIENCIES 5.3-1 
5.4 TIME SPAN OF BIO AS THE AUTHORIZATION BASIS

6.0 SAFETY MANAGEMENT

6.1 WASTE MANAGEMENT

6.2 CRITICALITY PROTECTION

6.2.1 K-, L-, and P-Reactor Disassembly Basins

6.2.2 K-Reactor Purification Area.

6.2.3 K-Reactor Assembly Area.

6.2.4 K-Reactor Moderator Storage Areas. $6.2-3$

6.2.5 K-Reactor Process Room

6.3 RADIATION PROTECTION

6.4 HAZARDOUS MATERIAL PROTECTION $6.4-1$

6.5 PROCEDURES AND TRAINING $.6 .5-1$

6.5.1 Site Procedures. $.6 .5-1$

6.5.1.1 Administrative Procedures. $6.5-1$

6.5.1.2 Operating Procedures

6.5.1.3 Maintenance Procedures. $6.5-2$

6.5.2 Training. $6.5-2$

6.5.2.1 Certified Personnel $.6 .5-3$

6.5.2.2 Qualified Personnel $6.5-3$

6.6 TESTING $6.6-1$ 
6.6.1 Unrreviewed Safety Question Process. $6.6-1$

6.7 SURVEILLANCE

6.8 MANTENANCE

6.9 CONDUCT OF OPERATIONS

6.10 QUALITY ASSURANCE

6.11 DECONTAMINATION AND DECOMMISSIONING

6.12 EXPERIMENTAL REVIEW.

6.13 EMERGENCY PREPAREDNESS

6.14 FIRE PROTECTION.

6.15 OCCUPATIONAL SAFETY AND HEALTH

$6.16 \mathrm{~K}-\mathrm{L}$ - AND P-REACTOR DISASSEMBLY BASIN SLUDGE REMOVAL PLANS

6.17 K-, L-, AND P-REACTOR DISASSEMBLY BASIN LEAK DETECTION

6.18 FUEL RETENTION TIME ANALYSIS, CHEMISTRY CONTROL; AND WATER QUALITY PLANS FOR K-, L-, AND P-REACTOR DISASSEMBLY BASINS

6.19 CONFIGURATION MANAGEMENT

7.0 SAFETY ENVELOPE.

7.1 EXISTING TECHNICAL SPECIFICATIONS $7.1-1$

7.2 ADDITIONAL ADMINISTRATIVE CONTROLS 
7.2.1 Disassembly Basin Water Chemistry Control Program.................... 7.2-1

7.2.2 Fire Loading ...............................................................................

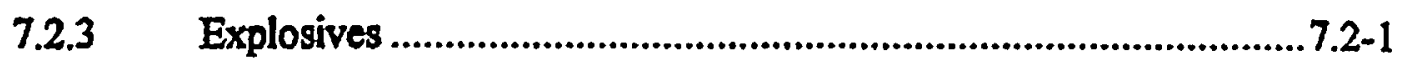

7.2.4 Hazardous Chemicals ..............................................................2.2-2

7.2.5 Disassembly Basin Inventory Limit................................................ 7.2.2

7.2.6 Machine Basin Cutting Saw Stop .............................................. 7.2-2

7.2.7 Criticality Bars........................................................................... 7.2.2

7.3 ADDITIONAL RESTRICTIONS ON OPERATION ....................................3-1

7.4 PROGRAMS FOR CONFORMANCE WITH APPLICABLE SAFETY STANDARDS .....................................................................................

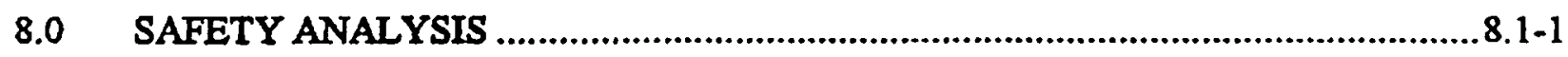

8.1 APPROACH FOR HAZARD IDENTIFICATION/CATEGORIZATION ......8.1-1

8.2 IDENTIFICATION OF CHEMICALS IN EXCESS OF OSHA THRESHOLD PLANNING QUANTITIES ....................................................8.2-1

8.3 DESCRIPTION OF PHA METHODS AND RESUL iS .............................. 8.3-1

8.3.1 Natural Phenomens...................................................................... 8.3-3

8.3.1.1 Winds........................................................................

8.3.1.2 Floods ......................................................................

8.3.1.3 Earthquake ...............................................................

8.3.1.4 Lightning...............................................................

8.3.1.5 Meteorites ................................................................13

8.3.1.6 Freezing Temperatures ............................................. 
- 8.3.1.7 Snow and Ice Induced Building Failure....................8.3-14

8.3.2 Process Phenomena ....................................................................14

8.3.2.1 Disassembly Basin Draindown ..............................8.3-15

8.3.2.2 Disassembly Basin Overfill........................................8.3-21

8.3.2.3 Inadvertent Criticality ..............................................8.3-36

8.3.2.4 Criticality in the Sludge Lining the Disassembly Basin Walls and Floors ..............................................8.3-37

8.3.2.5 Criticality in the Settler Tank ...................................8.3-38

8.3.2.6 Criticality in the Sand Filters.................................. 8.3-40

8.3.2.7 Criticality in the Deionizers....................................... 8.3-41

8.3.2.8 Loss of Disassembly Basin Cooling.........................8.3-42

8.3.2.9 Hazardous Chemical Spill ........................................8.3-43

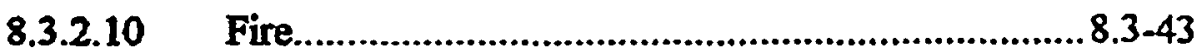

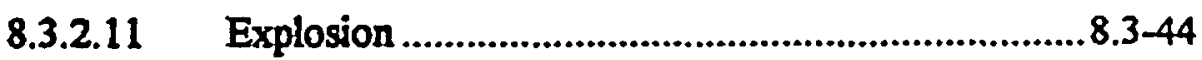

8.3.2.12 Aircraft Hazards ..................................................... 8.3-46

8.3.2.13 Loss of Power ........................................................ 8.3-47

8.3.2.14 Loss of Ventilation ................................................8.3-47

8.3.2.15 Internal Missiles..............................................................

8.3.2.16 Loss of Confinement................................................. 8.3-48

8.3.2.17 Loss of Heating ........................................................3-48

8.3.2.18 Toxic Gas Release .................................................8.3-49

8.3.2.19 Purification Events.................................................8.3-49 

8.3.2.20
Corrosion
8.3.2.21 Dropped Shipping Cask.
$8.3-53$

\subsection{IMPACT OF NORMAL OPERATIONS AND POSTULATED}

ACCIDENTS

8.4.1 Impact of Normal Operations on the Facility Workers, CoLocated Workers, Public, and Environment.

8.4.2 Impact of Postulated Accidents on the Co-Located Workers, Public, and Environment

\subsection{IDENTIFICATION OF POTENTIAL DESIGN, PROCEDURE, OR} EQUIPMENT VULNERABILITIES

\subsection{IDENTIFICATION OF CREDITED SYSTEMS AND OPERATOR} ACTIONS.

8.6.1 Buildings 105-K, 105-L, and 105-P Structures............................. 8.6-1

8.6.2 Aluminum Cladding of Fuel and Target Assemblies........................8.6-I

8.6.3 K-, L-, and P-Reactor Disassembly Basin Walls and Floors ...........8.6-2

8.6.4 Radiation Monitors ........................................................................6.6.

§.0.j K-, L, and P-Reactor Disassembly Basin Level Indication and Alarm Systems

8.6.6 Instrument Air System

8.6.7 Power System

8.6.8 K-, L-, and P-Reactor Filtered Water Makeụp Systems

8.6.9 K-, L-, and P-Reactor Disassembly Basin Overflow Weirs to Process Sewers.

8.6.10 K-, L-, and P-Reactor Disassembly Basin Cooling System Recirculation Pumps and Associated Piping and Valves. $8.6-4$ xi 
8.6.11 K-, Lr, and P-Reactor Disassembly Basin Filtration Systems ..........8.6-5

8.6.12 VTS Rows.and Anchor Supports, Hangers, Trolleys, and Disassembly Basin Monorail System

8.6.13 Cutting Saw and Saw Stop

8.6.14 Fuel Detection Gamms Monitors ...............................................8.6-6

8.6.15 MB Criticality Bars ......................................................................6.

8.6.16 HTS.Racks, Spacers, and Fuel Blocking System .......................... 8.6-6

8.6.17 Shipping Cask with Blanks and Cadmium Separator Plates..............8.6-7

8.6.18 Operator Actions ........................................................................8.6-7

8.7 Approach for Derivation of Estimates of System Unavailabilities and Operator Errors.

9.0 CONCLUSIONS $9.0-1$

9.1 SAFETY ANALYSES 9.1-1

9.2 SAFETY ASSURANCE PROGRAMS

9.3 STATUS OF ORDER COMPLIANCE $9.3-1$

9.4 IDENTIFICATION OF VULNERABILITIES 9.4-1

9.5 COMPENSATORY MEASURES $9.5-1$

9.6 OPERATIONAL HISTORY 9.6-1

9.7 RATIONALE BASIS FOR INTERIM SAFE OPERATION $9.7-1$ 
CONTENTS

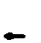

Page

10.0 REFERENCES, TABLES AND FIGURES $10.0-1$

10.1 REFERENCES. $10.1-2$

10.2 TABLES. $10.2-1$

10.3 FIGURES $10.3-1$ 


\section{LIST OF TABLES}

\section{-}

Table Title

Page

1 Categorization Of Natural Phenomena Events For K-Reactor In Cold Standby And L And P-Reactor Disassembly Basins

2 Categorization Of Process Phenomena Events For K-Reactor In Cold Standby And L- And P-Reactor Disassembly Basins.

2-1 Process Systems that will be Laid Up While K-Reactor is in Cold Standby $10.2-3$

5.1-1 DOE Orders and Open CSAs Relevant to K-Reactor in Cold Standby. $10.2-9$

5.1-2 DOE Orders, Open CSAs, and Exemption Requests Relevant to L- and PReactor Disassembly Basins $10.2-16$

8.3-1 Categorization Of Natural Phenomena Events For K-Reactor In Cold Standby And L - And P-Reactor Disassembly Basins.

8.3-2 Categorization Of Process Phenomena Events For K-Reactor In Cold Standby And L- And P-Reactor Disassembly Basins.

8.3-3 Individual Event Probabilities (Ref. 8-33) $.10 .2-24$

8.3-4 Fissile Material Inventories for K-, L-, and P-Reactor Disassembly Basins $10.2-25$

8.3-5 Fissile Isotopes Present in the Sludge of K-, L-, and P-Reactor Disassembly Basins 


\section{LIST OF FIGURES}

\begin{tabular}{|c|c|}
\hline Figure & Title \\
\hline & . \\
\hline 1 & Co-Located Worker Risk ...................................................................... 10.3-1 \\
\hline 2 & Offsite Public Risk \\
\hline $2-1$ & General Layout of Building 105-K........................................................ 10.3-2 \\
\hline $2-2$ & Major K-Area Layout in Relation to Disassembly Area................................10.3-3 \\
\hline $2-3$ & General Layout of Building 105-L \\
\hline $2-4$ & Major L-Area Layout in Relation to Disassembly Area ............................10.3-5 \\
\hline $2-5$ & General Layout of Building 105-P ....................................................... \\
\hline $2-6$ & Major P-Area Layout in Relation to Disassembly Area .............................10.3-7 \\
\hline $2-7$ & Disassembly Area - Building 105-K....................................................... 10.3-8 \\
\hline 2-8 & Disassembly Area - Building 105-L .......................................................... \\
\hline $2-9$ & Disassembly Area - Building 105-P....................................................... 10 \\
\hline $2-10$ & Flowchart of Irradiated Fuel Handling in Disassembly Basin ....................10.3-11 \\
\hline 8.4-1. & Co-Located Worker Risk ............... \\
\hline 8.4-2. & 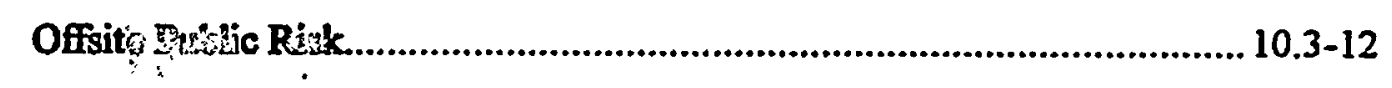 \\
\hline 8.4-3. & Co-Located Worker Risk with Consequence Definitions Displayed........... 10.3-13 \\
\hline 8.4-4. & Offsite Public Risk with Consequence Definitions Displayed.................... 10.3-13 \\
\hline
\end{tabular}




\section{LIST OF ACRONYMS}

\begin{tabular}{ll}
\hline AC & Air Conditioning \\
AACS & Airborne Activity Confinement System \\
AAV & Assembly Area Ventilation \\
ABS & Automatic Backup Shutdown System \\
ACC & Abnormal Condition Control \\
ALARA & As Low As Reasonably Achievable \\
Am-243 & Americium-243 \\
ANS & American Nuclear Society \\
ANSI & American National Standards Institute \\
API & Axial Power Indicator \\
APM & Axial Power Monitoring \\
B4C & Boron Carbide \\
BIO & Basis for Interim Operation \\
BTM & Berthold Tritium Monitor \\
C\&D & Charge and Discharge \\
CCR & Central Control Room \\
CCRH & Central Control Room Habitability \\
CCTS & Continuing Commitment Tracking System \\
CCTV & Closed Circuit Television \\
CI-252 & Californium-25? \\
CFR & Code of Federal Regulations \\
CH & Component Handling \\
CHR & Confinement Heat Removal \\
Ci & Curies \\
Cl & Chloride, Chlorine \\
Co-60 & Cobalt-60 \\
CP & Critical Protection \\
CRC & Criticality Review Committee \\
CRDS & Control Rod Drive System \\
& \\
\hline
\end{tabular}


LIST OF ACRONYMS (cont'd.)

\begin{tabular}{ll}
\hline CSA & Compliance Schedule Approval \\
CW & Cooling Water \\
CWS & Cooling Water System \\
D\&E & Deposit and Exit \\
EPP & Delta Pressure \\
DAC & Discharged Assembly Cooling \\
DAV & Disassembly Area Ventilation \\
DBE & Design Basis Event \\
DFWS & Domestic and Fire Water System \\
DI & Deionized \\
DMA & Diagnosis of Multiple Alarms \\
DNFSB & Defense Nuciear Facilities Safety Board \\
DOE & Department of Energy \\
DOE-HQ & Department of Energy - Headquarters \\
DOE-SR & Department of Energy - Savannah River \\
DWPE & Defense Waste Processing Facility \\
E\&I & Electrical and Instrument \\
EAL & Emergency Action Level \\
ECR & Electrical Control Room \\
ECW & Emergency Cooling Water \\
EDE & Effective Dose Equivalent \\
EDG & Emergency Diesel Generator \\
ECS & Emergency Cooling System \\
EEM & Essential Equipment Monitor \\
EFC & External Fission Counter \\
EKG & Electrocardiogram \\
EOF & Emergency Operations Facility \\
ES\&H & Environmental Safety and Health \\
ESH\&QA & Environmental, Safety, Health, and Quality Assurance \\
& \\
\hline
\end{tabular}




\begin{tabular}{|c|c|}
\hline FHA & Fire Hazards Analysis \\
\hline $\mathbf{g}$ & Acceleration of Gravity $\left(1 \mathrm{~g}=32.17 \mathrm{ft} / \mathrm{sec}^{2}\right)$. \\
\hline GM. & General Motors \\
\hline gpm & Gallons per Minute \\
\hline GS & General Services \\
\hline $\mathrm{H}_{2} \mathrm{O}$ & Light Water \\
\hline HAM & Figh Activity Moderator \\
\hline HAD & Hazards Assessment Document \\
\hline HBBS & Horizontàl Bundle and Bucket Storage \\
\hline HDM & Horizontal Disassembly Machine \\
\hline HLFM & High Level Flux Monitor \\
\hline HM & Health Monitors \\
\hline HTS & Horizontal Tube Storage \\
\hline HVAC & Heating, Ventilation, and Air Conditioning \\
\hline IC & Incident Control \\
\hline ICR & Instrument Control Room \\
\hline FFC & Internal Fission Counter \\
\hline KV & Kilovolt \\
\hline KW & Kilowatt \\
\hline LCO & Limiting Condition for Operativin \\
\hline Li-Al & Lithium-Aluminum \\
\hline LLW & Low Leved Waste \\
\hline LPMS & Loose Parts Monitoring System \\
\hline MB & Machine Basin \\
\hline MC\&A & Material Control and Accountability \\
\hline MCC & Motor Control Center \\
\hline MERITS & Methodically Engineered, Restructured and Improved Technical Specification \\
\hline MIA & Manual Incident Action \\
\hline MIP & (MC\&A) Implementation Plan \\
\hline
\end{tabular}


LIST OF ACRONYMS (cont'd.)

\begin{tabular}{ll}
\hline MRP & Management Requirement and Procedure \\
MSDS & Material Safety Data Sheets \\
MSI & Mean Sea Level \\
MTMS & Miscellaneous Temperature Monitoring System \\
MTS & Master Tracking System \\
NC & Not Credible \\
NFPA & National Fire Protection Association \\
NI & Negligible Impact \\
NIM & Nuclear Incident Monitor \\
NRC & Nuclear Regulatory Commission \\
NS & Nuclear Safety \\
OR & Occurrence Report \\
ORR & Operational Readiness Review \\
PA & Public Address \\
PAV & Purification Area Ventilation \\
PCM & Personnel Contamination Monitors \\
PDM & Power Density Monitor \\
PHA & Preliminary Hazards Analysis \\
PGA & Peak Ground Acceleration \\
PMF & Probable Mnxrimum Mtood \\
PMP & Probable Maximum Precipitation \\
PMT & Plant Modification Traveler \\
POS & Plant Operating Specification \\
ppb & Parts per Billion \\
ppm & Parts per Million \\
PS & Production Support \\
psf & Pounds per Square Foot \\
Pu-Be & Plutonium-Beryllium \\
PW & Process Water \\
\hline
\end{tabular}

rix 
LIST OF ACRONYMS (cont'd.)

\begin{tabular}{|c|c|}
\hline PWDG & Process Water Diesel Generator \\
\hline QAP & Quality Assurance Procedure \\
\hline $\mathbf{R A P}$ & Radiological Assistance Program \\
\hline $\mathrm{RC}$ & Recording Channel \\
\hline RC\&FIP & Radiological Control and Health Physics \\
\hline RBA & Radiological Buffer Area \\
\hline RCRA & Resource Conservation and Recovery Act \\
\hline $\mathbf{R D}$ & Reactor Division \\
\hline RDP & Reactor Division Procedure \\
\hline Re-DOC & Redocumentation \\
\hline REMACS & Remote Monitoring and Control System \\
\hline RER & Reactor Event Report \\
\hline $\mathbf{R I}$ & Reactor Incident \\
\hline $\mathbf{R Q}$ & Reportable Quantities \\
\hline $\mathbf{R R D}$ & Reactor Restart Division \\
\hline RTR & Roof Top Ratio \\
\hline $\mathbf{R W}$ & River Water \\
\hline SAR & Safety Analysis Report \\
\hline SCDHEC & South Carolina Department of Health and Environmental Control \\
\hline SEAT & Secretary of Energy Notice \\
\hline SIRM & Site Item Reportability and Issue Management \\
\hline SNM & Special Nuclear Material \\
\hline SRAC & Safety Related AC \\
\hline SROO & Savannah River Operations Office \\
\hline SRS & Savannah River Site \\
\hline SRW & Service Raw Water \\
\hline SSC & Structures, Systems, and Components \\
\hline SSS & Supplementary Safety System \\
\hline STCS & Short Term Compliance Statement \\
\hline
\end{tabular}


LIST OF ACRONYMS (cont'd.)

\begin{tabular}{ll}
\hline STD & Standard \\
SWP & Standing Work Permit \\
TEWM & Tritium Effluent Water Monitoring \\
Tm-170 & Thulium-170 \\
TQ & Threshold Quantity \\
TPQ & Threshold Planning Quantity \\
TR & Transformer Room \\
TS & Technical Specifications \\
TSC & Technical Support Center \\
TSR & Technical Safety Requirement \\
TWFM & Traveling Wire Flux Monitor \\
HCi/cC & Micro Curies per Cubic Centimeter \\
$\mu$ mho/cm & Unit of Conductivity-Micro mho per Centimeter \\
U & Unclassified \\
UPS & Uninterruptable Power Supply \\
USH & Universal Sleeve Housing \\
USQ & Unreviewed Safety Question \\
USQD & Unreviewed Safety Question Determination \\
V108 & Building 108 Ventilation \\
VAC & Volt Alternating Current \\
VAMS & Vibration and Acoustical Monitoring System \\
VDC & Volt Direct Current \\
VDM & Vertical Disassembly Machine \\
VEGP & Vogtle Electric Generating Plant \\
VTS & Vertical Tube Storage \\
WRS & Water Removal System \\
WSI & Wackenhut Services, Inc. \\
WSRC & Westinghouse Savannah River Company \\
wt \% & Weight Percent \\
& \\
\hline
\end{tabular}




\section{EXECUTIVE SUMMARY}

The Basis for Interim Operation (BIO) document for K-Reactor in Cold Standby and the L- and P-Reactor Disassembly Basins was prepared in accordance with the draft DOE standard for BIO preparation (dated October 26, 1993). The activities for the BIO preparation process included hazard identification, hazard categorization, and a preliminary hazards analysis. These activities, along with the review of the K-Reactor Safety Analysis Report (SAR), K-, L-, and P-Reactor Technical Specifications (TS), K-Reactor Cold Standby Plan, L-Reactor Cold Shutdown Plan, P. Reactor Standby Plan, and other safety documents, were used to compile the BIO.

$\mathrm{K}$-Reactor mission has changed from demonstrating and maintaining tritium production viability to placing K-Reactor in Cold Standby with no planned provision for restart. WSRC has prepared the Cold Standby Plan to achieve an orderly transition of K-Reactor to Cold Standby. Six major functions of the K-Reactor will be maintained operable during Cold Standby, and the equipment and components of K-Reactor necessary to support the six functions will be maintained operable. The six functions are to (1) provide property protection of government-owned equipment and facilities, (2) maintain facility habitability, (3) prevent the facility from becoming immediately unrecoverable, (4) store and process contaminated moderator, (5) handle and temporarily store irradiated fissile and hazardous material in the Disassembly Basin, and (6) store unirradiated reactor fuel in the K-Reactor Assembly Area. Additionally, equipment and systems of K-Reactor required to ensure environmental compliance will be maintained operable, as well as the equipment and systems required by the applicable K-Reactor Technical Specifications.

The remaining equipment will be deenergized, drained, laid up, and maintained in accordance with the K-Reactor Cold Standby Plan. Laid up equipment will not be removed unless the equipment removal is documented and readily replaceable. . Records during Cold Standby will be maintained in accordance with the requirements of the Cold Standby Plan.

K-Reactor in Cold Standby contains five main areas in which radionuclides are stored, processed, or maintained. These areas are the (1) Assembly Area, (2) Moderator Storage Areas, (3) Disassembly Basin, (4) Purification Ares, and (5) Process Room. The Assembly Area and Moderator Storage Areas have been examined in separate BIO documents, and the highlights from these documents are integrated into this BIO. The K-Reactor Disassembly Basin and Purification Area are examined in this BIO. Additionally, chemical hazards for K-Reactor in Cold Standby are examined in this BIO. The Process Room contains miscellaneous components (i.e., instrument rods, sparjets, and other stainless steel and aluminum reactor components) which have been irradiated in the Reactor Tank, as well as unirradiated boron carbide safety rods. However, these components pose no radioactive release potential.

This BIO also examines the $\mathrm{L}-$ and P-Reactor Disassembly Basins to ensure that the storage and handling of irradiated components in those basins and hazardous materials in their Disassembly Areas are bounded by the analyses performed for the K-Reactor Disassembly Basin. 
The relevant operating history of the Savannah River Site production reactors has been researched in this BfO to investigate problems that may arise with extended irradiated fuel storage in the Disassembly Basins and moderator processing in the K-Reactor Purification Area, and also to highlight compensatory measures implemented to avoid recurrence of these problems. The safety-related changes since the last safety documentation update and significant safety findings from the most recent DOE and WSRC audits and inspections have also been reviewed to provide additional insight. The increased time of storage of irradiated fuel assemblies in the Disassembly Basins is the major safety-related change in $\mathrm{K}-, \mathrm{L}$, and P-Resctors.

The existing safety documentation and authorization bases for $\mathrm{K}_{-}, \mathrm{L}$, and P-Reactors were examined to determine those that would serve as the authorization basis for K-Reactor in Cold Standby and the L- and P-Reactor Disassembly Basins. The bases documents identified for KReactor are its Safety Analysis Report, Cold Standby Plan, Technical Specifications, Safety System Classification List, Fire Hazards Analysis, Fire Protection Cold-Standby Status Report, BIO for the K-Reactor Assembly Area, and BIO for the K-Reactor Moderator Storage Areas. The bases documents identified for the L- and P-Reactor Disassembly Basins are the L- and PReactor Cold Shutdown Technical Specifications, L-Reactor Cold Shutdown Plan, P-Reactor Standby Plan, Transfer Packages for 100-L and -P Area Facilities, and the Safety System Classification List. By referencing these documents, the BIO now serves as the authorization basis for K-Reactor in Cold Standby and L- and P-Reactor Disassembly Basins. The order compliance status of K-Reactor in Cold Standby and L- and P-Reactor Disassembly Basins has been scrutinized, and the noncompliance issues have been examined for their safety impact. No noncompliance issue was identified that involved a significant increase in the probability or consequences of an accident or process hazard previously evaluated, nor created the possibility of a new or different kind of accident or process hazard not previously evaluated, nor involved a significant reduction in the margin of safety.

The programmatic approach for facility workers, co-located workers, and public safety has been described to demonstrate its thoroughness and adequacy in the following areas: Waste Management, Criticality Protection, Radiation Protection, Hazardous Material Protection, Procedures and Training, Testing sesrveilence, Maintenance, Conduct of Operations, Quality Assurance, Decontamination and Decommissioning, Experimental Review,. Emergency Preparedness, Fire Protection, Occupational Safety and Health, Disassembly Basin Sludge Removal Plans, Disassembly Basin Leak Detection, Fuel Retention Time Analysis, Chemistry Control, Water Quality and Configuration Management.

The operations of the R-Reactor Purification Area and the K-, L-, and P-Reactor Disassembly Basins have been examined in this BIO to ensure the adequacy of the safety envelope, and to develop and promulgate any new requirements ensuing from the Preliminary Hazards Analyses and the Hazards Assessment Documents. The existing K-, L-, and P-Reactor Technical Specifications were also reviewed. The review revealed the need for new administrative controls to preserve the safety analysis assumptions. 
The Safety Analysis Section is the accident and risk portion of the BIO document, and presents the impact of normal operations and postulated accidents upon the facility workers, co-located workers, and the public. Hazard assessments were performed for K-Reactor in Cold Standby and the L- and P-Reactor Disassembly Basins to determine the Facility Use Category resulting from an unmitigated accident. Based primarily on the uranium-235 and plutonium-239 inventory exceeding the theoretical limit for criticality, as well as the inventory of mixed fission products exceeding 1000 Curies, the K-, L, and P-Reactor Disassembly Basins are designated as a Hazard Category 2. The K-Reactor Assembly Area and Moderator Storage Areas have also been designated as Hazard Category 2 in separate hazard assessments for these areas.

A detailed chemical hazards screening has been performed for K-Reactor in Cold Standby and the $\mathrm{L}$ - and P-Reactor Disassembly Basins. There are no nonradioactive chemical hazards present in K-Reactor in Cold Standby or the L- and P-Reactor Disassembly Basins. Even though there is some nitric acid used, the quantities are low enough as to be screened from consideration. The trace amounts of elemental metals dissolved and suspended in the moderator (e.g., plutonium, cesium, strontium) stored in the K-Reactor Moderator Storage Areas do not represent chemical hazards in their elemental forms, nor is tritium or heavy water itself a chemical hazard. The only hazardous substance allowed in the K-Reactor Assembly Area is the asbestos contained in the Assembly Area walls, and the likelihood of the asbestos walls constituting a chemical hazard to the facility worker is judged not credible. The fuel assembly constituent metals (aluminum, uranium, and lithium) do not represent chemical hazards.

A comprehensive review of possible accidents associated with the K-Reactor Purification Area and K-, L-, and P-Reactor Disassembly Basins was performed in this BIO to identify postulated events. To determine the consequences of an accident, formal Preliminary Hazards Analyses were performed. Tables 1 and 2 identify the postulated natural and process events, their initiating event frequencies, resultant hazard event frequencies, the consequences, and the classification of the accident scenario based upon the dratt DOE standard DOE-STD-0019-93 (dated October 26, 1993). Figures 1 and 2 provide the composite curves of consequences and frequencies to the colocated worker and public from the four scenarios Design Basis Earthquake, (DBE), draindown, overfill, and inadvertent criticality) that were credible and that had associated adverse consequences. The results indicated that there were low consequences to the facility workers, colocated workers, public, and the environment from normal operation or postulated accidents of the K-Reactor Purification Area and the K-, L-, and P-Reactor Disassembly Basins. Based upon analyses, the scenario classes of the postulated accidents of K-Reactor in Cold Standby and Land P-Reactor Disassembly Basins were determined to be Class III (i.e., termed "marginal" by the BIO standard).

K-Reactor in Cold Standby will continue to store and handle unirradiated fuel and irradiated components and store and process contaminated moderator in the same manner as previously used except for the larger quantity of unirradiated fuel and contaminated moderator and in some cases contaminated moderator stored in new locations. The $\mathrm{L}-$ and P-Reactor Disassembly Basins 
will continue to store and handle irradiated components in the same manner as before. The current K-, L-, and P-Reactor Technical Specifications and the additional administrative controls provided in Section 7.2 serve as the safety requirement documents for K-Reactor in Cold Standby and the L- and P-Reactor Disassembly Basins. In addition, as shown in Section 8.0 of this BIO, the use of K-Reactor to safely store and handle unirradiated fuel and irradiated components and to store and process contaminated moderator and the use of $\mathrm{L}$ - and P-Reactor Disassembly Basins to safely store and handle irradiated components as has been done in the past present no new hazardous conditions or increased risk to the facility workers, co-located workers, public, or the environment. 


\subsection{INTRODUCTION}

At the Savannah River Site (SRS), K-Reactor is in Cold Standby in which a startup capability is maintained, but with no planned provision for restart. Cold Standby operations will be the continued storage and handling of unirradiated fuel and irradiated components and the storage and processing of contaminated moderator. Also, the L $\mathrm{L}$ and P-Reactor Disassembly Basins will continue to store and handle irradiated components.
\end{abstract}

The K-Reactor Assembly Area was designed to store unirradiated fuel tubes and assemblies, targets, and equipment to be charged into the Reactor Tank and continues to be used in that manner. The K-Reactor Moderator Storage Areas continue to store contaminated moderator in the moderator storage tanks and 55-gallon drums in a manner which is similar to previous moderator storage operations. The K-Reactor Purification Area will contimue to process contaminated moderator, as it was designed, until the existing inventory of contaminated moderator has been processed. The K-, L, and P-Reactor Disassembly Basins continue to store and handle irradiated components, as the basins were designed, though the components will be stored for a longer period of time than they have historically been stored in these basins. The KReactor Process Room will continue to store irradiated and unirradiated components (i.e., boron carbide safety rods, instrument rods, sparjets, and other stainless steel and aluminum reactor components) in the Reactor Tank. 


\subsection{REASON FOR THE BASIS FOR INTERIM OPERATION}

The purpose of this Basis for Interim Operation (BIO) is to establish an interim safety basis for KReactor in Cold Standby and to bound the operations of the L- and P-Reactor Disassembly Basins. This BIO demonstrates safety to facility workers through adherence to safety management programs. In addition to adherence to safety management programs, this BIO demonstrates safety to co-located workers and the public by identification of the safety envelope and presentation of the results of qualitative and semi-quantitative safety analyses (Ref 1-1). The BIO serves as the basis for the continued use of K-Reactor in Cold Standby for the purpose of the continued storage and handling of unirradiated fuel and irradiated components and the storage and processing of contaminated moderator and the continued use of $L$ - and P-Reactor Disassembly Basins for the purpose of irradiated component storage and handling. An approved BIO and the referenced documents in Section 4.0 are the upgraded authorization basis for KReactor in Cold Standby and the L- and P-Reactor Disassembly Basins and is considered as the baseline safety documentation against which Unreviewed Safety Question Determinations (USQDs) can be made in accordance with "Unreviewed Safety Question Screening and Evaluation Procedure," RDP 12.03 of WSRC Manual RD-1, Reactor Division Administrative Manual (Ref 1-2). 


\subsection{BACKGROUND OF K-REACTOR IN COLD STANDBY}

The SRS production reactors began operations in the earty 1950s. K-Reactor entered an outage in April 1988. K-Reactor was restarted in the spring of 1992 for Power Ascension Tests with plans for restarting the reactor for a full year of operation in the spring of 1993 after completion of the Cooling Tower modifications. The Department of Energy (DOE), however, re-directed Westinghouse Savannah River Company (WSRC) in an April 19, 1993, letter (Ref. 1-3) to place K-Reactor in Cold Standby with no planned provision for restart. In that same letter, DOE also directed WSRC to place L-Reactor in Cold Shutdown condition with no capability to restart. As part of the actions needed to comply with the direction provided by DOE, WSRC developed a plan to place K-Reactor into Cold Standby (Ref. 1-4). Also, from direction provided by DOE, WSRC developed the L-Area Cold Shutdown plan (Ref 1-5).

The designed mission of $\mathrm{K}$-Reactor was to receive, assemble, test, inspect, and store new fuel, unirradiated targets, and reactor components prior to their use in the resctor, provide support operations to the reactor, produce nuclear materials in the fuel assemblies by operating the reactor; and remove, store, and disassemble the fuel assemblies prior to shipment from K-Reactor to the Separations facilities. K-Reactor has five major areas: the Assembly Area, Moderator Storage Areas, Process Room, the Purification Area, and the Disassembly Basin Unirradiated fuel is stored in the Assembly Area. Reactor moderator is stored in the Moderator Storage Areas. The Process Room houses the Reactor Tank and irradiated and unirradiated materials that have not been discharged from the Reactor Tank. The Purification Area is used to purify the reactor moderator. The Disassembly Basin is used to store and handle irradiated components (i.e., fuel and target assemblies, control rods, source rods, reactor internals, etc.) after reactor operation and to prepare the irradiated components for shipment to the Separations facilities or the burial grounds.

\subsubsection{CURRENT MISSION}

The mission for K-Reactor chariged from demonstrating and maintaining tritium production capability to placing K-Reactor in Cold Standby with no planned provision for restart (Ref. 1.3 \&1-4). Though K-Reactor has been placed in Cold Standby, the Assembly Area will continue to store unirradiated fuel assemblies, the Disassembly Basin will continue to store and handle irradiated components prior to shipment to the Separations facilities or the burial grounds, the Moderator Storage Areas will contimue to store contaminated moderator, and the Purification Area will contime to treat contaminated moderator until the site inventory has been processed. Unirradiated fuel assemblies will continue to be handled, transported, and stored in the Assembly Area in the same manner and locations as before. However, a larger number of fuel assemblies and fuel tubes (total of three full Mark 22 charges plus spares) are now stored in the area. Irradiated components will continue to be handled and stored in the Disassembly.Basin in the same manner and locations as before, although for a longer period of time. The site inventory of contaminated moderator (except for moderator stored in the C-, L-, and P- Reactor storage tanks) will be consolidated in Phase $I$ of the moderator consolidation program in the K-Reactor 
Moderator Storage Areas. The contaminated moderator will continue to be stored in the storage tanks and stainless steel drums; however, in some cases the moderator will be stored in new locations. The contaminated moderator will continue to be processed in the same manner as before. The next phase of moderator consolidation will move the moderator presently stored in the $\mathrm{C}_{-}, \mathrm{L}_{-}$, and P-Reactor storage tanks to the K-Reactor Moderator Storage. Areas. Miscellaneous irradiated and unirradiated components (e.g., boron carbide safety rods, instrument rods, sparjets, and other stainless steel and aluminum reactor components) may continue to be stored in the Process Room (i.e., inside the Reactor Tank), though none of these reactor components are susceptible to the relesse of radioactive contamination.

To consolidate the unirradiated fuel, an additional six-stack rack and four-stack rack were moved from other similar SRS reactor buildings and placed in the K-Reactor Assembly Area near the existing racks. The additional racks expanded the storage capacity of unirradiated fuel tubes and assemblies from 810 to 1620 . To accommodate the additional contaminated moderator, the contaminated moderator will be stored in additional stainless steel drums in the Moderator Storage Areas of Building. 105- $\mathrm{K}$ and in the existing storage tanks as has been done in the past. To continue to store and handle the irradiated components, the Disassembly Basin will continue to be operated in the same manner as in the past. Also, to continue to handle and process contaminated moderator, the Purification Area will continue to be operated in the same manner as in the past. The operations of K-Reactor in Cold Standby and its structures, systems, and components are further discussed in Section 2.0 of this BIO.

The mission of the $\mathbf{L}$ - and P-Reactor Disassembly Basins will continue to be the storage and handling of irradiated components prior to shipment to the Separations facilities or to the burial grounds.

\subsubsection{PAST RELEVANT OPERATING HISTORY}

There have been 242 abnormal occurrences in the SRS production reactors which are relevant to K-Reactor in Cold Standby and the $L-$ and P-Reactor Disassembly Basins. Of the occurrences, nineteen events involved fuel or target assemblies being dropped to the basin fiour, tweiliy-one events involved the violation of assembly storage and handling or criticality rules; ten events involved operational disassembly errors, twenty-seven events involved releases of contaminated. Disassembly Basin water, twenty-six events involved improper shipment of fuel and target material, ten events involved $\mathrm{pH}$ above or below the operating limits, twenty-three events involved the Disassembly Basin level above or below the operating limits, seventeen events involved personnel contamination in the Disassembly Basin, two events involved fires, and eightyseven events involved miscellaneous process difficulties. The compensatory measures for these occurrences were to improve programs such as Conduct of Operations, to improve training, to improve attention to procedures, to correct procedures, and to repair defective equipment. Past relevant operating history is further discussed in Section 3.0 of this BIO. 


\subsection{STATUS OEEXISTING AUTHORIZATION BASIS}

The documents that constitute the authorization basis are those documents upon which DOE bases its conclusion that the activities of K-Reactor in Cold Standby and of the $\mathrm{L}$ and P-Reactor Disassembly Basins will be conducted safely and without undue risk to the facility workers, colocated workers, public, and environment.

The documents that serve as the current authorization basis for K-Reactor also serve in that capacity for the K-Reactor in Cold Standby. The documents that serve as the current authorization basis for the $L$ and P-Reactors also serve in that capacity for the $L$ - and P-Reactor Disassembly Basins. These documents are listed and discussed in Section 4.0 of this BIO and in the BIOs for the Assembly Area and Moderator Storage Areas (Ref. 1-6, 1-7). This BIO brings the authorization basis documents together by reference in one document.

\section{INFORMATION ONLY}




\subsection{STATUS OE COMPLANCE SCHEDULE APPROVALS}

Because the location and operations performed at K-Reactor in Cold Standby and L- and PReactor Disassembly Basins will remain the same as previously performed during routine reactor operations, the current site and reactor order compliance stattis is applicable to the continued use of K-Reactor to store and handle unirradiated fuel and irradiated components and to store and process contaminated moderator and the continued use of $L$ and P-Reactor Disassembly Basins to store and handle irradiated components.

The open compliance schedule approvals (CSAs) and DOE Order noncompliances for K-Reactor and $\mathrm{L}$ and P-Reactor Disassembly Basins involve 29 Orders. Of these, 17 were found to be relevant to K-Reactor in Cold Standby; most were programmatic in nature. There were 13 open CSAs and 4 exemption requests found to be relevant to the $L$ and P.Resctor Disassembly Basins. Additionally, there is presently one DOE Order which is under assessment to determine the status of compliance. Section 5.0 of this BIO further delineates the status of DOE Orders as applied to SRS and the status of compliance schedule approval and exemption requests associated with them. Section 5.0 also provides the compensatory measures and schedules associated with each noncompliance. 


\section{$-\quad 2.0$ FACHITY DESCRIPTION}

This BIO covers K-Reactor in Cold Standby, as defined in the Cold Standby Plan (Ref. 2-1), as well as the L- and P-Reactor Disassembly Basins. However, while the term "reactor" is used throughout this document for historical reasons, no fuel remains in the Reactor Tank. Therefore, K-Reactor is actually used for the storage of future and former reactor components. K-Reactor includes five major areas: the Process Room, Assembly Area, Moderator Storage Areas, Disassembly Area, and the Purification Area, as shown in Figures 2-1 and 2-2 (with exception to the moderator storage areas which can been seen in Reference 2-2 on figures 2-3 through 2-5). As noted above, this BIO also covers the L- and P-Reactor Disassembly Basins which are shown in Figures 2-3 through 2-6. Unless otherwise noted in this section, descriptions of the K-Reactor Disassembly Basin also apply to the L- and P-Reactor Disassembly Basins.

Radiological hazards of consequence have been identified in the following K-Reactor areas: Moderator Storage Areas, Assembly Area, Disassembly Area, and Purification Area. The hazards associated with the K-Reactor Moderator Storage Areas and Assembly Area have previously been evaluated in their BIOs (Ref. 2-2, 2-3). The following is a summary of the radiological hazards identified in the BIOs for the Moderator Storage Areas and Assembly Area:

- Moderator Storage Areas provide storage of up to approximately 230,500 gallons of contaminated moderator. The areas contain approximately 59,500 gallons of contaminated moderator in storage tanks and approximately 171,000 gallons of moderator stored in 55-gallon drums in the stack area, crane maintenance area, -40foot-elevation crossover area, -40 -foot-elevation access wells, and -40-foot-elevation motor rooms of Building 105-K.

- The unirradiated fuel storage areas in the Building 105-K Assembly Area have been expanded to accommodate up to 1620 unirradiated Mark 22 fuel tubes and assemblies (three Mark 22 reactor charges plus approximately 250 spare and replacement tubes and issemblies). To store the increased number of unirradiated assemblies, two sixstack racks and two four-stack racks have been provided in the Assembly Area.

During Cold Standby, the Disassembly Basin will provide long-term storage of fuel and target assemblies that have been irradiated in the reactors or placed in the basin for storage purposes. The Disassembly Basin allows fuel and target assemblies to be cooled and subsequently disassembled in a safe manner. Operations in this area are performed under water to shield operations personnel from the irradiated materials. The K- and L-Reactor Disassembly Basins each have a total volume of 3,400,000 gallons of water (Ref. 2-4 [Section 9.1.2], 2-5). The PReactor Disassembly Basin has a total volume of 4,800,000 gallons of water (Ref. 2-5). The basins are divided by walls into seven sections as follows (Figures 2-7, 2-8, and 2-9):

- Vertical tube storage (VTS) - including the Deposit and Exit (D\&E) canal

- $\quad$ Machine basin (MB)

- Emergency basin 
- Dry cave basin

- Inspection basin (monitor basin)

- Horizontal bundle and bucket storage (HBBS) basin

- $\quad$ Shipping transfer basin (pits)

The types of irradiated components in the Disassembly Basin include irradiated fuel assemblies, target assemblies, source rods, and control rods. These irradiated sources may cause both basin water and basin sludge contamination. Contamination in the basin can result from a number of sources. Diffusion of radionuclides through cladding imperfections, assembly corrosion, and component handling add contamination to the basin water and sludge (Ref. 2-4, Section 9.1.3). As determined by Section 8.0 of this BIO, the primary nuclides of concern with respect to basin contamination are tritium and cesium-137. It is estimated that there is up to $5.1 \times 10^{3} \mathrm{Ci}$ of tritium and $6.3 \mathrm{Ci}$ of cesium-137 in the K-Reactor Disassembly Basin water and up to $31.0 \mathrm{Ci}$ of tritium in the Disassembly Basin sludge (Ref. 2-6).

The K-Reactor Disassembly Basin currently stores 901 irradiated fuel assemblies (Ref. 2-7). Though a majority of the assemblies were irradiated in K-Reactor, some were irradiated in P-and L-Reactors and placed in the K-Reactor Disassembly Basin for storage. The basin contains 900 Mark 22 and 1 Mark $16 B$ assemblies. The K-Reactor Disassembly Basin also contains 549 irradiated targets, neutron sources, and other reactor components (Ref. 2-8).

The L-Reactor Disassembly Basin currently stores 516 Mark 16B irradiated fuel assemblies and 7320 irradiated targets, neutron sources, and other reactor components (Ref. 2-8).

The P-Reactor Disassembly Basin stores 456 irradiated fuel assemblies (53 Mark 16B, 396 Mark 22, and 2 Mark 42 fuel assemblies) and 542 irradiated targets, neutron sources, and other reactor components (Ref. 2-8).

Though K-Reactor is in Cold Standby and the L- and P-Reactor Disassembly Basins are in Cold Shutdown/Standby, chemicals will continue to be used in these areas $s_{\text {. }} \mathrm{Bv}$ comparison of the existing inventories of chemicals and the allowable quantities of chemicals against hazardous chemical screening criteria, the only hazardous chemicals of concem which were identified are nitric acid for the $\mathrm{K}_{-}, \mathrm{L}_{\text {, }}$, and P-Reactor Disassembly Areas and sodium hydroxide in solid form for the P-Reactor Disassembly Area.

The maximum quantities of nitric acid stored in the $\mathrm{K}_{-}, \mathrm{L}_{\text {, }}$ and $\mathrm{P}$-Reactor Disassembly Areas are 164, 100, and 70 pounds, respectively (Ref. 2-9). The maximum quantity of solid sodium hydroxide in the P-Reactor Disassembly Area is 22 pounds (Ref. 2-9). '

The contents of the Disassembly Basins for the K, L, \& P Reactors will continually be changed based on mission and needs of the Reactors Division and are assumed to be correct as of the dated reference from which the contents are taken. 


\subsection{DESIGNEAMASSION}

A K-Reactor Cold Standby Plan (Ref. 2-1) developed by Westinghouse Savannah River Company (WSRC) outlines plant configuration, organizational staffing, surveillances, environmental controls, emergency preparedness, radiological characterization, security, safety, and habitability activities required to achieve Cold Standby.

Similarly, the L-Reactor Cold Shutdown Plan (Ref. 2-10) and the P-Area Standby Plan (Ref. 211) developed by WSRC outline the corresponding activities required to achieve Cold Shutdown/Standby for those facilities. 


\subsection{PROCESSES}

The K-Reactor Cold Standby Plan (Ref. 2-1) delineates the plant configuration to support Cold Standby. To achieve Cold Standby, systems not required to support habitability or the extended storage of radionuclides will be placed in a lay-up condition. Since X-Reactor is in Cold Standby, no deliberate effort is planned to maintain plant equipment that would be required for a timely restart or to maintain reactor process water system chemistry. The equipment is expected to deteriorate from its current condition (Ref. 2-1). Equipment will not be removed or used as spare parts for other DOE complex needs until such time that DOE provides revised guidance. Records will be maintained in accordance with the requirements of the Cold Standby Plan (Ref. 2-1).

The L-Reactor Cold Shutdown Plan (Ref. 2-10) delineates the L-Reactor configuration to support Cold Shutdown. Because of the presence of fuel in the Disassembly Area, it is not possible to completely place the L-Reactor facilities in Cold Shutdown until fuel, moderator, and other materials can be removed to other facilities for further processing and/or interim storage. Water sources needed for safety showers, for the chilled water system for air conditioning, for Disassembly Basin activities, and for air compressor cooling are operated by the Power Department until no longer required. As long as moderator is present and personnel are required to be in L-Area it is necessary to operate some ventilation and radiation monitoring equipment for tritium control and environmental habitability. Environmental protection and public and employee safety are critical attributes of the implementation of Cold Shutdown (Ref. 2-10).

The P-Area Standby Plan (Ref 2-11) delineates the P-Reactor configuration to support Standby. P-Area lay-up began in 1991. Special equipment was installed in the Process Room to support dry discharge of the Reactor Tank. Unirradiated Mark 22 assemblies which were removed from the Reactor Tank were eventually moved to the K-Reactor Assembly Area. The Mark 60Bs, source rods, non-cadmium control rods, and spargers in the Reactor Tank were then discharged to the Disassembly Basin. Other reactor systems and equipment have been configured to allow for long-term safety and preservation. Some systems have been left in service to provide for the habitability of the buildaing or to support the Disassembly Basin (Ref. 2-11).

Table 2-1 provides a listing of the systems to be shut down and abandoned in place in K-Reactor. Water systems will be vented and drained. Piping systems will be blanked. Electrical equipment such as pumps and motors will be deenergized. Electrical instrument and control systems will be deenergized. Uninterruptable power supplies will be deenergized with batteries removed. Lube and fuel oil systems will be drained and removed in accordance with environmental restoration procedures. Most diesel cooling water systems will be drained and anti-corrosion additives added.

Potential hazards associated with K-Reactor will be reduced during Cold Standby. Removal of moderator from reactor systems will significantly reduce the risk of an accidental radionuclide release and reduce exposure to workers. During the initial phase of activities leading to Cold Standby, there was an increase in radiological and nonradiological waste streams due to defueling and equipment standby operations. However, during Cold Standby less waste will be generated 
due to reduced work activity and waste minimization practices. Fire hazards will be reduced due to systems being drained of flammable liquids, transient combustibles being removed, and the amount of work performed inside K-Reactor being reduced.

K-Reactor systems necessary to provide safe and environmentally sound long-term bulk storage of the remaining radionuclide inventory (in the form of moderator, unirradiated fuel assemblies, and irradiated materials) shall remain operational. Equipment and systems required to ensure environmental compliance will be maintained operable. Equipment and systems will be maintained operable as required by the applicable Technical Specifications and to support building habitability. The Reactor Department will continue to implement and maintain the conduct of operations program, staffing requirements, mission objectives, Technical Specifications, and safety requirements. The conduct of operations procedures have been modified to reflect the recent programmatic changes while maintaining the core emphasis of promoting and maintaining safe, efficient, and professional operations (Ref. 2-1).

The K-Reactor Cold Standby Plan provides for the continued upkeep of the equipment and components that will satisfy the following (Ref. 2-1):

- Provide property protection of government-owned equipment and facilities

- Provide an operable fire protection system

- Maintain a condition which does not render the K-Reactor in an immediately unrecoverable state

- Provide the capability to process moderator, as discussed in the Moderator Management Plan (Ref. 2-12), until no longer required to support operations

- Provide operation of the K-Reactor Disassembly Basin until the fissile and hazardous materials have been removed

- Support long-term storage of unirradiated reactor fuel

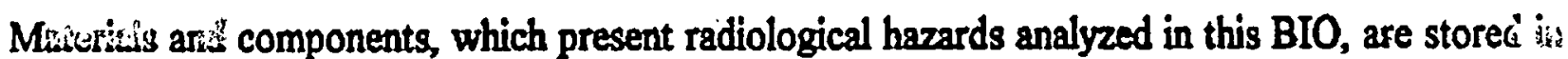
the K-, L-, and P-Reactor Disassembly Basins and the K-Reactor Purification Area. Therefore, a detailed discussion of the Disassembly Areas is provided in Section 2.2.1. Additional processes required to be operational are summarized in Sections 2.2.2 through 2.2.6.

\subsubsection{DISASSEMBLY AREAS}

The Disassembly Basins and their associated equipment will remain operational as long as radioactive material remains in the basins.

The following equipment will remain functional for the K-Reactor Disassembly Basin:

- Disassembly heat exchanger pump which provides a circulation path for basin water, however, no cooling water will be supplied to the heat exchangers 
- Disassembly deionizers, sand filters, settler tank, alum addition system and pumps - which provide a means of controlling basin water chemistry and clarity as well as preserving fuel integrity

- Filtered water system which provides a makeup water source for the basin. The basin makeup lines from both Cooling Water (CW-39) and River Water (RW-1) are blanked off

- Components handling equipment which provides for the movement, preparation, storage, and shipment of basin inventory

The Reactor Division Disassembly Basin Management Plan (Ref. 2-13) addresses the vulnerabilities associated with fivel and target material in the K-, L-, and P-Reactor Disassembly Basins. This plan provides for resolution of issues that were raised by Secretary OLeary's vulnerability assessment of DOE reactor irradiated material storage facilities (Ref 2-14). Immediate, intermediate, and long-term plans and assumptions are included (Ref. 2-13).

The basin management plan describes the activities being pursued by WSRC for the safe storage of fuel and target material in Disassembly Basins. Immediate actions were identified and completed upon detection of corrosive degradation of the inventory. No new immediate actions were determined to be required sibsequent to the assessment. Intermediate action plans include further criticality analyses, safety analyses upgrades, corrosion product containment, corrosion rate reduction, and basin water quality improvements. Phase-out processing is the long-term action plan for the majority of the fuel and target inventory and is consistent with current DOE guidance (Ref 2-15).

The cadmium rods in the basins will be cut up and shipped to a permitted mixed waste facility in accordance with the Cadmium Control and Safety Rod Disposal Plan (Ref. 2-16).

Basin water control and monitoring requirements have been revised to support the new mission (extended storage) of the Disassembly Basins. These new requirements are outlined in technical report Chemistry Control For The New Dikassembly Basin Mission (U) (Ref $=17$ ). The goal in Disassembly Basin management is to provide a better storage environment for fuel and target assemblies. As described in Reference 2-17, this will be accomplished by operating the deionizers as much as possible to reduce water conductivity, increasing surveillance, revising the chemistry limits and sampling frequencies, operating basin pumps to obtain maximum mixing, and improving control of water additions to the basin. Revised sampling limits and frequencies have been established and are listed in Reference 2-17. Chemistry sampling procedures DPSOL 105-6101A, "Sample Analysis Schedule and Control - Routine" (Ref. 2-18) and DPSOL 105-3729A, "Disassembly Basin Deionizer Sampling Requirements" (Ref. 2-19) and associated basin operation procedures (Ref. 2-20, 2-21, 2-22) have been updated to reflect the new sampling and operating requirements.

Basin level, temperature, and equipment status are monitored utilizing operator round sheets and alarms. Instrument air for the bubblers of the basin level instrumentation is supplied by the 
Building 108-K air compressors. Temperature indication is provided both at the local temperature indicator and via miscellaneous temperature monitoring system (MTMS).

\subsubsection{Disassembly Basins}

The K- and L-Reactor Disassembly Basins are large concrete basins containing 3,400,000 gallons of water each, varying in depth from 17 to 50 feet (Ref. 2-4 [Section 9.1.2], 2-23). The PReactor Disassembly Basin is similar to, but larger than the K- and L-Reactor Disassembly Basins, containing approximately $4,800,000$ gallons of water (Ref. 2-24). Concrete walls divide the basins into seven sections to permit isolating a portion of the basin in case maintenance requires draining surrounding water. The basin walls and floor are below ground level and constructed of steel-reinforced concrete. The concrete walls and floor range in thickness from 2.5 to 7 feet (Ref. 2-4. [Section 3.1.6], 2-23, 2-24). The Disassembly Basins were originally designed and constructed for a nominal $0.1 \mathrm{~g}$ earthquake statically applied to the dead and live loads. A recent scoping study structural assessment reveals the Disassembly Basin exterior walls and foundations may be capable of withstanding a $0.2 \mathrm{~g}$ earthquake however, there is no additional analysis to qualify the basin. (Ref. 2-25).

The Disassembly Basins consist of interconnected, water-filled (except dry cave) basins in which irradiated assemblies are stored, disassembled, prepared for shipping, and shipped for chemical processing or disposal. The Disassembly Basins are arranged into three major sections: the machine basin (MB), the vertical tube storage (VTS), and the transfer area as shown in Figures 27, 2-8, and 2-9. The MB is subdivided further into the machine area, dry cave, emergency disassembly, and the horizontal bundle and bucket storage (HBBS) area. The VTS includes the deposit and exit (D\&E) canal as well as the VTS area. The walls between the individual sections have narrow vertical openings that permit the transfer of material from one basin to another. Portable stop logs (stackable carbon steel sections with rubber edges) can be used to block these openings when necessary. Two pneumatically sealed isolation gates are also used to isolate the VTS basin from the MB (Ref. 2-4, Section 9.1.2). The Disassembly Areas also include equipment for cleaning and cooling the water and for handlin- the caske in which the irradiated material is shipped.

The primary source of makeup water to the Disassembly Basins is filtered water via the well water systems. The water level in the Disassembly Basins is measured as the number of inches below the 0-foot-elevation and is expressed as a negative number (e.g., -15 inches). The normal operating range for Disassembly Basin water level is -13.0 to -16.0 inches for $\mathrm{K}$ - and L-Reactors and -13.0 to -15.0 inches for P-Reactor. Disassembly Basin water level is maintained within this range by operations personnet. In addition, there are several alarms which actuate on the disassembly control panel in the Disassembly Areas and on the Nuclear Incident Monitor (NIM)/fuel failure panel in the Central Control Room (CCR) should the water level move outside of the operating range. A high level alarm, a low level alarm, and a very low level alarm are provided. The level indicating devices are bubblers, using instrument air to sense the water level.

Figure 2-10 presents a handling flow diagram of the Disassembly Basin under normal operations. 


\section{VERTCAC TUBESTORAGI}

When the assemblies are discharged from the Reactor Tank, they are moved to the D\&E canal in the Process Room, placed in the D\&E conveyor, and transferred to the Disassembly Basin side of the D\&E canal. The D\&E canal is a water-filled canal located under the shielding wall that separates the Disassembly Area from the Process Room. In the Disassembly Basin, the assemblies are transferred to hangers suspended from overtead monorails that are used to store and transport the irradiated assemblies throughout the Disassembly Area (Ref. 2-4, Section 9.1.2). The assemblies are initially stored in the VTS basin for a specified period of time to allow for decay of radioactive isotopes. This time varies with the types of material, since each material will decay at a different rate.

The VTS contains 48 rows, each about 25 feet long. Of these, Mark 22 assemblies can go on every row and other types of assemblies can go on every other row. Anchor supports secure each monorail to the overhead trusses. The fuel hangers are designed to hold two fuel assemblies or two target assemblies. For the storage of Mark 22 fuel, only one assembly is permitted by procedure per hanger and the remaining hanger position is mechanically blocked with a square piece of metal bolted to the hangers (Ref. 2-26).

In this configuration, the Mark 22 assemblies are maintained in a rectangular pitch of at least 12 inches between hangers and 18 inches between rows. The assemblies will be removed by trolley to the MB for disassembly in accordance with approved procedures.

\section{MACHINE BASIN (DISASSEMBLY OPERATIONS)}

Fuel and target assemblies are moved on hangers to the MB from the VTS using the overhead monorail system. The MB is where components are handled and prepared for shipping. Remotely operated machinery submerged in the basin is used to disassemble and handle the components. The machines used in the MB are as follows: foil, press, cutting saw and sheas machine; vertical disassisbly machine (VDM); horizontal disassembly machine (HDM); destacker; and assembly bundling table (Ref. 2-4, Section 9.1.2).

Fuel assemblies are individually transferred from the VTS to the MB where they are stored temporarily on a monorail to await disassembly. Administrative limits allow for a maximum of four fuel assemblies to be placed on this rail. An assembly is taken from the rail to the VDM where its inner target is removed. The inner target is stored on a hanger, and the resulting outer target and fuel sub-assembly are tranisferred to the cutting saw. At the cutting saw, two cuts are made to the sub-assembly to liberate the fuel from the outer target. The resulting two end-fittings are placed into scrap buckets for storage. The remaining sub-assembly is transferred to the HDM where the outer target and fuel are separated. The Mark 22, Mark 16B, and Mark 42 fuel that is extracted is transferred to the bundling station where it is placed with a maximum of three other fuel segments to make a bundle. Outer targets are stacked in groups of eight and processed into a target bundle. 
A foil, press, cutting saw, and shear machine is also used in the MB. This machine compresses and cuts scrap gennerated in the disassembly operations. Scrap that is generated during disassembly of Mark 22 assemblies is not processed through the foil, press, and shear machine. However, all the scrap that has accumulated from previous disassembly operations may eventually be processed through this machine.

\section{HORIZONTAL BUNDLE AND BUCKET STORAGE (BBBS)}

After the assemblies have been processed into bundles in the MB, they are transferred to the HBBS for storage prior to shipping. The slug/scrap buckets are also moved to the bucket storage area. A motor-operated carriage is used on an overhead monorail system to transport fuel into and out of the HBBS. This twin-hook hoist system contains an automatic load cut-off mechanism in case it accidentally lifts a section of the rack (Ref. 2-4, Section 9.1.2).

Tubular fuel is stored in horizontal storage racks after disassembly. These racks are designed to maintain the proper criticality spacing between bundles. They are connected at the tops in an inverted "V" arrangement to prevent fuel from being placed between the racks. The HBBS racks may have a series of grates over the slots in the racks to prevent a bundle from accidentally falling into the slot. With the grates (known as the fuet blocking system) in place, up to three bundles of Mark 22 and Mark 16B fuet can be stored in each slot. If the fuel blocking system is not used, no more than two fuel bundles can be stored in a fiel bundle slot of the rack.

Target slug and scrap buckets are not transported over the top of the horizontal storage racks at any time. Fissile stugs are stored in steel buckets. The buckets are stored on the basin floor separate from other materials. Irradiated material ready for shipping is transferred from the HBBS basin to the transfer bay.

\section{TRANSFER BAY}

The transfer bay is where the bundles, slug buckets, and scrap buckets are placed in shipping casks and loaded onto rail cars or trucks for delivery to the Separations Area or burial grounds. Two water-filled pits in the transfer bay are connected to the HIBBS basin by a canal. The shipping casks are lowered into or lifted out of the pits using an 85-ton overhead crane that can travel the length of the transfer bay. After the shipping casks are placed in one of the transfer pits, the irradiated material is placed in the casks using hoists mounted on the overhead monorail system. The loaded casks are then lifted out of the pits and placed onto trailers or rail cars for removal (Ref. 2-4, Section 9:1.2).

Only two Mark 22, Mark 16B, or Mark 42 fuel bundles are allowed in a shipping cask. There are five sections in a cask. Three positions are physically blocked with blanks (i.e., positions 2, 3, and 4) and two are open for fuel storage (i.e., positions 1 and 5). One fuel bundle is placed in each section (Ref. 2-26). Cadmium separator plates are installed in these cask sections to provide neutron absorption capabilities. They are also used to maintain the barriers between the cask 
sections. Once the plates and blanks are installed in the cask, they are blackness tested. The cadmium piates and blanks cannot be removed unless the cask is re-configured.

\subsubsection{Disassembly Basin Filtration System}

The Disassembly Basin filtration system maintains the Disassembly Basin water visual clarity within specifications for routine underwater work performed by component handling personnel. The system removes particulate and suspended solids in the basin water through use of sand filters.

The two sand filter feed pumps (803) in the K-Reactor Disassembly Basin will be operational in accordance with the Cold Standby Plan (Ref. 2-1). The pumps take suction from the VTS basin, via the D\&E canal, and from the MB. When the system is started, the sand filter feed pumps are primed using service clarified water which is water that is pumped from a well, degassified, and chemically treated to prevent algae growth and maintain $\mathrm{pH}$. The discharge line from the filter feed pump directs flow to the sand filters that are located outside of the Disassembly Area. The water flows through the filter media (anthracite and sand) where the particulate matter is removed. The filtered water flows out of the filtered water compartment and up into the elevated water storage tank which is the top part of the sand filter. The water in the storage tank rises until it reaches the overflow weir and flows into the overflow weir. The water then flows into the filter outlet piping to return to the Disassembly Basin.

Water in the sand filter sumps is transferred by gravity to the settler tank. If the water level in the settler tank gets too high, an overflow weir in the tank will allow the water to overflow to the Disassembly Basin through a 12-inch pipe. The settler tank aiso serves as a collection tank for water from various tanks, sumps, and rain water. The following lists the sources of water to the settler tank in K-Reactor:

- Gravity drain from the sand filter pumps

- Sand filter backwash draindown and waste outlet lines

- Sand filter nupture discs

- Leakage from sand fitter piping or components

- Pumped from Building 106-K (a retention basin that receives contaminated water from the Building 105- $\mathrm{K}$ heat exchanger bay sumps, motor room sumps, and pump room sumps)

- Pumped from the Building 109-K (a retention basin that receives water purged from the shield water system)

- Rain water 


\subsubsection{Disassembly Basin Cooling System}

The Disassembly Basin cooling system provides cooling of irradiated components. Discharged fuel and target assemblies generate fission product decay heat. These assemblies are stored in the VTS basin until they are moved to the MB in accordance with approved procedures.

Two basin water pumps supply Disassembly Basin water from the VTS basin to two pairs of heat exchangers (Ref. 2-1). The pumps are mounted above the VTS basin near the main entrance to the Disassembly Area. The discharge line of the basin water pump directs the basin water to the Disassembly Area roof where two heat exchangers are located. Water flows through an orifice flow meter and then splits into two headers where it is directed to the two heat exchangers. The water passes through the tubes of the heat exchangers. The outlet flow from each heat exchanger pair combines into a common header where it can be returned to the VTS basin or the D\&E canal. It should benoted however, that the heat exchangers cooling side has been drained.

\subsubsection{Disasgembly Basin Deionizers}

Radioactive particulate matter in the Disassembly Basin water can be removed by recirculating the water through the Disassembly Basin sand filters. To remove the radioactive ions, the basin water is circulated through deionizers in the Disassembly Basin deionizer system. For improved removal of cesium-137 from basin water, a zeolite deionizer is used in conjunction with other deionizers in the deionizer system.

There are eight portable deionizers available for use among K-, L-, and P-Reactor Disassembly Basins. The radioactive ions are removed by ion exchange with the resin in the deionizers. Some radionuclides cannot be removed by ion exchange. Tritium is one such muclide and can only be removed by purging water from the basin and adding fresh water. The Disassembly Basin deionizer system provides a flow path to purge water from the basin to the environment via the 50-million-gallon basin in each reactor area. The VTS is purged to reduce the tritium concentration of the total basin (VTS and MB) to below $0.40 \mu \mathrm{Ci} / \mathrm{ml}$ (Ref. 2-4).

The Disassembly Basin deionizer system is also used to help control the Disassembly Basin water $\mathrm{pH}$ through the use of mono bed (anion or cation), mixed bed (anion and cation), and zeolite deionizer (Ref 2-27). Basin pH range has been revised by Reference 2-17 to be maintained between 5.5 and 8.5. In the past, controlling $\mathrm{pH}$ was the major emphasis for preventing corrosion in the Disassembly Basins. Reference 2-17 has determined that strict pH control is of secondary importance to lowering conductivity and removing chloride ions. Therefore, the $\mathrm{pH}$ range has been expanded to 5.5 to 8.5 with action requirements added to the basin operation procedures to adjust $\mathrm{pH}$ if two consecutive samples are below 6.0 or above 8.0 (Ref. 2-17). Addition of nitric acid and sodium hydroxide can be used to bring the $\mathrm{pH}$ within limits. However, use of nitric acid and sodium hydroxide increases the conductivity of the basin water, therefore, $\mathrm{pH}$ is ordinarily controlled by use of deionizer beds. 
WSRC-TR-94-207-DV

REVISION 0

\subsubsection{WATER SYSTEMMS}

\subsubsection{Cooline Water System (CWS)}

The CWS has been placed in a standby configuration.

\subsubsection{Water Removal System (WRS)}

The WRS has been placed in a standby configuration except that the manually operated WRS 216 and 206.1 pumps continue to remove rainwater or other minor water sources from the Building 105-K sumps. In addition, the Building 108 sumps are operational. Associated alarms and level indicators provide indications of these water sources so that operations personnel can take appropriate action.

The level alarms associated with Buildings $106-\mathrm{K}$ and $109-\mathrm{K}$ provide indications of water leakage in the buildings.

The lined 50-million-gallon basin receives water removed from Building 105-K As required by the current procedures and South Carolina Department of Health and Environmental Control (SCDHEC) permits, the basin liner will be maintained, inspected, and repaired. Basin pumps remove the accumulated rainwater from the basin.

\subsubsection{Filtered Water System}

The filtered water system for K-Reactor provided makeup for the Disassembly Basin and for the Process Room spray system for emergency use during reactor charge and discharge operations. The Filtered Water System is being maintained however, the Process Room Spray System has been blanked off and is no longer in service

\subsubsection{Service Clarified Water}

The service clarified water will continue to provide cooling to the Building 108-1K and $108-2 \mathrm{~K}$ air compressors which are used by the breathing air and instrument air systems. The service clarified water system also provides water to the Disassembly Area and Purification Area equipment.

\subsubsection{Well Water System}

The well water system for K-Reactor provided water for the auxiliary services, mainly in Buildings $105-\mathrm{K}$ and $184-\mathrm{K}$, and replaced the original river water supply to the water treatment plant (Building 183-2K): The well water system continues to provide a source of water for service clarified water, filtered water, fire water, and domestic water. 


\subsubsection{Service Raw Water System}

The service raw wàter system serves as a backup water source to the high activity moderator condensers. The service raw water is tied to the river water and allows complete standby of Building 190-K.

\subsubsection{INSTRUMENT AND CONTROL AND ELECTRICAL SYSTEMS}

\subsubsection{Emergency Lighting System}

- The emergency lights provide lighting for building habitability, personnel evacuation, and for areas which require operator action during an emergency. The emergency lighting units are seismically qualified, self-contained lighting units.

\subsubsection{Safety Alarm System Flashing Lights - Proiect S-4683 (PA-System)}

Safety alarm system flashing lights provide warning to operations personnel for building habitability. The 903A, B, and C fan room portions of the system are not yet operational. Signs were posted at each entrance of the 903 fan rooms stating "WARNDNG - Safety Alarm System Flashing Lights are inoperable in Fan Room 903X. Minimize time in fan room when fan is running." This system upgrade was in response to life safety code/human factors upgrades. In the event of an emergency, the operations personnel inside the fan room would not be able to hear the PA system. The lights would alert the operations personnel to go to an area where the PA system is accessible

\subsubsection{Miscellaneous Tempernture Monitoring System (MTMS)}

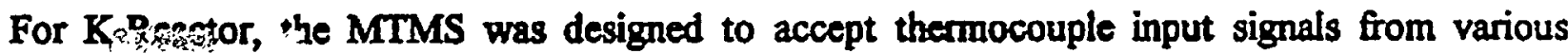
systems and process parameters, then provide display and alarm functions for plant operation. Two strip chart recorders termed " $\mathrm{A}^{\text {" }}$ and "B" were used to record the data. Temperature monitoring locations for K-Resctor "A" recorder included reactor bulk moderator, vertical tube storage and machine basin temperatures in the Disassembly Basin, Central Control Room ambient temperature, reactor thermal shield, and Reactor Tank support structure.

MTMS recorder " $A$ " and the associated RC-415 annunciator continues to monitor the Disassembly Basin temperatures (Technical Specification 3.9.4.1) (Ref. 2-28). MTMS recorder B and the bulk moderator Strip Chart Recorder have been turned off. The shutdown alarm panel bulk moderator alarm has been de-energized.

2.2.3.4 Remote Monitoring and Control System (REMACS)

REMACS 
Remote Monitoring and Control System (REMACS) was designed to provide remote monitoring of parameters and control of essential reactor equipment. It was intended for use if a reactor area was to be evacuated. The REMACS system will continue to be used to monitor essential equipment and parameters for the L \& P Reactor Buildings. The current operational plan for L \& $P$ Reactors is such that they will not be locally manned in their shutdown condition. Access and monitoring will be maintained via REMACS from the K-Reactor control room.

The following parameters will be monitored for L \& P Reactors respectively.

\section{L-Reactor}

Analog Inputs:

216-C \& 216-D sump level

1206A \& 1206B sump Level

216-H sump level

Disassembly Basin Level 1 \& 2

\section{Digitsl Inputs:}

General Radiation Alarm on the Misc. Annun. Panel

108-1 General Alarm on the Misc. Annun. Panel

108-2 General Alarm on the Misc. Annun. Panel

Instrument Air Alarm on the Misc. Annun. Panel

Plant Air Alarm on the Misc. Anmun. Panel

Disassembly Basin General Alarm on the Misc. Anunn. Paned

903A \& 903 C Running/Off alarm

NIM Alarm

Disassembly Basin Temperature Alarm on the 480.12 Panel

BTM Alarm on the 480.30 Panel

For P-Reactor:

Andog Inputs:

216-C \& 216-D sump level 
1206A \& 1206B sump Level

216-B sump level

Disassembly Basin Level 1 \& 2

Digital Inputs:

General Radiation Alarm on the Misc. Annun. Panel

108-1 General Alarm on the Misc. Anmun. Paned

108-2 General Alarm on the Misc. Anmun. Panel

Instrument Air Alarm on the Misc. Annun. Panel

Plant Air Alarm on the Misc. Annun. Panel

Disassembly Basin General Alarm on the Misc. Anumn. Panel

903B\& 903 C Running/Off alarm

NIM Alarm

BTM Alarm on the 480.30 Panel

\subsubsection{ENVIRONMENTAL/HABITABILITY MONTTORING}

\subsubsection{Miscellaneous Monitor}

Personnel contamination -monitors (PCMs) are pruvidisd in aigh traffic radiological buffer areas (RBAs); count rate meters are used in low traffic or minimal entry areas. Fixed criticality neutron dosimeters provide radiation monitoring in the Assembly and Disassembly Areas until all fuel and target assemblies are removed.

\subsubsection{Nuclenr Incident Monitors (NIMs)}

NIMS (including remote alarms) provide criticality monitoring to wam personnel of a criticality in the Assembly Area and Disassembly Area.

\subsubsection{Kannea}

Kannes provide tritium monitoring by measuring radioactive gases in the atmosphere sampled. The Kanne monitoring systems connsist of an intake or sample line, filter, flow meter, Kanne 
chamber, amplifier, recorder, air pump, exhaust line, and remote and local recorders. The current produced by ionization within the Kanne chamber is measured by a picoammeter and is continuously recorded. The Kanne systems have 6-decade logarithmic Keithley amplifiers.

To support the K-Reactor in Cold Standby, and the L- and P-Reactors in Cold Shutdown, Kannes are provided in the following locations:

- Disassembly Area

- 20-foot-elevation heat exchanger bay

- 40-foot-elevation pump room

- Storage tank room

- Purification Area

- Crane maintenance area

- +148-foot-elevation stack

- +66-foot-elevation seal head tank

- Process Room

- K-Reactor Moderator Storage Areas as delineated in its BIO (Ref. 2-2)

In addition, the Kannes are required to provide continuous monitoring in these areas.

\subsubsection{Berthold Tritium Moniton (BTMs)}

The BTMs are instruments designed to detect and measure the tritium present in a mixture of radioactive gases. The BTM uses a gas-flow proportional counter tube with a volume of 1.3 liters. The proportional counter tube uses P-10 as the counting gas. P-10 is a mixture of 90 percent argon and 10 pereent methane gas. The BTM detects tritium by using the rise-time discrimination principle. The tritium beta particles and the noble gas beta particles and gamma rays interact with the P-10 counting gas, causing ionizations to occur. The negative electrons from the ionization process must travel to a positively charged counting wire located in the counter tube (Ref. 2-29).

The resulting pulse-rise time due to a beta particle from tritium is different from the puise-rise time due to a gamma ray or beta particle from the noble gases. Discriminators sort pulses from the counter tube into one channel representing tritium activity and a second channel representing radioactive noble gases and background activity. A data acquisition system in the CCR converts the information from the two channels into tritium count rates. The tritium count rates are compared to alarm threshold values and utilized to periodically calculate Li 0 stack loss rates for the determination of airborne releases (Ref. 2-29). 
The BTM is calibrated annually and as necessary to maintain calibration limits. A channel test is performed quarterly to verify that the BTM accuracy has not changed by greater than $5 \%$ since the last calibration (Ref. 2-29).

The BTMs are used to alert the operations personnel of a moderator leak in the facility as well as provide additional alarms to protect worker safety.

\subsubsection{Groundwater Monitoring Wells}

The groundwater monitoring program at SRS gathers information to determine the effect of SRS facilities on groundwater quality. Samples of groundwater from monitoring wells are analyzed for radioactive and nonradioactive constituents and reported to assist the operating departments in meeting their responsibilities. There are a series of monitoring wells for the reactor areas where samples of groundwater are taken. Some of these wells are used to monitor for potential leakage from the basins. The wells currently used to monitor the basins provide insufficient information to determine whether there is leakage from the basins. See Section 6.16 of this BIO for proposed plans to improve leakage detection for the Disassembly Basins. The groundwater monitoring wells were not credited in the safety analyses discussed in Section 8.0 of this BIO for providing information to mitigate or prevent postulated events (Ref. 2-30)

\subsubsection{VENTILATION SYSTEM}

The ventilation system section is comprised of seven subsystems: airborne activity confinement system (AACS), central control room habitability (CCRH), Assembly Area ventilation (AAV) system, Disassembly Area ventilation (DAV) system, Purification Area ventilation (PAV) system, Building 108-K ventilation (V108) system, and miscellaneous ventilation system.

\subsubsection{Airhorne Activity Confinement System}

The AACS was designed to collect airborne particulate and halogen activity that might have been released from the reactor in the highly unlikely event of major reactor accidents. The system consists of moisture separators, high-efficiency particulate air filters, and halogen absorters in the exhaust air portion of the ventilation system. Air is exhausted from the reactor process areas through the separators, filters, and absorbers and discharged to the ventilation stack to mitigate the ground level consequence of a potential radioactive release by an elevated dispersion of gases. The AACS was operated continuously during reactor operation and maintained the Building 105$\mathrm{K}$ process areas under negative pressure to prevent any air outflow from bypassing the filters. Note that no credit is taken for the AACS use in any of the Preliminary Hazards Analysis (PHA) analyses.

During Cold Standby, two of the 903 exhaust fans, which are part of the main exhaust system, provide ventilation of Building $105-\mathrm{K}$ and exhaust through the ventilation stack. The $910 \mathrm{~A}$ and $\mathrm{B}$ 
fans provide ventilation from the below-grade supply and exhaust system. Two 909 fans each on the Far Side (C andD) and Near Side ( $J$ and $K$ ) provide temperature control in the motor rooms.

The 1230A fan at +66-foot-elevation maintains the actuator tower to Process Room EP and controls tritium accumulation during Cold Stardby.

The 904B fan and 912 fan back draft damper will keep the storage tank room at a negative pressure with respect to the personnel corridor to help contain tritium releases during Cold Standby.

Several dampers are operable in Cold Standby. The remote position of operable dampers is indicated on the ventilation panel (480.30) in the CCR. Operable dampers are remotely actuated from the ventilation panel. Some pneumatic dampers have been placed in the required standby position. The associated air receiver tanks were emptied and the air supply lines (both compressed air and standby air systems) have been valved out or capped to minimize the leakage potential in the operable portions of the compressed air system.

Three aluminum filter compartments (numbered 2 through 4 ) are located on the roof of Building $105-\mathrm{K}$ at the +55 -foot-elevation. These filter compartments provide filtration of the air prior to the inlet of the 903 fans which discharge to the ventilation stack.

Filter compartments Number 2 and 3 continue to provide Building 105-K air filtration and are clamped in the operating position as their normal configuration to provide wind load restraint. Both can be moved to the maintenance position for brief periods as long as administrative controls are in place to move them back to the operating position if wind speeds exceed specified criteria.

Filter compartment Number 4 is on the roof clamped approximately 4 inches from the operating position with covers installed for internal cleanliness. However, during Cold Standby, the inflatable nozzle seals are deflated and air flow through this compartment is not permitted since the compartment interior is still uncontaminated. The flapper actuating arms, either on the building nozzle or on the compartment, have been disabled to allow the flappera to semain closed while the compartment is in the operating position to help prevent insect and animal infestation and moisture infiltration. The drain line has been disconnected and capped on both the compartment and building ends.

Filter compartments Number 5 and 6 and the spare filter compartment are no longer stored on the roof. The compartment doors have been sealed closed. Blanks are installed in the inlet and outlet ducts to help prevent insect and animal infestation and moisture infiltration. Provisions will not be made to further seal junction boxes or the fire detection box. Stainless steel pipe plugs have been replaced with an acceptable plastic plug to prevent galling. The drain lines on the compartment and on the roof have been capped.

The building differential pressure indicators on the ventilation panel (480.30) in the CCR continue to provide indication that the AACS is operating. 
The $\mathrm{M}, \mathrm{S}$, and $\mathrm{G}$ anemometer probes, associated instrumentation, and remote indicators on the ventilation panel (480.30) in the CCR continue to be used for tritium release monitoring.

Disassembly Basin levels are maintained within the Technical Specification level which also maintains the water seal in the D\&E canal for Process Room FP control.

It should be noted that the filter compartments for AACS no longer provide filtration service because intermal filter elements have been removed. The air compartments do remain in place however to provide a ventilation path for the 903 fans

\subsubsection{Central Control Room Babitability}

During Cold Standby, the 914A \& B fans maintain positive pressure in the CCR with respect to the process areas and maintain temperature control (both heating and air conditioning).

\subsubsection{Assembly Area Veatilution System}

During Cold Standby, the 901 fan and its associated steam and chilled water coils provide environmental control of the Assembly Area.

The test pit supply fan (901.03) allows access into the -20-foot-elevation level of the Assembly Area. The final storage supply fan (901.04) and its associated steam coils provide environmental control of the final storage area.

\subsubsection{Dirassembly Axer Ventilution System}

During Cold Standby, the roof disassembly exhaust fas yizaintains the Disassembly Area air pressure slightly negative with respect to the personnel corridors to prevent possible migration of tritium.

\subsubsection{Purifkation Ares Ventilation}

The 907 fan and its associated discharge damper and steam coils support planned Purification Area activities. The 907 fan is the primary ventilation source for transformer room \#2.

The 929 fan and its associated steam and chilled water coils provide environmental control of the purification office and instrument room to support planned Purification Area activities and other possible standby activities. 


\subsubsection{Building 108-K Ventilation System}

The diesel generator buildings (Buildings 108-1 and 108-2) are served by the diesel generator ventilation system. The ventilation system consist of supply fans that take outdoor filtered air through a blast-resistant concrete structure located on the+roof and discharge through a duct network into the diesel generator buildings. The air is then exhausted by fans through blast resistant concrete outlet structures to the outdoors.

During Cold Standby, the exhaust fans provide ventilation to the buildings. The supply fans are not used. Additionally, the exhaust fans serving the battery rooms remain in service as long as batteries are present.

\subsubsection{Miscellaneous Ventilation System}

The following fans provide miscellaneous ventilation in various parts of Building $105-\mathrm{K}$ as follows:

109.30 Inhibitor room exhaust (until personnel activity and storage of contaminants in inhibitor room end)

203.02 Crane control room air conditioning ( $A / C$ ) unit (for environmental control until all charge and discharge [C\&D] operations are complete)

204x3-6 Purification Area toilet exhaust

209.05 Disassembly Area crane equipment room (until all C\&D operations are complete)

209.06 Dedeuterization hut exhaust

$901.08+15$-foot-elevation women's toilet and rod equipment room exhaust

912 . Storage tank room supply

930 Radiological Corst and Health Physics (RC\&HP) office and RC\&HP lab hood exhaust

934A +48-foot-elevation gas sample room heater

934B +48-foot-elevation gas sample room heater

$935 \quad 0$-foot-elevation personnel wing supply

$937+15$-foot-elevation iunchroom and men's toilet exhaust

$950 \quad$ RC\&HP office A/C supply

\subsubsection{MODERATOR PROCESSING FACILITIES}

The moderator processing facilities in the Purification Area of K-Reactor process the degraded and high activity moderator. When the mission for these facilities is complete, they will be placed in standby and drained. 


\subsubsection{Hiph Activity Moderator (HAM)}

The HAM system is one of two systems used to remove radioactive material and impurities from the process water. As such, the HAM system will continue to operate until the moderator is placed in storage. The HAM system is used to remove fission products and impurities from the moderator by an evaporation process.

A design change and a new procedure (DPSOL 105-454A) were implemented to operate the HAM system in a modified manner using the system evaporator instead of the auxiliary evaporator. This allows the HAM and dedeuterization systems (see Section 2.2.6.2) to operate simultaneously. The drum charging station (makeup room), system evaporator (-14-footelevation, F cell), evaporator condenser (-14-foot-elevation), evaporator condensate tank (-14foot-elevation), evaporator condensate tank pump (-14-foot-elevation), and associated piping, instrumentation, and controls are required to be operable. Operation of the HAM system requires the following support systems/equipment to be available: breathing air, steam, service raw water (or a substitute), ventilation (903 and $907 \mathrm{fan}, \mathrm{G}$ damper), and a forklift. The HAM system will operate for two to three years dependent upon manpower availability to handle the backlog of moderator.

\subsubsection{Dedeuterization}

The dedeuterization system is used to remove contaminated moderator from the deionizer resins. This process is accomplished by displacing the moderator from the resin with light water and performing an evaporation process.

Dedeuterization requires the flexible hoses (trailer space), auxiliary evaporator ( $E$ cell, -14-footelevation), auxiliary evaporator condenser (-14-foot-elevation), auxiliary evaporator condensate tank (-14-foot-elevation), auxiliary evaporator condensate tank pump (-14-foot-elevation), and associated piping instrumentation, and controls to remain operable. The support systems/equipment listed for the HAM system (see Section 2.2.6.1) and the following equipment are required: cell crane, 302 roll doors, stack area door, lead removal tool (can opener), and dedeuterization hut.

\subsubsection{MODERATOR STORAGE AREAS}

The moderator storage areas of Building 105-K have collectively been designated as the $\mathrm{K}$ Reactor Moderator Storage Areas. The stack area, crane maintenance area, -40 -foot-elevation crossover area, -40 -foot-elevation motor rooms, -40 -foot-elevation access wells, and storage tanks 204, 205, and 205-2 of Building 105-K were chosen as the locations to store the consolidated contaminated moderator. In the first phase of the consolidation, approximately 230,500 gallons of contaminated moderator is stored in the K-Reactor Moderator Storage Areas. Contaminated moderator contained in drums in $\mathrm{P}, \mathrm{L}, \mathrm{C}, \mathrm{R}$, and D-Areas was moved to Building $105-\mathrm{K}$ and placed in designated areas of the building along with drums already in Building 105-K. The contaminated moderator in K-Reactor's storage tanks remained in the tanks. The remainder 
of the site inventory of contaminated moderator is stored in the reactor storage tanks in $P, L$, and C- Areas. In the proposed next phase of the moderator consolidation, the remainder of the contaminated moderator (approximately 158,500 gallons) will be moved to the K-Reactor Moderator Storage Areas and stored in new tanks and/or drums. The Moderator Storage Areas are discussed in further detail in the Basis for Interim Operation (BIO) for the K-Reactor Moderator Storage Areas (Ref 2-2).

\subsubsection{ASSEMBLY AREA}

The storage capacity of unirradiated fuel in the Building 105-K Assembly Area has been expanded to accommodate up to 1620 unirradiated Mark 22 fuel assemblies (three Mark 22 reactor charges plus spare tubes and replacement assemblies). Also, lithium target tubes, lithium control rods, and other non-fissile reactor components may be stored in the area. (Fuel tubes are incomplete fuel assemblies which do not contain lithium target tubes.) To store the increased number of unirradiated fuel tubes and assemblies, a six-stack rack, a four-stack rack, and security cages were moved from other similar SRS reactor buildings to the Building 105-K Assembly Area near the existing four-stack rack and six-stack rack. The two six-stack racks and two four-stack racks will accommodate up to 1620 fuel assemblies. The Assembly Aree, including the final storage ares, is discussed in further detail in the Basis for Interim Operation (BIO) for the K-Reactor Assembly Area.(Ref. 2-3).

\subsubsection{CHARGE AND DISCHARGE MACHINE/DISCHARGED ASSEMBLY COOLING SYSTEM}

The charge and discharge machines are used to discharge components from the Reactor Tank.

After the charge and discharge machines have completed discharging the Besctos Tank in KReactor, they will be relocated to the crane maintenance area and deenergized. Lay-up activities will include draining the oil from the gearboxes on the charge and discharge machines and draining the D\&E conveyor gearbox.

Discharged assembly cooling (DAC) system standby activities will consist of blowing down with nitrogen the primary and secondary water stations and hoses. The water stations will then be drained to remove residual water. The primary and secondary moderator water stations will be drained. The moderator water hoses will be removed from the machines and drained. The flush tank in the crane wash area will be drained and the hoses disconnected. 


\subsubsection{ELECTRICAL SYSTEM IN K-REACTOR}

\subsubsection{Rermitted Diesels}

General Motors (GM) emergency diesel generator set \#1 and \#2- Fuel oil lines have been isolated from the diesels. The underground/above-ground tanks have been drained and removed. The cooling water system has been drained, and anti-corrosion additive has been added to the lube oil, fuel oil, and diesel jacket water system. Fuel oil lines inside the building have been drained.

Safeguards and security diesel generator- The Building 157-2K diesel generator (permitted), along with the Building 701-IK diesel generator (exempt), supports some of the security-related systems within the Building 105-K, 701-1K, and 701-2K areas. These diesels will remain operable as long as special nuclear material (SNM) within the area is maintained at appropriate quantities and attractiveness levels as outlined in DOE Order 5633.3 and/or at such time, the SNM is no longer considered attractive. For 107A-K diesels, see section 2.2.10.3.

\subsubsection{Building 151-1K}

Building 151-1K is the substation providing electrical power to K-Reactor. Building 151-1K receives electrical power from the SRS $115 \mathrm{KV}$ grid and supplies $13.8 \mathrm{KV}$. Additionally, the substation provides 480 Volts $A C$ for internal substation use as well as 125 Volts DC for external use. In addition, Building 151-K will be maintained during the Cold standby condition.

The 125 VDC power is supplied from battery back up motor generator sets which receive power from the internal substation 480 VAC system.

\subsubsection{Building Power}

The $13.8 \mathrm{KV}$ lines from substation Buildings $190-\mathrm{K}$ and $151-\mathrm{lK}$ supply power directly to $\mathrm{K}$ Reactor process water pump AC motors, directly to Building 190-K for supply, through transformers, to the cooling water pumps (no longer in use) and the service raw water pumps, to the containment substation, and to the transformer rooms (TRs) in Building 105-K where the power is transformed to $480 \mathrm{VAC}$.

During Cold Standby, one $13.8 \mathrm{KV}$ line will supply power to the Building 105-K transformer rooms which will be tied together through tie breakers. The transformer rooms provide $480 \mathrm{VAC}$ power to the reactor building. Power from the containment substation will provide backup power to the 903 ventilation fans. The Reactor Division does not have a requirement for two $115 \mathrm{KV}$ lines coming into K-Area. However, Building 151-1K will be maintained for K-Reactor in Cold Standby.

During a power supply emergency, the Building 107A-K emergency diesel generator will provide emergency power via breakers in the transformer rooms and by utilizing the existing Building 108 
switchgear and existing transformer room breaker interlocks. The Building 107A-K emergency diesel generator receives a start signal upon loss of emergency bus voltage in either TR 1, 2, or 4 . This scheme provides emergency power to the $903 \mathrm{C}$ fan, the Berthold Tritium Monitors, the security system, and building lighting, plus other loads the operator selects up to maximum of $800 \mathrm{KW}$. When the Building 107A-K emergency diesel generator is no longer required, it will be laid up.

\subsubsection{BALANCE OF PLANT - K-REACTOR}

\subsubsection{Process Steam.System}

The steam system is required for the moderator recovery and rework in the Purification Area (approximately three years) and freeze protection due to moderator being stored in K-Reactor Moderator Storage Areas (Ref. 2-2).

\subsubsection{Public Address Sratem}

The emergency public address (PA) System is maintained as long as K-Reactor remains staffed.

\subsubsection{Quterand Inner Shield Doon}

The doors remain operable until all reactor components have been discharged to the Disassembly Basin and no further entry of the Process Room is required by the C\&D machines. The shield door rain covers will be modified at the +48 -foot-elevation to prevent water leakage into Building 105-K.

\subsubsection{Comnressed Air Siritan}

The system remains operable to support breathing air, pneumatic actuators, and instrumentation. A preventive maintenance program will be maintained on all components of the system. Once KReactor decomtamination and decommissioning are complete, the compressors will be removed from servico.

\subsubsection{Bulding. Hoists}

Inspection of Assembly Area and Disassembly Area hoist equipment continues to be performed since fuel movement is required in K-Reactor. Other plant hoist equipment is maintained as needed. 


\subsection{SAFETY-RELATED CHANGES SINCE LAST SAFETY DOCUMENTATION UPDATE}

The safety-related change to the K-, L-, and P-Reactor Disassembly Basins was the extended time irradiated components will remain in storage prior to shipment to the Separation facilities or the burial grounds. Other safety-related changes to K-Reactor included deenergizing and deactivating most safety systems and components that supported reactor operation (Ref. 3-3). By placing KReactor in Cold Standby with no planned provisions for restart, only a few systems will be required for K-Reactor to ensure co-located and offsite doses from accidents associated with radiological and chemical hazards remain below the limits. The systems required are listed in Section 8.6 of this BIO along with systems for unirradiated fuel storage in Reference 3-1 and systems from moderator storage in Reference 3-2.

The systems for the storage and disassembly of fuel and target assemblies and processing of other irradiated components in the K-, L, and P-Reactor Disassembly Basins will be the same as currently used. The chemistry of the water in the K-, Ln, and P-Reactor Disassembly Basins will be improved in accordance with the Disassembly Basin Management Plan (Ref. 3-4).

The latest safety documentation update for K-Reactor in Cold Standby is discussed in Section 4.0 of this BIO and consists primarily of the K-Reactor Safety Analysis Report (Ref. 3-5), the KReactor Technical Specifications (Ref. 3-6), and the K-Reactor Cold Standby Plan (Ref. 3-3). These documents provide for storage and handling of unirradiated fuel and irradiated components and storage and processing of contaminated moderator. The latest safety documentation for Land P-Reactor Disassembly Basins is also discussed in Section 4.0 of this BIO. These documents consist mainly of the L- and P-Reactor Technical Specifications, L-Reactor Cold Shutdown Plan, P-Area Standby Ptan, and the Transfer Packages for 100-L and P Area Facilities. These documents provide for storage and handling of irradiated components. 


\subsection{SIGNIFICĀNT SAFETY FINDINGS FROM MOST RECENT OPERATIONAL READINESS REVIEW AND/OR INSPECTION/AUDIT}

DOE performed an Operational Readiness Review (ORR) +from May 13 through October 18, 1991, to assess WSRC's ability to restart and safely operate K-Reactor. The ORR was conducted in four major areas: operations, maintenance and surveillance, engineering and technical support, and organization and management. In addition, DOE assessed the adequacy of the closure process for issues in the Reactor Operations Management Plan (Ref. 3-7) and compliance with DOE Orders. The preliminary results of the review were presented to WSRC management during the exit meeting held on October 18, 1991. DOE issued the final ORR report on November 12, 1991 (Ref. 3-8) which identified 21 findings and 82 observations. The majority of the findings and observations were relevant to K-Reactor in Cold Standby because the findings and observations involve programmatic issues. WSRC submitted a letter to DOE on Noyember 7, 1991 (Ref. 3-9) which provided a discussion of the draft findings from DOE's ORR and described the WSRC action plans that would be implemented to address the findings before restart. Actions which addressed findings were completed prior to restart of K-Reactor. Action plans to address DOE's observations were transmitted to DOE in a WSRC letter dated December 3, 1991 (Ref 310). The actions to address DOE's observations are being tracked by the Master Tracking System (MTS) and the Continuing Commitment Tracking System (CCTS) until closure.

WSRC reassessments and independent DOE inspections were scheduled prior to the restart of KReactor in 1993. These inspections were never performed due to changes in the mission of $\mathrm{K}$ Reactor. The 1991 DOE ORR was the last inspection of K-Reactor.

Currently, there are 5 open ORR observations for K-Reactor and 15 open findings (taken from PReactor Safety Review Inspection Report September 1991) for P-Reactor. These observations and findings have ben reviewed to ensure that they do not impact the safety basis presented in this BIO and based on engincering judgment, they do not impact the safety basis presented in this BIO. 


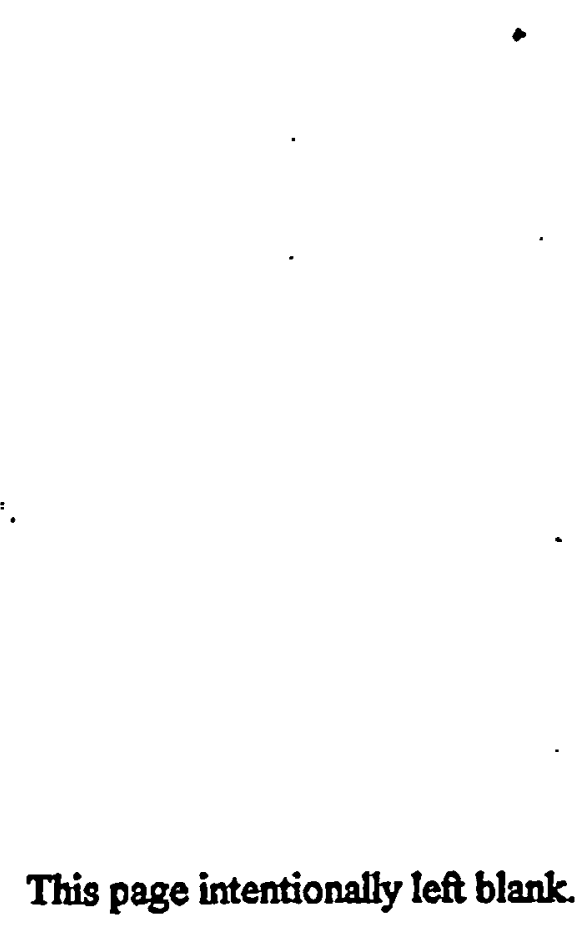

This page intentionally left blank. 


\section{- 4.0 SAFETY DOCUMENTATION}

Cold Standby operations in K-Reactor will be the continued storage and handling of unirradiated fuel and irradiated components and the storage and processing of contaminated moderator. Land P-Reactor Disassembly Basins will continue to store and handle irradiated components.

K-Reactor documents that currently authorize the storage and handling of unirradiated fuel and irradiated components and the storage and processing of contaminated moderator for K-Reactor in Cold Standby will continue to serve in that capacity. These documents and this BIO will constitute the authorization basis documents for K-Reactor in Cold Standby because the method and location of unirradiated fuel and irradiated component storage and handling and contaminated moderator processing and storage are the same as those used during K-Reactor operations (except that in some cases contaminated moderator has been stored in new locations). L- and PReactor documents that currently authorize the handling and storage of irradiated components in the L- and P-Reactor Disassembly Basins will continue to serve in that capacity. These documents and this BIO will constitute the authorization basis documents for the $\mathrm{L}$ and PReactor Disassembly Basins because the method and location of irradiated component storage and handling are the same as those used during L- and P-Reactor operations. The analyses discussed in Section 8.0 of this BIO evaluated the handling and storage of irradiated components in the K-, L-, and P-Reactor Disassembly Basins and the processing of moderator in the KReactor Purification Area. Also, the analyses discussed in Section 8.0 of Reference 4-1 evaluated the storage and handling of the increased number of unirradiated fuel assemblies in the K-Reactor Assembly Area, and the analyses discussed in Section 8.0 of Reference $4-2$ evaluated the storage of increased amounts of contaminated moderator stored in K-Reactor and storage of contaminated moderator in some new locations.

The documents listed below for K-Reactor in Cold Standby and the L- and P-Reactor Disassembly Basins are applicable in their entirety to the continued Cold Standby/Cold Shutdown missions of these areas except for the Safety Analysis Reports). In the case of the SARs, all sections are applicable with the exception of those discussions of systems, structures, components, programs, and analyses that are now addressed by this BIO and the BIOs for the KReactor Assembly Area and Moderator Storage Areas. For these superseded topics, the BIOs form the authorization basis for those items. The combination of the SARs and the BIOs comprehensively analyze all postulated accident events which could affect the workers, public, or the environment.

The following documents and this BIO serve as the authorization basis for K-Reactor in Cold Standby.

- Savannah River Site Production Reactor Safety Analysis Report. K Production Reactor. WSRC-SA-10003, Amendment 4, Westinghouse Savannah River Company, Aiken, SC, November 8, 1992.

- K-Reactor Cold Standby Plan Rev. 2 (U). RRD-940039, Westinghouse Savannah River Company, Aiken, SC, March 30, 1994. 
- Stvanner River Site Production Reactor Technical Specifications K Production Raactor. WSRC-TS-10003, Revision 16, Westinghouse Savannah Rjver Company, Aiken, SC, November 1, 1993.

- Basis for Interim Operation (BIO) for the K-Reactor Assembly Area (U). WSRC-TR93-500, Rev. 2, Westingtiouse Savannah River Company, Aiken, SC, March 1994.

- Basis for Interim Operation (BIO) for the K-Reactor Moderator Storage Areas (U). WSRC-TR-93-611, Rev. 1, Westinghouse Savannah River Company, Aiken, SC, May 1994.

The following documents and this BIO serve as the authorization basis for the L- and PReactor Disassembly Basins.

- Savannah River Site Production Reactor Technical Specifications I Production Reactor. WSRC-TS-10002, Revision 2, Westinghouse Savannah River Company, Aiken, SC, October 29, 1993.

- Savannah River Site Production Reactor Technical Specifications. P Production Reactor. WSRC-TS-10001, Revision 0, Westinghouse Savannah River Company, Aiken, SC, October 29, 1993.

For K-Reactor in Cold Standby and L- and P-Reactor Disassembly Basins, the documents listed above and this BIO collectively establish the safety basis, describe the areas and their operation, provide the plan for operator and other support services and equipment necessary during unirradiated fuel and irradiated components storage and handling and the storage and processing of contaminated moderator. The documents and this BIO also establish the safety envelope by delineating the restrictions on operations and administrative controls necessary for safe operations, provide the safety classification of structures, systems, and components during Cold Standby of K-Reactor and during handling and storage of irradiated components in L- and PReactor Disassembly Basins, and provide the technical baseline for fire protection.

In addition, the documents listed below also provide valuable information to support the safety basiss of the respective frilities.

For K-Reactor:

- Uniform Listinq of K-Reactor Systems, Acronyms and Functional Classification (I). WSRC-TR-90-42-133, Rev. S, Westinghouse Savannah River Company, Aiken, SC, April 28, 1994.

- K-Reactor Fire Hazards Analysis. WSRC-RP-92-834, Rev. 0, Westinghouse Savannah River Company, Aiken, SC, April 30, 1992.

- K-Reactor Fire Protection Project Cold Standby Status Report. SSD-SFP-93-0330, Rev. 1, Westinghouse Savannah River Company, Aiken, SC, November 18, 1993. 
For L\& P Disassemtly basins:

- L-Reactor Cold Shutdown Plan Revision One (U). RRD-940058, Westinghouse Savannah River Company, Aiken, SC, May 20, 1994.

- Rice, P. D. "P-Area Standby Plan,"RRD-910107, Westinghouse Savannah River Company, Aiken, SC, September 9, 1991.

- Transfer Package for 100-L Area Facilities (U). RRD-ENG-930083, Westinghouse Savannah River Company, Aiken, SC, September 30, 1993.

- Transfer Package for 100-P Area Facilities (U). RRD-ENG-930090, Westinghouse Savannah River Company, Aiken, SC, September 30, 1993.

- Uniform Listing of C. I, P, and R Reactor Systens Acronyms, and Functional Classification (U). WSRC-TR-94-01-090, Rev. 0, Westinghouse Savannah River Company, Aiken, SC, June 22, 1994.

The sections below discuss the salient features of these documents. 


\subsection{K-REACTOR SAFETY EVALUATION DOCUMENTS}

The safety evaluation documents that are part of the authorization basis documents for K-Reactor in Cold Standby are the K-Reactor Safety Analysis Report (SAR) and the K-Reactor Cold Standby Plan. These documents and their features are discussed below.

\subsubsection{K-REACTOR SAFETY ANALYSIS REPORT}

The current K-Reactor SAR (Ref. 4-3) was developed in accordance with DOE Orders 5480.6 and 5481.1B (Ref. 4-4, 4-5). These Orders require SARs, prepared for nuclear facilities, to follow appropriate Nuclear Regulatory Commission (NRC) regulatory guides on standard format and content of SARs. The K-Reactor SAR was developed based on the format and content guidance provided in Regulatory Guide 1.70 and NUREG-0800 (Ref 4-6, 4-7).

The DOE-approved K-Reactor SAR is the principal document of safety analyses made to determine that K-Reactor can be operated without undue risk to the public or to co-located workers. The K-Reactor SAR establishes the safety basis and provides assurance that K-Reactor can be designed, operated, maintained, and shut down safely in compliance with applicable laws and regulations.

The SAR for the SRS production reactors was originally prepared in the 1950s. The early versions of the SAR provided general descriptions of the plant design and procedural controls. The SAR has been periodically updated over the years. More recent revisions were made in September 1972, December 1978, September 1983, and October 1987. In July 1989, an upgraded SAR was issued for K-Reactor to more fully describe the safety basis of the reactor. The upgraded SAR followed, to the extent possible, the format and $g$ lelines of Regulatory Guide 1.70. The content of safety-related sections of the SAR was svised in subsequent amendments to conform with the requirements of NUREG-0800. Subsequent amendments to the upgraded SAR were made in July 1991, November 1991, July 1992, and November 1992.

WSRC has submitted a K-Reactor Compliance Assessment and Implementation Report (Ref. 4-8) for compliance with DOE Order 5480.23 (Ref. 4-9). The plan prescribes the steps to upgrade the authorization basis for K-Reactor through the development of Basis for Interim Operation (BIO) documents. BIO documents that reflect the Cold Standby condition, special nuclear material consolidation, and moderator consolidation are being prepared to support the Program Execution Guidance (Ref. 4-10) to place K-Reactor in Cold Standby. The BIOs will be used to satisfy the Technical Specification requirement to update the SAR annually. After DOE approval of the BIOs, WSRC will begin, if directed by DOE, to develop an updated SAR for K-Reactor. 


\subsubsection{K-RSACTOR COLD STANDBY PLAN}

In an April 19, 1993, letter (Ref. 4-10), DOE directed a change in the mission for K-Reactor from demonstrating and maintaining tritium production viability to placing K-Reactor in Cold Standby. Cold Standby is defined as that condition in which a startup capability is maintained, but with no planned provision for restart. In response to DOE's direction, WSRC issued the K-Reactor Cold Standby Plan (Ref. 4-11) which outlines WSRC's actions for placing K-Reactor in Cold Standby. The plan addresses the following:

- Plant configuration

- Surveillances

- Environmental controls

- Fire protection :

- Maintenance

- Occupational safety and health

$\therefore \quad$ Radiological characterization

- Reactor Division reorganization, staffing, and training

- Conduct of operation programs and procedures

- Authorization basis

- Standby Technical Specifications

- Emergency preparedness

- Safeguards and security

- DOE Order compliance and commitments

- Amixistrative procedures

- Savannah River Technology Center Cold Standby activities

- Independent oversight

- Schodule

The plan covers activities during and after the interim phases required to achieve an orderly transition of K-Reactor to Cold Standby. The plan meets the requirements of DOE Order 5480.6 (Ref. 4-4) and Work Authorization Package 1 of the April 19, 1993, DOE letter (Ref. 4-10). Through the implementation of this plan, WSRC will comply with the recommendations of Defense Nuclear Facilities Safety Board (DNFSB) 92-5 (Ref. 4-12) and Secretary of Energy Notice SEN-35-91 (Ref. 4-13) which promulgates the Nuclear Safety Policy.

The K-Reactor Cold Standby Plan summarizes activities required to align and maintain the structures, systerns, and components of K-Reactor in Cold Standby. The plan provides for the continued upkeep of equipment and components that are required for the following: 
- Providing property protection of government-owned equipment and areas

- Providing an operable fire protection system

- Preventing K-Reactor from being rendered immediately unrecoverable

- Processing and supporting long-term storage of moderator in Building 105-K storage areas

- Operating the Disassembly Basin until fissile and hazardous materials have been removed

- Supporting long-term storage of unirradiated reactor fuel in the Assembly Area

Additionally, the plan specifies those structures, systems, and components that are required to be operable to ensure environmental compliance, public and worker safety, and building habitability. Surveillance activities required during Cold Standby which were derived from an evaluation of the Technical Specifications, Environmental Protection, Environmental Regulatory, Best Management Practices, and Industrial Safety are listed in the plan.

The plan provides actions to place in Cold Standby those structures, systems, and components that are not required to be operable and ensures that they can be reactivated, if needed, in a costeffective and safe manner. Those activities include the following:

- Decontamination and a reduction of radiological hazards

- Stabilization and posting of radiological, hazardous, and toxic contaminated areas

- K-Reactor stabilization

- Uitimate disposition of materials currently stored in K-Reactor

- Configuration archiving

Since K-Reactor is in Cold Standby, no deliberate effort is planned to maintain plant equipment that would be required solely for a timely restart or to maintain primary system cniestistry. The KReactor Cold Standby Plan does not include provisions for a planned recovery and restarting KReactor.

The K-Reactor Cold Standby Plan discusses the environmental impact of the transition of KReactor to Cold Standby. This plan is a supplement to alternative 3 of the Reactor Operations Environmental Impact Statement for continued operation of K-Reactor discussed in the Final Environmental Impact Statement (Ref. 4-14). The plan specifies the environmental programs and activities which will continue and the monitoring and sampling equipment which will be maintained operable in the transition period and during Cold Standby.

The plan describes the reorganization of the Reactor Division, staff reductions, and training program changes required for the new mission of K-Reactor. The plan discusses provisions to maintain personnel with the skills necessary for Cold Standby including the development and implementation of a database that tracks key personnel and members of the "Core Competency" group who move to new assignments in the DOE complex or accept early retirement incentives. 
The K-Reactor Cold Standby Plan specifies the Conduct of Operation programs which will continue-as-is, be modified, or be terminated as the result of the new mission of the K-Reactor. The criteria for dispositioning the programs and the results of the evaluation presented in the plan supersede a WSRC letter to DOE, dated April 13, 1993, concerning the disposition of K-Reactor programs (Ref. 4-15). 


\subsection{K-REACTOR TECENICAL SPECIFICATIONS}

The current K-Reactor Technical Specifications (Ref. 4-16) were developed in accordance with DOE Grder 5480.6 (Ref. 4-4). This Order requires that Technical Specifications for DOE-owned reactors follow the requirements of Title 10 CFR Part 50, Section 50.36 (10 CFR 50.36), "Technical Specifications" (Ref. 4-17). The NRC subsequently issued draft NUREG-1431, Standard Technical Specifications. Westinghouse Plants (Ref. 4-18), in January 1991 as part of the commercial nuclear industry technical specifications improvement program. The current KReactor Technical Specifications comply with 10 CFR 50.36 and were developed based on the NUREG-1431 format for Westinghouse Plants (Methodically Engineered, Restructured and Improved Technical Specifications [MERITS]).

The DOE-approved K-Reactor Technical Specifications provide specific limits and controls to establish a safety margin within the bounds of the analyzed safety envelope established in the SAR. The Technical Specifications define the operating limits and surveillance requirements, the basis, safety boundaries, and management and administrative controls necessary to protect the health and safety of the public. They minimize the potential risk to workers from the uncontrolled release of radioactive or other hazardous materials and from radiation exposure due to inadvertent criticality. The Technical Specifications constitute an agreement or contract between DOE and WSRC regarding the safe operation of the K-Reactor.

Historically, SRS reactor operations have been controlled by the instructions in detailed operating procedures and by requirements established in Technical Standards. In 1975, safety requirements were established in the Technical Specifications and more specific controls were established in the Technical Standards to identify overall plant safety requirements. On December 18, 1990, the KReactor Technical Specifications were upgraded (Rev. 0) to reflect the NUREG-1431 format (MERITS) for the pre-restart activities and to incorporate relevant requirements from Technical Standards and operating procedures. Subsequent revisions through Revision 4 addressed outstanding restart issues. DOE approved Revision 4 of the Technical Specifications on October 24, 1991, for restart of the K-Reactor. Subsequent revisions were made to maintain the Technical Specifications reflective of K-Reactor as it existed and as it was analyzed in the SAR.

On August 5, 1993, DOE approved Revision 16 of the Technical Specifications which reflects the current mission of K-Reactor. Revision 16 of the Technical Specifications was implemented on November 1, 1993. The revision removed limits and controls that are no longer applicable with K-Reactor remuining in Cold Standby and with no planned provision to restart. The remaining Technical Specifications ensure that controls are established for fissile material handling and storage such that muclear criticality safety is maintained and for safe Disassembly Basin operation. Revisions to the Technical Specifications will continue to be made to keep the Technical Specifications current so that they reflect K-Reactor as it exists and as it is analyzed in the SAR or BIO. The K-Reactor Technical Specifications will be revised to incorporate the requirements of Section 7.2 that are related to K-Reactor in Cold Standby once this BIO is approved by DOE. Modifications to K-Reactor, design changes, and changes to the Technical Specifications shall be subjected to the Unreviewed Safety Question (USQ) process pursuant to RDP 12.03, 
"Unreviewed Safety Quẹstion Screening and Evaluation Procedure," of WSRC Manual RD-1 (Ref. 4-19).

WSRC has submitted a K-Reactor Compliance Assessment and Implementation Report (Ref. 420) for compliance with DOE Order 5480.22. (Ref. 4-21) discussing Technical Safety Requirements.

In 1991, the Plant Operating Specifications (POS) (Ref. 4-22) for K-Reactor were originally issued to specify the balance of the safety envelope requirements not covered by the K-Reactor Technical Specifications. However, the items for this expanded safety envelope were judged to warrant similar rigor and controls as the Technical Specifications. The POS procedure is to be used in conjunction with the Technical Specifications. In 1994, the POS has been updated to reflect K-Reactor in Cold Standby (Ref, 4-22). 


\subsection{K-REACTOR SAFETY SYSTEM CLASSIFICATION LIST}

The Uniform Listine of K-Reactor Systems, Acronyms. and Functional Classifications (Ref. 4-23) provides a current and complete tabulation of Nuclear Safety (NS), Critical Protection (CP), Production Support (PS), and General Services (GS) system titles, acronyms, and associated functional classifications for principal structures and components. The functional classification (i,c., NS, CP, PS, or GS) of structures, systems, and components are provided for Cold Standby. The report specifies the systems which have had their functional classifications changed due to the lay-up of the K-Reactor. The report provides functional descriptions of each system during Cold Standby and the classification justifications. 


\subsection{K-REACTOR FURE HAZARDS ANALYSIS}

The K-Reactor Fire Hazards Analysis (Ref. 4-24) provides credible fire scenarios within KReactor and then evaluates the impact of these potential fires on K-Reactor and its occupants. The analysis was based on the occupancy of $\mathrm{K}$-Reactor, its configuration of fire suppressant equipment, detection devices and methods, alarms, evacuation plans, construction, materials, current fire safety codes, and fire loading. 


\subsection{K-REACFOR FIRE PROTECTION PROJECT COLD STANDBY STATUS}

The K-Reactor Fire Protection Project Cold Standby Stas Report (Ref. 4-25) documents and updates the fire hazard present for K-Reactor in Cold Standby and the fire hazard to personnel, based on previously issued analyses and reports, and provides the technical baseline for fire protection improvements. The conditions, on which Reference 4-24 was based, such as combustible loading, plant configuration, fire suppression, K-Reactor structural configuration, and occupancy of K-Reactor. have been improved to diminish the fire hazards. The conditions evaluated in Reference 4-24 for the K-Reactor in operation bounds the condition of K-Reactor in Cold Standby.

The fire analysis and status reports (Ref. 4-24, 4-25) perform zone-by-zone analyses of $\mathrm{K}$. Reactor, where each fire zone included the effects of transient and permanent combustibles, physical dimensions of each fire zone, ventilation, floor drains, fire barriers, lighting levels, and comparison of materials and construction against nationally recognized safety data and codes. The reports establish the baseline of fire protection efforts in K-Reactor and establish the maximum possible and credible economic fire loss figures for K-Reactor. WSRC property accounting figures were used to establish these equipment and K-Reactor economic losses, and cleanup and recovery costs were included.

The reports provide an assessment of $\mathrm{K}$-Reactor's compliance with applicable DOE fire safety Orders and identify feasible and cost-effective recommendations to bring K-Reactor into the highest level of compliance possible with the DOE Orders. Where full compliance with a DOE Order could not be obtained due to the age and construction of K-Reactor, recommendations were made which will result in K-Reactor meeting the intent of the Order while also ensuring.the safety of the occupants, the public, and K-Reactor. These reports also serve as the basis for obtaining exemptions from DOE Orders. 


\subsection{K-REACTOR ASSEMBLY AREA BASIS FOR NTERIM OPERATION}

The BIO for the K-Reactor Assembly Area (Ref. 4-1) documents the hazard identification, hazard categorization, and preliminary hazards analysis for the Asserbly Area.(including the final storage area) of K-Reactor and establishes an interim safety basis by demonstrating safety to workers and the public through adherence to safety management programs, presentation of the operating envelope, and performance of a limited-scope accident analysis. The K-Reactor Assembly Area provides safe and environmentally sound long-term storage of up to 1620 unirradiated Mark 22 fuel tubes and assemblies in the Assembly Ares (and temporary storage of fuel assemblies in the final storage area). The BIO provides the following:

- A description of the areas and structures, systems, and components that are credited in the safety analyses

- Design and current missions of the areas

- Relevant operational histories including a discussion of significant safety-related changes to the areas and significant safety-related findings from recent reviews, inspections, and audits

- Listings and discussions of the authorization basis documents for the areas

- Compliance status of the areas with safety-related laws, regulations/orders, and - standards and associated compensatory measures for requirements for which the areas are not in compliance

- Discussions of the programmatic approach to safety management for the workers and the public

- Discussions of the operating envelope of the areas including the Technical Specifications and additional administrative controls

- Discussions of the approach and results of hazard identification and categorization

- Discussions and results of qualitative risk analyses of possible accident scenarios in the area by comprehensively identifying potential events and their initiators, estimating their frequencies and consequences, and displaying the results in a risk matrix

- Discaussions of the impact of normal operations and postulated accidents on the workers, public, and environment and the identification of potential design, procedure, and equipment vulnerabilities and the approach for deriving estimates of system unavailabilities and operator errors 


\subsection{K-RSACFOR MODERATOR STORAGE AREAS BASIS FOR INTERIM OPERATION}

The BIO for the K-Reactor Moderator Storage Areas (Ref. 4-2) documents the hazard identification, hazard categorization, and preliminary hazards analysis for the Moderator Storage Areas of K-Reactor and establishes an interim safety basis by demonstrating safety to workers and the public through adherence to safety management programs, presentation of the operating envelope, and performance of a limited-scope accident anslysis. The K-Reactor Moderator Storage Areas are the moderator storage tank room, stack area, crane maintenance area, -40-footelevation crossover area, -40-foot-elevation motor rooms, and -40-foot-elevation access wells. In Phase I of the moderator consolidation program, these areas contain approximately 59,500 gallons of contaminated moderator in the storage tanks and approximately 171,000 gallons in stainless steel drums. The next phase of moderator consolidation will involve moving approximately 158,500 gallons of moderator from the $C_{-}, L$, and P-Reactor storage tanks into the K-Reactor Moderator Storage Areas. The BIO for the K-Reactor Moderator Storage Areas (Ref. 4-2) only addresses the first phase of moderator consolidation and provides the same discussions as listed above in Section 4.6. 
WSRC-TR-94-207-DV

REVISION 0

\subsection{L- AND PREACTOR TECHNICAL SPECIFICATIONS}

The current L- and P-Reactor Technical Specifications (Ref. 4-26, 4-27) were developed in accordance with .DOE Order 5480.6 (Ref. 4-4). As stated in Section 4.2, DOE Order 5480.6 requires that DOE-owned reactors follow the requirements of 10 CFR 50.36 (Ref. 4-17). The current L- and P-Reactor Technical Specifications comply with 10 CFR 50.36 and were developed based on the NUREG-1431 (Ref. 4-18) format for Westinghouse Plants (MERTS).

The DOE-approved L- and P-Reactor Technical Specifications provide specific limits and controls to establish a safety margin within the bounds of the analyzed safety envelope established in the SARs. The Technical Specifications define the operating limits and surveillance requirements, the basis, safety boundaries, and management and administrative controls necessary to protect the health and safety of the public. They minimize the potential risk to workers from the unconirolled release of radioactive or other hazardous materials and from radiation exposure due to inadvertent criticality. The Technical Specifications constitute an agreement or contract between DOE and WSRC regarding the safe continued storage and handling of irradiated components in the L- and P-Resctor Disassembly Basins.

On October 29, 1993, DOE approved Revision 2 of the L-Reactor Technical Specifications and Revision 0 of the P-Reactor Technical Specifications to reflect their current missions. The revisions removed limits and controls that are no longer applicable with L- and P-Reactors in Cold Shutdown. The remaining Technical Specifications ensure controls are established for fissile material handling and storage such that muclear criticality safety is maintained and for safe Disassembly Basin operation. Section 5.0 of the Technical Specifications specifies the administrative framework for safe facility operation during Cold Shutdown and provides an overview of the principal programs and control documents used to maintain this condition. Revisions to the $\mathrm{L}$ - and P-Reactor Technical Specifications will continue to be made to keep the Technical Specifications current so that they reflect L- and P-Reactor Disassembly Basins as they exist and as they are analyzed in this BIO. The L- and P-Reactor Technical Specifications will be revised to incorporate the requirements of Section 7.2 that are related to the $L$ - and P-Reactor Disassembly Basins once this BIO is approved by DOE. Modifications to the L- and P-Reactor Disassembly Basins, design changes, and changes to the L- and P-Reactor Technical Specifications shall be subjected to the USQ process pursuant to RDP 12.03 of WSRC Manual RD-1 (Ref. 4-19).

WSRC has submitted exemption requests (Ref. 4-20 and 4-8) from the requirements of DOE Order 5480.22 (Ref. 4-21) and DOE Order 5480.23 (Ref. 4-9) for.L- and P-Reactors. These exemptions were requested based on the controls currently in place, the bounding analyses provided in this BIO, and the anticipated decontamination and decommissioning of L- and PReactors. 


\subsection{L-REACFOR COLD SHUTDOWN PLAN}

In an April 19, 1993, letter (Ref. 4-10), DOE directed a change in the mission for L-Reactor from serving as a backup source of tritium production to placing L-Reactor in Cold Shutdown with no capability of restart. In response to DOE's direction. WSRC issued the L-Reactor Cold Shutdown Plan (Ref. 4-28) which outlines WSRC's actions for placing L-Reactor in Cold Shutdown. The plan addresses the following activities that are relevant to the operation of the LReactor Disassembly Basin:

- Plant configuration

- Shutdown surveillances

- Environmental considerations

- Fire protection '.

- Maintenance

- Occupational safety and health

- Radiological control

- L-Reactor personnel staffing and training

- Conduct of operations

- Technical Specifications and Safety Analysis Report applicability

- Emergency preparedness

- Safeguards and security

- DOE Order compliance

- Administrative procectures

- Information archiving

The plan covers activities during and after the interim phases required to achieve an orderly transition of L-Reactor to Cold Shutdown. The plan meets the requirements of DOE Order 5480.6 (Ref. 44) and Work Authorization Package 2 of the April 19, 1993, DOE letter (Ref. 410). Through the implementation of this plan, WSRC will comply with the recommendations of DNFSB 92-5 (Ref 4-12) and Secretary of Energy Notice SEN-35-91 (Ref. 4-13).

The L-Reactor Cold Shutdown Plan summarizes activities required to align and maintain the structures, systems, and components of L-Reactor that are required for Cold Shutdown based on the L-Reactor Technical Specifications (Ref. 4-26) and on the need to ensure building habitability and environmental monitoring. Surveillance activities required during Cold Shutdown which were derived from the Technical Specifications, Plant Operating Specifications, Environmental Protection, Environmental Regulatory Compliance, Best Management Practices, and Industrial Safety are listed in the plan. 
The plan lists the structires, systems, and components that will be completely laid up with no provision for surveillance or maintenance.

The plan addresses the environmental impact of the transition of L-Reactor to Cold Shutdown and is a supplement to alternative 3 of the Reactor Operations Environmental Impact Statement for continued operation of L-Reactor discussed in the Einal Environmental Impact Statement (Ref. 4-14). The plan specifies the environmental programs and activities that will continue and the monitoring and sampling equipment that will be maintained and used in the transition period and during Cold Shutdown.

The plan identifies the program needs for L-Reactor in Cold Shutdown which focus on personnel safety, radiological condition control, conduct of operations, and environmental compliance. The programs are supplied by the division level programs for L-Reactor described in the L-Reactor Cold Shutdown Plan (Ref. 4-28).

The plan discusses the Technical Specifications for L-Reactor in Cold Shutdown and the controls they establish. The plan also states that there is no plan to update the L-Reactor Safety Analysis Report (Ref. 4-29) since this BIO will provide bounding analyses of the hazards associated with the Disassembly Basin of L-Reactor in Cold Shutdown.

The plan discusses the consolidation of the Emergency Response Organization operating out of the K-Reactor CCR and states the staffing requirements to cover the K-, L-, and P-Reactors.

The plan details an evaluation of L-Reactor in Cold Shutdown for compliance with DOE Orders and discusses the compliance schectule approvals and exemption requests that have been generated or revised for the current cold shutdown condition.

The plan lists the administrative procedure manuals that are necessary for L-Reactor in Cold Shutdown. 


\subsection{P-AREA STANDBY PLAN}

In response to DOE's direction to place P-Reactor in Standby, WSRC commenced to lay-up P. Reactor. WSRC.completed the discharge of fuel and targetrassemblies from the P-Reactor Tank on July 16, 1991. WSRC issued the P-Ares Standby Plan (Ref. 4-30) which outlines WSRC's actions for placing P-Reactor in Standby. The plan addresses the following activities that are relevant to the operations of the P-Reactor Disassembly Basin:

- Plant configuration and major equipment status

- Surveillances

- Maintenance

- Emergency plans

- Radiological characterization

- Security

- Environmental

- $\quad$ Fire protection

- Technical Specifications and Safety Analysis Report applicability

- Reactor Division personnel staffing

The plan covers activities during and after the interim phases required to achieve an orderly transition of P-Reactor to Standby. The plan summarizes activities required to align and maintain the structures, systems, and components of the P-Resctor Disassembly Basin until fissile and hazardous materials have been removed. Also, the plan describes the minimum staffing requirements for operating and support personnel. 


\subsection{TRANSFER PACKAGES FOR 100-L AND -P AREA FACILITES}

The Transfer Packages for 100-L and -P Area Facilities (Ref. 4-31, 4-32) were prepared to provide information regarding the status and condition of L-'and.P-Area facilities. The packages were a response to a verbal request by F. R. McCoy, III, of DOE on July 22, 1993, for additional information concerning surplus facilities.

The transfer packages provide the following information concerning the facilities of the $\mathrm{L}$ - and $\mathrm{P}$ Areas:

- Physical description and history

- Operability status of structures, systems, and components

- Safety status

- Radiological and chemical hazard inventories and contamination

- Special muclear material inventories

- Plans for removal, treatment, and disposal of radiological and chemical hazards, contamination, and special nuclear materials

- Compliance status with applicable DOE Orders, standards, and other regulatory requirements

- Required environmental monitoring systems and monitoring frequencies of radiological and nonradiological air and water effluents and of fire hazards

- Surveillance and maintenance plans associated with required structures, systems, and components

- Status of the safety envelope for the L- and P-Reactors in Cold Shutdown with no capability for restart

- Safeguard and security

- Staffing and training requirements

The tranafer packages also provide photographs and figures of the buildings and equipment of $L$ and $P$-Areas and layouts of radiation and contamination areas and radiological buffer areas of $L$ and P-Areas. 


\subsection{L- AND P-REACTOR SAFETY SYSTEM CLASSIFICATION LIST}

The Uniform Listing of $C, L, P$, and R Reactor Systems, Acronyms, and Functional Classifications (U) (Ref. 4-33) provides a current and çomplete tabulation of system titles, acronyms, and associated functional classifications for principal structures and components. The functional classification (i.e., NS, CP, PS, or GS) of structures, systems, and components in Land P-Reactors are provided for Cold Shutdown. The report also provides functional descriptions of each system during Cold Shutdown and the classification justifications. 


\section{$-$ \\ 5.0 COMPLIANCE STATUS}

The current site and reactor order compliance status is applicable to the continued use of $K$-Reactor in Cold Standby for the storage and handling of unirradiated fuel and irradiated components and the storage and processing of contaminated moderator. Also, the current site and reactor order compliance status is applicable to the $L$ - and P-Reactor Disassembly Basins in the continued use of the basins to store and handle irradiated components.

SRS has an extensive DOE Order compliance program which is part of the K-Reactor Cold Standby Plan, L-Reactor Cold Shutdown Plan, and the Transfer Package for 100-P Area Facilities (Ref. 5-1, 5-2, 5-3). These plans consist of the following:

- The evaluation of Level I Environmental Safety and Health (ES\&H) DOE Orders for applicability of: '.

- Unirradiated fuel assemblies present in the K-Reactor Assembly Area

- Irradiated fuel and target assemblies and other irradiated components in the K-, L-, and P-Reactor Disassembly.Basins

- Tritiated moderator in the K-Reactor Moderator Storage Areas and Purification Area

- Contamination above that which can reasonably be removed

This evaluation is complete. Level I ES\&H DOE Orders have been screened.

- The review of outstanding CSA Order actions and newly determined (redocumentation [Re-DOC] program) noncompliances and deficiencies

- The preparation of CSAs and exemption requests for the current conditions for $\mathrm{K}$-Reactor in Cold Standby and L- and P-Reactors in Cold Shutdown

- Long-Term Action - The preparation of additional CSAs and exemption requests for later conditions (i.e., for conditions in which fued and targets, moderator, and contamination are removed or moved within K-Reactor or irradiated comiponents are removed or moved within the L- and P-Reactor Disassembly Basins) based upon the knowledge gained from the prior steps following the standby/shutdown plans

Therefore, the program for resolving the noncompliances for K-Reactor in Cold Standby and Land P-Reactors in Cold Shutdown is a part of a larger program. 


\subsection{SAFETY-DELATED NONCOMPLIANCES}

To determine the current DOE Order noncompliances which are relevant to K-Reactor in Cold Standby and L- and P-Reactor Disassembly Basins, noncompliances for the SRS production reactors were examined. The relevant noncompliances concerned primarily either programmatic or generic issues. Altogether the open CSAs and DOE Order noncompliances for the production reactors numbered 29. Of these, 17 were found to be relevant to K-Reactor in Cold Standby. The relevant open CSAs were mostly concerned with generic, programmatic issues. Table 5.1-1 lists the 17 DOE Orders and open CSAs relevant to K-Reactor in Cold Standby. Additionally, DOE Order 5500.4A, "Public Affairs Policy and Planning Requirements for Emergencies," is under assessment to determine the status of WSRC compliance. There were 13 CSAs and 4 exemption requests identified which are relevant to the L and P-Reactor Disassembly Basins. These CSAs and exemption requests are listed in Table 5.1-2. 


\subsection{COMPENSATORY MEASURES AND SCHEDULES TO COME INTO COMPLINACE}

As noted in Section 5.1, noncompliances with DOE Orders associated with K-Reactor in Cold Standby and L- and P-Reactor Disassembly Basins are either of a generic or programmatic nature. Tables 5,1-1 and 5.1-2 contain the compensatory measures and schedules for each of these Orders. 


\subsection{SAFETY IMPACT OF NONCOMPLIANCES AND DEFTCDENCIES}

As noted in the referenced CSAs and exemption requests, these noncompliances are not judged to increase the hazard level which currently exists. In addition, they do not:

- Involve a significant increase in the probability or consequences of an accident or process hazard previously evaluated

- Create the possibility of a new or different kind of accident from an accident previously evaluated

- Involve a significant reduction in the margin of safety 


\subsection{TIME SPAN OF BIO AS THE AUTHORIZATION BASIS}

WSRC has submitted K-Reactor Compliance Assessment and Implementation Reports for compliance with DOE Order 5480.22 (Ref. 5-4, 5-5) and DOE Order 5480.23 (Ref. 5-6, 5-7). The reports prescribe the steps to upgrade the authorization basis for K-Reactor through the development of Basis for Interim Operation (BIO) documents (such as this one) and an upgraded SAR and Technical Safety Requirements (TSRs). BIOs that reflect the Cold Standby condition, special nuclear material consolidation, and irradiated nuclear material storage and handling and moderator consolidation are being prepared to support the April 19, 1993, Program Execution Guidance (Ref. 5-8) to place K-Reactor in Cold Standby and for continued use of the L- and PReactor Disassembly Basins.

As discussed in Section 4.0 of this BIO, the documents that serve as the existing authorization basis for K-Reactor during Cold Standby and this BIO constitute the authorization basis for KReactor in Cold Standby. The BIO for K-Reactor in Cold Standby brings the authorization basis documents together by reference in one document. Additionally, the BIO provides supplementary information in areas such as DOE Order compliance, safety analyses, and additional administrative controls. This document, and the other BIOs discussed above, will be used to satisfy the KReactor Technical Specification requirement to update the SAR annually. After DOE approval of these BIOs (and any additional BIOs to cover additional missions), the authorization basis will consist of the present SAR and BIOs.

Section 4.0 of this BIO also discusses the documents that serve as the existing authorization basis for the L- and P-Reactor Disassembly Basins. After DOE approval, this BIO will serve as the authorization basis for the L- and P-Reactor Disassembly Basins until such time, as directed by DOE, irradiated components are removed from the basins or the mission of the basins is changed. 
This page intentionally left blank. 


\subsection{CRITICAEITY PROTECTION}

The nuclear criticality safety program at SRS is delineated in Procedure Manual WSRC-IM-9313, Rev. 1, Nuclear Criticality Safety Manual (Ref. 6-2). Nuclear criticality safety is maintained by exercising control over the quantity and configurations of fissile materials and of associated materials that may affect reactivity.

Criticality is prevented by controlling a specified set of variables within sufficiently restrictive limits. The limits imposed upon each controlled variable are sufficient to prevent criticality when other controlled variables have their limiting values and when uncontrolled variables have their most reactive values. A controlled variable may be held within a limit by procedure, by equipment design, or by the physical properties of the materials.

A standing committee, Criticality Review Committee (CRC), composed of representatives from the Reactor Operations Department, the Reactor Engineering Department, Reactor Quality Assurance, and Engineering and Projocts Division, reviews one handling and storage ares in the reactor building quarterty and addresses criticality issues that arise in other areas in the reactor buildings. The reviews satisfy requirements to review each area at least once per year. The reviews address conformance to procedures, adequacy of procedures, and effectiveness of personnel training. A report on each review and follow-up action is submitted to the Reactor Operations Component Handling Manager.

A safety concern for the five main areas that comprise K-Reactor in Cold Standby and the Disassembly Basins of L- and P-Reactors is inadvertent criticality. This concem is described below for each area.

\subsubsection{K-, L-, AND P-REACTOR DISASSEMBLY BASINS}

The fissile materials to be stored in the K-Reactor Disassembly Basin are included in Mark 22 and Mark 16B fuel assemblies; Mark 31A, Mark 51, and thorium stugs; and calibration sources.

The fissile materials stored in the L-Reactor Disassembly Basin are included in Mark 16B and Mark 31A fued and target assemblies, calibration sources, and thorium slugs. The fissile materials stored in the P-Reactor Disassembly Basin are included in Mark 42, Mark 16B, and Mark 22 fuel assemblies; a Pu-Be source; and Am-243 slugs.

In order to prevent a credible criticality event involving the handling of fuel assemblies in the K-, L-, and P-Reactor Disassernbly Besins during normal operations, the Technical Specifications (Ref. 6-3, 6-4, 6-5), Limiting Conditions for Operations 3.9.3, impose restrictions for handling and storing fuel assemblies in the Disassembly Basins.

Safety design features supplemented by administrative controls are implemented to prevent a criticality incident during normal operations. General criticality rules are provided for the K-, L-, and P-Reactor Disassembly Basins as a whole. Safety features include storage racks with 
criticality-safe spacing. The storage techniques and the quantity and type of material in process at any time are limited by administrative safeguards and controls that are included in written operating procedures. Administrative controls are documented for K-Reactor in DPSOL 1053695-K, "Criticality Rules for Fuel Assemblies in Disassembly" (Ref. 6-6). Administrative controls for L- and P-Reactor Disassembly Basins are documented in DPSOL 105-0000L, "105 L Lay-up Rounds" (Ref. 6-7) and DPSOL 105-0000P, "105 P Lay-up Rounds" (Ref. 6-8).

Although a criticality incident would affect the personnel in the K-, L- and P-Reactor Disassembly Basins, there would be no significant offsite impact (Ref. 6-9) (i.e., offsite releases of radioactivity would be within the guidelines of 10 . CFR 100 [Ref. 6-10] as well as DOE Order 5400.5 and 40 CFR 61 [Ref. 6-11, 6-12]).

\subsubsection{K-REACTOR PURIFICATION AREA}

The fissile materials which may be in the Purification Area of K-Reactor are the contaminants removed from the moderator in the HAM and dedeuterization processes. The contaminated moderator contains trace amounts of plutonium; however, the trace amount of plutonium is well below the theoretical minimum critical mass (Ref. 6-6).

\subsubsection{K-REACTOR ASSEMBLY AREA}

The fissile material to be stored in the K-Reactor Assembly Area is contsined in Mark 22 fuel tubes and assemblies and calibration sources. The Mark 22 fuel is received, handled, transported, and stored in the Assembly Area.

The primary safety concern in the K-Reactor Assembly Ares is inadvertent criticality. Hangers (which provide separation between fuel assemblies) and borated concrete storage racks are used to prevent criticality during movement and storage of Mark 22 fuel assemblies. Calculations and muttiplication measurements of the fully loaded borated concrete storage racks confirmed subcriticality by a substantial amount (Ref. 6-13, Section 9.1.1.2.2).

In order to prevent a criticality event involving the handling of unirradiated fuel assemblies in the K-Reactor Assembly Area during normal operations, the Technical Specifications (Ref. 6-3), Limiting Conditions for Operations 3.9.3, impose restrictions for handling and storing fuel assemblies in the Assembly Area.

Safety design features supplemented by administrative controls are implemented to prevent a criticality incident during normal operations. General criticality rules are provided for the KReactor Assembly Area as a whole. Safety features include neutron-absorbing storage racks and drains designed to prevent the accumulation of water in fissile material storage areas. The storage techniques and the quantity and type of material in process at any time are limited by administrative safeguards and controls that are included in written operating procedures. Administrative controls are documented in DPSOL-105-3095A-PLKC, "Assembly Fuel Criticality Rules - Definition and Descriptions," and DPSOL-105-3095B-PLKC, "Assembly Fuel Criticality 
Rules - General Rules,". of DPSOP 25-2 (Ref. 6-14). Floor markings, rope barricades, and signs are used to define the zones for criticality control and are part of administrative controls.

Although a criticality incident would affect the personnel in the K-Reactor Assembly Area, there would be no significant offsite impact (Ref. 6-15) (i.e., offsite releases of radioactivity would be within the guidelines of 10 CFR 100 [Ref. 6-10] as well as DOE Order 5400.5 and 40 CFR 61 [Ref. 6-11, 6-12]).

\subsubsection{K-REACTOR MODERATOR STORAGE AREAS}

The fissile materials to be stored in the K-Reactor Moderator Storage Areas are contained in the form of trace amounts of plutonium in the drums and tanks of moderator. Criticality is not possible in the K-Reactor Moderator Storage Areas because the trace amount of plutonium is well below the theoretical minimum critical mass (Ref. 6-16).

\subsubsection{K-REACTOR PROCESS ROOM}

The fuel and target assemblies have been removed from the Reactor Tarik, therefore, no fissile material is present in the Process Room. 


\subsection{RADIATIŌN PROTECTION}

The policies, design, construction, and operational consideration, as well as the Radiation Protection Program at SRS, ensure that occupational radiation exposure to personnel is maintained As Low As Reasonably Achievable (ALARA). The ALARA policy, as delineated in Reference $6-i 7$, requires the separation of the radiation protection functions from other operational functions and direct communication lines to management. SRS has established a radiation protection program (ALARA Program) (Ref. 6-18, 6-19) for applicable site activities and provides a qualified (RC\&HP) organization to accomplish this goal.

The key elemen: in the ALARA program are the strength and consistency of SRS management support and invorvement. It is the policy of SRS management that employee safety is more important than production, quality, or costs. This concern includes the protection of employees from potential hazards of radiation. The commitment of SRS management to the ALARA concept is demonstrated by the following:

- Management's comprehensive understanding of the site progress and problems in reducing exposure

- Implementation of administrative programs and procedures, in conjunction with area design, to ensure that the occupational radiation exposure to personnel is maintained ALARA in conformance with DOE Order 5480.11 (Ref. 6-20)

- SRS management's assignment of high priority for notification and procedural changes to reduce radiation exposure

- Establishment of the Occupational Health Subcommittee of the SRS Site Safety Committee to provide oversight of the RC\&HP program and other occupational health concerns

- Management's review and approval of realistic and measurable ALARA goals to ensure that they reflect a full commitment to ALARA principles

- Monitoring of monthly progress towards the ALARA goals by SRS managers and supervisors

- Establishment of a training program to educate employees in fully comprehending control procedures and practices and to emphesize that compliance with these policies and procedures is a condition of employment

In order to carry out SRS maragement's commitment to ALARA programs and principles, radiation protection design features and the RC\&HP program, as described in Reference 6-18, have been developed and utilized at SRS.

The objective of radiation protection design features is to reduce personnel and public exposures, in conjunction with a program of controlled personnel access to and occupancy of radiation areas, to levels that are ALARA and within the dose standards of DOE Orders 5480.11 and 5400.5 (Ref. 6-20, 6-11). During the evaluation process of K-Reactor in Cold Standby, and L- and P- 
The Reactor Tank has been drained; therefore, no liquid release potential exists. The sources of airborne and liquidredioactivity in these areas are used for the evaluation of personnel protection measures and dose assessment. Procedures and design are the primary measures used to ensure that exposures are kept ALARA during anticipated personnel activities in areas of the site containing radioactive materials.

The RC\&HP program consists of guidelines, management and worker philosophies, practices, instructions, and procedures that are used to accomplish administrative controls of site personnel activities, work practices, effluent releases from the site waste shipments, and their records. It provides technical support for radiological studies and for radiological training programs. 


\subsection{HAZARDOUS MATERIAL PROTECTION}

SRS complies with the applicable requirements for control of personnel exposure to hazardous materials. There are no hazardous chemicals/materials used, stored, or allowed in K-Reactor in Cold Standby and L- and P-Reactor Disassembly Basins which could adversely affect the health and safety of the public or pose a reasonable risk to workers, except those permitted by the chemical control program. 


\subsection{PROCEDURES AND TRAINING}

\subsubsection{SITE PROCEDURES}

Site procedures have been developed to ensure that routine, off-normal, and emergency activities are conducted in a safe manner. Reactor operations, maintenance, and administrative procedures are written to guide the applicable activities described in Appendix A of Regulatory Guide 1.33 (Ref. 6-22). The procedures are prepared, reviewed, and approved in accordance with writing guides and governing quality assurance and administrative procedures. These procedures are designed to be used by the operating organization to ensure that the limits in the Technical Specifications a he additional restrictions and administrative controls delineated in Section 7.0 of this $\mathrm{BIO}$ are :xceeded.

\subsubsection{Administrative Procedures}

SRS administrative procedures specify the policies, practices, requirements, and instructions necessary for site personnel regarding general site operation. The procedures govern changes to procedures, conduct of operations inside and outside the control room, requirements of personnel training, and changes to systems or equipment that affect safety. This ensures that activities are consistently performed in a way that has been reviewed and approved by independent oversight groups. The administrative procedures include, but are not limited to, the following (Ref. 6-21, 623 through 6-40):

- $\quad$ SRS. Radiological Control, WSRC Procedure Manual 5Q

- Reactor Area Emergency Plan, WSRC Procedure Manual 6Q7

- $\quad$ SRS Conduct of Operations, WSRC Procedure Manual 2S

- Reacter Divisjon Administrative Manual, WSRC Procedure Manual RD-1

- Reactor Quality Assurance and Assessment Department Administrative Manual, WSRC Procedure Manual RD 8.1

- Reactor Division Maintenance Deparment Administrative Manual, WSRC Procedure Mamial R3.2

- Quality Assurance Manual, WSRC Procedure Manual IQ

- Reactor Engineering Department Administrative Manual, WSRC Procedure Manual R5.1

- Work Control Manual, WSRC Procedure Manual RD 3.1

- SRS. Conduct of Engineering and Techrical Support WSRC Procedure Manual E7

- Reactor Division. Zeactor Chemistry Manual, WSRC Procedure Manual RD 2.2

- Reactor Division Fire Protection Program Manual, WSRC Procedure Manual RD 4.1 
- Technical Baseline Program Manual. WSRC Procedure Manual R5.3

- Reactor Division Administrative Manual Training WSRC Procedure Manual RD 6.1

- Conduct of Training WSRC Procedure Manual R6.1

- Peer Evaluation Standard, WSRC Procedure Manual R6.2

- Reactor Restart Division Administrative Manual Procedures, WSRC Procedure Manual RD 7.1

- Blanning Scheduling and Cost Control RRD Administrative Manual WSRC Procedure Manual R13.1

- $\quad$ Conduct of Waste Managements WSRC Procedure Manual R14.1

\subsubsection{Operating Procedure:}

Operations, including abnormal conditions, are controlled by detailed operating procedures as described in Reference 6-38. Operating procedures are approved before use and are prepared to maintain normal operation within the requirements of Technical Specifications. Abnomal Condition Control (ACC) procedures specify actions to be taken to place the K-, L-, or P-Reactor in a safe condition during unusual situations. Emergency procedures specify measures to be taken in evacuating $\mathrm{K}, \mathrm{L}$, or P-Resctor and are compatible with emergency and disaster plans developed for the overall site. Operating and ACC procedures are assigned a numerical code for identification. The code defines the building with which the procedure is associated and identifies the system and function for which the procedure is used.

\subsubsection{Maintenance.Procedurs}

Maintenance procedures maintain safety-related equipment at the required quality level to perform its intended function. These procedures include provisions for repair or replacement of equipment at the time of failure. Maintenance includes both preventive and corrective maintenance. The Reactor Operations Department authorizes maintenance work and determines if the work has been completed satisfactorily.

Other procedures, such as Radiation Contamination and Control procedures, Special and Reactor Special procedures, and Security procedures are provided to support operation. These are as important as operating procedures and follow similar development, verification, authorization, and implementation requirements.

\subsubsection{TRAINING}

The SRS Staff Training program has been developed and implemented to ensure the following:

- Personnel are effectively trained and qualified to safely operate and maintain the site throughout its design life. 
- Changes are adequately understood and accepted by the operating staff, and resulting problems or deficiencies are properly dispositioned.

The Operating and Maintenance Training program has been developed and implemiented based on DOE Orders 5480.18 and 5480.6 (Ref. 6-41, 6-42); American National Standards Institute/American Nuclear Society (ANSVANS) 3.1-1981 (Ref. 6-43); NUREG-0737 (Ref. 644).

Two categories of personnel are trained:

- Certified Personnel

- Qualified Personnel

\subsubsection{Certified Personned}

The training program addresses certification of Component Handling Supervisors in accordance with DOE Order 5480.20 (Ref. 6-45) delineated in RDP 6.01, Reactor Persenned Selection Qualification and Training (Ref. 6-46). Initial training, continuing training, and retraining of certified Component Handling Supervisors are carried out by formal classroom instnuction and on-the-job training. The instruction and training address fuel handling safety, the impact of fuel handling on safety, and actions to be taken during abnormsl and emergency conditions. Initial certification depends on satisfactory completion of comprehensive written examinations, oral examination by an oral board, satisfactory physical condition, general health, and higher supervisor's judgment of general qualifications. Recertification of Component Handling Supervisors is biennial and depends in part on the satisfactory completion of a comprehensive written examination, job performance evaluations, and oral examinations.

\subsubsection{Qualified Perrogned}

Reactor Supervisors, Reactor Building Operators, and Component Handling Operators are qualified in accordance with DOE Order 5480.20 (Ref 6-45). The qualification is carried out by formal classroom instruction, computer-assisted instruction, and on-the-job training through initial training, contimuing training, ind retraining. Initial qualification of Resctor Supervisors, Reactor Building Operators, and Component Handling Operators depends on satisfactory completion of a comprehensive written, oral, and operating examination; satisfactory physical condition; general health; and higher supervisor's judgment of general qualifications. Continuing training will be based on the systerns remaining operable and by generic training requirements such as radiation worker training, general employee training, administrative programs, and safety programs. 


\subsection{TESTING}

The DOE and WSRC recognize the need for testing. WSRC has committed to ensuring adequate review and spproval of the test requirements and procedures used to conduct testing as well as the administrative controls used to control testing in the field. DOE approval of testing conducted within the K-Reactor and within the L- and P-Reactor Disassembly Basins is required, and testing will be controlled by formalized requirements using previously approved operating, surveillance, and special test procedures. Reactor Operations management is required to authorize testing conducted within the areas (Ref. 6-47). Any subsequent tests or experimentation conducted within K-Reactor or the L \& P-Reactor Disassembly Basins will use the USQD process through which a Plant Modification Traveler (PMI) will be included. The USQD process is described below.

\subsubsection{UNREVIEWED SAFETY QUESTION (USQ) PROCESS}

The WSRC USQ process is required by DOE Order 5480.21 (Ref. 6-76) and is implemented by the WSRC 11Q Manual (Ref. 6-75), Procedure 3.10 (7/19/94). Proposed activities, such as facility modifications, equipment modifications, operating procedure revisions which change the operational steps or intent of the procedure, other activities that could affect safe operation of the facility and potential inadequacies (anatytical errors or omissions) in the facility safety analysis, are evaluated by the USQ process. The USQ process evaluation determines if the proposed activity or potential inadequacy is within the current DOE approved facility safety envelope and the risk (product of frequency vs. consequences) associated with the proposed activity are within the DOE accepted facility risk. The proposed activity must be approved by DOE if a USQ Evaluation (USQE) indicates that a USQ is involved with the activity. If no USQ is involved, WSRC implements the activity without DOE approval. Guidelines for determining if a USQ exists, based on changes in frequency and consequence of accidents, are contained in WSRC IIQ Manual (Ref. 6-75), Procedure 3.10 (7/19/94). 


\subsection{SURVEILEANCE}

With the mission of the reactors changing from Operation to Cold Standby and Cold Shutdown, surveillance activities have been evaluated in the areas. of Technical Specifications, Plant Operating Specifications, Operations, Environmental Regulatory, Best Management Practices, and Industrial Safety. These surveillance activities are identified in this BIO and the K-Reactor Cold Standby Plan, L-Reactor Cold Shutdown Plan, K-, L-, and P-Reactor Technical Specifications, and K-Reactor Plant Operating Specifications (Ref. 6-48, 6-49, 6-3, 6-4, 6-5, 650). The planned surveillances for the reactors are as follows:

\section{Technical Specification}

- Fissile material permitted configuration

- Neutron transmissionborated concrete storage racks

- Periodic verification of neutron transmission/cadmium plates in 70-ton shipping casks

- Periodic verification of cadmium plates configuration in 70-ton shipping casks

- Disassembly Basin level and temperature

- Periodic check/calibration of Disassembly Basin temperature instrumentation

- Periodic check/calibration of Disassembly Basin level instrumentation

- Spacers in fuel horizontal storage rack in Disassembly Basin without the fuel blocking system

- Fuel blocking system in Fiel horizontal storage rack in Disassembly Basin

\section{Plant Operating Specifications}

- Compressed air system operation

- Disassembly Basin operation - chemical control

- Periodic inspection of effluent monitoring operability/calibration on the Berthold tritium monitor and hot wire anemometers for all monitoring

- Periodic monitor outfall condition of all areas

- Periodic verification of ventilation exhaust stack flow

- AC power source for 100-K Area verification

- Building 107A-K diesel generator operation

\section{Of. ztions}

- Periodic inspection and testing of the nuclear incident monitoring system

- Periodic floor drain inspection 
- Periodic exterior doorway inspection

- Periodic security cage inspection

- Periodic inspection of temperature in Buildings 105- $K,-L$, and $\cdot P$

- Periodic inspection of the heating system in Buildings 105-K, $-L$, and $-P$

- Periodic inspection of the Kanne monitoring systems in Building 105-K

- Periodic inspection of the Berthold tritium monitoring system for Building 105-K

- Periodic inspection of irradiated fuel in K-, L-, and P- Reactor Disassembly Basins for evidence of accelerated corrosion of fuel assemblies

- Verification of correct machine basin cutting saw stop position before use

\section{Environmental Regulatory}

- Inspection of staging areas for Resource Conservation and Recovery Act (RCRA) compliance

- Certification of hot wire anemometers for National Emission Standards for Hazardous Air Pollutants compliance

- Inventory of material safety data sheets for chemicals present in the area for Occupational Safety Health Act and Emergency Planning and Community Right to Know Act compliance

- Inventory of oil on active underground storage tank systems

- Leak tightness testing of underground storage tanks containing petroleum products

- Maintenance of run $\log$ for active permitted diesels

\section{Best Management Practicss}

- Outfall checks for housekeeping, safety, and accessibility to ensure ease and safety of sampling and to identify and mitigate potential permit violations

- Checks on satellite accumulation areas to ensure RCRA compliance

- Monitor ground water conditions to ensure quality of data and monitor release of radionuclides

- Walk down areas for general regulatory compliance

- Surveillances of personnel training records for compliance with the Spill Prevention Control and Countermeasure Plan and the Best Management Practices Plan required by the Clean Water Act

- Surveillance of personnel for compliance with RCRA 


\section{Industrial Safety}

- Tritium monitor operability

- Ventilation operation

- General building walkthrough

- Combustible/explosive material control

- Public address system operability

- Elevator inspection

- Lifting and handling equipment

- Emergency lighting

The majority of the surveillance requirements for the $L$ and P-Reactor Disassembly Basins are performed in accordance with DPSOL 105-0000-L, "105 L Lay-up Rounds" (Ref. 6-7) and DPSOL 105-0000-P, "105 P Lay-up Rounds" (Ref. 6-8). 


\subsection{MAINTERANCE}

Maintenance has a primary role in ensuring safe and reliable plant operation. To carry out this role, a strong maintenance philosophy and culture based on sound and respected principles have been developed.

A commitment was made to improving the reactor maintenance program at SRS based upon the results of audits performed. In early 1989, a site-wide Maintenance Improvement Plan was issued. That plan formed the basis for the Reactor Maintenance Improvement Plan which was instituted prior to K-Reactor restart. That plan was superseded by the Reactor Maintenance Implementation Plan, which now reflects K-, L-, and P-Reactors' downgraded missions. This plan contains the following elements (Ref 6-51):

- Maintenance Department organization and administration

- Training and qualification of maintenance personnel

- Maintenance facilities

- Corrective, predictive, and preventative maintenance

- Maintenance procedures

- Planning, scheduling, and coordinating maintenance

- Control of maintenance activities

- Post-maintenance testing

- Procurement of parts, materials and service

- Material, receipt, storage, inspection, and handling

- Control and calibration of measuring and test equipment

- Maintenance tools and equipment control

- Station material condition inspection

- Management involvement

- Maintenance history

- Anslyses of maintenance problems

The existing work management system and work control proceturo DMP 3.01 in WSRC Procedure Mamual RD 3.1 (Ref. 6-30) is used to control corrective and preventive maintenance activities in K-Reactor in Cold Standby and in the L- and P-Reactor Disassembly Basins. 


\subsection{CONDUCT OF OPERATIONS}

Westinghouse Savannah River Company of Westinghouse Electric Corporation operates SRS for the U.S. Department of Energy under Contract DE-AC-09-89SR18035. Wackenhut Services, Inc. (WSI) provides protective services for SRS under direct contract to DOE. The SRS reactors are operated by WSRC under a contract administered by the Savannah River Operations Office (SROO) of the DOE. DOE headquarters staff also participates by providing programmatic and regulatory direction.

WSRC is a full-scope, self-sufficient, site management and operation organization designed to accomplish the DOE-SR protuction mission efficiently and cost-effectively while ensuring safe, secure, and environmentally sound operations.

The President of WSRC reports to the Executive Office of Westinghouse Electric Corporation. This placement of WSRC within the corporate reporting structure indicates the high priority given to SRS and ensures management attention at the highest level of the corporation. Westinghouse has assigned a single, onsite executive, the WSRC President, the responsibility and accountability for managing WSRC. Personnel within WSRC who are required for regular day-to-day effort in connection with SRS management and the operating contract are located at or near the site.

Conduct of operations procedures have been implemented at SRS through WSRC Procedure Manual 2S, Conduct of Operations (Ref. 6-24). The manual contains a very detailed and comprehensive organization including diagrams, duties, and responsibilities with interfaces specified in the following areas:

- Shift Tumover

A formal shift tumover program ensures each operator and supervisor is provided the knowledge required to adequately and safely discharge the responsibilities of the shift position or assignment. The shift tumover checklist identifies a number of items and conditions appropriate for shift tumover, including system status, any Limiting Condition for Operation (LCO) in effect, explanation of abnormalities/alarms/ annunciators, logs, and instructions to be reviewed, and changes in radiological status. The oncoming shift personnel are required to have read and signed the applicable shift turnover check sheets.

- Communications

The purpose of the area audible communications system is to alert site personnel to normal, abnormal, or emergency conditions. Reference $6-\dot{2} 4$ establishes guidelines for reliable and accurate transmission of information on the operating shif and for uniform and enforceable policies for the control of wireless communication in the reactor building. The emergency action procedure identifies the types of emergency announcement to be made over the public address system. The control room has the capability for overriding other users (except security) of the public address system for 
emergency announcements. The emergency communications system is tested periodically.

\section{Lockouts}

Lockouts are used to control equipment by removing equipment from service or by retuming off-line equipment to service. Lockouts protect workers and equipment during maintenance activities. WSRC Procedure Manual 8Q (Ref. 6-52) Procedure 32, "Hazardous Energy Control (LockoutTagout) provides the means of writing instructions for the isolation and restoration of equipment and systems to ensure the safety of personnel and equipment during maintenance, modification, inspection, and testing sctivities.

- Notification/Reporting

Events requiring notification of offsite personnel and/or regulatory agencies can occur frequently. Information has to be granted and transmitted in a consistent, systematic, and controlled method in accordance with DOE Orders and national security requirements. DOE Order 5000.3B (Ref. 6-53) lists the requirements for occurrence reporting and processing. At SRS, these requirements are addressed in Management Requirement Procedure (MRP) 4.10, "Site Issues and Employee Concem Coordinator," of WSRC Procedure Manual IB (Ref. 6-54) and Procedure Manual 9B, "Site Item Reportability and Issue Management (SIRMM)," (Ref. 6-55).

- Control of Equipment and Systems

The operating shift must be aware of how equipment and systems will function for operational purposes. Reference 6-24 states that the Shift Managers and the Components Handling Senior Supervisor are responsible for status control of systems. The Control Room Supervisors shall maintain the system's status notebook in the control room. Control Room Supervisors also are required to log changes in system status in the system status notebook. Reference 6-24 addresses the actions necessary to restore equipment to service after maintenance activities.

\section{Independent Verification}

The function of an independent verification program is to verify that site systems and equipment critical to safe reactor operation are configured as intended. Reference 624 establishes guidelines for implementing an independent verification program within the Resctor Operations organization. It also includes the qualifications required for individuals assigned to perform independent verification. It also states that components of safety-related systems on the safety system classification lists (Ref. 656, 6-57) are subject to independent verification.

\section{Control of Operating Procedures}

Reference 6-24 requires that activities shall be performed in accordance with approved procedures. Quality Assurance Procedure (QAP) 5-1, "Instruction, Procedures and Drawings," of WSRC Quality Assurance Manual 1Q (Ref. 6-28) specifies that activities affecting quality shall be prescribed by and perfomed in accordance with 
documented procedures. MRP 3.27, "Management of Division and Department Level Procedures," of WSRC Procedure Manual IB (Ref. 6-54) and DMP 7.1, "Development and Control of Reactor Operations, Component Handling, and Maintenance Procedures," of WSRC Procedure Manual RD 7.1 (Ref. 6-38) specify the requisements that must be met in preparing, revising, and approving procedures.

As a result of the recent changes in mission and staffing levels at $K-, L$, and P-Reactors, the Conduct of Operations Procedure has been reviewed to identify areas to be modified to accommodate those changes. $L$ - and P-Reactor Disassembly Basin staffing will consist of operators who will provide shift and day coverage. Some day supervision will be present, but shift operations will report through the K-Resctor Shift Supervisor. L- and P-Reactor Disassembly Basins Technical Specifications staffing requirements are a qualified operator or a qualifed supervisor or a qualified Shift Technical Coordinator stationed within the K-Reactor CCR. Surveillance of the L- and P-Reactor Disassembly Basins by operators will be by Rounds Sheets (Ref. 6-7, 6-8).

Procedures determined to be safety-related will be modified to reflect the changes in mission and will continue to be in effect. 


\subsection{QUALITY_ASSURANCE}

The WSRC quality assurance program is implemented within the Reactor Division on a graded basis as described in the WSRC Policy Manual (WSRC-1-01) (Ref. 6-17), "WSRC Quality Assurance Management Plan" (Ref. 6-58) and the WSRC Qtuality Assurance Manual (WSRC 1Q) (Ref. 6-28). Activities affecting quality, safety, and/or reliability of Reactor Division operations, products, and services are performed in accordance with documented and approved procedures appropriate for the tasks to be performed. Procedures are used to ensure that quality assurance requirements are planned and systematically implemented as part of the performance of the activity. The quality assurance program provides for the indoctrination and training of personnel, as necessary, to ensure that suitable proficiency is achieved and maintained (Ref. 6-35).

Personnel who perform quality verification activities within the Reactor Division are qualified and/or certified, as appropriate, based on the requirements of the WSRC Quality Assurance Manual. Qualifications/certification programs include documentation of capability through either written tests and/or physical demonstrations of skill and continued maintenance of the individual's proficiency based upon retraining or continued satisfactory performance (Ref. 6-35). 


\subsection{DECONTAMINATTION AND DECOMMISSIONING}

Because K-Reactor in Cold Standby and the L- and P-Reactor Disassembly Basins are continuing use areas, this section is not applicable. 


\subsection{EXPERIAENTAL REVIEW}

Because no experiments are performed in K-Reactor in Cold Standby or the L- or P-Reactor Disassembly Basin, this section is not applicable. 


\subsection{EMERGENCY PREPAREDNESS}

A Reactor Emergency Plan and Site Emergency Plan (Ref. 6-23, 6-59) have been developed and implemented at SRS. These plans include the following:

- A description of the response organization, authorities, responsibilities, and relationship with the SRS Technical Support Center (TSC)/Emergency Operations Facility (EOF) established for responding to an emergency situation that may arise

- A description of emergency classification system and associated emergency action levels (EALs)

- The plans and procedures to be followed

- The staffing and training needs of the emergency response organization

- The areas, equipment, and resource requirements

- Emergency assessment and notification procedures

- Personnel protection procedures

- Criteria for how the effectiveness and readiness of emergency operations will be determined

- Interfaces with the overall SRS program

- Provisions for notification and activation of reactor emergency response team

- Technical assessment and mitigation of area emergency conditions

- Media/public information

The Site Emergency Plan (Ref. 6-59) and the MRP 4.08, "Events, Conditions, and Concerns Determination," of WSRC Procedure Manual IB (Ref. 6-54), satisfy the requirements contained in the DOE 5500 Series Orders. K-, L-, and P-Reactors have consolidated their emergency response into one organization operating out of the K-Reactor Central Control Room. Normal shift staffing consists of four shifts with a supervisor, a shift technical coordinator, shift clerk, and operators to perform building surveillances in the resctors. RC\&HP is staffed with an inspector stationed at each reactor $(K, L$, and $P$ ) and a supervisor which covers the reactors collectively. A minimum of one qualified supervisor, qualified technical coordinstor, or qualified operator shall be stationed within the K-Reactor CCR at all times. 


\subsection{FIRE PRETECTION}

The SRS Fire Protection program (Ref. 6-60) has been established to ensure that, in the event of a fire, the public is protected from uncontrolled releases of radioactive materials to the environment. The program utilizes fire detection and extinguishing systems and equipment, administrative controls and procedures, and trained personnel to meet these goals. The following principles have been established to prevent and mitigate the consequences of potential fires:

- Prevention of fires through strict administrative control of ignition sources and combustible and flammable materials and employee training

- Prompt detection and suppression of fires

Water for fire protection is provided by the domestic and fire water system (DFWS). Fire protection water is provided from a connection to the service clarified water system. A fire is detected and suppressed by smoke and heat detectors, fire alarm systems, manual hose stations, and fire extinguishers. These systems are augmented by stationary and roving fire patrols and by manual fire suppression capabilities. Roving fire patrols for L- and P-Reactors have been discontinued based on low combustible loading, minimal ignition sources, and the L- and PReactor Cold Shutdown mission. Operators using round sheets provide fire watches (Ref. 6-7, 6-8).

The reactors have several smoke detectors in them which are connected to the sitewide fire alarm systern. There are chemical extinguishers throughout the reactors. Security personnel are continuously stationed in K-Reactor and could report fires immediately.

Administrative controls are in place to ensure that the fire protection program is properly implemented and maintained. The Reactor Division Fire Protection program is described in WSRC Procedure Manual RD 4.1, Reactor Division - Fire Protection Propram Manual (Ref. 633). Fire extinguishers are controlled by DPSOL 105-1879C, "Monthly Patrol, and emergency lighting is controlled by DPSOL 105-1879D, "Emergency Lighting System Test, of DPSOP 33044 (Ref. 6-61); and emergency response personnel and equipment are controlled by WSRC Procedure Manual 6Q7, Reactor Area Emergeney Plan (Ref. 6-23).

As delineated in the K-Reactor Cold Standby Plan, L-Reactor Cold Shutdown Plan, and the PArea Standby Plan (Ref. 6-48, 6-49, 6-62) fire hazards were significantly reduced in Cold Standby of K-Reactor and Cold Shutdown of L and P-Reactors due to systerms being drained of flammable liquids, transient combustibles being removed, and work being reduced inside K-, L-, and P-Reactors. Nonessential batteries were removed from the areas and nonessential systems were de-energized. The fire patrol has been replaced by operators utilizing operator round sheets (Ref. 6-63, 6-7, and 6-8). Fire protection is supported by the currently installed fire water system and detection system. (HalonTM systems were disabled in Buildings 105 through 108). DMP 4.01, "Reactor Division Fire Protection Program," (Ref. 6-64) of WSRC Procedure Manual RD 4.1 (Ref. 6-33) was revised to reflect the Cold Standby/Cold Shutdown status of the reactors; DMP 4.03, "Control of Transient Combustibles, " (Ref. 6-65) was modified to reflect the reduced 
hazard condition; and DMP 4.04, "Fire Protection Flame/Spark Permits for Cutting, Welding, and Grinding Accidents's (Ref. 6-66) was modified to reflect the reduced hazard condition. A passive protection inspection (fire barriers/fire doors) procedure was incorporated in Procedure Manual RD 4.1. 


\subsection{OCCUPATIONAL SAFETY AND BEALTH}

The occupational safety and health of the facility workers is carried out through the Industrial Safety and Hygiene program. The goals of the Industrial Safety and Hygiene program are to provide a hazard free work environment. This program is accomplished by reviewing work packages, procedures, and operations which may involve worker exposure to chemicals, biological, or physical hazards. After determination of a hazard to the facility worker, the program assures that the hazard is either minimized or eliminated.

Implementation of safety requirements in WSRC Procedure Manuals 2Q, $4 Q$, and $8 Q$ Procedure 88 \& 89 (Ref. 6-60, 6.67, 6.52) is achieved through training and facility worker commitments. Specific training programs such as lock, try, and tag; basic hazards communication; and occupant fire safety are provided to facility workers on an annual basis. In addition to this, each employee is advised annually through the personal development process or a safety commitment letter that obeying safety nules and working safely are a condition of employment. Similarly, as a result of the direction provided in WSRC 8Q manual, WSRC safety enginetrs conduct a triennial safety review of all the facilities at SRS.

Any time that a modification is made to K-Reactor or L- or P-Reactor Disassembly Ares, a safety review per Procedure 51 of WSRC Procedure Manual 8Q (Ref. 6-52) is performed.

Life safety and fire safety walkdowns are performed in K-Reactor and L- and P-Reactor Disassembly Areas in accordance with Procedure DMP 4.05 of Reactor Division Manual RD 4.1 (Ref. 6-33). This procedure serves to inspect these areas on a monthly basis in order to identify and correct life safety deficiencies within the Reactor Division. Each finding is reported to the appropriate manager and tracked for resolution of the concem. 


\subsection{K-, L AND P-REACTOR DISASSEMBLY BASW SLUDGE REMOVAL PLANS}

The Disassembly Basins have a layer of sludge that covers their floors and walls. The sludge is composed mostly of oxides of iron and aluminum, plus other cations, which contribute greatly to the corrosion of the fuel (see Section 8.0 for a complete discuission of the sludge content and corrosion). Since the sludge negatively impacts corrosion, it is scheduled for removal (along with any scrap material in the bottom of the basins). The sludge on the floors and walls of the basins will be removed using a vacuuming technique. Criticality concerns regarding the vacuuming process concentrating fissile isotopes have been addressed in Reference 6-9 and are detailed in Section 8.0. 


\subsection{K-, L, AND P-REACTOR DISASSEMBLY BASIN LEAK DETECTION}

Currently, leak detection from the Disassembly Basins is performed by water sampling at a number of monitoring wells. However, the monitoring wells are not optimally located for leak detection from the Disassembly Basins. Plans are to drill new wells which are more optimally located to better detect leakage from the Disassembly Basins (Ref. 6-68). The drilling of the new monitoring wells is scheduled for 1995 . Additionally, plans are being made for the installation of a more sensitive level measurement system in the Disassembly Basins (Ref. 6-9). 


\subsection{FUEL RETENTION TIME ANALYSIS, CHEMISTRY CONTROL, AND WATER QUALITY PLANS FOR K-, L, AND P-REACTOR DISASSEMBLY BASINS}

The K-, L-, and P-Reactor Disassembly Basins have historically been used as cooling basins where materials discharged from the Reactor Tanks were temporarily stored before being shipped to the Separations facilities for processing. While the Reactor and Separations facilities were operating, materials usually spent 10 to 18 months in the basins before being processed. Limits for water chemistry in the basins were set at levels which prevented cladding failures due to aluminum pitting corrosion based on this short-term storage time. Though water chemistry was controlled, the primary protection against corrosion of the aluminum-clad fuel was to minimize the storage time prior to shipment to the Separations facilities.

The Separations facilities at SRS have been shutdown since 1988 because of safety upgrades, new regulations, and policy changes. Additionally, there is the possibility that separations processing operations will be delayed another three to four years due to an Environmental Impact Statement for the Separations facilities. In order to prevent aluminum pitting corrosion from causing safety concerns such as radionuclide release and criticality, a better Disassembly Basin storage environment must be achieved (Ref. 6-69).

As a result of extended storage times in the Disassembly Basins, corrosion of the aluminum-clad fuel has become evident. Pitting corrosion is the dominant mode. The primary causes of pitting corrosion is the attack of aluminum from chloride and heavy metal ions and the galvanic couples that result from dissimilar metals.

The conductivity of the K-, L-, and P-Reactor Disassembly Basins has been near $200 \mu \mathrm{mho} / \mathrm{cm}$ in the last few years and is currently about $135 \mu \mathrm{mho} / \mathrm{cm}$. Chloride contents range from 6 to 20 $\mathrm{ppm}$. Sludge and debris in the bottom of the Disassembly Basins is primarily iron and aluminum oxides and acts to concentrate the corrosion causing impurities to increase by a factor of about 10 times (Ref. 6-70, 6-71).

Corrosion of aluminum-clad reactor fuel and target alloys in the Disassembly Basins is believed to be caused by a number of factors which are operating at the same time. The most important of these factors are:

- High water conductivity

- High basin water impurities

- $\quad$ Sludge (source of concentration of corrosive ions, i.e., $\mathrm{Fe}, \mathrm{Cl}$ )

- Galvanic couples between stainless steel and aluminum-clad and couples between different aluminum alloys

- Scratches and dents in protective oxide coating on fuel and target cladding

- Relatively stagnant water (Ref. 6-70, 6-71)

6.18-1

UNCLASSIFIED CONTROLLED NUCLEAR INFORMATION 
All of these factors have to be addressed to ensure successful long-term water storage of aluminum alloys inthe Disassembly Basins. A basin cleanup program has been underway at SRS which involves sludge and debris removal, operation of the portable mixed-bed deionizer water purification systèm as much as possible to lower conductivity and improve water chemistry, increasing surveillance by revising the chemistry limits and sample frequencies, operating the available basin pumps to obtain maximum mixing, improving control of water additions to the basins, and elimination of galvanic couples where possible by moving the fuel and target assemblies to the HBBS. Dissssembly Basin cesium-137 activities will be reduced by operating the existing deionizers filled with organic resin and deionizers or some other vessels filled with zeolite ion exchange material. The water chemistry goals to reduce the corrosion potential in the basins in order to provide a better storage environment are:

- Reducing conductivity ( $<180 \mu \mathrm{mho} / \mathrm{cm}$ with goal of $<10 \mu \mathrm{mho} / \mathrm{cm})$

- Obtaining better mixing through recirculation of besin water through Disassembly Basin cooling system

- Improving water chemistry surveillance with new sampling limits and frequencies (goal of chlorides, nitrates, nitrites, and sulfate anion concentrations $<1$ ppm)

- Reducing cesium-137 activity

- Improving control of basin water additions (eliminate water additions unless the addition will not degrade basin chemistry in emergency situations) (Ref. 6-69, 6-70, 6-71)

These activities are expected to reduce the initiation of new pitting corrosion and slow down the existing basin corrosion processes. With this improved basin storage environment, fuel and target assemblies are expected to corrode at a slower rate than they have previously.

Since most of the fuel and target assemblies have now been stored in the Disassembly Basins for over 5 years without exceeding the radionuclide operating limits and with only small accumulations of fissile material in the sludge at the bottom of the basins and in the filtration systems, storage of these reactor components under an improved basin storage environment for 3 or 4 additional years is expected to result in insignificant increases in the radionuclide activity of the basin water and insignificant increases in the sccumulation of fissile materials. By achieving a basin conductivity gosl of $<10 \mu \mathrm{mho} / \mathrm{cm}$, the initiation of new pits will almost cease and the penetration rate of existing pits will be reduced, thus further reducing any increases in radionuclide ectivity and fissile material accumulation over this extended storage period (Refs. 6-69, 6-70, 6-71). 


\subsection{CONE:TURATON MANAGEMTNT}

A Configuration Control Program, as described in Procedure Manual TE, Configuration Management Mamul (Ref, 6-72) and the WSRC 1E (11/15/94) Mamual (Ref. 6-73) is established to:

- Identify and docament the technical baseline of safety related structures, systems, components, and computer software

- Ensure that changes to the technical baseline are propecty developed, assessed, approved, ispued, and implemented through the use of the following:

- Change Control Review Boards

- Setpoint control

- Design control

- Software contral.

- Technical review and approval process, including performance of a USQ screening/evaluation and review of environmental documentation

- Document contral

- Verification and acceptance process

- Compliance urditing

Maintain a system for recording, safeguarding, and indicating the status of technical baseline documemition.

A Baselining Assessment was performed on the $\mathbf{K}, \mathbf{L}$ and $\mathbf{P}$ Reactor Disassembly Basins Configuration Management (CM) program. The objective of this assessment was to review and evaluate the current status of the program and to identify any programmatic deficiencies therein relative to site CM requiremenes. This assessment identified several-issues with variances from sound CM practicen. Reference 6-74 documents this assessment and provides the conclusions for these issues and ascociated recommendations for disposition of findings and program enhancements. The asessment concluded that, overall, many of the CM objectives were adequately corind in the program procedures and that processes are in place to control change to the facility and to the documents that define the facility. 


\subsection{SAFETY ENVELOPE}

Unirradiated reactor fuel and irradiated components continue to be handled and stored and contaminated moderator contimues to be stored, handled, and processed in K-Reactor during Cold Standby. Though the number of unirradiated fuel tubes andassemblies that can be stored in the Assembly Area has essentially doubled, the amount of moderator that can be stored has increased, and the amount of time that irradiated components were historically stored in the Disassembly. Basin has been exceeded, the methods of storing, handling, and processing these materials remain consistent with the techniques used in the past. This section provides the operating restrictions, administrative controls, and other safety requirements that are necessary to preserve the validity of the safety analyses assumptions and to ensure that K-Reactor (and L- and P-Reactor Disassembly Basins) is operated within the required conditions bounded by the analyses. The safety analyses which evaluated the continued handling and storage of irradiated components and processing of contaminated moderator as has been done in the past in K-Reactor in Cold Standby (and L- and PReactor Disassembly Basins) are discussed in Section 8.0 of this BIO. The safety analyses which evaluated consolidation of unirradiated Mark 22 fuel tubes and assemblies in the K-Reactor Assembly Area and the consolidated storage of contaminated moderator in the K-Reactor Moderator Storage Areas are discussed separately in their respective BIOs (Ref. 7-1, 7-2). The operating restrictions, administrative controls, and other safety requirements delineated in this section are adhered to through the execution of the safety management programs discussed in Section 6.0 of this BIO. The program and procedures delineated in Sections 7.2 and 7.3 are the responsibility of the Reactor Operations Department. The requirements of Sections 7.2 and 7.3 will become a part of the K-Reactor Technical Specifications once this BIO is approved by DOE. Similarly, the requirements of Sections 7.2 and 7.3 which are applicable to $L$ and P-Reactor will become part of their Technical Specifications. 


\subsection{EXISTING TECHNICAL SPECIFICATTONS}

The K-, L-, and P-Reactor Technical Specifications documents (Ref. 7-3, 7-4, 7-5) serve as the current safety requirements documents for K-Reactor in Cold Standby and L- and P-Reactor Disassembly Basins. Based on the current mission for the.Savannah River Site, the Technical Specifications establish the conditions and limitations to place and maintain the K-Reactor in Cold Standby with no planned provision to restart the reactor and the ongoing storage and processing of irradiated materials in the L and P-Reactor Disassembly Basins. Tho Technical Specifications ensure that controls are established for fissile material handling and storage such that nuclear criticality safety is maintained and for maintaining Disassembly Basin water levels and temperatures such that basins overflow, inadequate personnel shielding, or inadequate cooling do not occur.

Revision 16 of the K-Reactor Technical Specifications was approved by DOE on August 5, 1993 and implemented on November 1, 1993. This revision removes limits and conditions that are no longer applicable with K-Reactor in Cold Standby with no planned provision to restart. Revisions 2. and 0 of the $L$ - and P-Reactor Technical Specifications, respectively, were approved by DOE on October 29, 1993 to reflect their current missions. The revisions removed limits and controls that are no longer applicable with $\mathrm{L}$ - and P-Reactors in Cold Shutdown. The remaining Technical Specifications ensure that the operations which will continue in K-Reactor during Cold Standby and in the $L_{-}$and P-Reactor Disassembly Basins (i.e., unirradiated fuel handing and storage in the K-Reactor Assembly Area and irradiated component handling and storage in K-, L-, and PReactor Disassembly Basins) will be maintained within the bounds of the initial analyses and that the assumptions of those analyses are preserved.

The safety analysis documents which evaluate the possible accidents of K-Reactor in Cold Standby and $\mathrm{L}-$ and P-Reactor Disassembly Basins are the Preliminary Hazards Analyses (PHAs) (Ref. 7-6 through 7-9) and criticality analyses (Ref. 7-10 through 7-16). The additional administrative controls provided in Section 7.2 of this BIO and the additional requirements of the BIOs for the K-Reactor Assembly Area and Moderator Storage Areas (Ref. 7-1, 7-2) maintain the assumptions made in the new PHA analyses (Ref. 7-6 through 7-9) and new criticality analyses (Ref. 7-11 through 7-16) and ensures that operations are maintained within the bounds of these analyses. The safety analysis documents are further discussed in Section 8.0 of this BIO and in the BIOs for the Assembly Area and Moderator Storage Areas (Ref. 7-1, 7-2). The current Technical Specifications for K-, L-, and P-Reactors (Limiting Conditions for Operation, 3.9.3, 3.9.4.1, and 3.9.4.2), along with the additional administrative controls specified in Section 7.2 of this BIO, as well as, the additional requirements specified in Sections 7.2 and 7.3 of the BIOs for the Assembly Area and Moderator Storage Areas, address the requirement needed to prevent and mitigate postulated accidents in K-Reactor while in Cold Standby and the L- and P-Reactor Disassembly Basins.

As discussed in Section 4.2 of this BIO, the Technical Specifications were-teveloped in accordance with DOE Order 5480.6 (Ref. 7-17), Title 10 Code of Federal Regulations Part 50, Section 50.36 (Ref. 7-18), and NUREG-1431 (Ref. 7-19) format for Westinghouse Plants 
(Methodically Engineered, Restructured and Improved Technical Specifications [MERITS]). The current K-, Lr, and P-Reactor Technical Specifications meet the intent of DOE Order 5480.22 (Ref. 7-20), but da not comply with some of the content and format provisions. WSRC has submitted a Compliance Assessment and Implementation Report (Ref. 7-21) for DOE Order 5480.22 with a compliance schedule and compensatory measures for $\mathrm{K}$-Reactor and an exemption request for $\mathrm{L}$ - and $\mathrm{P}$-Reactors. 


\subsection{ADDTIONAL ADMINISTRATIVE CONTROLS}

The following administrative controls are necessary to preserve the validity of the safety analyses assumptions in the PHA (Ref. 7-6) for K-Reactor in Cold Standby and in the PHA (Ref. 7-9) for the $L-$ and P-Reactor Disassembly Basins and to ensure that K-Reactor and the $L-$ and P-Reactor Disassembly Basins are operated within the required conditions bounded by the analyses. The additional administrative control required to preserve the validity of the Assembly Area and. . Moderator Storage Areas PHAs (Ref. 7-7, 7-8) are provided in Section 7.2 of the BIOs for these areas (Ref. 7-1, 7-2).

\subsubsection{DISASSEMBLY BASIN WATER CHEMISTRY CONTROL PROGRAM}

The Disassembly Basin Water Chemistry Control Program, delineated in Reference 7-22, establishes water chemistry limits and goals, surveillance requirements, sludge and debris removal objectives, mixed-bed deionizer water purification and filtration systems operation objectives, cooling system recirculation objectives, controls for water additions to the basin, gatvanic couples elimination objectives, and zeolite ion exchange operation objectives. The Disassembly Basin Water Chemistry Control Program, as established by Reference 7-22 and subsequent revisions, shall be adhered to in order that the water chemistry for the K-, L and P-Reactor Disassembly Basins will be improved such that the initiation of new pitting corrosion is reduced and the existing basin corrosion processes are slowed down.

The irradiated fuel in the K-, L- and P-Reactor Disassembly Basins shall be periadically inspected for evidence of accelerated corrosion and degradation of fuel assemblies.

The tritium content of the water in the K-, L-, and P-Reactor Disassembly Basins shall be less than or equal to $1.51 \times 10^{-3} \mathrm{Ci} / \mathrm{gal}$. The cesium-137 radioactivity of the water in the $\mathrm{K}$-, $\mathrm{L}$-, and P-Reactor Disassembly Basins shall be less than or equal to $1.70 \times 10^{-6} \mathrm{Ci} / \mathrm{gal}$.

\subsubsection{FIRE LOADING}

Combustible materials shall be minimized in or around K-Reactor except as delineated by the fire protection program.

\subsubsection{EXPLOSTVES}

Explosives or potentially explosive materials shall not be permitted in or around K-Reactor except for delivery truck fuel and batteries and ammunition carried by the security forces. Diesel fuel for various diesels, emergency vehicles, and construction vehicles such as cranes and backhoes will also be permitted on an as needed basis. 


\subsubsection{HAZARDOUS CHEMICALS}

Hazardous chemicals shall not be permitted in K-Reactor except as permitted by the chemical control program.

\subsubsection{DISASSEMBLY BASIN INVENTORY LIMTT}

No additional SNM shall be added to the K-, L, or P-Reactor Disassembly Basins without an USQD screening/evaluation being performed.

\subsubsection{MACEINE BASIN CUTTING SAW STOP}

The machine basin cutting saw stops in the $\mathrm{K}-, \mathrm{L}$, and P-Reactor Disassembly Basins shall be adjusted and verified for each. fuel type before end-fittings are cut from the fuel assembly to ensure the saw does not cut into the fuel region of the assembly.

\subsubsection{CRITICAITTY BARS}

Criticality bars shall be used with the K-, L-, and P-Reactor bundling stations during fuel bundling operations. 


\subsection{ADDITIONAL RESTRICTIONS ON OPERATION}

There were no restrictions on operation found to be necessary to preserve the validity of the safety analyses assumptions in the PHA (Ref. 7-6) for K-Reactor in Cold Standby or in the PHA (Ref. 7-9) for the-L- and P-Reactor Disassembly Basins or to ensure that K-Reactor and the Land P-Reactor Disassembly Basins are operated within the required conditions bounded by the analyses. The additional restrictions on operation required to preserve the validity of the - Assembly Area and Moderator Storage Areas PHAs (Ref. 7-7, 7-8) are provided in Section 7.3 of the BIOs for these areas (Ref. 7-1, 7-2). 
WSRC-TR-94-207-\$V REVISION 0

\subsection{PROGRAMS FOR CONFORMANCE WITH APPLICABLE SAFETY STANDAR్̄ S}

Programs which ensure conformance with applicable safety standards are discussed in Section 6.0 of this BIO. 
This page intentionally left blank. 
WSRC-TR-94-207-DU

REVISION 0

\section{$-\quad 8.0 \quad$ SAFETY ANALYSIS}

\subsection{APPROACH FOR HAZARD IDENTIFICATIONLCATEGORIZATION}

The purpose of K-Reactor in Cold Standby is to provide continued safe and environmentally sound storage and handling of unirradiated fuel assemblies and irradiated fuel, targets, and other reactor components, safe and environmentally sound storage and processing of contaminated moderator, arid safe storage of chemicals necessary for the continued operation of these activities. While the term "reactor" is used for historical reasons, no fuel remains in the Reactor Tank. Therefore, the K-Reactor complex is actually areas which are used for the storage, handling, and processing of these reactor items and contaminated moderator. K-Reactor includes five major areas, the Disassembly Basin, Purification Area, Assembly Area, Moderator Storage Areas, and Process Room (Reactor Tank): The K-Reactor Disassembly Basin contains irradiated fuel and target assemblies (900 Mark 22 fuel assemblies, 1 Mark 16B fuel assemblies, 90 Mark 31A target slugs, 16 Mark 50A slugs, and 82 Mark 60B target assemblies), $169 \mathrm{Co}-60$ slugs, $192 \mathrm{Li}-\mathrm{Al}$ control rods, $4 \mathrm{Cf}-252$ source rods, and 3,400,000 gallons of contaminated light water (Ref 8-1). The Purification Area contains equipment for processing degraded and contaminated moderator (up to the equivalent of twelve 55-gallon drums of contaminated moderator). The Assembly Area contains up to 1620 unirradiated Mark 22 fuel tubes and assemblies (three full Mark 22 charges, plus spare tubes and replacement assemblies). The Moderator Storage Areas contain up to approximately 230,500 gallons of contaminated moderator (59,500 gallons in storage tanks and 171,000 gallons in 55-gallon drums). The Moderator Storage Areas are the -40 -foot-elevation moderator storage tank room; stack area; crane maintenance area; -40 -foot-elevation crossover area; -40-foot-elevation motor rooms; and -40-foot-elevation access wells. Miscellaneous irradiated and unirradiated reactor components (e.g., boron carbide safety rods, instrument rods, sparjets, and other stainless steel and aluminum reactor components) will remain in the Reactor Tank. The miscellaneous irradiated and unirradiated reactor components in the Reactor Tank do not pose a radioactive contamination release potential.

The purpose of $\mathrm{L}$ - and P-Reactor Disassembly Basins are to provide continued safe storage and handling of irradiated fuel, targets, and other reactor components, and safe storage of chemicals necessary for the continued operation of these activities as has been done in the past. The $L$ Reactor Disassembly Basin contains irradiated fuel and target assemblies (516 Mark 16B fuel assemblies, $5 \mathrm{Tm}-170$ slugs, 4 Mark 31A assemblies, 1 Mark 50A slug, 6,525 Mark 31A slugs, and 1 Mark $16 \mathrm{~B}$ inner target), $603 \mathrm{Co}-60$ slugs, $23 \mathrm{Li}$-Al control rods, $4 \mathrm{Cf}-252$ source rods, 1 $\mathrm{Pu}-\mathrm{Be}$ source, $135 \mathrm{Li}-6$ spanger slugs and $18 \mathrm{Pu}$ monitor pins, and 3,400,000 gallons of contaminated light water (Ref. 8-1). The P-Reactor Disassembly Basin contains irradiated fuel and target assemblies (2 Mark 42 fuel assemblies, 396 Mark 22 fuel assemblies, 53 Mark 16B fuel assemblies, 81 Mark 60B assemblies, $1 \mathrm{Co}-60$ slug, $2 \mathrm{Cf}-252$ slugs, and 60 Mark 51 slugs), $305 \mathrm{Li}$-Al control rods, $2 \mathrm{Cf}-252$ source rods, $1 \mathrm{Pu}-\mathrm{Be}$ source, and $90 \mathrm{Li}-6$ sparger slugs, and $4,800,000$ gallons of contaminated light water (Ref. 8-1). 
It will be shown that the hazards in K-Reactor bound those of the L- and P-Reactor Disassembly Basins.

Hazards assessments for K-Reactor in Cold Standby have been performed to determine the overall hazard categorization (Ref. 8-2, 8-3, 8-4). Radiological hazards of consequence have been identified in the following K-Reactor major areas: Disassembly Basin, Purification Area, Assembly Area, and Moderator Storage Areas. The overall categorization is based on the. consequences of a postulated radionuclide and/or chemical release from K-Reactor, as well as the potential for a criticality event.

For the purpose of the hazard assessment, K-Reactor in Cold Standby is considered to be all buildings within the K-Reactor limited area fence and those buildings outside the K-Reactor limited area fence specifically related to K-Reactor processes (Buildings 190-K, 151-K, 152-K, and $183-\mathrm{K}$ ).

Hazards assessments for $\mathrm{L}$ - and P-Reactor Disassembly Basins have also been performed to determine the overall hazard categorization (Ref. 8-5, 8-6). The overall categorization is based on the consequences of a postulated radionuclide and/or chemical release, as well as the potential for a criticality event.

The criteria for determining the radiological hazard categorization are provided in DOE-STD1027-92 (Ref. 8-8) and the criteria for determining the chemical hazard categorization are provided in WSRC-MS-92-206 (Ref 8-9). In DOE Order 5480.23 (Ref. 8-7), three hazard categories are defined. A facility is designated as Hazard Category 1 if the analysis shows the potential for significant offsite consequences, Hazard Category 2 if the hazards analysis shows the potential for significant onsite consequences, and Hazard Category 3 if the analysis shows the potential for significant localized consequences only. A facility that does not exceed the Hazard Category 3 threshold criteria but still possesses some amount of radioactive material is considered a Radiological Facility. A facility is designated as General Use if it poses no radiological hazard and minimal, below specified threshold values, chemical hazards.

In general, the radiological evaluation is accomplished by comparing the inventory of each radionuclide to the threshold quantities provided in Table A.1 of DOE-STD-1027-92 (Ref. 8-8). In addition, the quantity of mixed fission products is also considered.

The analysis of the chemical inventory begins with a comparison of each chemical to the Reportable Quantities (RQs) of 40 CFR 302.4 (Ref. 8-10), the threshold planning quantities (TPQs) of 40 CFR 355 (Ref. 8-11), and the threshold quantities (TQs) of 29 CFR 1910.119 (Ref. 8-12). Analysis is not required for any chemicals that do not exceed the RQs of 40 CFR 302.4, the TPQs of 40 CFR 355, or the TQs of 29 CFR 1910.119 because chemicals in quantities less than those listed are generally accepted by the public. Following the initial screening process, the chemicals are evaluated in accordance with the criteria of WSRC-MS-92-206 (Rof. 8-9). The criteria for determining the hazard categorization of nuclear facilities based on the radiological and chemical evaluations are established as follows: 


\section{Hazard Categery 1-}

- The facility has the potential for significant offsite consequences based on total Curie content, potential material forms, and maximum energy for dispersion available. Oniy Category A reactors or facilities désignated by the Program Secretarial Officer (PSO) are designated as Hazard Category 1 in accordance with the directions of DOE-STD. 1027-92 (Ref. 8-8).

- A postulated release of any hazardous chemical results in an airborne concentration greater than its Emergency Response Planning Guideline 3 (ERPG-3, Ref. 8-9) value at the site boundary.

- For chemical compounds that have been identified as confirmed or suspected carcinogens, the calculated incremental cancer risk (ICR) is greater than or equal to 2.00 at the site boundary.

\section{Hazard Category 2}

- The quantity of any radionuclide exceeds the Hazard Category 2 threshold quantity provided in Table A.1 of DOE-STD-1027-92 (Ref. 8-8). This quantity is based on 1 rem at 100 meters (onsite) as determined in 10 CFR 30 and modified by DOE.

- The minimum critical mass limit for any fissile material as specified in ANSI/ANS 8.1 (Ref. 8-13) is exceeded.

- The total quantity of mixed fission products, where the individual radionuclides have been determined is greater than 1000 Curies.

- Where there are combinations of radioactive materials, the sum of the ratios of the quantity of each radionuclide to the Hazard Category 2 thresholds exceeds 1.0.

- A postulated release of any hazardous chemical results in an airborme concentration greater than its ERPG-3 (Ref. 8-9) value onsite at a distance of 100 meters.

- For chemical compounds that have been identified as confirmed or suspected carcinogens, the calculated ICR is greater than or equal to 2.00 onsite at a distance of 100 meters.

\section{Hazard Category 3}

- The quantity of any radionuclide exceeds the Hazard Category 3 threshold quantity provided in Table A1 of DOE-STD-1027-92 (Ref. 8-8). This quantity is based on 10 rem at 30 meters for a 24-hour exposure.

- Where there are combinations of radioactive materials, the sum of the tatios of the quantity of each radionuclide to the Hazard Category 3 thresholds exceeds 1.0.

- A postulated release of any hazardous chemical results in an airbome concentration greater than its ERPG-3 (Ref. 8-9) value at the facility. 
- For chemical compounds that have been identified as confirmed or suspected carcinogens, the calculated ICR is greater than or equal to 2.00 locally at the facility.

\section{Radiological Facility}

- Where there are combinations of radioactive materials, the sum of the ratios of the quantity of each radiomuclide to the Hazard Category 3 thresholds is less than one but greater than zero.

\section{General Use Facility}

- The term "General Use" is used when: 1) a postulated release of any hazardous chemical results in an airbome concentration less than its ERPG-3 (Ref. 8-9) value at a distance of 30 meters or 2) the calculated ICR, for chemical compounds that have been identified as confirmed or suspected carcinogens, is less than 2.00 at adistance of 30 meters.

In compliance with the DOE standard, the hazard categorization is determined by comparing the K-Reactor inventory against threshold quantities of radionuclides as set forth in DOE-STD-102792 (Ref. 8-8). Hazard assessments for the Assembly Area and Moderator Storage Areas (Ref. 8$3,8-4)$ were performed separately and in both cases, these areas were designated as Category 2. The assessment of the radiological hazards associated with K-Reactor in Cold Standby (including the Purification Area) which were not separately assessed primarily focused on the Disassembly Basin. The Disassembly Basin radiomuclide inventory consists of fission products, production materials, and residual target and fuel materials contained in the irradiated fuel assemblies, target assemblies, source rads and control rods. A comparison of the inventories of these radionuclides with the threshold limits provided in Table A.1 of DOE-STD-1027-92 demonstrated the following:

- The quantities of total mixed fission products in the Disassembly Basin were greater than the Hazard Category 2 threshold limit.

- The total mass of fissile materials in the Disassembly Basin, determined from criticality limits as well as from threshold quantity evaluation, was above the minimum critical mass limits specified in ANSU/ANS 8.1-1983 (Ref. 8-13).

The chemical inventory of K-Reactor and the allowable chemical list in K-Reactor were compared against the criteria stated above and there were no chemicals identified as non-radiological hazardous chemicals (Ref 8-15).

The analysis conducted to determine the hazard categorization is performed without credit taken for engineered features or administrative controls. Examples of engineered features and administrative controls are those specific facility features (not including site location) such as building containment, stacks, equipment, systems, actions, or operating conditions, that are established to control risk. For chemical hazards, credit is to be taken for the existing location 
and the physics of a material release and dispersion, but not for containment, confinement, shielding, protection systems, administrative controls, or human activities.

Based on the radiological and muclear criticality hazards assessments of K-Reactor performed in accordance with DOE-STD-1027-92 (Ref. 8-8), the Purification Area is designated Hazard Category 3 and the Disassembly Basin is designated Hazard Category 2 (Ref. 8-2). As a result of the Hazard Category 2 designation of the Disassembly Basin, Assembly Area (Ref. 8-3), and Moderator Storage. Areas (Ref 8-4), K-Reactor in Cold Standby is designated as a Hazard Category 2 Nuclear Facility because the highest category segment in the facility is Hazard Category 2.

Similarly, the $L_{-}$and P-Reactor Disassembly Basins are designated Hazard Category 2 (Ref. 8-5, 8-6). 


\subsection{IDENTIFICATION OF CHEMICALS IN EXCESS OF OSHA THRESHOLD PLANNING QUANTITIES}

The method of determining which chemicals are hazardous and then determining the extent of the hazard is based upon the methodology in Reference 8-9 and is as follows. First, the chemical inventory for K-Reactor in Cold Standby and the L- and P-Reactor Disassembly Basins (Ref. 815) was obtained. In addition to the inventory, the allowable chemicals list (Ref. 8-16) for the 100 Areas were reviewed to ensure all chemicals possible in the reactors were addressed. This list of chemicals included many normal household items such as soaps, cleaning supplies, paints, oils, and insect sprays. Per 40 CFR Part 355.20 (Ref. 8-11), the Environmental Protection Agency (EPA) definition of "hazardous chemicals" specifically excludes the following:

"Any substance to the extent it is used for personal, family, or household purposes or is present in the same form and concentration as a product packaged fordistribution and use by the general public."

Using this criteria, many of the chemicals were excluded based on the methodology/guidelines delineated by Reference 8-9. The remaining chemicals along with the maximum quantities and the material safety data sheet (MSDS) numbers are given in the hazard assessment documents (HADs) for K-Reactor in Cold Standby and the L- and P-Reactor Disassembly Basins (Ref. 8-2, $8-5,8-6)$. These are then further screened against the criteria provided in Reference 8-14. These criteria are as follows:

1. The material is a sample.

2. The material is used in a laboratory setting, in laboratory scale quantities.

3. The material is commonly used in industry and/or by the general public. This includes any substance to the extent it is used for personal, family, or household purposes or is present in the same form and concentration as a product packaged for distribution and use by the general public (e.g., motor oil, gasoline, diesel fuel, etc.) -

4. The material is obviously a solid under normal circumstances and does not present an airbome concern.

5. The material is not considered hazardous (no acute, chronic, or carcinogenic effect) to humans as a result of inhalation.

6. The material has a vapor pressure of $<0.5 \mathrm{~mm} \mathrm{Hg} @ 25^{\circ} \mathrm{C}$ and a calculated ERPG-2 (Ref. 8-9) concentration > 1 ppm.

The HADs (Ref. 8-2, 8-5, 8-6) show that the only remaining material after applying this criteria is nitric acid for K-, L-, and P-Resctors and sodium hydroxide in solid form for P-Reactor. Following the methodology of Reference 8-14, the maximum quantity of nitic_acid for any reactor building (164lbs) (Ref. 8-2, 8-5, 8-6) was compared against the lesser of the SARA Title III threshold planning quantity (1000 lbs [Ref. 8-11]), the reportable quantity (1000 lbs [Ref. 8$10]$ ), and the threshold quantity (500 lbs [Ref. 8-12]). Similarty, the maximum quantity of solid 
sodium hydroxide in P-Reactor (22 lbs) was compared against the reportable quantity (1000 lbs [Ref. 8-10])

Since the maximum quantity of nitric acid (164 lbs.) is less than all three hazardous material quantities, nitric acid can be screened from consideration. Also since the maximum quantity of solid sodium hydroxide in P-Reactor $(22 \mathrm{lbs})$ is less than the reportable quantity, sodium hydroxide can be screened from consideration.

Therefore, there are no non-radiological hazardous chemicals identified in sufficient quantities in K-Reactor in Cold Standby (Ref 8-2) or L- or P-Reactor Disassembly Basins (Ref. 8-5, 8-6).

Section 7.2.4 of this (BIO) ensures that chemicals other than those on the allowable chemical list are not permitted in K-, L, and P-Reactor and that those chemicals that are allowed do not exceed the specified maximum limits.

In addition to the chemical hazards assessment discussed in the HAD for K-Reactor in Cold Standby (Ref. 8-2) and the HADs for $L$ and P-Reactor Disassembly Basins (Ref. 8-5, 8-6), additional chemical hazards assessments were performed separately for the Assembly Area and Moderator Storage Areas of K-Reactor (Ref. 8-3, 8-4). There were no hazardous chemicals identified in these areas except for asbestos in the walls of the Assembly Area. The HAD for the Assembly Area (Ref. 8-3) assessed the asbestos in the walls of the Assembly Area and concluded that the probability of the walls constituting a chemical hazard is judged not credible. Therefore, the probability of exposure of personnel to asbestos fibers during high-energy events is judged to be negligible. 


\subsection{DESCRIPTION OF PHA METHODS AND RESULTS}

The purpose of the (PHA) of K-Reactor (Ref 8-17) is to provide a qualitative risk analysis of possible accident scenarios in K-Reactor during its Cold Standby mission, in support of this BIO, that were not evaluated in separate PHAs for the Assembly Area and Modarator Storage Areas of K-Reactor (Ref. 8-18, 8-19). The PHA for K-Reactor in Cold Standby in conjunction with the PHAs for the Assembly Area and Moderator Storage Areas, comprehensively identifies potential events associated with K-Reactor in Cold Standby and their initiators, estimates their frequencies and consequences, and displays the results in a risk matrix. Similarty, the PHA for the L- and PReactor Disassembly Basins comprehensively identifies potential events associated with the $L$ and P-Reactor Disassembly Basins and their initiators, estimates their frequencies and consequences, and displays the results in a risk matrix. This is needed to ensure that the $\mathrm{K}$ Reactor analyses bound the $\mathrm{L}-$ and P-Reactor Disassembly Basin analyses. The identification of the comprehensive accident spectrum, the semi-quantitative determination of the frequencies and consequences of those accidents, and the presentation of the results of the analysis in a risk matrix satisfy the requirements in the DOE standard (Ref. 8-20). Where possible, actual accident frequency data are used, and where none is available, the frequency is either explicitly calculated or estimated by engineering judgment. The PHA focuses attention on those scenarios that are of greatest concern (i.e., highest risk).

Each accident scenario has its own assumptions. In general, the following assumptions were made that are applicable to the entire accident scenario spectrum. They are:

1. The tritium content of the water in the K-, L-, and P-Reactor Disassembly Basins are calculated by assuming a tritium content equal to the operating limit of $0.4 \mu \mathrm{Ci} / \mathrm{ml}$ (Ref. 8-21, Table 1). This is equal to $1.51 \times 10^{-3} \mathrm{Ci} / \mathrm{gal}$. The cesium-137 content of the water in the K-, L-, and P-Reactor Disassembly Basins are calculated by assuming a cesium-137 content equal to the operating limit of $1000 \mathrm{dpm} / \mathrm{ml}$ (8-21, Table 1). This is equal to $1.70 \times 10^{-6} \mathrm{Ci} / \mathrm{gal}$. It is also assumed $3,400,000$ gallons of water reside in each of the K- and L-Reactor Disassembly Basins (Ref. 8-22, 8-23) and 4,800,000 gallons of water resides in the P-Reactor Disassembly Basin (Ref 8-23).

2. The radionuclides present in the sludge at the bottom of each Disassembly Basin are assumed to be negligible compared to the radionuclides in the irradiated fuel. References 8-24, 8-25, and 8-26 calculate the following fissile isotopic content of the sludge of the K-, L, and P-Reactor Disassembly Basins: 


\begin{tabular}{|c|c|c|c|}
\hline $\begin{array}{l}\text { Isotope } \\
-\end{array}$ & $\begin{array}{c}\text { K Basin } \\
\text { Mass (g) }\end{array}$ & $\begin{array}{c}\text { L Basin } \\
\text { Mass (g) }\end{array}$ & $\begin{array}{c}\text { P Basin } \\
\text { Mass (g) }\end{array}$ \\
\hline U-233 & 0.7 & 1.6 & ND \\
\hline U-235 & 906.9 & 125.5 & 179.7 \\
\hline Pu-239 & 191.3 & 17.8 & 61.7 \\
\hline Pu-241 & 3.8 & 0.3 & ND \\
\hline Am-242m & 3.3 & 0.6 & ND \\
\hline Cm-243 & 1.9 & 0.5 & ND \\
\hline
\end{tabular}

Notes: ND-None Detectable

Reference 8-67 calculates the concentration of non-fissile isotopes in the sludge of KReactor Disassembly Basin through various chemical, analytical, and spectroscopy methods based on a total sludge mass of $1.8 \times 10^{8}$ grams (Ref. 8-24):

\begin{tabular}{|l|c|c|c|}
\hline \multicolumn{1}{|c|}{ Isotope } & $\begin{array}{c}\text { Sample } \\
\text { concentration } \\
(\mu \mathrm{Ci} / \mathrm{g})\end{array}$ & $\begin{array}{c}\text { Total } \\
\text { Sludge } \\
\text { Mass }(\mathrm{g})\end{array}$ & $\begin{array}{c}\text { Isotope } \\
\text { Amount } \\
(\mathrm{Ci})\end{array}$ \\
\hline $\mathrm{Co}-60$ & $3.96 \times 10^{-2}$ & $1.8 \times 10^{8}$ & $7.1 \times 10^{0}$ \\
\hline $\mathrm{Ru}-106$ & $3.10 \times 10^{-3}$ & $1.8 \times 10^{8}$ & $5.6 \times 10^{-1}$ \\
\hline $\mathrm{Sb}-125$ & $3.39 \times 10^{-3}$ & $1.8 \times 10^{8}$ & $6.1 \times 10^{-1}$ \\
\hline $\mathrm{Cs}-137$ & $3.44 \times 10^{-3}$ & $1.8 \times 10^{8}$ & $6.2 \times 10^{-1}$ \\
\hline $\mathrm{Ce}-144$ & $2.47 \times 10^{-3}$ & $1.8 \times 10^{8}$ & $4.4 \times 10^{-1}$ \\
\hline $\mathrm{Eu}-154$ & $5.40 \times 10^{-4}$ & $1.8 \times 10^{8}$ & $9.7 \times 10^{-2}$ \\
\hline Eu-155 & $3.49 \times 10^{-4}$ & $1.8 \times 10^{8}$ & $6.3 \times 10^{-2}$ \\
\hline
\end{tabular}


Thus, the sludge isotopic content is negligible compared to the irradiated fuel isotopic content.

The trittum concentration of the sludge is $0.172 \mu \mathrm{Ci} / \mathrm{ml}$ (Ref. 8-21), and thus the sludge of K-Reactor Disassembly Basin contains:

$$
\cdot(0.172 \mu \mathrm{Ci} / \mathrm{ml})\left(1 \mathrm{ml} / \mathrm{cm}^{3}\right)\left(1.8 \times 10^{8} \mathrm{~cm}^{3}\right) \doteq 31 \mathrm{Ci}
$$

Thus the sludge tritium content is also assumed negligible.

3. All moderator has been drained and dried from the process water system (Ref. 8-27).

4. Building 105-K roof, including the Disassembly Area roof and Purification Area roof, will withstand a wind-induced ventilation stack failure (i.e., the Building 105-K roof will withstand direct and indirect damage from a falling ventilation stack. The Disassembly Area roof is too far away to be directly impacted by a falling ventilation stack).

5. Operator rounds are assumed to occur every 12 hours for the Disassembly Basin.

6. For the purposes of these analyses, any event with a probability of less than $1 \times 10^{-6} / \mathrm{yr}$ will be considered not credible and will not be analyzed further.

The accident scenario spectrum is divided into two main subgroups: naturally occurring phenomena and process phenomena. Each subgroup is then subdivided into actual accident scenarios, and their respective frequencies, forces, and consequences are calculated or estimated. The scenario classes are defined in Attachment 1 of Reference 8-20.

The results of the analysis of each initiating event discussed in this BIO and the corresponding scenario are summarized in the risk matrix of Tables 8.3-1 and 8.3-2. The results of the analyses of the postulated events in the K-Reactor Assembly Area and Moderator Areas are provided in References $8-18$ and $8-19$, respectively.

\subsubsection{NATURAL PHENOMENA}

The natural phenomena scenarios are:

Straight Winds/Tomadoes

Stack Failure (straight winds induced)

Missiles (tornado induced)

Floods

Earthquake

Lightning

Meteorites 


\section{Freezing Temperature}

Snow añd Ice induced building failure

\subsubsection{Winds}

High winds (straight winds and tomadoes) at SRS present a potential destructive force to the structures in K-, L, and P-Areas. The isotopes stored in K-Reactor (i.e., Disassembly Basin, . . Purification Area, Assembly Area, Moderator Storage Areas, and Process Room), and the $L-$ and P-Reactor Disassembly Basins generally are not subject to wind damage, as Buildings 105-K, 105-L, and 105-P are reinforced concrete structures hardened to withstand $1000 \mathrm{psf}$ forces (windspeeds in excess of $600 \mathrm{mph}$ ) (Ref. 8-28, Section 3.3). However, the Buildings 105-K, 105$L$, and 105-P ventilation exhaust stacks are designed to withstand winds up to only $185 \mathrm{mph}$ (Ref. 8-29). Winds greater than $185 \mathrm{mph}$ may cause the stacks to fail; however, as stated in Section 8.3, Buildings 105-K, 105- $\mathrm{L}$, and 105-P will withstand the falling stack debris due to their reinforced concrete structure. Additionally, other buildings in K-Area are built to withstand 20 psf. Also, some ancillary structures of the $\mathrm{K}$-, $\mathrm{L}$, and P-Reactor Disassembly Basins reside outside Buildings 105-K, 105-L, and 105-P. The buildings/structures outside of Buildings 105-K, 105-L, and 105-P will conservatively be assumed to fail, and the falling debris will be assumed to cause damage only if it is physically able to strike the area. Any hazardous material stored in one of these buildings/structures will be conservatively assumed to be released.

\section{BUILDING DAMAGE}

Buildings 105-K, 105-L, and 105-P are designed to withstand 1000 psf forces. This corresponds to a wind velocity in excess of $600 \mathrm{mph}$ which is considered not credible. Winds that can damage these structure are therefore not credible. No further analysis need be done on Buildings 105-K, 105-L, and 105-P for winds. However, some K-, L-, and P-Reactor Disassembly Basin ancillary structures (e.g., deionizers, settler tank, sand filters) reside outside the reinforced concrete structures and are vulnerable to straight wind and tornado damage. These events are bounded by process phenomena covered in Section 8.3.2.

Ventilation exhaust stack failure is dealt with in Section 8.3.1.1.2. As described in Section 8.2, no other buildings in $\mathrm{K}-, \mathrm{L}$, and P-Areas within the scope of this analysis contain any hazardous materials which need to be analyzed.

\section{Straight Winds/Tornado Probabilities}

The various straight wind and tornado speed probabilities associated with the Savannah River Site are provided in References 8-28 and 8-30, respectively. As stated above, Buildings 105-K, $105-$ $\mathrm{L}$, and 105-P are hardened to withstand 1000 psf forces and that winds of a sufficient speed to damage Buildings 105-K, 105-L, and 105-P are not credible.

8.3-4 
Forces Associated with Strajeht Winds/Tornadoes

Not Applicable since Buildings 105-K, 105-L, and 105-P are reinforced concrete structures that will withstand credible winds.

\section{ConseguencsadDamage Associated with Straight WindsurTornadoes}

Not Applicable since Buildings 105-K, 105-L, and 105-P are reinforced concrete structures that will withstand credible winds.

\section{STACK FAUURE}

Another scenario involves a high wind causing a structural failure of the Buildings $105-\mathrm{K}, 105-\mathrm{L}$, and 105-P ventilation exhaust stacks. The ventilation exhaust stacks represents large-sources of stored energy (owing to their hieight and mass) and have been postulated to damage equipment and materials in Buildings 105-K, 105-L, and 105-P. The exhaust stacks are seismically qualified; however, they are not designed to withstand winds greater than 185 mph (Ref. 8-29). Two mechanisms for stack failure damage are discussed for the stack: direct and indirect stack hit.

\section{Stack Failure Probabilities}

Two scenarios involving stack failure have been examined and are discussed below:

\section{Direct Stack Hit on Buildings 105-K, 105-L, and 105-P}

This scenario involves the Buildings $105-\mathrm{K}, 105-\mathrm{L}$, and $105-\mathrm{P}$ ventilation stack debris falling directly on the roofs. However, as stated in Section 8.3, Building 105-K roof over the Purification Area will absorb the energy of falling stack debris without damaging the radionuclide storage or chemical hazard storage because the structure is reinforced concrete capable of withstanding a 1000 psf blast. The K-, L-, and P-Reactor Disassembly Area roofs cannot be damaged by the stacks because the stacks cannot physically fall on the roofs.

\section{Indirect Stack Hit on Buildingt 105-K, 105-L, and 105-P}

This scenario involves the Buildings $105-\mathrm{K}, 105-\mathrm{L}$, and 105-P ventilation stack materials falling in the general Buildings 105-K, 105-L, and 105-P areas (but not directly over any radionuclide or chemical hazard storage) causing damage to the Buildings 105-K, 105-L, and 105-P structures which could propagate (i.e., structural failure propagation, or flying debris) and uitimately affect the radiological and chemical hazards stored there. This scenario is not applicable to Buildings $105-\mathrm{K}, 105-\mathrm{L}$, and 105-P, as they will withstand the falling stack debris because the structures are reinforced concrete capable of withstanding a $1000 \mathrm{psf}$ blast. 


\section{Forces Associated with Stack Failure}

Building 105-K will withstand the 105-K ventilation exhaust stack failure. The Buildings 105-L and 105-P ventilation stacks cannot reach the Disassembly Area roofs of $L$ and P-Reactors.

\section{Consequences/Drmage Associated with Stack Failure}

Not applicable, as the failure of the Buildings 105-K, 105-L, and 105-P ventilation stacks damaging the radiological and chemical hazards stored is not credible.

\section{MISSILES}

Tomado and straight wind induced missiles have the possibility to produce damage to the stored radiological and chemical hazards, a separate type of accident quite apart from the wind damage described in Section 8.3.1.1. In Reference 8-31, Fujita concluded that very high straight winds sufficient to move missiles accompany the same meteorological conditions that produce tornadoes. Therefore, only tomado missiles are analyzed. Missiles are postulated to have the ability to penetrate small thickness of steel and concrete. The smaller missiles (wooden planks, small steel pipes) appear in all tomadoes considered. The most massive objects, such as utility poles and automobiles, appear as missiles only in the strongest tornadoes. Missiles would not penetrate the reinforced concrete of Buildings 105-K, 105-L, and 105-P and therefore would not damage radionuclide or chemical containing components residing therein.

\section{Missile Probabilities}

The probability of missiles striking during a tomado is assumed to be an order of magnitude less than the occurrence of the tomado itself, with damaging strikes even less likely (Ref 8-31). Thus, the wind speed probabilities in Reference 8-30 can also be used to estimate the probability of tomado induced missiles as well as the probability of tornadoes themsetves.

Because Buildings 105-K, 105-L, and 105-P are reinforced concrete structures and designed to 1000 psf, some damage may occur from the missiles but penetration of the walls would not occur. The missiles will not damage the radionuclide or chemical containing components in the structures. However, the entrances to the buildings are vulnerable to missile strikes (Ref. 8-31).

Because these entrances are only a small portion of the overall area of the buildings, the corresponding potential for damage is extremely low. Reference 8-28, Section 3.3.2.1, states that "... the probability of tornado missiles passing through openings and striking the stored fuel assemblies is negligible." Even in the unlikely event that a missile were to penetrate an entrance, only a small number of components containing radiological or chemical hazards would be impacted (Ref. 8-17). 
Some Disassembly Basin ancillary structures (Disassembly Basin deionizers, settler tank, sand filters) reside outside the concrete reinforced structure and are vulnerable to missile damage. These events are bounded by process phenomena covered in Section 8.3.2.

\section{Forces Associated with Missiles}

Not applicable for Buildings $\ddot{105-K}, 105-\mathrm{L}$, and 105-P because the buildings will withstand .. credible missiles.

\section{Consequences/Damage Associated with Missiles}

Not applicable for Buildings 105-K, 105-L, and 105-P because the buildings will withstand credible missiles.

\subsubsection{Floods}

The K-, L and P-Reactors are located on high ground, with the entrance to the K-Reactor building at approximate grade elevation of 270 feet above mean sea level (msl). The site is approximately 190 feet above the minimum river level and 45 feet above probable maximum flood (PMF) level. The access openings to all safety-related structures are located at least 6 inches above the nominal grade. As a result, Buildings 105-K, 105-L, and 105-P are not subject to flooding (Ref. 8-28).

The maximum historical flow of the Savannah River of 360,000 cubic feet per second (cfs) corresponds to an approximate elevation of $118 \mathrm{feet}$ above the msl at the Vogtle Electric Generation Plant (VEGP) directly across the river from the SRS. The PMF for the Savannah River where Upper. Three Runs Creek enters the river is approximately 1,001,000 cfs. This information is based on Appendix B to the NRC Regulatory Guide 1.59 at the VEGP opposite the SRS, and precludes consideration of the domino-type failure of upstream dams. - The calculated PMF water level is 138.5 feet. The water level for the Savannah River was conservatively determined by the US Army Corp. of Engineers' HEC-2 computer program (Ref. 8-28).

There are no significant dams or impoundment's on the SRS that could affect the safety of K-, L-, or P-Reactor. However, there are several dams upstream on the Savannah River. A domino failure of these dams coincident with the Corps of Engineering Standard Project Flood has been considered in the licensing of the VEGP. The peak flood elevation at VEGP is 141 feet above msl. The reactor areas are over 100 feet above this level; however, the cooling water pumping facilities and the 484-D powerhouse are below the peak flood elevation and would be forced from service (Ref. 8-28).

Streams on the SRS site may overflow from a local intense precipitation. A study was performed for Defense Waste Processing Facility (DWPF) which is within 5 miles of K-, L, and P-Reactors and on similar terrain. The 6 hour, 10 square-mile probable maximum precipitation (PMP) is 31 
inches, with a maximum intensity of 15.7 inches in 1 hours. This rainfall was conservatively increased to 19 inches in 1 hour and used to generate the PMF. The peak stage corresponding to the PMF occurs at 224.5 feet above msl in the McQueen Branch, roughly six miles North-North East of K-, L-, and P-Reactors. This water level is still 45 feet below the reactor site grade (Ref. 8-28). Even if water were to enter Buildings $105-\mathrm{K}, 105-\mathrm{L}$, and 105-P during extremely heavy rain, no damage to the components containing radiological and chemical hazards would occur. Rain water which might enter the K-Reactor Purification Area will not raise the drums of moderator because the drums and their contents are heavier than light water. The rain water would rise and recede from the Purification Area with no adverse affect. Rain water may accumulate on the K-, L-, and P-Reactor Disassembly Basin deionizer pads. If a deionizer pad is under imminent danger of overflowing and creating an environmental release, the water can be pumped to the Disassembly Basin. The Disassembly Basin could then overflow as the result of the water addition. Section 8.3.2.2 addresses the overfill of the Disassembly Basin.

\section{FLOOD PROBABILITIES}

A flood is not credible, based on the information above.

\section{Forces Associated with a Flood}

Not applicable since a flood is not credible.

\section{Consequences/Damage Associated with a Food}

Not applicable since a flood is not credible.

\subsubsection{Earthquake}

An earthquake presents unique hazards to K-Reactor in Cold Standby, and the $\mathrm{L}^{-}$and P-Reactor Disassembly Basins. The main area of focus of an earthquake is within the Disassembly Basins. The (DBE) for K-, L-, and P-Reactors has a maximum horizontal ground acceleration of $0.2 \mathrm{~g}$ (Ref. 8-28). This can cause damage to nonseismicalty qualified equipment and structures within and outside of Buildings 105-K, 105- $\mathrm{L}$, and 105-P including the Disassembly Basins. In addition, the Purification Area contains non seismically qualified equipment that may fail during a seismic event.

The Disassembly Basins were designed and constructed to be qualified for a blast load and a nominal $0.1 \mathrm{~g}$ earthquake statically applied to the dead and live load (Ref 8-28). This included a foundation investigation by the US Army Corps of Engineers. The Disassembly Basin walls interfacing with the reactor building were later reviewed (Blume) in 1967 for a $0.2 \mathrm{~g}$ Housner response spectrum (Ref. 8-28). A recent structural scoping study assessment reveals the KReactor Disassembly Basin exterior walls and foundations should be capable of withstanding a 
$0.2 \mathrm{~g}$ earthquake however, there is no additional analysis to qualify the basin. (Ref. 8-32). Minor leakage could occur through an expansion joint or cracks in the retaining walls resulting from an earthquake. Leakage through these openings would be very slow (Ref 8-32). The median failure of the assembly hangers is also assumed to occur at 0.56 Peak Ground Acceleration (PGA) based on engineering judgment and the observed ruggedness and good condition of the monorail and support columns.

Additional detailed seismic assessments of the Disassembly Basin were not performed. Rather, a - screening was performed to determine what structures and components would be important in preventing or mitigating the accident conditions considered in the basin risk assessment. A qualitative assessment was then made as to the vulnerability of those structures and components. Based on similarities to structures and components considered in the reactor seismic PRA, fragility curves were assigned to those components (Ref 8-33).

For the Disassembly Basins, there are four general exposure scenarios as a result of the DBE scenarios:

1. Source term from evaporation of spilled Disassembly Basin water

2. Source term from the uncovering of fuel (draindown event) and evaporation of water spilled from the basin

3. Source term from a criticality event in the basin

4. Source term from a criticality event in the basin and evaporation of water spilled from the basin

The scenario which leads to the spillage of Disassembly Basin water during an earthquake (scenario 1 above) comes from a crack in the Disassembly Basin wall or opening of a joint in the wall between the basin and the Process Room. For just a spillage event to occur (i.e., no draindown or criticality), the draindown flow rate must be less than the makeup rate of 1,500 gpm, electric power must be available for alarms and level indicators, makeup water must be available to the basin, the operator must discover that the basin is leaking by either damage surveillance or low level alarms, and manually start the basin makeup.

In addition to a crack in the Disassembly Basin wall, a scenario which could lead to spillage from the Disassembly Basin is makeup or pump priming water lines failing and raising the water level to above the overflow weirs. The flow rate from a broken filtered water makeup or a service clarified water pump priming line would be relatively small $(<100 \mathrm{gpm})$ and would not exceed the capacity of the overflow weirs. Therefore, Disassembly Basin water would only be lost to the process sewer.

Another scenario which could lead to spilled Disassembly Basin water which could evaporate would be failure of the filtration or cooling system components. There are various pumps, pipes and components in each system that could fail during a DBE that could lead to water spillage. 
Draindowns occur when the earthquake opens a crack in the basin such that the flow rate is greater than the makeup rate (scenario 2). Also, if the crack size is such that the flow rate is less than the makeup rate of $1,500 \mathrm{gpm}$, draindowns can still occur if normal electrical power is not available to operate the makeup pumps, if no source of makeup water is available, or if the operator does not acknowledge the low basin level alarms or discover the basin is leaking and manually start the makeup.

The third scenario involves a criticality occurring when assemblies fall from the hangers and collect in a critical configuration. In addition if the basin is cracked, draindown is assumed to occur since no operator will be able to open the makeup valve due to the high radiation levels from the criticality (scenario 4).

The following assumptions were made during the analysis of a DBE with respect to the Disassembly Basin:

- The assessment of facility vulnerabilities to seismic events is qualitative. Quantitative fragility estimates are based on detailed assessments of similar structures and components which were performed for the K-Reactor seismic PRA (Ref. 8-34).

- The site hazard curve developed for the K-Reactor seismic PRA is assumed to be applicable for the basin anatysis, as well.

- A seismically-induced leak in the basin is assumed to occur since it could potentially lead to fuel exposure.

- If a seismically-induced basin leak rate is initially greater than $1500 \mathrm{gpm}$ (the makeup capacity), no credit is given to makeup, even though the leak rate will decrease as the basin level falls.

\section{EARTHQUAKE PROBABILITIES}

The probability of a $0.2 \mathrm{~g}$ design basis earthquake (DBE), as measured by Peak Ground Acceleration (PGA), is $2.0 \times 10^{-4} / \mathrm{yr}$ (Ref. 8-28).

The following discussion gives the equipment failure probabilities which are used to create the overall probabilities of occurrence of each of the scenarios given above. Reference 8-33 gives more information to these equipment failure probabilities and how they are applied in the overall probabilities of occurrence for each scenario.

The median failure of the joint between the basin and Process Room is assumed to occur at 0.56 PGA. This fragility is based on detailed analyses of the 186 and 107 basins (Ref. 8-34). This is used to determine the draindown probability associated with a DBE of $5.3 \times 10^{-3}$ /yr (Ref. 8-33).

The median failure of the assembly hangers is also assumed to occur at $0.56 \mathrm{POA}$ based on rugged construction of the monorail and support columns and engineering judgment. For a criticality to occur, more than four assemblies must fall from their storage position and they must 
gather on the basin floor in a critical configuration. It is assumed that the assemblies fall at the time of the earthquake and the criticality occurs before Disassembly Basin water drains down. This information is used to give a criticality probability associated with a DBE of $5.3 \times 10^{-3} / \mathrm{yr}$ (Ref. 8-33).

The median failure of the electrical power grid is assumed to occur at 0.35 PGA based on Reference 8-34. For a DBE, this corresponds to a $0.15 / y r$ frequency of failure. In addition, normal electrical power is subject to spurious failure; the frequency used is $2.73 \times 10^{-4} / \mathrm{yr}$ (Ref. 833).

The median failure of filtered water/well water pumps is assumed to occur at 0.35 PGA based on the commercial grade equipment being as rugged as the electrical power grid (Ref 8-34). For a $\mathrm{DBE}$, this corresponds to a $0.15 / \mathrm{yr}$ frequency of failure. In addition to the pumps failing, there are a variety of ways that makeup water can be made unavailable to the Disassembly. Basin as shown in Table 8.3-3 (Ref. 8-33).

Operators failing to discover and respond to low basin level during surveillance is expected to occur with a probability of 0.125 per occurrence due to the high stress level during an event (Ref. 8-34). Also, operators failing to respond to basin low level alarms is expected to occur with a probability of 0.125 per occurrence due to the high stress level during an event (Ref. 8-34). The DBE can cause the failure of the Disassembly Basin level instrumentation with a probability of $0.15 / y r$. In addition to operators failing to respond to basin low level, alarms and indicators can fail which may also prevent the operator from identifying a dropping basin level. These probabilities are also given in Table 8.3-3 (Ref. 8-33).

There are several accident scenarios for each of the initiating events associated with earthquakes. The contributing frequencies (equipment faiture and/or operator error), initiating frequencies, and the sum of those frequencies are provided below for each earthquake scenarios.

The probability of a spill of Disassembly Basin water caused by a DBE induced crack in the basin is $2.95 \times 10^{-7}$ /yr (Ref. 8-33). The failure of the filtered water makeup valve is given as $9.2 \times$ $10^{-3}$ /yr (Table 8.3-3). Combining this with the DBE probability of $2.0 \times 10^{-4} / \mathrm{yr}$ gives $1.84 \times$ $10^{-6} / y r$. The likelihood of the electrical power supply to the filtered water or service clarified water pumps during an DBE is given in Reference $8-34$ as $8.5 \times 10^{-1} / \mathrm{yr}$. In addition, the pumps themselves are only expected to survive a DBE with a probability of $8.5 \times 10^{-1} / y r$. Therefore, combining all of these probabilities would result in an overall probability of $1.33 \times 10^{-6} / \mathrm{yr}$ (Ref. 833) for a draindown caused by a DBE induced crack in the basin. During a DBE, it is customary to assume that if one part of a system fails that the rest of the system would fail. Therefore, the filtered water system or the service clarified water system would be expected to fail in multiple places and the likelihood of water actually flowing to the failed valves in the Disassembly Basin would be considered not credible. 
Vent and drain valves, pipe interfaces with equipment, instrumentation and the rupture disk at the sand filter could failand drain water from the cooling system on the roof of the Disassembly Basin or onto the ground-around the sand filter. It is expected that the equipment would fail with a probability of between $1.5 \times 10^{-1} / y r$ to $9.2 \times 10^{-3} / y r$. Therefore, combining this probability with the probability of a DBE of $2.0 \times 10^{-4} / \mathrm{yr}$ gives the failure probability of equipment during a DBE of between $3.0 \times 10^{-5} / \mathrm{yr}$ to $1.84 \times 10^{-6} / \mathrm{yr}$ (Ref. 8-33). These probabilities show that it is possible that some of the scenarios of equipment failures could lead to water loss from the basin. However, during a DBE, it is customary to assume that if one part of a system fails that the rest of the system would fail. Therefore, the maximum amount of water that would be spilled would be the capacity of the Disassembly Basin filtration or cooling system.

The probability of a draindown of the Disassembly Basin exposing fuel caused by a DBE with the flow rate from the leak being greater than $1,500 \mathrm{gpm}$ is $4.22 \times 10^{-7} / \mathrm{yr}$. The probability of a draindown of Disassembly Basin water exposing fuel caused by a DBE and no electrical power following a DBE is $6.33 \times 10^{-8} / y r$. The probability of a draindown of Disassembly Basin water exposing fuel caused by a DBE and no makeup water available following a DBE is $8.60 \times 10^{-8} / y r$. The probability of a draindown of Disassembly Basin water exposing fuel caused by a DBE and no operator action to start makeup water following a DBE is $1.06 \times 10^{-8} / y \mathrm{r}(\operatorname{Ref} 8-33)$.

As discussed in Reference 8-33, the probability of a criticality in the Disassembly Basin following a DBE is $8.44 \times 10^{-7} / \mathrm{yr}$.

The probability of a criticality and a draindown of the Disassembly Basin following a DBE is 4.49 $\times 10^{-9}$ /yr (Ref. 8-33).

As discussed in Section 8.3.2.19, the probability of a radionuclide release in Purification Area from a DBE is $2.0 \times 10^{-4} / \mathrm{yr}$ (Ref. 8-17).

\section{Forces Associated with an Earthquake}

The forces associated with earthquakes are accelerations (vertical and horizontal motion) of the building structures and equipment. The forces are measured in terms of fractions of $\mathrm{g}$ forces $(1 \mathrm{~g}$ $=32.17 \mathrm{ft} / \mathrm{sec}^{2}$ ) corresponding to the probabilities given in Reference 8-28.

\section{Consequences/Damage Associated with an Earthquake}

As noted previously, the accidents of concern in earthquake related events are 1) evaporation of spilled Disassembly Basin water, 2) fuel being uncovered due to draindown and-evaporation of spilled water, 3) criticality in the basin, and 4) criticality in the basin along with a draindown of the Disassembly Basin. In all cases, there are a number of accident scenarios for each initiating event 
which can lead to the accidents of concern. In each case, the initiating event frequency are given in Table 8.3-3. Four of the scenarios associated with irradiated fuel/target storage in the Disassembly Basin (i.e., DBE, Disassembly Basin draindown, Disassembly Basin overfill, and inadvertent criticality) were combined in a probabilistic manner in the analysis discussed in the PHA (Ref. 8-17). Since each of these events contains numerous end-states (depending upon automatic and/or-operator actions, fault-tree probabilities, and the physics of each event), a Monte-Carlo type method (Ref. 8-17) was used which integrates the fault-tree end states of all four events (and their respective sub-events) into one consequence versus frequency curve. It is from this composite risk curve that worker and public dose estimates are derived. The combined radiological consequences to the co-located worker and public versus various frequencies are further discussed in Section 8.4.2.

The consequences associated with a DBE are less for $\mathrm{L}$ and P- Reactors than those for KReactor because there is less radionuclide inventory in their Disassembly Basins than in K-Reactor Disassembly Basin. Therefore, K-Reactor Disassembly Basin consequences bound I- and PReactor Disassembly Basin consequences.

\subsubsection{Lightning}

Lightning could be a threat to electrical power, or a fire hazard. However, lightning will seek tall structures and Buildings 105-K, 105-L, and 105-P have the Buildings 105-K, 105- L, and 105-P ventilation exhaust stacks and the actuator towers near them to collect any lightning bolts. In addition, Buildings 105-K, 105-L, and 105-P structures are not combustible and have a negligible fire loading inside. Therefore, lightning damage is not likely and would be a low hazard if it did occur. Also, the probability of lightning causing radionuclide or chemical release is judged not credible.

\subsubsection{Meteorites}

A meteorite strike on Buildings 105-K, 105-L, and 105-P is postulated which could possibly result in damage to their Disassembly Basins, equipment and structures, and a radionuclide release. According to the DWPF SAR (Ref. 8-35, Chapter 9), the frequency of a meteorite strike on an SRS facility, approximately the size of reactor building, is calculated to be less than $2.0 \times 10^{-}$ $10 / y$ regardless of the meteorite weight. Due to this low expected frequency of occurrence, this event is considered not credible.

\subsubsection{Freezing Temperatures}

The chemicals and Disassembly Basin water in Buildings 105-K, 105-L, and 105-P and moderator in the K-Reactor Purification Area, may be subject to freezing temperatures if heat is lost in Building 105-K, 105-L, or 105-P. The probability of freezing temperatures is $1.6 \times 10^{-1} / \mathrm{yr}$ (Ref. 8-35). The probability of the Disassembly Basin water freezing causing leakage and subsequent 
radionuclide release, drums or equipment in the Purification Area containing moderator freezing causing the release of their contents, and chemical freezing causing containers to burst and release their contents is considered not credible as further discussed in Section 8.3.2.17.

\subsubsection{Snow and Ice Induced Building Failure}

Due to the warm climate at the SRS, large accumulations of snow and ice (which could potentially collapse the roofs) are rare. Table 2.3-2 of Reference 8-28 lists the recurrence intervals of ice accumulations at SRS. From this table, the amount of ice present at a recurrence interval of $1,000,000$ years (i.e., probability of $1 \times 10^{-6} / \mathrm{yr}$ ) can be estimated as about 1.7 inches or approximately 8 pounds of ice per square foot. The roofs of Buildings 105-K, 105-L, and 105$P$ can support 1000 psf, therefore the event causing a problem can be considered not credible. Snow accumulation greater than 1000 psf, leading to the collapse of a roof causing radionuclide or chemical release, is also judged not credible.

\subsubsection{PROCESS PHENOMENA}

The process phenomena are:

Disassembly Basin Draindown

Disassembly Basin Overfill

Inadvertent Criticality

Criticality in Basin Sludge

Criticality in the Settler Tank

Criticality in the Sand Filters

Criticality in the Deionizers

Loss of Disassembly Basin Cooling

Hazardous Chemical Spill

Fire

Explosion

Aircraft Crash

Loss of Power

Loss of Ventilation

Internal Missiles

Loss of Confinement

Loss of Heating 


\author{
Toxic Gas . \\ Purification Events \\ Fuel Corrosion in Disassembly Basin \\ Dropped Shipping Cask
}

\title{
8.3.2.1 Disassembly Basin Draindorn
}

The Disassembly Basin draindown events are a family of related process events that involve the potential to lose shielding (i.e., light water) over the irradiated materials in the Disassembly Basin, or spill contaminated Disassembly Basin water into an uncontrolled area. The following events have been identified as potential scenarios for a Disassembly Basin draindown event:

- Filtration system leak, $1,000 \mathrm{gpm}$

- Cooling system leak, 4,000 gpm

- Deionizer leak, $70 \mathrm{gpm}$

- Emergency cooling water pipe failure/leakage

- Structural fault in a basin wall

Each of the initiating events for the Disassembly Basin draindown event leads to between 10 and 25 fault tree end states, depending on automatic and operator actions that are credited, and errors or random failures that occur. Further complicating the analyses is that a number of different damage states may occur. For these reasons, a statistical approach to the event has been used to quantify the consequences and the frequencies. (Ref 8-36, 8-17).

General assumptions for the K-, L-, and P-Reactor Disassembly Basins used in each of the analyses are:

- Materials are not raised close to the surface of the basin, except very infrequently for visual inspection, and under strict RC\&HP and supervisory guidance.

- The confinement heat removal (CHR) system is disabled by installing a blind flange in the piping inside of the Disassembly Basin (CHR inlet) and by installing a blind flange on the piping at the -40 -foot-elevation pump room (CHR exit).

- The emergency cooling water (ECW) pump suction from the Disassembly Basin is disabled by installing a blind flange on the piping out of the Disassembly Basin. Therefore, there are 4 short sections of pipe (approximately 20 linear feet before a closed isolation valves) in the emergency pump suction well.

- The basin cooling system will be operated continuously using both recirculating pumps to maintain a well mixed basin for chemistry control, and to retard cocrosion. A well mixed basin provides more accurate samples and eliminates temperature and concentration gradients in the water. The mixing can eliminate possible localized "hot spots" of chlorides that can greatly increase corrosion in localized areas. Mixing 
probably will not retard the overall corrosion rate, but can prevent localized increased corrosion rates. Disassembly Basin heat exchangers are used as a flow path for Disassembly Basin water but will have no cooling water supplied as it is not required to maintain basin temperatures within acceptable limits.

- The sand filters will be operated approximately 36 weeks on-line per year and the remaining time off-line for maintenance. Only one sand filter is used for each of the $\mathrm{K}$ and P-Reactor Disassembly Basin, as one has been retired due to leakage problems in these areas. L-Reactor Disassembly Basin has two sand filters.

- The deionizers for the K-, L-, and P-Reactor Disassembly Basins will be operated approximately by 3.5 days on-line (typical time to deplete). The deionizers are expected to operate 42 days during the year with regeneration of the beds occurring when they are off-line. This assumption does not take into account the use of the portable zeolite deionizer. Currently, Reactors Division is using a portable zeolite deionizer to control Cs-137 concentrations when and where ever needed. The analysis did not take into account that this deionizer would be used. However, the consequences from the deionizer system accident scenario is bounded by structural fault in the basin wall scenario. The deionizer system analysis will be revised for the anmual BIO update.

- The level indicating devices in the basin associated with CHR alarms are disabled.

Operator action (when assumed in the fault tree branch) is assumed to begin 60 mimutes after the event takes place (plus a 60 minute standard deviation to cover a 2 hour emergency response action time).

\section{FULTRATON SYSTEM LEAK}

The K-, L-, and P-Reactor Disassembly Basin filtration systems maintain the Disassembly Basins water visual clarity within specifications by removing particulate and suspended solids in the basin water via sand filters fed by two sand filter feed lines. One of the two sand filters in the $\mathrm{K}$ - and $\mathrm{P}$ Reactor Disassembly Basins is no longer in service, so a total of one $1000 \mathrm{gpm}$ feed line is actually used to supply the remaining sand filter. L-Reactor Disassembly Basin has two sand filters. If the $1000 \mathrm{gpm}$ sent to the sand filter is not replenished (due to leak or misdirection), a $1000 \mathrm{gpm}$ draindown will ensue (2000 gpm leak for L-Reactor). This event bounds the natural phenomena damage (missile, tornado, straight-wind) to the sand filters.

\section{COOLING SYSTEM LEAK}

The K-, L-, and P-Reactor Disassembly Basin cooling systems operate to provide mixing within the basins. Two pumps take suction from each basin to supply $2000 \mathrm{gpm}$ each to the two pairs of heat exchangers. Thus, if the heat exchanger shell, piping, or valve leaks, or a valve position error occurs, a draindown of up to $4000 \mathrm{gpm}$ may take place. This event bounds the natural phenomena damage (missile, tornado, straight-wind) to the heat exchangers. The $4000 \mathrm{gpm}$ flow 
rate is conservative since the K-Reactor Cold Standby Plan and L-Reactor Cold Shutdown Plan indicate only one cooling system pump will operate in each basin (Ref. 8-27).

\section{DEIONIZER SYSTEM LEAK}

The deionizer systems remove charged radioactive particles in the $\mathrm{K}-, \mathrm{L}$, and P-Reactor Disassembly Basin water via ion exchange with resin in the deionizers. The deionizers are . supplied with Disassembly Basin water either indirectly from the filtration systems, or directly from the Disassembly Basin cooling system. In either case, the maximum flow that may be diverted from each of the Disassembly Basins is $70 \mathrm{gpm}$ (Ref. 8-37).

\section{ECW PIPE FAILURE/LEAKAGE}

The emergency cooling water system, which provided an emergency source of cooling water to the cooling water header CW-2, once took suction from the K:, L-, and P-Reactor Disassembly Basins. However, the inlet pipes to the ECW pumps have been isolated by a closed isolation valve or gate valve and blind flanged right outside the Disassembly Basins. This results in four short pieces of pipe before the isolation for each basin which could fail. A pipe break in the ECW pump suction lines is possible, with a resultant flow from the 24-inch pipe of approximately 40,000 gpm (Ref. 8-37). This analysis of a Disassembly Basin draindown associated with a pipe break in the ECW pump suction line conservatively assumes that the suction well sluice gate is open. With the suction well shice gate closed, the amount of water lost would be reduced. Layup plans call for the sluice gate to be closed and locked.

\section{STRUCTURAL FAULT IN THE BASIN WALL}

A structural fault in a K-, L-, or P-Reactor Disassembly Basin wall may result from a dropped shipping cask impacting the floor or walls of the Disassembly Basin, or may be the result of a random fault in a basin wall. Either way, an uncontrolled release of basin water results. The dropped shipping cask is analyzed. in Section 8.3.2.21.

\section{Disassembly Basin Draindorn Probabilities}

The accidents of concem in basin draindown events are 1) loss of contaminated water to the environment and 2) reduced shielding. In all cases, there are a number of accident scenarios for each initiating event which can lead to the accidents of concern.

\section{Filtration System Leak Probabilities}

Reference 8-37 states the filtration system is operated typically with a frequency of 36 weeks out of a year with maintenance performed during the other weeks as needed. Reference 8-37 
conservatively models this frequency of system operation in conjunction with events that cause a loss of flow back to the basin, and calculates the frequency as $6.99 \times 10^{-3} / \mathrm{yr}$.

\section{Cooling System Leak Probabilities}

Reference 8-37 conservatively models this frequency of system operation in conjunction with events that cause a loss of flow back to the basin, and calculates the frequency as $2.08 \times 10^{-2} / \mathrm{yr}$. Note that this frequency is considerably higher than natural phenomena which may cause a cooling system leak, such as tomado, straight wind, or missile damage to the heat exchangers.

\section{Deionizer System Leak Probabilities}

Reference 8-37 states that the deionizer system is used intermittently, and it is depleted within 3.5 days of being placed in service. The deionizers are expected to operate 42 days during the year with regeneration of the beds occurring when they are not in service. Thus the duty cycle assumed for the analysis in Reference $8-37$ is $70 \mathrm{gpm}$ flow for 42 days during the year, then 0 gpm flow for 323 days during the year.

Reference 8-37 conservatively models this frequency of system operation in conjunction with events that cause a loss of flow back to the basin and calculates the frequency as $1.92 \times 10^{-3} / \mathrm{yr}$.

\section{ECW Pipe Failure/Leakage Probabilities}

From Reference 8-37, the following data are used in calculating the probability of ECW pipe failure:

Piping external leakage frequency:

Conditional probability of rupture given leakage:

Length of vulnerable piping:
$3.4 \times 10^{-9} / \mathrm{hr}-\mathrm{ft}$

0.04

$20 \mathrm{ft}$.

Thus, the initiating event frequency is $2.4 \times 10^{-5} / \mathrm{yr}$.

\section{Structural Fault in the Basin Wall Probabilities}

For the random fault events, the commercial nuclear power data base searched by Reference 8-37 yielded 2 events in approximately 2000 reactor-years of operating experience. Reference 8-37 then conservatively assumed that the database captured only one-half of the actual basin wall fault events, for a total of 4 events $/ 2000$ reactor-years $=2.0 \times 10^{-3} / y r$ for a probability of a random fault causing a crack in one of the Disassembly Basins. 


\section{FORCES ASSOCIATED WITH DISASSEMBLY BASIN DRAINDOWN}

\section{Forces Associated with Filtration System Leak}

The forces associated with a filtration system leak are negligible.

\section{Forces Associated with Cooling System Leak}

The forces associated with a cooling system leak are negligible.

\section{Forces Associated with Deionizer System Leak}

The forces associated with a deionizer system leak are negligible.

\section{Forces Associated with ECW Pipe Failureheakage}

A pipe rupture leading to a $40,000 \mathrm{gpm}$ draindown would produce large forces, causing significant mechanical/high-energy damage to equipment and physical plant. However, the focus in the PHA (Ref. 8-17) is the radionuclide release and/or chemical hazards release.

\section{Forces Associated with a Structural Fault in the Basin Wall}

The commercial nuclear operating experience search conducted by Reference 8-37 yielded 2 events, with leak rates of $6 \mathrm{gpm}$ and approximately $0 \mathrm{gpm}$ (negligible). Reference 8-37 then conservatively assumed the leak rate to be bounded by the $70 \mathrm{gpm}$ deionizer system leak.

\section{CONSEQUENCES/DAMAGE ASSOCIATED WITH DISASSEMBLY BASIN DRAINDOWN}

The Disassembly Basin draindown events could potentially cause the irradiated materials to lose shielding (i.e., light water) if sufficiently severe, and also severely reduce the ability of the basin to cool the irradiated materials. The fuel produces decay heat, and the ability of air to remove that heat will determine whether the fuel reaches melting temperatures or achieves a steady-state temperature below melting. Pyrophoricity of the uranium portion of the assemblies exposed to air is not a problem, as the U-Al alloy content of the Mark 22, Mark 42, and Mark 16B is not pyrophoric. The Mark 31A slugs are not pyrophoric because an oxide layer has formed, preventing further oxidation (Ref. 8-38). The targets are also not pyrophoric because the target material is an alloy of lithium and alumimum.

In order to conservatively assess the damage from the draindown event, the following concerns were addressed: 


\section{MELTING OF IRRADLATED FUEL ASSEMBLIES IF UNCOVERED}

For the limiting case of 62.1 W/assy for fuel assemblies in K-, L-, and P-Reactor Disassembly Basins, the calculations (Ref. 8-17, 8-39, 8-40, 8-41) show that the fuel temperatures achieve a maximum of $188^{\circ} \mathrm{C}$ in the VTS and $276^{\circ} \mathrm{C}$ in the HBBS. These fuel temperatures are well below the melting temperature of $646^{\circ} \mathrm{C}$ for U-Al (Ref. 8-40). Therefore, the fuel cannot melt.

The consequences to the co-focated worker and the public from spillage of basin water, cither to the air or to river water/aquifers and from direct radiation from uncovered fued

Three damage source term scenarios are possible for each draindown event, depending upon the severity of the event fault tree. They are:

1. Displaced Water Evaporation. The basin water contains Cs-137 and H-3, which become the radiomuclides for the source term.

2. Reduced Shielding and Displaced Water Evaporation. The water level drops (fuel still covered), permitting increased gamma shine, plus the source term from Cs-137 and H-3.

3. Uncovered Fuel and Displaced Water Evaporation. This is a more severe case of number 2, above. The water level drops below the level of the fuel, permitting direct gamma shine, plus the source term from Cs-137 and $\dot{\mathrm{H}}-3$.

The consequence's to the co-located worker and the public from reduced shielding over the irradiated materials in the basin and the drop in the basin level associated with each scenario

The consequences of direct radiation ("shine") to the co-located worker and the public from unshielded irradiated fuel assemblies and other materials have been calculated (Ref 8-36). The doses are scenario dependent, as they vary with the amount of draindown, which is a function of the draindown rate, the duration of each scenario, and operator actions (if any). The draindown rates have been identified in each accident description section (above); however, the maximum draindown is often limited by the physical layout of the piping in the Disassembly Basin. For example, once the basin has drained past the inlet of a certain pipe, that pipe can no longer take suction from the basin and consequently the draindown halts. Also, automatic and operator actions (such as water makeup and isolation) have been considered in the fault trees in each scenario.

Four of the scenarios associated with irradiated fuel/target storage in the $K_{-}, L_{-}$, and P-Reactor Disassembly Basins (i.e., DBE, Disassembly Basin draindown, Disassembly Basin overfill, and inadvertent criticality) were combined in a probabilistic manner in the analysis discussed in the PHA (Ref 8-17): Since each of these events contains numerous end-states (depending upon automatic and/or operator actions, fault-tree probabilities, and the physics of each event), a Monte-Carlo type method (Ref. 8-17) was used which integrates the fault-tree end states of all four events (and their respective sub-events) into one consequence versus frequency curve. It is 
from this composite risk curve that worker and public dose estimates are derived. The combined radiological consequences to the co-located worker and public versus various frequencies are further discussed in-Section 8.4.2.

The hazards for a draindown event are the same for the $L$ - and P-Reactor Disassembly Basins but the consequences are less than those for the K-Reactor Distssembly Basin because there is less radionuclide inventory and water contamination in the $\mathrm{L}$ and P-Reactor basins thian is in KReactor Disassembly Basin. Therefore, K-Reactor Disassembly Basin consequences bound L and P-Reactor Disassembly Basin consequences.

\subsubsection{Disassembly Basin Overfill}

Overfill events were identified as process hazards due to the potential to spill the contaminated Disassembly Basin water into an uncontrolled area, or to the process sewer.

The water level in the $\mathrm{K}-, \mathrm{L}$, and P-Reactor Disassembly Basins is measured as the number of inches below the 0 -foot level and is expressed as a negative number (e.g., -15 in.). The normal operating range for $\mathrm{K}$ - and L- Reactor Disassembly Basin levels is -13.0 to -16.0 inches, while $\mathrm{P}$ Reactor Disassembly Basin level is -13.0 to -15.0 inches. Several alarms will actuate on the disassembly control panel in the associated Disassembly Area and on the NIM/fuel failure panel in the Central Control Room (CCR). A high level alarm is received at a level of -12.5 inches (for K, L-, and P-Reactor Disassembly Basins), a low level alarm is received at -16.5 inches (for K- and L-Reactor Disassembly Basins) and -15.5 inches (for P-Reactor Disassembly Basin), and a very low alarm is received at -17.5 inches (for $\mathrm{K}$ - and L-Reactor Disassembly Basins) and -16.5 inches (for P-Reactor Disassembly Basin). The level indicating devices are bubblers, using instrument air to sense the water level (Ref. 8-28, 8-22).

The normal source of makeup water to the $\mathrm{K}-, \mathrm{L}-$, and P-Reactor Disassembly Basins is from the filtered water system through two makeup water lines. One of the lines supplies the MB, while the other supplies the VTS basin (Ref. 8-28). Filtered water to each basin is supplied through a manual block valve and then to a pneumatically operated butterfly valve. The water then flows into the respective section of the Disassembly Basin. Filtered water can be automatically controlled, but is not usually operated in this manner. Makeup water addition is normally manually controlled via the manual block valves. The emergency cooling water pump suction header CW-39 and the river water header RW-1 were once alternative sources of makeup water to these Disassembly Basins. Each of these alternate sources of water have been drained and isolated from the Disassembly Basins (Ref. 8-27), and are not considered as sources.

If the level of a Disassembly Basin increases too high, the water will overflow into the process sewer. This could result in an uncontrolled release of slightly radioactive liquid to the environment. The process sewer is monitored via grab samples for the Cold Standby condition. Grab samples are taken twice a day $(K, L, P)$ to detect tritium, along with gross betgamma. The sample analysis and Control Schedule (SANSCO), dictates the frequency and analyses required. DPSOLs 105-6101A Rev. 18 "Sample Analysis-Schedule and Control Routine" describes the 
schedule", 6101B Rev. 12-PCN01, "Sample Description and Location" has the sampling description", and 6101C Rev. 8-PCN02, "Sample Analysis Schedule and Control-Data Sheets 1, 2, \& 3 Sample Schedule" is used for tracking of the samples taken. The K-, L-, and P-Reactor Disassembly Basins do not have level reduction equipment should water level increase. The normal method of reducing excess amounts of water is by using the deionizers to scrub the water and purge it to the waste trailers or by adjusting the volume of water remaining in the deionizers. In emergency conditions however, $K$ Reactor has a permitted percolation field and $L$ \& $P$ Reactors have seepage basins in order to take water from the basin which may have to be purged.

To control against the overflow of a Disassembly Basin to the 0-foot-elevation floor, overflow weirs in the Disassembly Basins will allow the basin to overflow directly to the process sewer if level increases too high. The flow rate through each weir is designed to be $275 \mathrm{gpm}$ if level is 2 $1 / 2 \mathrm{in}$. above the weir and $1000 \mathrm{gpm}$ if level is 6 in above the weir (Ref. 8-28, 8-22). This would allow slightly radioactive water to drain to the unmonitored process sewer.

The key assumptions used in the overfill scenarios regarding K, L-, and P-Reactor Disassembly Basins operation and configuration for K-Reactor in Cold Standby and L - and P-Reactors in Cold Shutdown are detailed below.

- The K-, L-, and P-Reactor CHR system has been disabled by installing a blind flange in the piping inside each of their Disassembly Basins (CHR inlet) and by installing a blind flange on the piping at the -40-foot-elevation pump room sump (CHR exit). Also, the CHR makeup addition lines are disabled with blind flanges (Ref. 8-27).

- The K-, L, and P-Reactor ECW pump suction from each Disassembly Basins is disabled by installing a blind flange on the piping out of the Disassembly Basin. Therefore, there are 4 short sections of pipe at the approximate -20-foot-elevation in the emergency pump suction well that are all blanked off.

- The K-, L-, and P-Reactor CW-1, CW-2, and CW-39 lines are drained.

- The basin cooling system for the K-, $\mathrm{L}$, and P-Reactor Disassembly Basins is used to maintain a well mixed pool for chemistry control, and to retard corrosion.

- The sand filters will be operated on approximately by 36 weeks on-line per year, and the remaining time down for maintenance. Only one sand filter is used in K- and PAreas, as one in each area has been retired due to leakage problems. L-Area has two sand filters.

- The level indicating devices in the basins associated with the CHR alarms are disabled.

- Materials are not raised close to the surface of the basin, except very infrequently for visual inspection, and under strict RC\&HP and supervisory guidance.

Disassembly Basin overfill may be initiated by any failure that allows water to be inadvertently added to the basin. Initiators for overfill events are as follows:

Unattended water hoses (10 gpm) 
- Service clarified water sources to the filtered water pump priming lines (30 $\mathrm{gpm})$

- Heat exchanger valve failures or heat exchanger tube leaks (20 gpm)

- Settler tank $(60,000$ gallons $)$

- Rain to the sand filter/deionizer sumps (10 gpm) .

- Filtered water makeup line to the machine basin (1300 gpm)

- $\quad$ Filtered water makeup line to the VTS basin (1300 gpm)

- Failure to stop basin makeup following successful mitigation of a $70 \mathrm{gpm}$ draindown

- Failure to stop basin makeup following successful mitigation of a $1000 \mathrm{gpm}$ draindown

- Failure to stop basin makeup following successful mitigation of a $4000 \mathrm{gpm}$ draindown

\section{DISASSEMBLY BASIN OVERFILL PROBABIITIES}

As noted previously, the accident of concern in basin overfill events is either the overflow of contaminated water to the process sewer or to the 0-foot elevation floor. In all cases, there are a number of accident scenarios for each initiating event which can lead to the accidents of concern. Each of these initiators were quantified with a fault tree and with data analyses (Ref. 8-42) as discussed below.

\section{Hoses}

The initiator for unattended water hoses is modeled by a single event. Plant specific data from the REAC database was used to quantify this event, for a total of 64 reactor years for $P, L, K$, and $C$ -Reactors during the early 1970's to the late 1980's. There was one event identified where an unattended water hose inadvertently raised the basin level. This occurred in P-Area on June 24, 1980. Therefore, the basic event is quantified with the frequency $1 / 64$ yrs $=1.56 \times 10^{-2} / \mathrm{yr}$. The overall frequency of hoses causing overflow to the process sewer is $1.79 \times 10^{-4 / y r}$ and the overall frequency of hoses causing overfiow to the 0 -foot-elevation is $2.96 \times 10^{-8} / \mathrm{yr}$.

\section{Service Clarified Water Sources To The Filtered Water Pump Priming Lining}

The initiator associated with service clarified water is modeled by inadvertent service clarified water addition to the D\&E canal or the MB. Service clarified water is supplied to the filter feed pumps in order to prime the pumps prior to being place on-line. Inadvertent addition to the basin may occur if the service clarified water supply to the filter feed pump remains open following filtration system start-up or if the manual valves supplying service clarified water to the pumps fail open or leak. The calculated frequency of this initiator is $3.94 \times 10^{-2} / \mathrm{yr}$. The overall frequency 
of service clarified water causing overflow to the process sewer is $4.52 \times 10^{-4} / \mathrm{yr}$ and the overall frequency of service clarified water causing overflow to the 0 -foot-elevation is $7.48 \times 10^{-8} / \mathrm{yr}$.

\section{Heat Erchanger Valve Failures or Heat Exchanger Tube Leaks}

The initiator associated with the basin heat exchangers is modeled as basin heat exchanger tube leaks, or heat exchanger vent valve failures. Vent valve failures include human error, spuriously failing open, and leaking through. Again, the REAC data was used to determine the heat exchanger tube leak frequency. Three events were identified in which tube leaks added water to the basin (C-Area, March 31, 1974, C-Area, March 12, 1982, P-Area, June 6, 1980). Therefore, the heat exchanger tube break event is quantified with the frequency of $3 / 64$ yrs or $4.7 \times 10^{-2} / y r$. The overall calculated frequency of this initiator is $1.07 \times 10^{-1} / y$ r. The cooling water supply to the heat exchangers has been flanged off during Cold Standby of K-Reactor and Cold Shutdown of $\mathrm{L}-$ and P-Reactors. Therefore, cooling water leaking into the K-, L-, or P-Reactor Disassembly Basin from the heat exchangers is not possible.

\section{Settler Tank}

The initiator for settler tank water addition is modeled by a single basic event. A search of the REAC database identified one event where a settler tank transfer inadvertently raised the basin level. The event occurred in K-Area on January 20, 1992. Therefore, the basin event is quantified with frequency of $1 / 64$ or $1.56 \times 10^{-2} / y$. The overall frequency of water from the settler tank causing overflow to the process sewer is $1.79 \times 10^{-4} / y$ r.

\section{$\underline{\text { Rain }}$}

The initiator for rain water addition is modeled by a single basic event. The REAC database has no events identified where rain inadvertently raised the basin level. However, recently in K-Area (September 1993), rain threatened to enter the Disassembly Basin due to building flooding. Therefore, this event is included in the 64 years of experience to generate a frequency of 1/64 or $1.56 \times 10^{-2} / \mathrm{yr}$. The overall frequency of rain causing overflow to the process sewer is $1.57 \times 10^{-2} / \mathrm{yr}$ and the overall frequency of rain causing overflow to the 0-foot-elevation is $2.60 \times 10^{-6} / \mathrm{yr}$.

\section{Filtered Water Makeup Line to the Machine Basin}

The initiator associated with filtered water addition to the MB is modeled as failure of the manual supply valve to the MB. The manual supply valve failures considered include human error (left open after filtration system start-up), spuriously failing open, and leaking through. The calculated frequency of manual supply valve failure is $1.99 \times 10^{-2} / \mathrm{yr}$. The overall frequency of filtered water 
line to the machine basin causing overflow to the process sewer is $1.04 \times 10^{-3} / y r$ and the overall frequency of filtered water line to the machine basin causing overflow to the 0 -foot-elevation is $1.72 \times 10^{-7}$ /yr.

\section{Filtered Water Makeup Line to the VTS Basin}

The initiator associated with filtered water addition to the VTS is modeled as failure of the manual supply valve to the VTS. The manual supply valve failures considered include human error (left open after filtration system start-up), spuriously failing open, and leaking through. The calculated frequency is $1.99 \times 10^{-2} / \mathrm{yr}$. The overall frequency of filtered water makeup line to the VTS basin causing overflow to the process sewer is $1.42 \times 10^{-3} / y r$ and the overall frequency of filtered water makeup line to the VTS basin causing overtlow to the 0-foot-elevation is $1.72 \times 10^{-7} / y$.

\section{Failure to Stop Basin Makeup Following Successful Mitigation of a 70 gpm Draindown}

The initiator for filtered water makeup not being stopped following a successfully mitigated 70 gpm draindown is modeled by a single basic event. This event originated from the Disassembly Basin draindown accident analysis and includes all overfill event frequencies from the fault trees associated with a $70 \mathrm{gpm}$ loss/makeup. These frequencies total to an overall frequency of $5.68 \times 10^{-6} / \mathrm{yr}$. The overall frequency of failure to stop basin makeup following successful mitigation of a $70 \mathrm{gpm}$ draindown causing overflow to the process sewer is $6.51 \times 10^{-8} / \mathrm{yr}$ and the overall frequency of failure to stop basin makeup following successful mitigation of a $70 \mathrm{gpm}$ draindown causing overflow to the 0 -foot-elevation is $1.06 \times 10^{-11} / \mathrm{yr}$.

\section{Failure to Ston Basin Makeun Following Successful Mitigation of $\mathbf{1 0 0 0}$ gpm Draindown}

The initiator for filter water makeup not being stopped following a successfully mitigated 1000 $\mathrm{gpm}$ draindown is modeled by a single basic event. This event originated from the Disassembly Basin draindown accident analysis and includes all overfill event frequencies from the fault trees associated with a $1000 \mathrm{gpm}$ loss/makeup. These frequencies total to an overall frequency of 2.01 $x 10^{-5} / y$ r. The overall frequency of failure to stop basin makeup following successful mitigation of a $1000 \mathrm{gpm}$ draindown causing overflow to the process sewer is $1.05 \times 10^{-7} / \mathrm{yr}$ and the overall frequency of failure to stop basin makeup following successful mitigation of a $1000 \mathrm{gpm}$ draindown causing overflow to the 0 -foot-elevation is $1.74 \times 10^{-10} / \mathrm{yr}$.

Failure to Stop Basin Makeup Following Successful Mitigation of a 4000 gpm Draindown

The initiator for filter water makeup not being stopped following a successfully mitigated 4000 gpm draindown is modeled by a single basic event. This event originated from the Disassembly 
Basin draindown accident analysis and includes all overfill event frequencies from the fault trees associated with a $4000 \mathrm{gpm}$ loss/makeup. These frequencies total to an overall frequency of $3.26 \times 10^{-5} / y r$. The overall frequency of failure to stop basin makeup following successful mitigation of a $4000 \mathrm{gpm}$ draindown causing overflow to the process sewer and 0-foot-elevation is $3.26 \times 10^{-5} / \mathrm{yr}$. .

\section{FORCES ASSOCIATED WITH DISASSEMBLY BASIN OVERFILL}

The only force associated with Disassembly Basin overfill is water flowing to the environment.

\section{CONSEQUENCES/DAMAGE ASSOCLATED WITH DISASSEMBLY BASIN OVERFTLL}

Overfill of the $\mathrm{K}-, \mathrm{L}$ - and P-Reactor Disassembly Basins is hazardous because of the release of potentially contaminated water to either the process sewer, uncontrolled areas of the 0-footelevation, or outside of the building to the environment. Overflow of the Disassembly Basin occurs first to the overflow weirs which drain directly to the process sewer. In the 4,000 $\mathrm{gpm}$ overflow scenario, the overflow weirs flow rate would be overcome and may overflow to the 0 foot-elevation. In all the other scenarios, the overflow weirs would handle the additional water to the basin, unless the overflow weirs were clogged. The maximum amount of water overflowing a Disassembly Basin considered is 60,000 gallons to the process sewer or 240,000 gallons to the 0 foot-elevation (releasing tritium and cesium-137 to the environment).

The hazards for an overfill event are the same for the L- and P-Reactor Disassembly Basins but the consequences are less than those for the K-Reactor Disassembly Basin because there is less radionuclide inventory in $\mathrm{L}$ and P-Reactor Disassembly Basins than is in the K-Reactor Disassembly Basin. Therefore, K-Reactor Disassembly Basin consequences bound $L$ - and PReactor Disassembly Basins. All of the HADs for K, L, \& P-Reactors were prepared using actual basin inventory. L has a greater plutonium inventory, but the largest contributor to the basin water radionuclide level is predominantly tritium and cesium with very minute amounts of dissolved solids.

Four of the scenarios associated with irradiated fuel/target storage in the Disassembly Basin (i.e., DBE, Disassembly Basin draindown, Disassembly Basin overfill, and inadvertent criticality) were combined in a probabilistic manner in the analysis discussed in the PHA (Ref. 8-17). Since each of these events contains numerous end-states (depending upon automatic and/or operator actions, fault-tree probabilities, and the physics of each event), a Monte-Carlo type method (Ref. 8-17) was used which integrates the fault-tree end states of all four events (and their respective subevents) into one consequence versus frequency curve. It is from this composite risk curve that worker and public dose estimates are derived. The combined radiological consequences to the co-located worker and public versus various frequencies are further discussed in Section 8.4.2. 


\subsubsection{Inadvertent Criticality}

Due to the large amounts of fissile material present in the form of irradiated fuel and target assemblies, plus the presence of water to sufficiently moderate the fissile material, criticality is possible in several segments of the K-, L-, and P-Reactor Disassembly Basins. Approximately 900 Mark 22 fuel assemblies, 1 Mark 16B fuel assembly, and the equivalent of 5 Mark 31A assemblies (90 slugs) are estimated to reside in the K-Reactor Disassembly Basin.' L-Reactor Disassembly Basin contains approximately 516 Mark 16B fuel assemblies, 6525 Mark 31A slugs, 4 Mark 31A assemblies, and 1 Mark 50A slug. P-Reactor Disassembly Basin contains approximately 396 Mark 22 fuel assemblies, 53 Mark 16B fuel tubes, and 2 Mark 42 fuel assemblies. The total fissile material inventories for the $\mathrm{K}-, \mathrm{L}$, and P-Reactor Disassembly Basins (Ref. 8-2, 8-5, 8-6) are shown in Table 8.3-4. In this section, the conclusion is drawn that a criticality event in $\mathrm{K}$ bounds a similar event in $\mathrm{L}$ and $\mathbf{P}$ because there will be less handling and disassembly (i.e., cutting of endfittings of assemblies, separation of targets from fuel tubes, movement of targets and fuel tubes to bundling operations, bundling of fuel and target tubes, movement of fuel tube bundles to the racks in HBBS) in $\mathrm{L}$ and $\mathrm{P}$ basins than in $\mathrm{K}$. This is because a large percentage of the fuel assemblies in $\mathrm{L}$ and $\mathrm{P}$ basins have already been disassembled and are now in the storage racks of HBBS. With limited handling, the probability is significantly reduced in spite of the large amount of fissile material stored in the basin because there is a low likelihood of the fissile material configuration changing from the previously analyzed subcritical configuration. The majority of the fuel in $\mathrm{K}$, however, is in the VTS and will need to be disassembled and moved. The disassembly and movement of the fuel is the primary contributor to the potential for criticality. The larger amount of Pu-239 in L contributes to the increased probability of a criticality there, however, the contribution of disassembly and movement operations to the probability of criticality in $\mathrm{K}$ outweighs the contribution of higher Pu-239 content to criticality in $\mathrm{L}$.

Unlike K-Reactor Disassembly Basin, most of the assemblies in L and P-Reactor Disassembly Basins are in the HBBS or transfer bay. This means that these assemblies do not need to be handled or disassembled in the VTS or MB, thus lowering the possibility of operator errors leading to inadvertent criticality.

In Reference 8-43, four criticality scenario fault trees have been constructed for the $\mathrm{K}$-, $\mathrm{L}$ - and $\mathrm{P}$ Reactor Disassembly Basins, one each for the major segments of the Disassembly Basins:

- Criticality in vertical tube storage

- Criticality in the machine basin

- Criticality in the horizontal bundle and bucket storage

- Criticality during shipping cask loading

Three of these fault trees contain multiple pathways whereby criticality is achieved; only the horizontal bundle and bucket storage has a single pathway to criticality. The fault trees contain numerous branches for system malfunctions, following/not following operating procedures, 
human error, and general engineering judgments. A summary of the most important contributors to the total frequency of criticality for each segment are described below:

\section{CRITICALITY IN VERTICAL TUBE STORAGE}

The VTS has two criticality concerns. The concerns are:

- More than four assemblies come into a critical configuration by hanger failure, monorail failure, or mishandling of assemblies.

- Any four assemblies come into a critical configuration by misalignment on the hangers into a square pitch configuration of less than 3.2 inches.

From the first mechanism the only credible scenario of a criticality is that the operator mishandles an assembly which results in the assembly falling to the basin floor. The operator fails to detect the misplaced assembly and continues this process at least four more times. Given that five assemblies have been misplaced by the operator, they are assumed to accumulate into a critical configuration. Reference 8-44 provides the guidelines for fuel movement in VTS. According to this reference, a maximum of two Mark 22 assemblies can be transported at any given time in the basin. The operator in this scenario is credited with using a checklist during fuel movement. Credit is also taken for the presence of an independent verifier during the fuel movement process. The second mechanism was eliminated since the assemblies are maintained in a rectangular pitch by design of at least 12 inches by 18 inches and cannot be moved from vertical orientation while on hangers.

In determining the criticality scenarios in the VTS and the probabilities associated with each scenarios, the following assumptions were used:

- No new assemblies or housing will be moved into VTS

- Each monorail row is held up by 18 anchor supports.

- Each monorail row is capable of holding 21 hangers.

- All assemblies will eventually be disassembled and reduced through the machine basin. It is assumed that this will take approximately two months from the time processing begins.

- Two anchor supports on a monorail row must fail in order to cause sufficient damage to the monorail row to dislodge assemblies from their hangers. Due to the good condition of the hangers and routine inspections, these failures are assumed to be independent. These inspections are assumed to be conducted on a quarterly basis concurrent with the basin inspection.

- Only one operator is necessary to move assemblies in VTS.

- Given the configuration of the assembly array in VTS, a single assembly constitutes approximately 10 degrees of a 360 degree radius. 
- The probability of a dropped assembly displacing a neighboring assembly is a probability of $2.0 \times 10^{-1} / y r$ (Ref. 8-43). The hanger design largely prevents this from happening; corrosion is a consideration.

Because only a few assemblies reside in the $\mathrm{L}$ and P-Reactor VTSs, their iniadvertent criticality probabilities are bounded by the K-Reactor VTS probabilities.

\section{CRITICAIITY IN THE MACHINE BASIN}

The fuel processed in the MB has four.criticality concerns. The concerns are:

- Processing a single fuel assembly through the foil, press, and shear is a criticality concern since it changes the geometry of the fuel assembly when its pieces are placed in a scrap bucket.

- Criticality is a coricern with cutting of a fuel assembly by accumulating several assembly end-fitting containing fuel in a scrap bucket.

- Criticality is a concern with the accumulation of target assemblies with fuel into a target stack. Criticality is possible if more than four target assemblies with fuel are brought together in a stack.

- Criticality is possible with fuel assemblies whenever more than the equivalent of four entire fuel assemblies are brought together. This could occur if more than one bundle of fuel accumulates in the bundling station prior to transfer to the HBBS.

Of the criticality scenarios postulated in the MB, only two remained credible as discussed below:

1. The operator fails to separate the fuel from the target sub-assembly and fails to use the hand-held gamma detector on the target before placing it in the target stack. The operator continues to make this error at least four more times. Eight targets are placed in a stack before they are placed into bundles. It is assumed that five fuel assemblies that are placed in a target stack will result in a critical configuration. The operators in the area are credited with recognizing the error.

2. During the fuel bundling process, the operators fail to use the criticality bar and the operator fails to remove the bundle before processing another fuel bundle. The operator error for failure to use the criticality bar was taken from site specific data (REAC database). The operator error for failure to remove the existing bundle was derived from Reference 8-45. In this event, the operators in the area were credited with being able to detect the error and credit was given for the presence of an independent verifier. If the operators fail to use the criticality bar and fail to remove the existing fuel bundle, they are assumed to place the second fuel bundle on top of the first one with a resultant critical configuration.

In determining the criticality scenarios in the MB and the probabilities associated with each scenarios, the following assumptions were used: 
- The operator is not permitted to place fuel in the scrap pile. The operator is required to test sccap that will be placed on this pile with a hand-held gamma detector to ensure that there is no fuet in the scrap.

- The foil, press, and shear is equipped with a gamma detector that will automatically shut off the process if fuel is detected in the scrap..

- The operators are required by procedure to separate fuel and target portions of an assembly before placing the target into a stack.

- The operator must use a hand-held gamma detector prior to placing a target in a stack.

- Up to eight targets can accumulate in a stack before they are placed into a target bundle.

- Four operators are present during disassembly and bundling operations.

- All Mark 22 assemblies processed through the machine basin do not contain inner housings.

- The hand-held underwater gamma detector is tested on a daily basis during use.

- A specific type of fuel/housing is processed for several days before switching to another fuel/housing type.

- The fuel has been irradiated for a sufficient length of time such that the foil, press, and shear gamma detector will detect any fuel placed into the press.

- It is assumed up to ten assemblies can be processed through the machine basin per day. Furthermore, if the end-fittings of an assembly are cut such that fuel remains in the end-fitting, it is assumed that this error must continue for at least two days before enough fivel is accumulated in the scrap bucket to constitute a criticality concern.

- One fuel assembly from a disassembled fuel assembly is sufficient to be a criticality concern if it is processed through the foil, press, and shear machine.

Because fewer fuel and target assemblies will be disassembled in the $\mathrm{L}$ and P-Reactor MBs than in the K-Reactor MB, their corresponding inadvertent criticality probabilities are bounded by the K-Reactor MB probabilities.

\section{CRITICALITY IN THE HORIZONTAL BUNDLE AND BUCKET STORAGE}

Fuel bundle storage in the horizontal bundle and bucket storage (HBBS) historically has been four fuel assemblies placed in a bundle and two bundles (along with a spacer) stored in a horizontal bundle storage rack slot. To allow for increased storage by using additional racks or reracking in the existing racks, criticality analyses have been performed (Ref. 8-46) and a Technical Specification change has been submitted (Ref. 8-47).

With these new storage options, three methods of storage will be allowed:

1. Two bundles of four assemblies each and spacer to prevent insertion of a third bundle. 
2. Three bundles of three Mark $16 \mathrm{~B}$ assemblies each and a fuel blocking system (grating over the racks) to prevent the dropping of a fourth bundle near the bundles in the slot.

3. Three bundles of four Mark 22 assemblies each and a fuel blocking system to prevent the dropping of a fourth bundle near the bundles in the slot.

Of these storage options, all have been analyzed for criticality concerns (Ref. 8-47, 8-46).

\section{Storage Option 1}

One scenario could lead to a criticality in the HBBS, accumulation of more than three bundles or loose assemblies in a rack. The two variations of this scenario are presented below:

1. Following maintenance, the maintenance operator fails to replace the spacer in the storage rack. The loading operator mistakenly loads three bundles into ore rack and the supervisor fails to detect this error. During transfer of another bundle to the racks, the twin hook hoist mechanism bolt fails, causing the bundle to drop. The bundle is located over the rack at the time and it falls into the same storage rack that contains three bundles. The frequency of occurrence of this event is approximately $8.9 \times 10^{-11} /$ yr (Ref. 8-43).

2. Following maintenance, the maintenance operator fails to replace the spacer in the storage rack. The loading operator mistakenly loads three bundles into one rack and the supervisor fails to detect this error. During transfer of another bundle to the racks, an assembly breaks free from the bundle while the twin hook hoist is located over the rack. The assembly falls into the same rack that contains the three bundles. The frequency of occurrence of this event is also approximately $8.9 \times 10^{-11}$ /yr (Ref. 8-43).

In determining the criticality scenarios in the HBBS and the probabilities associated with each scenarios, the following assumptions were used:

- Spacers are always used in the racks. The only time a spacer is removed is during maintenance to the racks. Even though routine maintenance is not condicted on the racks, it is assumed that maintenance is necessary at least once a year.

- Maintenance is performed on a given rack as needed and does not affect the surrounding racks. Furthermore, only the spacer in the given rack is removed during maintenance.

- Only one operator is necessary to move material into and out of the HBBS area.

- All bundles contain four assemblies.

- It will take approximately six months to remove an estimated 117 bundles from the $\mathrm{K}$ Reactor HBBS. Furthermore, it will take approximately two months to re-fill this area with the estimated 108 bundles generated from Mark 22 disassembly operations for 
the assemblies currently stored in K-Reactor VTS. These bundles will not be inmediately removed from HBBS.

- It takes àpproximately 15 minutes to load a bundle into HBBS.

\section{Storage Option 2}

A criticality study (Ref. 8-46) was conducted to determine the safe critical configuration of fuel assemblies given a new storage configuration for the most reactive assemblies, including Mark 22 and Mark 16B assemblies. Specifically, this proposed storage configuration was that the number of permissible bundles in a slot would be increased from two to three (requiring the removal of the slot spacer), and a fuel blocking system (a grating structure) would be placed on top of the individual slots to prevent a dropped assembly from falling into a slot.

As a result of the criticality study, it was determined that the most reactive assemblies (Mark 16B

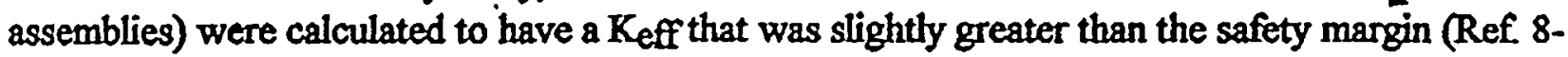
46). This criticality study evaluated a configuration equivalent to three bundles (containing four assemblies each) in a slot with a dropped fourth bundle in the same slot (Ref. 8-46). It was also determined through this study that reducing the number of Mark 16B assemblies per bundle from four to three achieved the desired safety margin.

Based on these findings, the proposed storage configuration (for Mark 16Bs) is a maximum of three fuel bundles per slot (with three assemblies/ bundle) and the addition of a grating system that will cover a slots (Ref. 8-47).

Two scenarios could lead to a criticality in the HBBS (option 2):

1. The machine basin operators place four assemblies (Mark 16Bs) in a bundle. The operator that loads these bundles of four Mark 16B assemblies into the HBBS storage racks fails to detect this error. The loading operator fails to place the grating over a slot after loading three bundles. This operator then erroneously attempts to load four bundles (containing four assemblies) into one slot. The frequency of occurrence of this event is approximately $2.3 \times 10^{-7} / \mathrm{yr}$ [Ref. 8-43].

2. The operator fails to place the grating over a slot after loading three bundles into the slot. The operator then places four bundles in a slot (with the fourth bundle protruding above the slot) and the supervisor fails to detect this error. While transporting another bundle over the same rack, an assembly breaks free from the bundle and lands next to the slot containing four bundles. The frequency of occurrence of this event is approximately $1.6 \times 10^{-8} / \mathrm{yr}$ [Ref. 8-43].

In determining the criticality scenarios in the HBBS (Option 2) and the probabilities associated with each scenario, the following assumptions were used.

- All assemblies in VTS will be transferred to HBBS in one year 
- Empty slots are available for the placement of newly generated bundles

- A maximum of 14 racks can be placed in HBBS in L-Area

- All bundles currently in HBBS contain three assemblies

- The rack structures will not fail due to corrosion before the new racks are installed.

- For bundles containing three assemblies apiece, the placement of four bundles in a slot with a fitth bundle or single dropped assembly placed adjacent to the fourth bundle . . results in a critical configuration. For bundles containing four assemblies apiece, the placement of three bundles in a slot with a fourth bundle or single dropped assembly falling into the same slot results in a critical configuration.

- The bundles currently in storage in the racks will not be placed in temporary storage prior to loading them into the new racks.

The overall frequency of criticality for the proposed storage of fuel in HBBS is approximately 2.8 $\times 10^{-7} / y r$ [Ref. 8-43]. This is for L $/$ Reactor Disassembly Basin based on re-racking the HBBS (i.e., moving all of the current bundles plus the new bundles [approximately 84] generated from disassembly of the fuel assemblies in the VTS). For the HBBS, this probability is slightly higher than the K-Reactor HBBS probability. However, with more assemblies in K-Reactor VTS, the increased processing of the assemblies results in criticality for the entire K-Reactor basin being at a greater probability than that of L-Reactor Disassembly Basin.

\section{Storage Option 3}

The proposed option of three bundles of four Mark 22 assemblies each and a grating over the racks to prevent the dropping of a fourth bundle near the bundles in the slot will be used primarily in K-Reactor Disassembly Basin to remove the fuel assemblies currently stored in the VTS to the HBBS. There are approximatety 108 bundles of fuel to be moved from the VTS to the HBBS. The Option 1 analysis calculates the same operation only using 2 bundles per slot instead of three. The use of 2 bundles per slot results in more rack slots (54) being used and a greater opportunity for error. With only 36 slots being used when 3 bundles are used per slot, there is one-third less opportunities for error by the operators. Also, with the fuel blocking system in place, a fuel bundle or assembly could only be dropped in the slot where bundles are being placed that has its grating removed. Therefore, the Option 1 analysis bounds Storage Option 3.

Because fewer assemblies are to be removed from L- and P-Reactors VTSs and stored in the HBBS and fewer assemblies as a whole (those presently in HBBS and those to be placed after processing in VTS) are to be removed from the L- and P-Reactor HBBS, the inadvertent criticality potential in the HBBS is bounded by that of K-Reactor HBBS.

\section{CRITICALITY DURING SHIPPING CASK LOADING}

Shipping cask loading has two criticality concerns. These concerns are: 
- Placement of two bundles in a section such that the bundles are in a critical configucation (side-by-side). This scenario is initiated by an operator error following cask maintenance or configuration activities.

- Placement of three bundles into two adjacent cask sections. The only mechanism by which bundles could be placed in a critical configuration is by placing them side-byside without the cadmium separator plates intact.

For the cask loading criticality scenario to be credible, the maintenance personnel would have to fail to install at least one blank and one cadmium plate in the cask following maintenance. They would also have to fail to perform a blackness test on the plates after they are installed. The loading personnel would then have to fail to detect this error and place two bundles into the same section of the cask.

In this scenario, the maintenance personnel are assumed to fail to place a blank and a cadmium plate in the section directly adjacent to section "1" or "5". The maintenance operators are credited with the ability of one of the operators to detect the other's error. They are also credited with the possibility that they will detect their error with the blackness test. By failing to install the cadmium plate and blank, a section of the cask has the capability to hold two bundles. The loading personnel are credited with performing an inspection of the cask using a checklist prior to loading. They must also fail to load the bundle into the proper cask section and instead place it in the cask section with another bundle. In this configuration, the bundles are assumed to be placed side-by-side.

In determining the criticality scenarios during cask loading and the probabilities associated with each scenarios, the following assumptions were used:

- The only time the plates and/or blanks are removed from a cask is during maintenance or cask configuration activities. Maintenance is conducted annually and the casks are assumed to remain in their required configuration throughout the shipping of one type of assembly.

- The cask and contents are highly visible to the loading personnel. Therefore, it was assumed that these personnel could detect any previous operator errors in cask configuration.

- Two operators place the blanks and cadmium separator plates in the cask after maintenance or during re-configuration of the cask. These same two operators are required by procedure to conduct the blackness test on the plates after they are installed.

- It is assumed that it takes approximately two hours to completely load and remove a cask. It is further assumed that out of this time, it takes 45 minutes to load each bundle into the cask.

- The loading operator and supervisor can detect the maintenance operator errors through visual inspection of the shipping cask. 
- Five casks are available for shipping. Furthermore, approximately 60 shipments must be made to clear the K-Reactor HBBS of its Mark 22 inventory.

- The crittcality concerns for shipment of scrap buckets are negligible in comparison to the shipment of Mark 22 assemblies.

- Once configured for shipment of the one specific type of assembly, the casks are not re-configured until the entire inventory of the type of assembly has been removed.

Becauso fewer assemblies are to be removed from L- and P-Reactor VTSs, MBs, HBBSs, and transfer bays and placed in shipping casks than in K-Reactor, the inadvertent criticality potential during shipping cask loading is bounded by the K-Reactor analysis.

\section{INADVERTENT CRITICALTTY PROBABILTTES}

As noted previously, the areas of the Disassembly Basin where criticality is a concam are: 1) vertical tube storage, 2) machine basin, 3) horizontal bundle and bucket storage, and 4) transfer bay during shipping cask loading. In all cases, there are a number of accident scenarios for each initiating event which can lead to the accidents of concern. In each case, the initiating event frequency as well as the sum of the accident frequencies are given for information.

\section{Criticality in Vertical Tube Storage}

The most likely scenario for criticality in K-Reactor VTS is an operator mishandling and dropping five assemblies on the basin floor. This scenario has a probability of occurrence of $2.3 \times 10^{-6} / \mathrm{yr}$ (Ref 8-43). The total frequency of occurrence of an inadvertent criticality in K-Reactor VTS from all events considered is approximately $2.8 \times 10^{-6} / y t$ (Ref. 8-43). This bounds L- and PReactor VTSs criticality probabilities, as there are fewer fuel assemblies in L- and P-Reactor VTSs than in the K-Reactor VTS.

\section{Criticality in the Machine Basin}

The most likely scenario for criticality in the K-Reactor MB is an operator failing to separate the fuel from the target sub-assembly five times during disassembly operations, failing to use the hand-held gamma detector each time, and placing all of the targets on the target stack. This scenario has a probability of occurrence of $4.9 \times 10^{-6} / y r$ (Ref. 8-43). The second most likely scenario is an operator failing to use a criticality bar and failing to remove a complete fuel bundle before assembling another fuel bundle. This scenario has a probability of occurrence of $4.7 \times 10^{-6} / y r$ (Ref. 8-43). The total frequency of occurrence of an inadvertent criticality in the $\mathrm{K}$-Reactor MB from all events considered is approximately $1.1 \times 10^{-5} / \mathrm{yr}$ (Ref. $8-43$ ). This bounds $\mathrm{L}$ - and P-Reactor MBs criticality probabilities, as there are fewer fuel assemblies in L- and 
P-Reactor VTSs that will be disassembled and placed in target and fuel bundles in the MBs than in the K-Reactor VTS

\section{Criticality in the Horizontal Bundle and Bucket Storage}

Criticality scenarios in the HBBS have been analyzed for the three methods of storage of fuel bundles in the HBBS racks.

The first storage method involves the use of spacers and the limit of two fuet bundles per rack slot. The first of two postulated criticality scenarios associated with the first storage method involves a maintenance operator failing to replace the spacer in the rack slot, the loading operator mistakenly losding three bundles into one slot and the supervisor failing to detect this error coupled with another bundle being transferred over this slot and the twin hook hoist mechanism bolt failing. This scenario has a frequency of $8.9 \times 10^{-11} / y r$ (Ref 8-43). The second_postulated scenario associated with the first storage method involves a-maintenance operator failing to replace the spacer in the rack slot, the loading operator mistakenly loading three bundles into one slot and the supervisor failing to detect this error coupled with another bundle being transferred over this slot and an assembly falling from the bundle. This scenario has a frequency of $8.9 \times 10^{-11}$ /yr (Ref. 8-43). The total frequency of occurrence of an inadvertent criticality in the $\mathrm{K}$-Reactor HBBS from all scenarios for the first storage method is approximately $2.7 \times 10^{-10} / \mathrm{yr}$ (Ref. 8-43). This bounds $L$ and P-Reactor HBBSs criticality probabilities, as there are fewer fuel assemblies in L- and P-Reactor VTSs (that will be evenly be placed in the HBBSs) and HBBSs than in the K-Reactor VTS and HBBS.

The second storage method involves the use of the fuel blocking system and the storage of Mark $16 \mathrm{~B}$ fuel bundles. The first of two postulated criticality scenarios associated with the second storage method is the machine basin operator error of placing four Mark 16B fuel assemblies in the bundles; operator error in placing three Mark $16 \mathrm{~B}$ bundles with four assemblies each in a slot; failure of the operator to place the grating over the slot after the three bundles are-Joaded; and the operator then erroneously attempting to load a fourth bundle (with four Mark 16B fuel assemblies) into the slot. The frequency of occurrence for the event is approximately $2.3 \times 10^{-7} / y r$ (Ref. 8-43). The next postulated criticality scenario associated with the second storage method is the failure of the operator to replace the grating over a slot after loading three bundles. The operator then places four bundles in a slot (with the fourth bundle protruding above the slot) and the supervisor fails to detect this error. While transporting another bundle over the same rack, an assembly breaks free from the bundle and lands next to the slot containing four bundles. The frequency of occurrence of this event is approximately $1.6 \times 10^{-8} / \mathrm{yr}(\operatorname{Ref} .8-43)$.

The third storage method involves the use of the fuel blocking system and the storage of Mark 22 fuel bundles. The first storage method bounds the third storage method, therefore, no formal probability analysis was made. 


\section{Criticality During the Shipping Cask Loading}

The scenario for criticality during the shipping cask loading in the K-Reactor transfer bay is a maintenance personnel failing to install at least one blank and one cadmium plate, failure to perform a blackness test on the plates after they are installed, failure of the loading operator to detect this error, and the loading operator placing two bundlos into the same section of the cask. This scenario has a frequency of $4.5 \times 10^{-6} / \mathrm{yr}$ (Ref. 8-43). The total frequency of occurrence of an inadvertent criticality during shipping cask loading in the K-Reactor transfer bay from all events postulated is approximately $4.5 \times 10^{-6} / y r$ (Ref, 8-43). This bounds L- and P-Reactor shipping cask loading criticality probabilities, as there are fewer fuel assemblies in L- and PReactor Disassembly Basins (that will be loaded in shipping casks) than in the K-Reactor Disassembly Basin.

\section{Forces Associated with Inadvertent Criticality}

Unplanned criticalities usually produce a brief burst of energy in the form of heat, mechanical energy, electromagnetic radiation, and charged and neutral particle radiation.

\section{Consequences/Damage Associated with Inadvertent Criticality}

Four of the scenarios associated with irradiated fuel/target storage in the K-, L-, and P-Reactor Disassembly Basins (i.e., DBE, Disassembly Basin draindown, Disassembly Basin overfill, and inadvertent criticality) were combined in a probabilistic manner in the analysis discussed in the PHA (Ref 8-17). Since each of these events contains numerous end-states (depending upon automatic and/or operator actions, fault-tree probabilities, and the physics of each event), a Monte-Cario type method (Ref. 8-17) was used which integrates the fault-tree end states of all four events (and their respective sub-events) into one consequence versus frequency curve. It is from this composite risk curve that worker and public dose estimates are derived. The combined radiological consequences to the co-located worker and public versus various frequencies are further discussed in Section 8.4.2.

The consequences for an inadvertent criticality in P- and L-Reactor Disassembly Basins are the same as the corresponding inadvertent criticality for K-Reactor Disassembly Basin.

\subsubsection{Criticality in the Sludge Lining the Disassembly Basin Walls and Floors}

The fissile radionuclides of concern in K-, L-, and P-Reactor Disassembly Basins are uranium-235 and plutonium-239, which are present in large amounts in the irradiated fuel and targets, and in small amounts in the sludge which lines the walls and floors of the Disassembly Basins. Trace amounts of other fissile isotopes also are present in the sludge. The estimated amounts of each fissile isotope present in the sludge of the K-, L-, and P-Reactor Disassembly Basins are given in Table 8.3-5. 
Note that the entire mixture of isotopes must also be considered when evaluating criticality potential for the sludge, not just whether or not each individual isotope is below its applicable subcritical mass limit. For a mixture such as the sludge, the sum-of-the-ratios method is applicable, where each isotope is divided by its applicable subcritical mass limit and the resultant ratios summed over all isotopes. Several additional complicating factors are present, such as the fact that iron-54, uranium-238, and americium-241 present in the sludge have significant thermal neutron absorption cross-sections, meaning that they reduce the neutron multiplication ratio, $\mathrm{K}_{\mathrm{eff}}$. Reference 8-24 performs the necessary calculations for the sludge in the K-Reactor Disassembly Basin and gives a conservative sum-of-the-ratios (including several correction and complicating factors) of 0.88 , below the conservative ratio limit of 0.90 (Ref. 8-24) deemed necessary for subcriticality. Thus, the sludge in the K-Reactor Disassembly Basin cannot go critical. There is an insufficient quantity of fissiie material in the sludge of the $L$ and P-Reactor Disassembly Basins to go critical (Ref. 8-25, 8-26).

\subsubsection{Criticality in the Settler Tank}

A settler tank is used as part of the basin filtration system for each of the K-, L-, and P-Reactor Disassembly Basins. Its function is to serve as a collector of water and material that is forced out of the sand filters and into the sand filter sumps via a backwash process used to purge the sand filters when the pressure drop across them becomes excessive. The residue from the sand filters is then allowed to settle to the bottom of the settler tank, and the surface water then returned to the Disassembly Basin (Ref. 8-28, Section 9.1.3.2).

The tank itself has a 7500 gallon capacity (Ref. 8-28, Fig. 9.1-9), and is a right circular cylinder approximately 22 feet in diameter, with the bottom few feet tapering down to a cone. Any material not retained by the sand fitters will end up in the settler tank, thus, there is a possibility of fissile material accumulation. With the presence of light water, the accumulated fissile material creates a

potential for criticality. The cone-shaped portion of the settler tank will tend to concentrate the particulates, thus increasing the possibility of a critical concentration forming. The geometry of the cone is a more conducive to criticality than a cylinder or slab.

\section{PROBABILTIES ASSOCIATED WITH CRITICALITY IN THE SETTLER TANK}

The water in the VTS has been sampled (Ref 8-67) to determine its radionuclide content (especially fissile nuclides). Reference 21 showed no detectable fissile nuclides in the VTS water sample. The water intake to the sand filters (and hence the settler tank) from the Disassembly Basins has not been shown to draw sludge (which may contain sparse concentrations of fissile nuclides) from the bottom of the basins.

Although the cone-shaped portion can concentrate fissile nuclides, the concentration of fissile nuclides in the basin (which is where the settler tank ultimately obtains its fissile nuclides) is too small to form a critical configuration. References 8-24 8-25, and 8-26 show best estimates of the 
inventories of sludge in the K-, L, and P-Reactor Disassembly Basins. The estimated inventories of uranium-235 are about 907, 126, and 180 grams in the sludge of K-, L-, and P-Reactor Disassembly Basins, respectively, and 191, 18, and 62 grams of plutonium-239, respectively. Other fissile nuclides are also present, but in far smaller amounts (Ref. 8-24, 8-25, 8-26).

Although the amount of uranium-235 in the sludge of the K-Reactor Disassembly Basin exceeds the theoretical minimum amount necessary for criticality (700 grams, [Ref 8-13]), and the sludge plutonium-239 inventory is a substantial fraction of the theoretical minimum amount necessary for criticality (450 grams, [Ref. 8-131), these amounts cannot be present in the settler tank, for the reasons stated below:

- the K-Reactor basin water which feeds the filtration system contains lower amounts of fissile materials (Ref. 8-67) than does the sludge, and the water is taken in such a way that sludge has not been transported through the filtration system. This is judged to be true by the observation of lack of change in the sludge layer in the basin

- due to the weight of fissile material constituents, they are more likely to precipitate to the floor of the Disassembly Basin than to remain suspended in basin water and be transported through the filtration system

- assuming that the basin sludge has never been removed or the settler tank thoroughly cleaned, the sludge in the K-Reactor Disassembly Basin should have a substantially higher fissile material content than the settler tank

Therefore, the K-Reactor settler tank would have only a fraction of the fissile material constituents of the basin sludge and would be less than the theoretical minimum amounts necessary for criticality. Additionally, other constituent matter (metals such as iron and aluminum, non-metallic materials such as sand, and non-fissile radionuclides such as uranium-238) occupy most of the volume of the basin sludge and the material collected in the settler tank. Thus, the actual amount of fissile radionuclides in the settler tank is far less than the estimated entire basin inventory. Furthermore, the theoretical minimum mass for criticality is computed for ideal conditions, such as no neutron poisons present, spherical geometry of the fissile nuclide with interstitial moderator present, and optimal temperature of moderator. The settler tank cannot credibly achieve these ideal conditions under normal operational conditions. The lack of ideal geometry and the constituent composition are estimated to increase the minimum amount of fissile material required for a criticality to well above 700 grams of uranium-235 or 450 grams of plutonium-239, or the sum-of-the-ratios of fissile nuclides. Therefore, criticality occurring in the K-Reactor settler tank is judged not credible.

The fissile nuclides in the sludge of the $\mathrm{L}$ and P-Reactor Disassembly Basins are sufficiently low that theoretical minimal masses for criticality or the sum-of-the-ratios of fissile nuclides are not met (Ref. 8-25, 8-26). Therefore, criticality occurring in the L or P-Reactor Disassembly Basin is not credible. 


\section{FORCES ASSOCIATED WTTH CRITICALITY IN THE SETTLER TANK}

Not applicable, because a criticality in the K-, L-, and P-Reactor Disassembly Basins settler tanks is not credible.

\section{COÑSEQUENCES/DAMAGE ASSOCIATED WITH CRTICALTTY IN THE SETTLER TANK}

Not applicable, because a criticality in the $\mathrm{K}_{-}, \mathrm{L}$, and P-Reactor Disassembly Basins settler tanks is not credible.

\subsubsection{Criticality in the Sand Filters}

The sand filters are used as part of the Disassembly Basin filtration system for each of the $\mathrm{K}$,, $\mathrm{L}$, and P-Reactor Disassembly Basins. The sand filters remove particulate and suspended materials in the Disassembly Basin water, and maintain clarity of the water to allow for visual inspection of basin materials. If enough fissile material accumulates in the sand filters and enough moderator is present in the form of light water passing through the filters, criticality may occur. The fissile isotopes embedded in the sand filters are expected to be primarily uranium and plutonium (since these are available in abundance from the irradiated fuel), but may also include other fissile radionuclides present in the sludge lining the basin walls and floor.

The sand filter is 11 feet in diameter, and the active portion is 36 inches long (Ref 8-28, Section 9.1.3.2). The active materials are sand (silicon dioxide) and anthracite (carbon). The flow through each sand filter is rated at $1500 \mathrm{gpm}$ (Ref 8-28, Section 9.1.3.2). Alum (potassium aluminum sulfate) is added to the water before it reaches the filters in order to assist coagulation of particulate. When the sand filter fills with residue, the filter is purged via backwash (either manually, or automatically when the pressure drop across the sand filter is high enough).

\section{PROBABIITIES ASSOCIATED WITH CRTICALITY IN THE SAND FLTERS}

The water in the K-Reactor VTS has been sampled (Ref. 8-67) to determine its radionuclide (especially fissile radiomuclide) content. Reference 8-67 showed no detectable fissile radionuclides in the VTS water sample examined. Even if the sludge from the bottom of the Disassembly Basin were drawn into the sand filters, the sand filters would not go critical due to the large (11 feet diameter) cylindrical geometry of the sand filters (Ref. 8-49). Also, it has been shown in References 8-24, 8-25, and 8-26 that the sludge cannot go critical. Section 8.3.2.4 discusses the criticality analysis of the Disassembly Basin sludge. The detectable mass of material taken from the sand filters is on the order of 10E-7 grams (Ref. 8-49). The mass required to reach aerial density for this filter is approximately 35.3 grams of U-235 mass. 


\section{FORCES ASSOCIATED WTH CRTTCALITY IN THE SAND FTTERS}

Not applicable, as criticality is not credible in the K-, L-, and P-Reactor Disassembly Basins sand filters.

\section{CON̄SEQUENCES/DAMAGE ASSOCIATED WITH CRITCALITY IN THE SAND FUTERS}

As discussed above, the sand filters cannot go critical due to the inability of fissile particulates to concentrate in the large ( 11 feet in diameter) sand filters.

Not applicable, as criticality is not credible in the $\mathrm{K}, \mathrm{L}$, and P-Reactor Disassembly Basins sand filters.

\subsubsection{Criticality in the Deionizers}

The deionizers remove ionized particulate and suspended materials in the Disassembly Basin water of each of the K-, Lr, and P-Reactor Disassembly Basins via ion exchange with resin in the deionizers. The deionizers also maintain the water conductivity within operating limits to keep corrosion of the aluminum components in the basin at a minimum. If enough fissile material accumulates in the deionizers and enough moderator is present in the form of light water passing through the deionizers, criticality may occur. The fissile isotopes embedded in the deionizers are expected to be primarily uranium and plutonium (since these are available in abundance from the irradiated fuel), but may also include other fissile isotopes present in the shudge lining the basin walls and floors.

The K-, L-, and P-Reactor Disassembly Basins have 8 deionizers, each mounted on trailers (for easy transportation to the 200 Area for regeneration) (Ref. 8-50). The deionizers receive water from the discharge of the VTS filter feed pump (Ref. 8-50). The water flow through each deionizer is rated at $70 \mathrm{gpm}$ (Ref 8-50). The piping to the deionizers has a manifold which allows multiple deionizers to be hooked up in series or in paralled.

Each deionizer is slightly different in design and valving, but the differences are not important for the purposes of this criticality evaluation. A typical deionizer is a cylindrical vessel 5 feet in diameter and 8.875 feet tall, and contains approximately $62 \mathrm{ft}^{3}$ of ion-exchange resin or a quantity of zeolite (Ref 8-50).

When the deionizer beds become exhausted (incapable of removing ions), they are regenerated. This is done when (Ref. 8-50):

1) Instrumentation indicates a large pressure drop across the deionizer; and RC\&HP personnel measure radiation levels to be $20 \mathrm{mR} / \mathrm{hr}$ or greater, or,

2) Radiation activity levels of any radionuclide exiting the deionizer is within $75 \%$ or greater of that radionuclides inlet activity level. 


\section{PROBABILITES ASSOCCIATED WITH CRITICALITY IN THE DEIONIZERS}

Due to the geometry of the deionizers, the particulates that do accumulate in the deionizers cannot reach concentrations conducive to criticality. The water in the K-Reactor VTS has been sampled (Ref. 8-67) to determine its radionuclide (especially fissile radionuclide) content. Reference 8-67 showed no detectable fissile radionuclides in the VTS water sample examined. The water intake to the deionizers from the Disassembly Basins has not been shown to draw sludge (which may contain sparse concentrations of fissile nuclides) from the bottom of the basins. Even assuming some sludge may be present in the basin water and accumulates in the deionizer, it has been shown in References 8-24, 8-25, and 8-26 that the sludge cannot go critical, as discussed in Section 8.3.2.4. The deionizers also tend to accumulate iron-54 and other ions present in the sludge and water that have significant thermal neutron absorption cross-sections (Ref. 8-67), reducing the reactivity of the deionizer beds. Finally, since the deionizer resins are replaced when radiation levels are $20 \mathrm{mR} / \mathrm{hr}$ or greater, it is very unlikely that the minimum theoretical amount of fissile radionuclides necessary for criticality (e.g., $450 \mathrm{~g}$ for plutonium-239 or $700 \mathrm{~g}$ for iranium235 [Ref. 8-13]) could accumulate before other radionuclides caused the deionizers to exceed the $20 \mathrm{mR} / \mathrm{hr}$ level.

\section{FORCES ASSOCIATED WITH CRITICALITY IN THE DEIONIZERS}

Not applicable, as criticality is not credible in the K-, L-, and P-Reactor Disassembly Basins deionizers.

\section{CONSEQUENCES/DAMAGE ASSOCIATED WITH CRITICALITY IN THE DEIONIZERS}

Not applicable, as criticality is not credible in the K-, L-, and P-Reactor Disassembly Basins deionizers.

\subsubsection{Loss of Disassembly Basin Cooling}

The K-, Ln, and P-Reactor Disassembly Basins house irradiated fuel and target assemblies, each emitting varying amounts of decay heat. As shown in the K-Reactor in Cold Standby PHA and Pand L-Reactor Disassembly Basins PHA (Ref. 8-17, 8-51), the irradiated fuel assemblies currently in the $\mathrm{K}-, \mathrm{L}$, and P-Reactor Disassembly Basins have relatively low decay heat since the assemblies have been in the basins for an extended period of time or were not irradiated for a long period of time. Conservative calculations performed in the PHAs (Ref. 8-17, 8-51) show that the basin water cannot reach boiling temperature (100_C), and in fact reaches temperatures of only 77_C if the air is maintained at 45 _C and the maximum heat generation rate is used for all assemblies in the basins. In addition, an analysis performed in Reference 8-52 states that forced cooling through the heat exchanger is not necessary, evaporative cooling is adequate. However, in each basin, recirculation of Disassembly Basin water through the heat exchanger is maintained 
to provide mixing in the basin. The recirculation path will provide sufficient circulation to allow heat to be removed from the basins by evaporation.

\section{LOSS OF DISASSEMBLY BASIN COOLING PROBABMITIES}

The cooling system for each of the K-, L, and P-Reactor Disassembly Basins will not be operated as discussed in Reference 8-52, however a cooling water pump will circulate the basin water. through the heat exchangers of each basin though no cooling water will be available. Therefore, the frequency of cooling for the $\mathrm{K},, \mathrm{L}$, and P-Reactor Disassembly Basins being unavailable is unity.

\section{FORCES ASSOCIATED WTTH LOSS OF DISASSEMBLY BASIN COOLING}

There were no adverse forces associated with loss of cooling for the K-, L-, and-P-Reactor Disassembly Basins (Ref. 8-52).

\section{CONSEQUENCES/DAMAGE ASSOCIATED WITH LOSS OF DISASSEMBLY BASIN COOLING}

No adverse consequences from the loss of cooling for the K-, L-, and P-Reactor Disassembly Basins were identified (Ref. 8-52).

\subsubsection{Hazardous Chemical Soin}

This event is discussed in Section 8.2.

\subsubsection{Fire}

The fire loading in and around the entire K-Reactor (i.e., Disassembly Basin, Purification Area, Assembly Area, Moderator Storage Areas, and Process Room) and the L- and P-Reactor .Disassembly Basins will be restricted administratively (see Section 7.2.2). Combustible loads are light in K-Reactor during Cold Standby (Ref. 8-27) and in L- and P-Reactors during Cold Shutdown (Ref. 8-53, 8-54). Fires that start in areas of Buildings 105-K, 105-L, and 105-P with heavier combustible loadings (such as the crane maintenance area and -40-foot-elevation motor rooms) are not expected to spread to other areas (Ref. 8-55) and thus will not threaten the areas of K-Reactor containing hazardous material or the $\mathrm{L}-$ and P-Reactor Disassembly Basins.

\section{FIRE PROBABIIITIES}

The probability of a fire occurring in K-Reactor in Cold Standby and in the L- and P-Reactor Disassembly Basins can be estimated by using the Reference 8.55 sitewide fire probability of 6.05 
$\times 10^{-5}$ per year per 10,000 square feet of facility. Buildings $105-\mathrm{K}$ and $105-\mathrm{L}$ are approximately 150,000 square feet and Building 105-P is approximately 135,000 square feet (Refs. 8-51 \& 8-17). These areas were determined based on facility drawings presented in the Fire Hazards Analysis. The 0-foot-elevation was chosen because the basins reside on that elevation. Other elevations were not included because the flooring separating the levels provides an adequate fire barrier. Buildings $105-\mathrm{K}$ and $105-\mathrm{L}$ have a corresponding probability of a fire of $9.1 \times 10^{-4} / \mathrm{yr}$ and Building 105-P has a fire probability of $8.2 \times 10^{-4} / \mathrm{yr}$. Using the entire Buildings $105-\mathrm{L}$ and 105-P square footage instead of the area of their corresponding Disassembly Basins is conservative since only the basin areas needed to be considered.

\section{FORCES ASSOCIATED WITH FIRE}

The danger of a fire is the possibility of uncontrolled release of radionuclides, such as evaporating Disassembly Basin water. Hazardous chemicals could also be released in the same manner, such as the boiling and bursting of drums containing chemicals.

\section{FIRE CONSEQUENCES}

The probability of a fire is limited since no combustible materials are permitted in or around $\mathrm{K}$ Reactor in Cold Standby or the L- and P-Reactor Disassembly Basins except as permitted by the fire protection program (Ref 8-27). In addition, in the event of a fire due to the small amount of combustible materials (such as cleaning supplies), the extent of the fire will be small and localized.

Note that the storage area of the radionuclide or chemical hazards is comparatively large and the building construction is concrete throughout in the case of Buildings 105- $\mathrm{K}, 105-\mathrm{L}$, and 105-P. Therefore, any relatively small localized fire would not be expected to affect significant amounts of radionuclides. The radiological consequences of a fire in Buildings 105-K, 105-L, and 105-P are expected to be a small fraction of the consequences of the combined Disassembly Basin scenarios discussed in Section 8.4.2.

\subsubsection{Explosion}

Vehicles will be used periodically in and around the K-Reactor in Cold Standby and $\mathrm{L}$ - and PReactor Disassembly Basins and will add a possibility of explosions which could damage equipment or storage areas and release radionuclides or hazardous chemicals. For example, the delivery trucks have fuel tanks and batteries. An explosion could cause a pressure wave strong enough to damage the Disassembly Basin or cause missile damage to storage drums of hazardous chemicals. Several volatile chemicals are stored and/or used in the K-, L-, and P-Areas, such as acetylene for welding, propane for vehicles, diesel fuel for emergency generators, gasoline, and ammunition carried by security forces. 


\section{EXPLOSION PROBABILITIES}

Most of the explasive materials discussed above are not stored near K-, L-, and P-Reactor Disassembly Basin related structures or equipment, and when used near equipment or structures, it is only for a short time. In addition, administrative controls on handling, storing, and using explosive materials decrease the probability of explosions. No incidence of explosion was identified for any reactor at SRS during a search of reactor incident reports for the period from the early 70's to the present. Since no explosions have been observed, rare event theory can be applied (Ref. 8-30). The rare event theory was applied in the PHA (Ref 8-17) to determine the probability of an explosion. Approximately 100 reactor-years have elapsed at SRS, thus the probability can be conservatively estimated as 3.0 x 10-2/yr. Reference 8-30 notes that this method may be overiy conservative if the observation period is small.

In addition to the probability of an explosion, two other factors must be considered in order to estimate the threat of radionuclide release or chemical hazard release (chemical hazard release is dealt with in Section 8.2). They are:

- The fraction of explosions that are powerful enough to cause damage to the $\mathrm{K}$-, $\mathrm{L}$, , or P-Reactor Disassembly Basin is conservatively estimated at $1.0 \times 10^{-3} /$ explosion. This is reasonable since much of the Disassembly Basin structure is blast resistant and much of the equipment has a low probability of failure from $0.2 \mathrm{~g}$ seismic forces (see earthquake, Section 8.3.1.3).

- The fraction of explosions that are close enough to cause damage to the $K_{-}, L_{-}$, or $P_{-}$ Reactor Disassembly Basin is conservativety estimated at $1.0 \times 10^{-2} /$ explosion.

The total probability of an explosion causing radionuclide or chemical release from the $\mathrm{K}_{-}, \mathrm{L}_{\text {, }}$, or P-Reactor Disassembly Basin is:

$$
3.0 \times 10^{-2} / \mathrm{yr} .1 .0 \times 10^{-3} * 1.0 \times 10^{-2}=3.0 \times 10^{-7} / \mathrm{yr}
$$

Thus, this event is estimated to be not credible.

\section{FORCES ASSOCTATED WTTH EXPLOSION}

Not applicable since an explosion causing radionuclide or chemical release is considered not credible for the K-, L-, or P-Reactor Disassembly Basin. For explosions outside Building 105-K, $105-\mathrm{L}$, or 105-P, only three Disassembly Basin ancillary structures could be affected. They are the sand filters, the heat exchangers, and the deionizer system. If these systems were to be damaged by an explosion, their losses would be bounded by the Disassembly Basin draindown events (see Section 8.3.2.I). 


\section{CONSEQUENCES/DAMAGE ASSOCIATED WITH EXPLOSION}

Not applicable since an explosion causing radionuclide or chemical release from the $K_{-}, L_{-}$, or $P$ Reactor Disassembly Basin is considered not credible. Consequences of an explosion affecting the Disassembly Basin ancillary structures outside Building 105-K, 105-L, or 105-P are bounded by the Disassembly Basin draindown events discussed in Section 8.3.2.1.

\subsubsection{Aircraft Hazards}

The K-Reactor SAR states that, except for the Wackenhut Services, Inc. (WSI) helicopter pad, there are no airports within 10 miles of the three reactor sites (Ref. 8-28). The closest airports are Barnwell County Airport, which is 11 miles east of P-Area. The next nearest airport is the Burke County Airport, which is approximately 19 miles southwest of K-, L-, and P-Areas.

Airplane and helicopter crashes into Building 105-K, 105-L, or 105-P and Disassembly Basin ancillary structures outside Building $105-\mathrm{K}, 105-\mathrm{L}$, or $105-\mathrm{P}$ are postulated which could damage the K-, L-, or P-Reactor Disassembly Basin or their ancillary structures and release radionuclides.

\section{AIRCRAFT HAZARD PROBABILITIES}

Airplane and helicopter crashes were considered separately as accidents which could lead to a radionuclide release from K-Reactor in Cold Standby or the L and P-Reactor Disassembly Basins.

The actual collision area of each of the Buildings 105-K, 105-L, and 105-P is equal to the sum of the floor areas of the 0 -foot-elevation and the projected area of the above ground structure. The PHA (Ref. 8-17) calculates the collision area for each of the Buildings 105-K, 105-L, and 105-P as $239,258 \mathrm{ft}^{2}$ or $8.6 \times 10^{-3} \mathrm{mi}^{2}$. Using the entire Building 105-L and 105-P square footage instead of the area of their corresponding Disassembly Basins is conservative since only the basin areas needed to be considered.

Airplane Crash - According to the DWPF SAR (Ref. 8-35), the frequency of airplane crashes at $\mathrm{SRS}$ is $5.6 \times 10^{-5}$ crashes/(year-mi ${ }^{2}$ ). The overall frequency of an airplane crash into Building 105-K, 105-L, or 105-P is thus estimated to be $5.6 \times 10^{-5}$ crashes $/\left(\right.$ year- $\mathrm{mi}^{2}$ ) $\times 8.6 \times 10^{-3} \mathrm{mi}^{2}$ or $4.81 \times 10^{-7}$ crashes/yr. Since the expected frequency of an airplane crash in Building $105-\mathrm{K}$, 105-L, or $105-\mathrm{P}$ is below $1 \times 10^{-6} / \mathrm{yr}$, this event is considered not credible.

Helicopter Crash - According to the DWPF SAR (Ref. 8-35), the frequency of helicopter crashes at SRS is $4.1 \times 10^{-11} \mathrm{crashes} /\left(\mathrm{yr}-\mathrm{ft}^{2}\right)$. As calculated above, the total effective target area of each of the Buildings 105-K, 105-L, and 105-P is $239,258 \mathrm{ft}^{2}$. Thus, the overall frequency of a helicopter crash into Building $105-\mathrm{K}, 105-\mathrm{L}$, or $105-\mathrm{P}$ is $4.1 \times 10^{-11}$ crashes/(yr- $\left.\mathrm{ft}^{2}\right) \times 239,258$ $\mathrm{ft}^{2}=9.8 \times 10^{-6}$ crashes/yr. The frequency of helicopter crashes is bound to be less than that 
calculated above from operating restrictions. The number above is based on the assumption that a crash at any SRS location is equally probable. Helicopters, however, are not permitted to fly over operating areas (Ref 8-35). Moreover, a helicopter is likely to be able to avoid building impact, even if a loss of power occurs directly over the building. Based on these arguments, the helicopter crash frequency is judged to be less than $1.0 \times 10^{-6}$ crashes/yr. Also, the damage from a helicopter crash will not be severe enough and widespread enough to create a release more than a small fraction of the consequences of the release associated with a Disassembly Basin draindown or overfill discussed in Section 8.4.2.

\section{FORCES ASSOCLATED WITH AIRCRAFT ACCDENTS}

Not applicable since an aircraft crash is not credible.

\section{CONSEQUENCES/DAMAGE ASSOCIATED WITH AIRCRAFT ACCIDENTS}

Not applicable since an aircraft crash is not credible.

\subsubsection{Loss of Power}

A loss of power would shut off the ventilation system in Building 105-K, 105-L, or 105-P for a period of time, leading to increased chances of freezing the water in the K-, L-, or P-Reactor Disassembly Basin, moderator in the K-Reactor Purification Ares, or chemicals during cold weather. The loss of ventilation would cause operating personnel to take the appropriate actions to prevent any long term damage to the radionuclide and chemical storage structures if the loss of ventilation continued. The potential for chemical, moderator, or water to fieeze if heat is lost is covered more thoroughly in Section 8.3.2.17. In addition, most radiological monitoring would be lost in a loss of power event as discussed in Section 8.5.

\subsubsection{Loss of Yentilation}

A loss of ventilation in Building 105-K, 105-L; or 105-P would shut off the fans supplying heated air for a period of time, leading to increased chances freezing the water in the K-, L-, or PReactor Disassembly Basin, moderator in the K-Reactor Purification Area, or stored chemicals. The loss of ventilation would cause operating personnel to take the appropriate actions to prevent any long term damage to the chemicals, Purification Area, or Disassembly Basin if the loss of ventilation continued. The potential for chemical, moderator, or water to freeze if heat is lost is covered more thoroughly in Section 8.3.2.17. In addition, stack release radiological monitoring would be lost as discussed in Section 8.5. There are two fans, one operating and one backup, to supply ventilation which leads to radiological monitoring. Also, the steam lines supplying the heating coils would still be operating and giving off heat. 


\subsubsection{Internal Missiles}

Rotating machinery (pumps, fans, motors) have the potential to generate missiles that could cause radionuclide release. Massive and rapid failure of various pumps, compressors, fans, diesel engines, and motor-generator sets is considered not credible because of the conservative design, material characteristics, inspections, quality control during fabrication and assembly, and prudent operation as applied to the particular component (Ref. 8-28, Section 3.5.1.1.1). Also, should this event actually occur, the chances of it affecting radionuclide storage sites (e.g., the Disassembly Basin) or chemical storage sites are small since the event is localized. Thus, the probability of internal missiles leading to a radionuclide release or chemical release is judged not credible.

\subsubsection{Loss of Confinement}

Fuel assembly cladding is the primary confinement and the K-, L-, and P-Reactor Disassembly Basins are the secondary confiriement for most of the stored radionuclides in Buildings 105-K, $105-\mathrm{L}$, and 105-P. Some fuel assembly cladding has been penetrated by corrosion which has allowed small amounts of fuel and fission products to migrate to the basin water, but gross failures have not occurred in the basins. Ancillary systems such as cooling, deionizing, and filtration systems and the Disassembly Basin walls and floors are the primary confinement for contaminated K-, L-, and P-Reactor Disassembly Basin water. K-, L-, or P-Reactor Disassembly Basin could fail and cladding could be damaged during some high energy events. This scenario can be analyzed by noting the following:

- The K-, L-, or P-Reactor Disassembly Basin (secondary confinement) failure is bounded by the DBE event (Section 8.3.1.3), which includes several basin damage scenarios.

- The failure of ancillary systems confinement of contaminated K-, L-, or P-Reactor Disassembly Basin water is bounded by the Disassembly Basin draindown event (Section 8.3.2.1).

- The primary confinement failure (fuel assembly mechanical damage) is bounded by the inadvertent criticality event (Section 8.3.2.3), which releases far more radionuclides (including noble gases) than mechanical damage to any particular fuet assembly or (less likely) any group of assemblies.

- The probability of having primary containment failure (fuel) and having secondary containment failure (K-, L, or P-Reactor Disassembly Basin) and having consequences greater than either the DBE or the inadvertent criticality or the Disassembly Basin draindown (the conjunction of three probabilities) is judged not credible. The last two occurrences are judged to have especially low probabilities so that even if some fuel failures have already occurred due to corrosion, the conjunction of the remaining two probabilities is still not credible.

Therefore, the loss of confinement is bounded by either the DBE, the inadvertent criticality, or the Disassembly Basin draindown event. 


\subsubsection{Loss of Heating}

The loss of heating to the K-, L-, or P-Reactor Disassembly Area could allow the air temperature to reach the freezing point of $\mathrm{H}_{2} \mathrm{O}\left(0^{\circ} \mathrm{C}\right)$. If the light water freezes, the $\mathrm{K}$-, $\mathrm{L}$, or P-Reactor Disassembly Basin walls could crack and when the water melted, a radionuclide release (and basin draindown) could occur. Also, the contaminated moderator in the equipment and 55-gallon drums in the K-Reactor Purification Area could freeze upon a loss of heating in Building 105-K if the air temperature were allowed to reach the freezing point of heavy water $\left(\mathrm{D}_{2} \mathrm{O}\right)\left[3.8^{\circ} \mathrm{C}\right]$. The drums or equipment could crack and when the moderator melted, a radionuclide release could occur. Also, some of the moderator purification equipment of the K-Reactor Purification Area is located outside of Building 105-K and is susceptible to freezing and releasing the contaminated moderator when the moderator melts. In addition, freezing of chemicals could also occur, with associated bursting of containers and release of chemicals. Reference $8-45$ gives a frequency of $7.5 \times 10^{-3} / \mathrm{yr}$ for probability of a generic heater failure. However, there is adequate heat load in Building 105-K to allow sufficient time to take compensatory measures to prevent basin water, moderator inside the Purification Area, or chemicals from freezing and adequate heat load in Buildings 105-L and 105-P to allow sufficient time to take compensatory measures to prevent the basin water from freezing. Additionally, the K-, L-, or P-Reactor Disassembly Basins contains a significant embedded heat source in the form of decay heat from irradiated fuel and targets. The K-Reactor Purification Area is also contained inside thick concrete walls (which hold their temperature) and as such the air temperature of the Purification Area would not drop to the moderator freezing point quickly.

During cold weather $\left(7.2^{\circ} \mathrm{C}\left[45^{\circ} \mathrm{F}\right]\right.$ ), freeze protection procedures are performed twice daily and the status of the steam supply system is checked (Ref. 8-56, 8-57). Therefore, problems with the steam supply would be detected and resolved quickly. In addition, the PHA calculation (Ref 819) indicates, that for any combination of temperature and curation, the K-, L or P-Reactor Disassembly Basin or K-Reactor Purification Area would never reach the light or heavy water freezing point long enough to freeze the Disassembly Basin water inside the moderator in drums or equipment of the Purification Area sufficiently to cause cracking. Therefore, basin water or moderator in the Purification Area freezing causing leakage and subsequent radionuclide release, and chemical freezing causing container bursting and subsequent chemical release is considered not credible for Buildings 105-K, 105-L, and 105-P. Some ancillary equipment or structure associated with the basins or Purification Area which are located outside could reach the freezing point of heavy and light water and release a small quantity of contaminated light water or moderator. However, even if the basin water or moderator were to freeze, the consequences of the release would be a small fraction of the consequences discussed in Section 8.4.2.

\subsubsection{Toxic Gas Release}

The major hazards from chemical or toxic gas releases are explosions of flammables and dispersion, particularty to the control rooms. Risks due to chemical releases are covered in Section 8.2. 


\subsubsection{Purification Events}

Two operations in -the Purification Area of Building 105-K are continuing in order to place deionizer resins and moderator in storage. In the first process, moderator is displaced from deionizer resin and evaporated in the dedeuterization system. In the second process, drummed moderator is evaporated in the distillation evaporator which is part of the high activity moderator (HAM) system. Both of these systems are used to remove fission products and other impurities from the moderator.

\section{PURIFICATION EVENTS PROBABMITIES}

Events which could release moderator from the dedeuterization or HAM systems include natural and process phenomena. The systems are inside the Purification Area, Seismic Category I, concrete reinforced structure, which will withstand a DBE and high wind events. It is. assumed that the Building 105-K exhaust stack could fail at winds greater that 185 mph (Ref 8-29) but that the Purification Area roof would withstand the debris with minimal failure and no damage would be expected for the dedeuterization and HAM systems. The dedeuterization and HAM system equipment is not designed to withstand a DBE and will be conservatively assumed to fail.

Process phenomena which are possible would be operator errors induced spills or overflows. Evaporator or condenser leaks could also occur. Since the dedeuterization and HAM systems are not designed to withstand a DBE, the probability of either system releasing radionuclides is equal to the probability of the occurrence of a DBE, which equals $2.0 \times 10^{-4 / y x}$ (Ref. 8-33).

\section{FORCES ASSOCIATED WITH PURIFICATION EVENTS}

The forces from leaks, overflow or spillage events are negligible.

\section{CONSEQUENCES/DAMAGE ASSOCIATED WITH PURIFICATION EVENTS}

Normally, the inventory of contaminated moderator in the dedeuterization and HAM systems is less than or equal to the equivalent of six 55-gallon drums for each system. The tritium concentration of these drums is less than or equal to 11 curies per liter. The release of contaminated moderator from the Purification Area as the result of a DBE would involved no more that the equivalent of twelve 55-gallon drums in the dedeuterization and HAM systems. Drums stored on the floor of the Purification area would not be affected by the DBE since the area is Seismic Category I. The consequences of the release of twelve 55-gallon drums worth of contaminated moderator from the dedeuterization and HAM systems following a DBE are bounded by the consequences of the release of a conservatively estimated 4650 drums worth of contaminated moderator from the K-Reactor Moderator Storage Areas during a DBE (Ref. 8-19). 
The total consequences of the very conservative maximum postulated release of 4650 drums worth of contaminated inoderator by a ground release from the K-Reactor Moderator Storage Areas was calculated to be (Ref. 8-58):

- 316.4 mrem Effective Does Equivalent EDE for the maximally exposed co-located worker at 640 meters (independent of sector) and meteorological conditions not exceeded $50 \%$ of the time.

- $\quad 89.9$ mrem EDE for the maximally exposed offsite individual at the worst sector (accounting for the Cooling Tower effect) and meteorological conditions not exceeded $99.5 \%$ of the time.

Using the Reference 8-58 results for the K-Reactor Moderator Storage Areas, the consequences for the release of contaminated moderator from the Purification Area during a DBE can be derived as follows:

- Maximally exposed co-located worker. $(12 / 4650) * 316.4 \mathrm{mrem}$ EDE $=0.8 \mathrm{mrem}$ EDE

- Maximally exposed offsite individual: $(12 / 4650) * 89.9 \mathrm{mrem}$ EDE $=0.2 \mathrm{mrem}$ EDE

\subsubsection{Corrosion}

The original design and purpose of the K-, L-, and P-Reactor Disassembly Basins were to store irradiated fuel and target assemblies for a period of 10-18 months following discharge from the reactor while awaiting processing in the Separations facilities. With irradiated fuel and target basin residence times greater than 18 months, corrosion has become a concern.

The aluminum-clad fuel and targets are subject to electrochemical corrosion. The corrosion is caused by the attack of chloride ions and other heavy metal ions (nitrites, nitrates, sulfates, iron, copper, mercury) upon the ahuminum. The corrosion is of the pitting type, where imperfections or scratches in the clad surface serve as initiation sites for the corrosion. Once a pit forms in the clad, chloride (and other) ions are attracted to the pit, concentrating the chemistry in the region of the pit and speeding the corrosion process. The sludge in the bottom of the basins is the source of most of the ions (Ref. 8-59). The corrosion is enhanced by galvanic potential at the junction of dissimilar metals, such as between the aluminum clad and stainless steel buckets or hangers.

Efforts are underway to improve the water quality in the K-, L-, and P-Reactor Disassembly Basins which should reduce the initiation of new pits but may not slow the corrosion at current pits. At current levels of chlorides and conductivity (approximately 6 to $20 \mathrm{ppm}$ and 135 $\mu \mathrm{mho} / \mathrm{cm}$, respectively), corrosion of aluminum cladding is almost certain as discussed in References 8-60, 8-61, and 8-62. Experience with lower levels of contaminants (chlorides in the $\mathrm{ppb}$ range and conductivity $<1 \mu \mathrm{mho} / \mathrm{cm}$ ) shows aluminum-clad fuel can be stored-for more than 10 years without signs of corrosion. 
The corrosion of fuel and target assemblies release radionuclides into the K-, L, and P-Reactor Disassembly Basins, and increases the activity of the K-, L-, and P-Reactor Disassembly Basin water. The deionizers control the level of contaminants and radionuclides in the water.

The corrosion of fuel assemblies in the basins can also lead to redistribution of the fissile materials from the fuel assemblies, thereby raising the possibility of a critical mass forming in the basins. Two possibilities exist:

- The fissile material could be dislodged from the fuel in particles small enough to be suspended in the basins (thereby being subject to transport throughout the filtration systems of the K-, L, or P-Reactor Disassembly Basin).

- The fissile material could crumble in chunks large enough to collect and form a critical mass on the basin floors.

The possibility of suspended fissile particulates forming a critical mass in the basins is juidged not credible, as the filtration system will be removing the particulates faster than the particulates can accumulate in the basin water. Realistically, the first possibility leads to the need for the filtering system to remove an increase in the fissile particulates. The fissile particulates may then concentrate in either the settler tank, sand filters, or deionizers. These possibilities are covered in Sections 8.3.2.5, 8.3.2.6, and 8.3.2.7, respectively.

The second possibility can be evaluated by noting that the cylindrical fuel assemblies are already in a more reactive geometry than the slab or pile configuration that would develop through corrosion. The change from the cylindrical configuration would very likely be a detriment to reactivity. For instance, the K-Reactor Assembly Area PHA (Ref. 8-18) explored the possibility of unirradiated fuel assemblies being crushed or "pancaked". Reference 8-63 found that the reactivity of the pancaked assembly was not increased compared to the undamaged assembly. The chunks that do accumulate on the floor are very unlikely to reconfigure in a more reactive state, even if more than one assembly's worth of chunks happens to accumulate. This is due to the increased volume of the Disassembly Basin floor versus the compact volume of the fuel assemblies themselves, and the nature of the corrosive constituent to spread out in the volume which it occupies. Periodic inspections of the basins that take place (and actions to clean up debris) will decrease the possibility that enough debris could accumulate to form a critical mass. Therefore the second possibility of corrosion debris forming a critical mass is judged not credible. Section 6.0 further discusses the chemistry control and water quality plans for the K-, L, and PReactor Disassembly Basins. The PHAs (Ref. 8-17, 8-51) provides further discussion on fuel retention time. The fuel retention time analysis qualitatively concludes that since the fuel assemblies and targets have now been stored in the K-, L-, and P-Reactor Disassembly Basins for over 5 years without exceeding the radionuclide operating limits and with only small accumulations of fissile material in the sludge at the bottom of the basins and in the filtration systems, storage of these reactor components under an improved basin storage environments for 3 or 4 additional years is expected to result in insignificant increases in the radionuclide activity of the basin water and insignificant increases in the accumulation of fissile materials. By achieving a basin conductivity goal of $<10 \mu \mathrm{mho} / \mathrm{cm}$, the initiation of new pits will almost cease and the penetration rate of existing pits will be reduced, thus further reducing any increases in 
radionuclide activity and fissile material accumulation over this extended storage period (Ref. 859).

\subsubsection{Dropped Shipping Cask}

The dropped shipping cask accident is capable of causing structural damage (cracking concrete) to the floors of the K-, L-, and P-Reactor Disassembly Basins due to the mass of shipping cask . . (approximately 70 tons) and its energy from an elevated position. The PHAs (Ref. 8-17, 8-51) analyzed the consequences of a loaded transfer cask being dropped into a Disassembly Basin transfer pit. The crack in the basin floor may then cause leakage of the basin water, leading to a form of the Disassembly Basin draindown scenario. The leak rate from the K-, L-, or P-Reactor Disassembly Basin is a function of the crack size and the soil physical properties, such as permeability. The maximum leak rate from cracks in a Disassembly Basin result from a shipping cask dropping is conservatively estimated to be $105 \mathrm{gpm}$.

\section{DROPPED SHIPPING CASK PROBABIITTIES}

For the dropped shipping cask event, it is noted that many transfer operations have been conducted safely and without incident over the life of the reactors. Since no shipping cask drops have been observed, rare event theory can be applied (Ref. 8-30). The rare event theory was applied in the PHAs (Ref. 8-17, 8-51) to determine the probability of a dropped shipping cask Approximately 100 reactor-years have elapsed at SRS, thus the probability can be conservatively estimated as $3.0 \times 10^{-2} / y r$. Reference $8-30$ notes that this method may be overty conservative if the number of observations is small, but the result is in line with other draindown scenario probabilities.

\section{FORCES ASSOCIATED WITH A DROPPED SHIPPING CASK}

The PHAs (Ref. 8-17, 8-51) compute a bounding basin crack size which is a function of cask orientation, cask size, and soil physical properties. A maximum flow rate of approximately 105 gpm was calculated for the maximum leak rate from a basin crack associated with a dropped shipping cask. This leak rate is bounded by several other leak rates analyzed in the Disassembly Basin draindown scenario discussed in Section 8.3.2.1. The forces due to the leak itself (105 gpm) are negligible.

\section{DROPPED SHIPPING CASK CONSEQUENCES}

Because the maximum leak rate from a K-, L, or P-Reactor Disassembly Basin crack associated with a dropped shipping cask is $105 \mathrm{gpm}$ (Ref. 8-17, 8-51), the consequences of a dropped shipping cask are bounded by several other Disassembly Basin draindown scenario $\widehat{s}$ analyzed in Section 8.3.2.1, which have greater leak rates (for example, filtration system leak at $1000 \mathrm{gpm}$ ). 


\subsection{IMPACT OTF NORMAL OPERATIONS AND POSTULATED ACCIDENTS}

The PHA for K-Reactor in Cold Standby (Ref. 8-17), PHA for the L-, and P-Reactor Disassembly Basins (Ref. 8-5I), and the PHAs previously performed for the K-Reactor Assembly Area and Moderator Storage Areas (Ref. 8-18, 8-19) serve as the basis for determining the impact of both normal operations and postulated accidents on the public, workers, and environment. The impact of normal operations and postulated accidents is presented in the following sections.

\subsubsection{IMPACT OF NORMAL OPERATIONS ON THE FACILTY WORKERS, CO-LOCATED WORKERS, PUBLIC, AND ENVIRONMENT}

Normal operation of K-Reactor in Cold Standby and the L- and P-Reactor Disassembly Basins involves the storage, handling, and preparation for shipment of irradiated fuel_and target assemblies, control rods, source rods, and other miscellaneous reactor components in the Disassembly Basins; receipt, handling, and storage of unirradiated Mark 22 fuel tubes and assemblies in borated concrete storage racks in the K-Reactor Assembly Area and assemblies on hangers in the Final Storage Area; and receipt, handling, storage, and processing of contaminated moderator in storage tanks and 55-gallon drums in the K-Reactor Moderator Storage Areas and Purification Area.

As stated in Section 7.0 of this BIO, hazardous chemicals and explosive and potentially explosive materials are not permitted in K-Reactor or the L- or P-Reactor Disassembly Basins. As discussed in Section 8.2 above and in the PHAs (Ref. 8-18, 8-19) for the Assembly Area and Moderator Storage Areas, there are no non-radiological hazardous chemicals identified in sufficient quantities in K-Reactor during Cold Standby to pose a hazard to the facility workers, co-located workers, public, or the environment.

The radiological hazards associated with the normal operations of K-Reactor (including the Assembly Area and Moderator Storage Areas) and L- and P-Reactor Disassembly Basins have been evaluated in the PHAs (Ref. 8-17, 8-18, 8-19, 8-51). The radiological hazards in K-Reactor, other than those previously evaluated in the PHAs for the Assembly Area and Moderator Storage Areas, and the $L$ and P-Reactor Disassembly Basins consists mainly of the various radionuclides contained in the irradiated fuel and target assemblies, irradiated components which were used in the $\mathrm{K}-\mathrm{L}$-, and P-Reactors, as well as a smaller number of radioactive sources used in and around the reactors such as for instrumentation and calibration. In addition to the radionuclides in the irradiated fuel and target assemblies and reactor components in the $\mathrm{K}, \mathrm{L}$, , and P-Reactor Disassembly Basins, the water in the basins contain radionuclides. Currently, the only radionuclides in measurable quantities are cesium-137, -138 , strontium-89, -90 , and $\mathrm{H}-3$ (tritium). Only cesium-137 and H-3 are in a significant quantity (Ref. 8-41). Also, the dedeuterization and HAM systems in the X-Reactor Purification Area will continue to evaporate moderator to remove fission products. The main radiological hazard with this operation is releasing the tritiated moderator from either system (Ref. 8-27). Only negligible quantities of gaseous, liquid, and solid effluents are possible during normal operations of K-Reactor during Cold Standby and the L- and 
P-Reactor Disassembly Basins. This condition is based on the restrictions that no radioactive material are allowed except those irradiated reactor components in the $\mathrm{K}$-, L- and P-Reactor Disassembly Basins, unirradiated Mark 22 fuel assemblies in the K-Reactor Assembly Ares, and contaminated moderator in the K-Reactor Moderator Storage Areas and Purification Area. This is based also on the nature of the fuel and sealed drums and tanks and the precautionary measures taken to prevent the release of hazardous and radioactive material. The impact of normal operations on the facility worker, co-located worker, public, and the environment is therefore insignificant. RC\&HP personnel will be involved with the movement of irradiated reactor components, contaminated unirradiated fuel assemblies, and contaminated moderator and will establish ALARA requirements for the facility workers as discussed in Section 6.0.

\subsubsection{IMPACT OF POSTULATED ACCIDENTS ON THE CO-LOCATED WORKERS, PUBLIC, AND ENVIRONMENT}

The analyses of K-Reactor in Cold Standby and L- and P-Reactor Disassembly Basins, which were not previously analyzed in the PHAs for the Assembly Area and Moderator Storage Areas, are discussed in Section 8.3 above. These analyses primarily involve scenarios associated with the K-, L and P-Reactor Disassembly Basins but include areas such as the K-Reactor Purification Area. The impact of postulated accidents associated with the K-Reactor Assembly Area and Moderator Storage Areas are provided in the BIOs (Ref. 8-64, 8-65) for these areas.

The analyses of the K-, L- and P-Reactor Disassembly Basins determined that four scenarios were credible and had associated adverse consequences. These Disassembly Basin scenarios are DBE, Disassembly Basin draindown, Disassembly Basin overfill, and inadvertent criticality. The PHA (Ref. 8-17) combined the consequences versus frequencies for these four Disassembly Basin scenarios to present the overall risk to the co-located worker and offsite public associated from operating the basins. This can be seen in Figures 8.4-1 and 8.4-2 for the co-located worker and offiste public. These figures represent the mean risk to the appropriate receptor as well as bouding $95 \%$ confidence levels.

These figures may then be assessed against the respective criteris from Reference 8-20 for risk to the co-located worker and the offsite public. The criteria include a frequency component and a consequence component, and so may be plotted on the same graph as Figures 8.4-1 and 8.4-2. The criteria from Reference 8.20 inhabit blocks of risk space, with lines of constant frequency parallel to the $\mathrm{X}$-axis, and lines of constant consequence parallel to the $\mathrm{Y}$-axis. These blocks are labeled according to the criteria presented in Reference $8-20$ (i.e., "low", "marginal", "serious", and "major"). Figures 8.4-3 and 8.4-4 present the information in Figures 8.4-1 and 8.4-2 plotted along with the criteria outlined in Reference 8-20. As can be scen from Figures 8.4-3 and 8.4-4, the four accidents analyzed together, taken at the bounding $95 \%$ confidence level, represent a risk that is termed "marginal" in the DOE standard and show that the consequences to the co-located worker and the public are low (i.e., $<0.5$ rem for the co-located worker and $20 . \mathrm{T}$ rem for the public) for all frequencies. It should be noted that Figures 8.4-1 through 8.4-4 represent the total integrated risk and are for information only. These figures should not be used for USQ evaluations. 
A bounding analysis was performed to determine the consequence to the maximally exposed colocated worker and offsite individual associated with K-Reactor Purification Area events. The bounding case conservatively estimated that the twelve drums worth of contaminated moderator in the dedeuterization and HAM systems would be released during a DBE because the systems are not seismically qualified. Using the consequence analysis for the Moderator Storage Areas, the consequence of the twelve drums worth of contaminated moderator was determined. The consequence results for the Purification Area indicated that the dose to the maximally exposed co- located worker is $0.8 \mathrm{mrem}$ EDE and the maximally exposed offsite individual is $0.2 \mathrm{mrem}$ EDE. 


\subsection{DENTIFICATION OF POTENTIAL DESIGN, PROCEDURE, OR EQUIPMENT VULNERABILTTES}

The potential design, procedure, and equipment vulnerabilities associated with K-Reactor in Cold Standby and the L- and P-Resctor Disassembly Basins, which were not previously identified in the BIOs (Ref. 8-64, 8-65) for the Assembly Area and Moderator Storage Areas, are discussed. below.

Buildings 105-K, 105-L, and 105-P are Seismic Category I, Building Class I structures. The walls and roof of the structures are designed to withstand 1000 psf forces and would therefore not be susceptible to damage from credible earthquakes, tornadoes, and straight winds. Failure of the Buildings 105-K, 105-L, and 105-P ventilation exhaust stacks during seismic and high wind events would not cause sufficient damage to the Buildings 105-K, 105-L, and 105-P structures, where the K-, L-, and P-Reactor Disassembly Basins and K-Reactor Purific . on Area are housed, to damage the basin, equipment, or drums and cause a release. However, during earthquakes or a shipping cask drop event, the K-, L-, and P-Reactor Disassembly Basins may develop cracks in the walls or floors or leak through the expansion joints. Also during earthquakes, drums and equipment containing moderator in the K-Reactor Purification Area may be susceptible to damage since the equipment is not seismically qualified and non-seismic equipment/systems may fall on the equipment or drums. Additionally, the K-, L , and P-Reactor Disassembly Basins ancillary structures (i.e., deionizers, settler tanks, and sand filters) reside outside the reinforced concrete Building 105-K, 105-L, and 105-P structures and are vulnerable to credible DBE, tornadoes, and straight winds. The combined consequences to maximally exposed co-located worker and the public from the release of radionuclides associated with an DBE, Disassembly Basin draindown, Disassembly Basin overfill, and inadvertent criticality were less than the medium consequence thresholds of 500 mrem for the maximally exposed co-located worker and $100 \mathrm{mrem}$ for the maximally exposed offsite individual (Ref. 8-20).

Shipping casks weighing approximately 70 tons are loaded into and out of the $\mathrm{K}-, \mathrm{L}$, and $\mathrm{P}$ Reactor Disassembly Basin transfer bays in order to move irradiated fuel and target bundles to the Separations facilities for processing. Due to their weight and elevated position over the basins, structural damage to the $\mathrm{K}-\mathrm{L}$, and P-Reactor Disassembly Basin floors is likely should a cask be dropped. The crack in the basin floor may allow leakage of contaminated basin water to the environment.

In addition to DBE and shipping cask drop events, failures of valves, piping, and systems and operator errors could result in water draining from the K-, L, and P-Reactor Disassembly Basins exposing the workers to unshielded irradiated material or spilling contaminated water into an uncontrolled area. The K-, L, and P-Reactor Disassembly Basin water makeup, level indication, and level alarm systems, and their associated power and instrument air and operating personnel actions to discover a low level in the basins or respond to the basin low level alarmand establish makeup to the basins are credited in the calculated combined risks to the co-located worker and public for DBE, Disassembly Basin draindown, Disassembly Basin overfill, and inadvertent criticality events. Should these systems be unavailable or the basin water levels not be maintained 
in compliance with the Limiting Condition for Operation (LCO) 3.9.4.2 in the K-, L-, and PReactor Technical Specifications, prior to the initiation of DBE or Disassembly Basin draindown events or operating personnel fails to establish makeup to the basins, the consequences and risks to the co-located worker and public may exceed those evaluated in the PHAs (Ref. 8-17, 8-51).

Failures of valves or operator error could result in overfilling of the $\mathrm{K}$-, L-, and P-Reactor Disassembly Basins spilling contaminated water into uncontrolled areas and the process sewer. The K-, L-, and P-Reactor Disassembly Basin level indications, level alarm systems, and their associated power and instrument air and operating personnel actions to discover a high level in the basins or respond to the basin high level alarm and stop inadvertent water additions to the basins are credited in the calculated combined risks to the co-located worker and public for the DBE, Disassembly Basin draindown, Disassembly Basin overfill, and inadvertent criticality events. Should these systems be unavailable or the basin water level not be maintained in compliance with LCO 3.9.4.2, prior to the initiation of a Disassembly Basin overfill event or operating personnel fail to stop the inadvertent water addition to the basins, the consequences and risks to the colocated worker and public may exceed those evaluated in the PHAs (Ref. 8-17, 8-51).

The handling of fuel and target assemblies in the K-, L , and P-Reactor Disassembly Basins present opportunities for an inadvertent critical configuration to be achieved. Hand-held gamma detector used by operating personnel and cutting saw stops are credited to ensure that fuel assemblies are not cut or placed in a target bundle. Maintenance operating personnel are credited in replacing the blanks and cadmium plates in the shipping cask after maintenance or reconfiguration of the shipping casks and for performing a blackness test. Operating personne! are credited in allowing only one Mark 22 fuel assembly per hanger, in limiting the number of fuel assemblies and fuel bundles which are configured together, in property using criticality bars associated with fuel bundling operations and spacers and fuel blocking system in the fuel bundle storage racks, and in limiting the number and arrangement of fuel bundles loaded into shipping cask. This equipment and operator action is credited in calculating the combined risk of the DBE, Disassembly Basin draindown, Disassembly Basin overfill, and inadvertent criticality events. Should the gamma detectors fail or operating personnel fail to follow established procedures in handling fuel and target assemblies in the K-, L, and P-Reactor Disassembly Basins, contrary to the additional administrative controls listed in Sections 7.2.5, 7.2.6, and 7.2.7 and LCO 3.9.3, the consequences and risks to the co-located worker and public may exceed those evaluated in the PHAs (Ref. 8-17, 8-51).

The K-, L, and P-Reactor Disassembly Basins house irradiated fuel and target assemblies which emit decay heat. In order for basin evaporation to remove heat such that the basin water is maintained at reasonable temperatures to minimize corrosion, recirculation of the Disassembly Basin water through the heat exchanger is maintained in accordance with the additional administrative controls stated in Section 7.2.1 to provide mixing in the basins, however, no cooling water will be available to the heat exchangers. Also the basin water temperature is maintained below $45^{\circ} \mathrm{C}$ in accordance with LCO 3.9.4.1 as stated in the K-, L-, and P-Reactor Technical Specifications. 
The K-, Lr, and P-Reactor Disassembly Basins have historically stored materials discharged from the Reactor Tanks in the basins for 10 to 18 months before sending the material to the Separation facilities to be processed. The Separations facilities at SRS have been shutdown since 1988 because of safety upgrades, new regulations, and policy changes and extended storage may continue for another three to four years during the preparation of an Environmental Impact Statement. As a result of extended storage times in the $K-, L$, and P-Reactor Disassembly Basins, corrosion of the aluminum-clad fuel has become evident. Pitting corrosion is the. dominant mode. One of the primary causes of pitting corrosion is the attack of alumimum from chloride and heavy metal ions. Pitting corrosion is accelerated by the gatvanic couples that result from dissimilar metals. A breach of the fuel and target assembly cladding can lead to leakage of fission products and other radiomuclides to the basins (Ref. 8-60). Also, the fissile materials in the forms of uranium and plutonium compounds may precipitate from the fuel assemblies and collect on the basin floors and/or in the filtration systems (i.e., sand filters, settler tank, and deionizer). An accumulation of sufficient quantities of fissile material in these areas could potentially result in a criticality. Small amounts of uranium-235 and plutonium-239 and trace amounts of other fissile isotopes are present in the sludge. References 8-24, 8-25, and 8-26 has conservatively shown that the mixture of fissile isotopes present in the sludge does not constitute a criticality concern. In order to prevent aluminum pitting corrosion from causing safety concerns such as radionuclide release and criticality, an improved Disassembly Basin storage environment must be achieved for the K-, L-, and P-Reactor Disassembly Basins (Ref. 8-59).

An analysis of the basin storage conditions indicates that a number of factors may be operating at the same time to cause corrosion of the aluminum-clad alloys. Among those factors playing roles are high water conductivity, basin water chemistry, sludge on the basin floor, and galvanic couples between dissimilar metals in the basins. The conductivity of the $\mathrm{K}-\mathrm{L}, \mathrm{L}$, and P-Reactor Disassembly Basins has been near $200 \mu \mathrm{mho} / \mathrm{cm}$ in the last few years and is currently about 135 $\mu \mathrm{mho} / \mathrm{cm}$. Chloride contents range from 6 to $20 \mathrm{ppm}$. Sludge and debris in the bottom of the Disassembly Basins are primarily iron and aluminum oxides and act to concentrate the corrosion causing impurities by a factor of about 10 times.

A basin cleanup program has been underway at SRS which involves sludge and debris removal, operation of the portable mixed-bed deionizer water purification systems as much as possible to lower conductivity and improve water chemistry, increasing surveillance by revising the chemistry limits and sample frequencies, operating the available basin pumps to obtain maximum mixing, improving control of water additions to the basins, and elimination of galvanic couples where possible by going to the HBBS. Basin cesium-137 activities will be reduced by operating the existing deionizers filled with organic resin and a deionizer or some other vessel filled with zeolite ion exchange material. These activities are expected to reduce the initiation of new pitting corrosion and slow down the existing basin corrosion processes. With this improved basin storage environments, fuel assemblies and targets are expected to corrode at a slower rate than they have previously.

Since most of the fuel assemblies and targets have now been stored in the K-, L-, and P-Reactor Disassembly Basins for over 5 years without exceeding the radionuclide operating limits and with only small accumulations of fissile material in the sludge at the bottom of the basins and in the 
filtration systems, storage of these reactor components under improved basin storage environments, as required by the additional administrative controls stated in Section 7.2.1, for 3 or 4 additional years is expected to result in controllable increases in the radionuclide activities of the basin water and insignificant increases in the accumulation of fissile materials. Also, periodic inspections of the basins, as required by the additional administrative controls stated in Section 7.2.1, will decrease the possibility that enough fissile material accumulating to form a critical mass. By achieving a basin conductivity goal of $<10 \mu \mathrm{mho} / \mathrm{cm}$, the initiation of new pits should . almost cease and the penetration rate of existing pits will be reduced, thus further reducing increases in radionuclide activity and fissile material accumulation over this extended storage period (Ref. 8-59). Further analysis will be necessary for storage beyond the 3-4 year time frame.

A fire could occur in Buildings 105-K, 105-L, and 105-P, but due to administrative controls limiting the fire loading in these buildings, the fire would be small and localized and would have limited affect. A fire could conceivably cause the uncontrolled release of radionuclides by evaporating water from the $K_{-}^{\prime}, L_{n}$, or P-Reactor Disassembly Basin water or could possibly cause drums or containers of chemicals to boil and burst releasing hazardous chemicals. Because only a small amount of contaminated basin water or chemical containers would be affected by a small and localized fire, the consequences to co-located workers and the public would be only a small negligible fraction of the consequences from the release associated with the combined scenarios (DBE, Disassembly Basin draindown, Disassembly Basin overfill, and inadvertent criticality). Should there be a significant fire load in an area, due to failure to comply with the additional administrative controls stated in Section 7.2.2, the consequence of a fire in that area could exceed those evaluated in the PHAs (Ref. 8-17, 8-51).

Explosions could occur in Buildings 105-K, 105-L, and 105-P, but due to administrative controls associated with handling, storing, and using explosive materials in these buildings, the probability of an explosion occurring in Building 105-K, 105- , or 105-P is reduced. An explosion could cause a pressure wave strong enough to damage the $\mathrm{K}-, \mathrm{L}$-, or P-Reactor Disassembly Basin or cause missile damage to storage drums of chemicals. Should explosive materials be handled, stored, or used contrary to the additional administrative controls stated in Section 7.2.3, the consequence of an explosion could exceed those evaluated in the PHAs (Ref. 8-17, 8-51).

There are currently no non-radiological hazardous chemicals in $\mathrm{K}-\mathrm{Reactor}$ or in the $\mathrm{L}$ - or PReactor Disassembly Basin in sufficient quantities to pose a safety concern to the workers, public, or the environment. Should hazardous chemicals be brought into K-Reactor or in the L- or PReactor Disassembly Basin that are not on the allowable chemical list or in excess of the maximum allowable quantities, contrary to the additional administrative controls stated in Section 7.2.4, the safety concerns may be created (Ref. 8-51).

There may be small leaks in the $\mathrm{K}$-, L-, and/or P-Reactor Disassembly Basins releasing contaminated water to the environment. These potential leaks are difficult to confirm due to the evaporation which occurs from the surface of the basins. Water samples from monitoring wells around K-, L-, and P-Areas are used to detect leaks from the K-, L-, and P-Reactor Disassembly Basins. However, the monitoring wells are not optimally located for leak detection from the K-, $\mathrm{L}$, and P-Reactor Disassembly Basins. Plans are to drill new wells which will be optimally 
located to improve leak detection (Ref. 8-66). Drilling is scheduled for 1995. Additionally, plans are being made for the installation of a more sensitive level measurement system in the K-Reactor Disassembly Basin in order to determine if small leakage from the basin is occurring (Ref 8-17). 


\subsection{DOENTIFICATTON OF CREDITED SYSTEMS AND OPERATOR ACTIONS}

The PHAs for K-Reactor in Cold Standby and L- and P-Reactor Disassembly Basins (Refs. 8-17, 8-51) credit to varying degrees the availability of structures, systems, and components and operator actions to either prevent or mitigate the consequences of accidents. The complete listing in this section serves to identify not only those structures, systems, and components and proper operator actions that are included for consideration into the Reactor Technical Specifications . (LCOs and Administrative Controls) but also those items that serve to protect the facility worker, the environment, and the ALARA principle. Only those items from the sections below that were required under the current Technical Specification inclusion criteria (10CFR50.36) are incorporated into the current Reactor Technical Specifications or listed in Section 7 of this BIO.

The structures, systems, and components and operator actions for preventing or mitigating some of the postulated accident scenarios associated with the Assembly Area and Moderator Storage Areas are discussed in the BIOs of those areas (Refs. 8-64, 8-65).

\subsubsection{BUILDINGS 105-K, 105-L, AND 105-P STRUCTURES}

Buildings 105-K, 105- $\mathrm{L}$, and 105-P are multi-story, reinforced concrete structures and are designed to a blast resistance of 1000 psf and Seismic Category I (Ref. 8-18). The structures are credited for preventing damage to $\mathrm{K}$-, L-, and P-Reactor Disassembly Basins and K-Reactor Purification Area from falling structural debris and missiles in design basis earthquakes, tomadoes, and straight winds. (See Sections 2.3.1 of this BIO for further discussion of the Buildings 105-K, 105-L, and 105-P structures.)

\subsubsection{ALUMINUM CLADDING OF FUEL AND TARGET ASSEMBLIES}

The aluminum cladding of fuel and target assemblies provides the primary confinement for the fission products, fissile materials, and other radionuclides contained in the fuel and target assemblies. The thickness of the ciladding varies from 0.02 to 0.03 inches.

The aluminum cladding of the fuel assemblies are credited to some degree in the analyses of all postulated accidents for providing confinement of radionuclides and fissile material contained in the fuel assemblies in a manner which minimizes their release to the $\mathrm{K}-, \mathrm{L}$-, and P-Reactor Disassembly Basins. Should the aluminum cladding be breached fissile material may precipitate onto the basin floors or be carried into the filtration systems potentially forming a critical masses. Also, the basin water radioactivity level may rise to unacceptable levels and pose increased consequence to the workers, public, and environment should the water leak to the environment or an uncontrolled area. 


\subsubsection{K-, L, AND P-REACTOR DISASSEMBLY BASIN WALLS AND FLOORS}

The K-, Lr, and P=Reactor Disassembly Basin walls and floors provide the secondary liquid confinement for the fission products, fissile and target materials, product materials, and other radionuclides contained in the fuel and target assemblies, control rods, source rods, and miscellaneous irradiated reactor components. The walls and floors of the basins also serve as the primary confinement of approximately 3,400,000 gallons for K- and L-Reactor Disassembly Basins and 4,800,000 gallons of contaminated basin water contained in the P-Reactor Disassembly Basins. (See Section 2.3.2 of this BIO for further discussion of the K-, L, and PReactor Disassembly Basin walls and floors.)

The Disassembly Basin walls and floors are credited to some degree in the analyses of all postulated accidents for providing confinement of contaminated basin water in a manner which minimizes its release to the environment. The floors and wall are designed to withstand all scenarios except DBE and the dropping of a shipping cask

\subsubsection{RADIATION MONTTORS}

Kanne monitors are located in the K-, L, and P-Reactor Disassembly Areas and K-Reactor Purification Area. The Kanne monitors continuously measure the airborne radiation in the areas and record the results in the monitor room. Also, a Kanne monitor is used to monitor exhaust gases from the Buildings 105-K, 105-L, and 105-P ventilation exhaust stacks at the +148 -foot elevation. The information from the Kanne monitors alerts workers in the area of a contaminated water or moderator leaks. Also, this information can be used by operating personnel to investigate and contain any leakage of contaminated water or moderator and therefore minimize the consequences of the leak. (See Sections 2.3.4.1 for further discussion of the Kanne monitors.)

Berthold tritium monitors (BTMs) detect tritium in the airborne release from the Buildings 105-K, 105-L, and 105-P ventilation exhaust stacks. An increase in the tritium activity of the stack exhaust is an indication that a leak contaminated moderator or water has occurred. This information can be used by operating personnel to investigate and contain any. leakage of contaminated moderator or water and therefore minimize the consequences of the leak. The Buildings 105-K, 105-L, and 105-P ventilation streams can be monitored by the Berthold Tritium Monitors through the stack exhausts ( +148 -foot-elevation sample point). (See Sections 2.3.4.2 for further discussion of the BTMs.)

Additionally, process sewer and ground water are monitored via periodic sampling and laboratory analysis to determine if any radionuclides are reaching the environment. 


\subsubsection{K-, L-, AND P-REACTOR DISASSEMDLY BASIN IAEVL INDICATION AND ALARM SYSTEMS}

The K-, L-, and P-Reactor Disassembly Basin level indication and alarm systems provide waming to the operating personnel of anomalies in the basin water levels which may be an indication of a draindown or overfill of the basins. There are three level alarm settings; high, low, and very low. This information can be used by operating personnel to investigate and contain any leakage of contaminated water from an overfill or draindown of the basins and therefore minimize the - . consequences of the leak and to add makeup water to the basins if necessary. (See Section 2.3.5 of this BIO for further discussion of the $\mathrm{K}-, \mathrm{L}_{-}$, and P-Reactor Disassembly Basin level indication and alarm systems.)

The K-, L, and P-Reactor Disassembly Basin level indication and alarm systems are credited to some degree in the analyses of DBE, Disassembly Basin draindown and overfill events, and the shipping cask drop event for providing a warning to the operating personnel of leakage from the basins by overfill or draindown. The operator can then stop the leakage by eliminating the water addition in the case of an overfill or to initiate the addition of makeup water in the case of draindown and stop the leakage if possible.

\subsubsection{INSTRUMENT AIR SYSTEM}

The K-, L-, and P-Reactor Disassembly Basin level indicating devices are bubblers, using instrument air to sense the water level. Since the instrument air system is a support system for the K-, L-, and P-Reactor Disassembly Basin level indication systems, air must be available to maintain the level indication system operable as discussed in Section 8.6 .5 above. (See Sections 2.3.6 of this BIO for further discussion of the instrument air system.)

\subsubsection{POWER SYSTEM}

The K-, L, and P-Reactor Disassembly Basin level indication and alarm systems and the K-, L-, and P-Reactor Disassembly Basin makeup water pumps and radiation monitors use electrical power to function. Since the electrical power system is a support system for these required systems, electrical power must be available to maintain the systems operable as discussed in Sections 8.6.4, 8.6.5, 8.6.8, and 8.6.18.

\subsubsection{K-, L , AND P-REACTOR FULTERED WATER MAKEUP SYSTEMS}

The K-, L-, and P-Reactor Disassembly Basin filtered water makeup systems are used to provide water to the K-, L-, and P-Reactor Disassembly Basins to compensate for any losses, thus aiding level control to the K-, Lr, and P-Reactor Disassembly Basins. The water level is maintained at a narrow range in order to provide shielding and cooling to the irradiated materials in the basins, while minimizing the risk of overflow of contaminated water to uncontrolled areas and the 
process sewer (See Sections 2.3.9 for further discussion of the K-, L-, and P-Reactor Disassembly Basin filtered water makeup systems.)

The natural and process accident analyses that credit this system are those that involve a loss of Disassembly Basin water level control, such as DBE, draindown, overfill, and inadvertent criticality. The filtered water makeup system is credited in these events to provide the correct amount of water to the Disassembly Basin to compensate for any losses, thus minimizing the consequences of these events. If the system is not credited, shielding is reduced and the . radiological consequences to the co-located worker and the public are increased for the draindown, DBE, and inadvertent criticality scenarios. If the filtered water makeup is not or can not be stopped by the operator due to operator error or equipment failure, an overfill event may occur which could results in the release of contaminated basin water to uncontrolled areas and the process sewer.

\subsubsection{K-, L-, AND P-REACTOR DISASSEMBLY BASIN OVERFLOW WEIRS TO PROCESS SEWERS}

The K-, L-, and P-Reactor Disassembly Basin overflow weirs are used to direct water overflowing from the basins into the process sewers, thus minimizing the chances of the contaminated water entering uncontrolled areas. The process sewers are the proper exit path for overflow of contaminated basin water.

The natural and process accident analyses that credit this system are those that involve a loss of Disassembly Basin water level control, such as DBE and overfill. If the overflow weirs are not in place or should they become clogged, the contaminated water may overflow to uncontrolled areas.

\subsubsection{K-, 'L, AND P-REACTOR DISASSEMBLY BASIN COOLING SYSTEM RECIRCULATION PUMPS AND ASSOCIATED PIPING AND VALVES}

The K-, L, and P-Reactor Disassembly Basin cooling system recirculation pumps (and associated piping and valves) are used to provide the motive force necessary to ensure mixing of the Disassembly Basin water. Stagnation of the basin water could cause temperature and water chemistry gradients. Localized ion and temperature increases can cause localized increases in the aluminum cladding corrosion rate and provide inaccurate samples of the basin water chemistry. (See Sections 2.2.1.3 and 7.2.1 of this BIO for further discussion of the $\mathrm{K}_{-}, \mathrm{L}_{\text {- }}$, and P-Reactor Disassembly Basin cooling system recirculation pumps and associated piping and valves.)

The K-, L, and P-Reactor Disassembly Basin recirculation systems are credited to some degree in the analyses of all postulated accidents for helping to improve basin water chemistry and thus reducing corrosion by eliminating water chemistry gradients. Also, the recirculation system aids in cooling the basin If the system were not used, the chances of corrosion, improper water chemistry, and basin water temperatures would gradually increase. 


\subsubsection{K-, L-, AND P-REACTOR DISASSEMBLY BASIN FILTRATION SYSTEMS}

The K-, Lr, and P-Reactor Disassembly Basin filtration systems maintains the $\mathrm{K}$-, $\mathrm{L}$, and $\mathrm{P}$ Reactor Disassembly Basin water chemistry within limits to reduce corrosion of the aluminum cladding of irradiated fuel and target assemblies and to maintain the water's visual clarity within specifications for routine underwater work performed by Component Handling personnel. The system removes particulates, suspended solids, and ions in the basin water through use of sand filters, settler tank, and deionizers. (See Sections 2.2.1.2, 2.3.10, and 7.2.1 of this BIO for further discussion of the K-, L-, and P-Reactor Disassembly Basin fittration systems.) The Disassembly Basin filtration systems also helps to maintain the basin water within radiological and chemical specifications by filtering out the particulates and solids.

The K-, L-, and P-Reactor Disassembly Basin filtration systems are credited to some degree in the analyses of all postulated accidents for providing basin water within radiological and chemical specifications to reduce corrosion and to maintain visual clarity in a manner which minimizes personnel error while working with underwater basin components. If the system were not available, fuel and target assembly corrosion would increase and the chance of operator and personnel error would increase associated with movement of these components.

\subsubsection{VTS ROWS AND ANCHOR SUPPORTS, HANGERS, TROLLEYS, AND DISASSEMBLY BASIN MONORAIL SYSTEM}

The K-, L-, and P-Reactor VTS rows and anchor supports, hangers, trolleys, and the K-, L-, and P-Reactor Disassembly Basin monorails provide spacing between fuel assemblies stored in VTS to ensure a subcritical configuration of the assemblies. The assemblies are maintained in a rectangular pitch by design of at least 12 inches by 18 inches of the VTS rows, hangers, trolleys, and Disassembly Basin monorail. This pitch is adequate to ensure criticality does not occur. A blank is bolted to one of the two positions of a hanger to ensure that no more than one Mark 22 fuet assembly is placed on a hanger. The structural integrity of the anchor supports which hold up each VTS row ensures that sufficient damage to the rows will not occur in a manner to dislodge assemblies from their hangers unless multiple supports of the row fails (i.e., one failed anchor support on a row will not damage the row such that assemblies are dropped from their hanger). The VTS rows and anchor supports, hangers, trolleys, and Disassembly Basin monorail system are further discussed in Sections 2.3.8.

The VTS rows and anchor supports, hangers, trolleys, and Disassembly Basin monorail system are credited in the inadvertent criticality event for preventing a criticality by providing adequate spacing between fuel assemblies. Also, the structural integrity of this equipment was credited for preventing a credible criticality from the failure of the equipment.

\subsubsection{CUTTING SAW AND SAW STOP}

After the inner target is removed from a fuel assembly, the end-fitting of the assembly is cut to enable the fuel tubes to be separated from the outer target. An underwater saw in the machine 
basin is used to cut the end-fitting from the assembly. The machine basin cutting saw is equipped with a saw stop thatensures cuts are not made through the fuel region. The saw stops are set for each type of fuel essembly. If the fuel region of assemblies were cut, these pieces could potentially be assembled in a critical configuration. (See Sections 2.3.11 and 7.2.6 for further discussion of the saw stop.)

The machine basin cutting saw stop is credited in the inadvertent criticality event for preventing a criticality by ensuring that cuts are not made into the fuel region of assemblies thereby eliminating - the potential for pieces of fuel assemblies from being inadvertently assembled.

\subsubsection{FUEL DETECTION GAMMA MONTTORS}

A radiation detector is provided at the MB foil, press, and shear. This detector identifies strong gamma fields present in irradiated fuel to prevent the processing of scrap containing fuel. Handheld gamma monitors are used'by the operator to determine if any fuel is present in the USHs and to determine if any fuel is present in target assemblies being placed in target bundles.

These monitors are credited by the inadvertent criticality event in order to reduce the chances of fuel forming a critical configuration. If the monitors were not operable or not used, the chances of inadvertent criticality would increase.

\subsubsection{MB CRITICALITY BARS}

The criticality bars are used in the MB to prevent more than four fuel assemblies from being processed into a fuel bundle, thereby preventing a critical configuration of fuel from occurring. If the criticality bars are not used property while assembling a fuel bundle, the likelihood of criticality occurring is increased. (See Section 7.2.7 for further discussion of criticality bars.)

The criticality bars are credited in the analysis of the inadvertent criticality event for reducing the possibility of a critical configuration of fuel from being assembled.

\subsubsection{HTS RACKS, SPACERS, AND FUEL BLOCKING SYSTEM}

The horizontal bundle and bucket storage racks, spacers, and fuel blocking system are used to store irradiated fuel bundles awaiting shipping to the Separations facilities. The racks are connected at the tops in an inverted "V" arrangement to prevent fuel from being placed between the racks. The spacers of the racks are designed to limit the number of fuel bundles allowed in the fuel bundle slots of the racks. The spacers are used when the fuel blocking system is not utilized. The fuel blocking system prohibits bundles from being accidentally dropped into the fuel bundle slots of the racks. (See Sections 2.3.12 and 2.3.15 of this BIO for further discussion of the HBBS racks, spacers, and fuel blocking system.) 
The HBBS racks, spacers, and fuel blocking system are credited in the inadvertent criticality event associated with the-Disassembly Basin for providing criticality-safe spacing while storing fuel bundles in the HBBS. If the spacers or fuel blocking system are not used by operating personnel during loading of fuel bundles in the HBBS racks, the chance of inadvertent criticality would increase.

\subsubsection{SHIPPING CASK WTTH BLANKS AND CADMIUM SEPARATOR PLATES}

The shipping cask is used to transport irradiated materials (bundles, slug buckets, and scrap buckets) for delivery to the 200 Area in a criticality-safe and radiologically safe manner. The blanks provide criticality protection by increasing the spacing between fuel assemblies (reducing the neutronic reinforcement), and the cadmium separator plates provide neutron absorption, again lowering the neutron multiplication rate. The shipping cask itself is designed to dissipate heat generated by irradiated materials, and also to provide shielding from those materials (See Section 2.3.14 of this BIO for further discussion of the shipping cask.)

The shipping cask is credited in events involving the transportation and loading of the shipping cask (dropped shipping cask, inadvertent criticality within the shipping cask). If the cadmium plates or blanks are not used, the chances for inadvertent criticality increase.

\subsubsection{OPERATOR ACTIONS}

Operators (including maintenance operating personnel) are credited with preventing or discovering accidents and/or mitigating the consequences of accidents on a probabilistic basis. Fault tree analyses consider operator actions, failure to follow procedures, and operator error in determining the risk associated with events, and assign the failure or success of these actions based on historical data in analogous situations. Operator action is credited especially in personnel-intensive activities such as MB fuel assembly machining and bundling-assembly tasks. Inadvertent criticality, draindown, overfill, and DBE, as well as, other less serious events credit proper operator action in accordance with generally accepted probabilistic risk analysis principles. If proper operator actions are not taken according to these principles, both the frequency and the consequences of process and natural events would be increased. Operator actions required for the K-Reactor in Cold Standby and L- and P-Reactor Disassembly Basins are further discussed in Section 7.2. 


\subsection{APPROACH FOR DERIVATION OF ESTIMATES OF SYSTEM UNAVAILABIITIES AND OPERATOR ERRORS}

As noted in Section 8.6, the credited systems are the Buildings 105-K, 105-L, and 105-P structures, aluminum cladding of fuel assemblies, K-, L-, and P-Reactor Disassembly Basin walls and floors, radiation monitors, Disassembly Basin level indication and alarm systems, instrument air system, electrical power system, filtered water makeup systems, Disassembly Basin overflow. weirs, Disassembly Basin cooling systems, Disassembly Basin filtration systems, VTS rows and anchor supports, hangers, trolleys, Disassembly Basin monorail systems, MB cutting saw stops, hand-held gamma detector, MB criticality bars, HBBS racks, spacers and fuel blocking system, and shipping cask blanks and cadmium separator plates.

Buildings 105-K, 105-L, and 105-P are passive structures and are therefore always available. Buildings 105-K, 105-L, and 105-P are not susceptible to high energetic events such as design basis earthquakes, tomadoes, or straight winds.

The aluminum cladding of the fuel and target assemblies is a passive feature, however, the aluminum cladding is susceptible to corrosion, especially pitting corrosion, from the attack of chloride ions and other heavy metal ions (nitrites, nitrates, sulfates, iron, copper, mercury) upon the aluminum. Analyses have concluded that the storage of fued and target assemblies under improved basin water quality conditions would not result in unscceptable increases in the radionuclide levels of the basin water or the accumulation of unacceptable amounts of fissile material from the corrosion of the assemblies.

The K-, L-, and P-Reactor Disassembly Basin walls and floors are also passive components. As such, the walls and floors are always available. The walls and floors are designed to provide leakfree confinement of basin water unless the walls and/or floors are damaged during a DBE or shipping cask drop event.

The radiation monitors (BTMs) in Building 105-K monitor the Moderator Storage Areas (except the stack ares) and Purification Areas. The BTMs notify operating personnel of possible contaminated water and moderator leakage so that investigation and containment of any leakage can occur, thereby minimizing the consequences of the leak. The ventilation from the $\mathrm{K}$-, $\mathrm{L}$, and P-Reactor Disassembly Areas does not exhaust through the AACS or the Buildings 105-K, 105L, or 105-P ventilation exhaust stacks, therefore, the Disassembly Area ventilation exhaust is not monitored by BTMs. To reduce the likelihood of unavailability of the Kanne monitors in Buildings 105-K, 105-L, and 105-P, and the BTMs in Building 105- $\mathrm{K}$, there are redundant monitors in the areas. Additionally, the surveillance interval for these monitors (BTMs are calibrated every three months) is sufficient to ensure that the radiation monitors are adequately maintained and capable of performing their function.

The K-, L-, and P-Reactor Disassembly Basin overflow weirs are also passive compenents and as such, are always available. 
The following K-, L-, and P-Reactor Disassembly Basin systems/components are subject to periodic inspection, maintenance, and surveillance to ensure their operability:

- The Disassembly Basin level indication and alarm systems, associated instrument air system, and associated electrical power

- The Disassembly Basin temperature indication and alarm systems, and associated electric power

- The filtered water makeup systems

- The Disassembly Basin filtration system

- The MB cutting saw stops

- The hand-held gamma monitors

- The MB criticality bars used in the fuel bundling process

- The HBBS rack spacers and fuel blocking system

- The shipping cask blanks and cadmium separator plates

- The installed gamma monitors on the machire basin equipment

The operator error which must be protected against for the K-Reactor Moderator Storage Areas is primarily allowing the Building $105-\mathrm{K}$ temperature to drop below $38.9^{\circ} \mathrm{F}$. This is controlled by an additional restriction on operations of the Moderator Storage Areas BIO (Ref. 8.65 and resultant operating procedures). In addition, the additional administrative controls of Reference 65 and resultant operating procedures prevent personnel from bringing significant combustibles, explosives, or hazardous chemicals into the moderator storage areas and from stacking drums too high.

Operator errors which must be protected against for the K-Reactor Assembly Area are primarily restrictions on the number of fuel tubes and assemblies that may be outside of the borated concrete storage racks in the Processing and Handling Room at any one time (i.e., four fuel assemblies). This is controlled by the Technical Specifications and resultant operating procedures. In addition, the administrative controls prevent personnel from bringing combustible or explosive material into the vicinity of the stored unirradiated fuel in the Assembly Area. 
This page intentionally left blank. 
WSRC-TR-94-207-DV

REVISION 0

\section{$\overline{-}$ \\ 9.0 CONCLUSIONS}

Unirradiated reactor fuel and irradiated components continue to be handled and stored and contaminated moderator continues to be stored, handled, and processed in K-Reactor during Cold Standby. In addition, irradiated components continues to be handled and stored in the $\mathrm{L}$ and PReactor Disassembly Basins. Though the number of unirradiated fiel tubes and assemblies that can be stored in the Assembly Area has essentially doubled, the amount of contaminated moderator that can be stored has increased and in some cases stored in new locations, and the amount of time irradiated components have remained in the Disassembly Basins exceeds the historical storage time, the methods of storing, handling, and processing these materials remain the same as used previously.

K-Reactor in Cold Standby and the L- and P-Reactor Disassembly Basins were determined to be a Category 2 Nuclear Facility per the hazard assessments in References 9-1 through 9-5. These hazard assessments were based mainly on the inventory of fuel, mixed fission products, and contaminated moderator exceeding the threshold limits and the potential for a criticality.

The postulated events that may occur in K-Reactor have been analyzed in this Basis for Interim Operation (BIO) and the BIOs for the Assembly Area and Moderator Storage Areas (Ref. 9-6, 97). Additionally, it has been shown that the postulated events for the K-Reactor Disassembly Basin bound the $\mathrm{L}$ and P-Reactor Disassembly Basins. As shown in Section 8.0 of this BIO, the release of contaminated water and/or criticality in the Disassembly Basins or release of contaminated moderator from the K-Reactor Purification Area were determined to be possible in many of the postulated events, however, the consequences to the co-located workers and the public were determined to be below the medium consequence thresholds of $500 \mathrm{mrem}$ for the maximally exposed co-located worker and $100 \mathrm{mrem}$ for the maximally exposed offsite individual (Ref. 9-8). Based on the results of the analyses, as shown in Tables 8.3-1 and 8.3-2, the scenario class for the postulated accidents were determined to be Class III (i.e., "marginal") in the BIO standard (Ref. 9-8). The BIO for the Moderator Storage Areas also has shown that though the release of contaminated moderator was possible in many of the postulated events, the consequences to the co-located workers and the public were below the medium consequence thresholds and therefore, the scenario class for the Moderator Storage Areas' postulated events were Class III. The BIO for the Assembly Area has shown that criticality was not credible for the postulated events and that the scenario class for the Assembly Area's postulated events were Class IV (i.e., "negligible"). 
WSRC-TR-94-207-DU

REVISION 0

\subsection{SAFETY ANALYSES}

Normal operation of K-Reactor in Cold Standby involves the storage, handling, and preparation for shipment of irradiated fuel and target assemblies, control rods, source rods, and other miscellaneous reactor components in the Disassembly Basin; handling, and storage of unirradiated Mark 22 fuel tubes and assemblies in borated concrete storage racks in the Assembly Area (and assemblies on hangers in the final storage area); and handling, storage, and processing of contaminated moderator in storage tanks and 55-gallon drums in the Moderator Storage Areas and Purification Area. Explosive and potentially explosive materials are not permitted in KReactor. As discussed in Section 8.2 and in the BIOs (Ref. 9-6, 9-7) for the Assembly Area and Moderator Storage Areas, there are no non-radiological hazardous chemicals identified in sufficient quantities in K-Reactor during Cold Standby to pose a hazard to the facility workers, co-located workers, public, or the environment. Therefore, unless contaminated water leaks from the Disassembly Basin, sealed containers of contaminated moderator are damaged in the Moderator Storage Areas or Purification Ares, or unirradiated fuel assemblies in the Assembly Area are damaged by abnormal events or accidents, the exposure to workers and the public is insignificant.

The results of the analyses for K-Reactor in Cold Standby were presented in Section 8.0 of this BIO and in the BIOs for the Assembly Area and Moderator Storage Areas (Ref. 9-6, 9-7).

The analyses of K-Reactor in Cold Standby, which were not previously analyzed in the BIOs for the Assembly Area and Moderator Storage Areas, primarily involve scenarios associated with the Disassembly Basin but include areas such as the Purification Area. The analysis results for the four credible scenarios with associated adverse consequences (i.e., DBE, Disassembly Basin draindown, Disassembly Basin overfill, and inadvertent criticality) were combined on a risk curve for the maximally exposed co-located worker and offsite individual. The results show that the consequences to the co-located worker and the public are low (i.e., $<500$ mrem for the co-located worker and $<100$ mrem for the public) for all frequencies. The results of the analysis for the Purification Area indicate that the dose to the maximally exposed co-located worker is $0.8 \mathrm{mrem}$ and the dose to the maximally exposed offsite individual is $0.2 \mathrm{mrem}$ EDE based on the ground release of up to twelve 55-gallon drum worths of contaminated moderator that can be in the area.

Criticality has been postulated in the Assembly Area for the events in which fuel assemblies are ejected from borated concrete storage racks or the racks are damaged enough to remove borated concrete, however, safety analyses (Ref. 9-6) have shown that the probability of criticality associated with these events is in the non credible range (i.e., $<10^{-6}$ ).

The results of the accident analyses for the Moderator Storage Areas show that the maximum amount of moderator that can possibly be released during a postulated event (i.e., design basis earthquake) is the equivalent of 4650 drums (Ref. 9-7). The consequences to co-tocated workers and the public were conservatively assumed to be released at ground level. The estimated consequences, in terms of EDE, are: 


\section{Total Ground Releases}

Maximally exposed co-located worker at 640 meters from K-Reactor is: approximately 316.4 mrem EDE

Maximally exposed offsite individual is: approximately 89.9 mrem EDE

Therefore, the exposure to co-located workers and the public from postulated events in the KReactor in Cold Standby are of low consequence, less than the medium consequence thresholds of. . 500 mrem for the co-located worker and $100 \mathrm{mrem}$ for the maximally exposed offsite individual (Ref. 9-8).

As noted previously, these results bound the situation in the $\mathbf{L}$ and P-Reactor Disassembly Basins. 


\subsection{SAFETY ASSURANCE PROGRAMS}

The Safety Assurance Programs are described in Sections 6.0 and 7.0 of this BIO.

The Safety Management Program covers a broad spectrum' of issues from hazard identification and assessment to hazard control during design and operations to enhance worker and public safety.

The safety and protection of the facility workers during accidents and normal operations are provided by the following safety management programs:

\begin{tabular}{|cl|cl|}
\hline$\cdot$ & Waste Management & $\bullet$ & Decontamination and Decommissioning \\
\hline$\cdot$ & Criticality Protection & $\bullet$ & Experimental Review \\
\hline$\cdot$ & Radiation Protection & $\bullet$ & Emergency Preparedness \\
\hline$\cdot$ & Hazardous Material Protection & $\bullet$ & Fire Protection \\
\hline$\cdot$ & Procedures and Training & $\bullet$ & Occupational Safety and Health \\
\hline$\cdot$ & Testing & $\bullet$ & $\begin{array}{l}\text { Disassembly Basin Sludge Removal } \\
\text { Plans }\end{array}$ \\
\hline$\cdot$ & Surveillance & $\bullet$ & Disassembly Basin Leak Detection \\
\hline$\cdot$ & Maintenance & $\bullet$ & Fuel Retention Time Analysis, Chemistry \\
\hline$\cdot$ & Conduct of Operations & & $\begin{array}{l}\text { Control, and Water Quality Plans for the } \\
\text { Disassembly Basins }\end{array}$ \\
\hline$\cdot$ & Quality Assurance & $\bullet$ & Configuration Management \\
\hline
\end{tabular}

Section 7.0 of this BIO and the Technical Specification for K-, L-, and P-Reactors provide the operating restrictions, administrative controls, and other safety requirements that are necessary to preserve the validity of the safety analysis assumptions and to ensure that K-Reactor in Cold Standby and the $L$ and P-Reactor Disassembly Basins are operated within the required conditions bounded by the analyses. Though the number of unirradiated fuel tubes and assemblies that can be stored in the K-Reactor Assembly Area has essentially doubled, the amount of moderator that can be stored in K-Reactor has increased, and the amount of time irradiated components has remained in the K-, L, and P-Reactor Disassembly Basins exceeds the historical storage time, the methods of storing and handling these materials remain the same as used previously. 


\subsection{STATUS QF ORDER COMPLIANCE}

As noted in Section 5.0 of this BIO, K-Reactor in Cold Standby will maintain a startup capability but with no planned provision for restart. Cold Standby operations in K-Reactor will be the continued storage and handling of unirradiated fuel and irtadiated components and the storage and processing of contaminated moderator. L- and P-Reactor Disassembly Basins continue to store and handle irradiated components in their Cold Shutdown status. As such, the current site and reactor order compliance status is applicable to this expanded use.

The K-Reactor Cold Standby Plan identifies an extensive DOE Order Compliance Program at SRS. A review of the Orders applicable to K-Reactor in Cold Standby identified that WSRC is not in compliance in 17 cases and has one additional Order in which the compliance status is under assessment or is otherwise pending. There were 13 CSAs and 4 exemption requests identified which are relevant, to the $\mathrm{L}$ and P-Reactor Disassembly Basins. The relevant DOE Orders in which the Disassembly Areas are not in compliance are primarily of a generic or programmatic nature. In general, these roncompliances are not judged to increase the hazard level which currently exists. In addition, they do not:

- Involve a significant increase in the probability or consequences of an accident or process hazard previously evaluated

- Create the possibility of a new or different kind of accident from an accident previously evaluated

- Involve a significant reduction in the margin of safety 


\subsection{IDENTIFIGATION OF VULNERABLITIES}

The structures of Buildings 105-K, 105-L, and 105-P are not susceptible to failure during design basis earthquakes, tomadoes, and high winds, however, during seismic and shipping cask drop events, the Disassembly Basin may develop cracks and rélease contaminated basin water to uncontrolled areas or the environment. Also, nonseismically qualified equipment in the K-Reactor Purification Area could rupture during seismic events releasing contaminated moderator to the environment. The consequences of these releases are low as discussed in Section 8.4.2.

Failure of valves, piping, and systems associated with the K-, L, and P-Reactor Disassembly Basins and operator errors may result in draindown or overfill of the basins. Draindown and overfill of the Disassembly Basins could result in contaminated water draining to uncontrolled areas or to the process sewer. Also, the draindown of the basins could expose operating personnel to unshielded irradiated material. The consequences of the release of contaminated water and exposure of personnel to unshielded irradiated material associated with the draindown and overfill of the basins are low as discussed in Section 8.4.2.

Fuel and target assemblies are handled by personnel in the K-, L-, and P-Reactor Disassembly Basins during disassembly operations, bundling operations, and loading of shipping cask. Critical configuration of fissile material may be created during the handling and preparation of fuel and target assemblies in the basins. Operating procedures limit the number of fuel assemblies and fuel bundles that may be placed together, the spacing between assemblies and bundles, and the number of fuel bundles that may be placed in a shipping cask consistent with the K-Resctor Technical Specification LCO 3.9.3 as well as corresponding L- and P-Reactor Technical Specifications. Also, operating procedures establish requirements on the mumber of fuel assemblies that can be placed on a hanger, in the use of hand-held gamma detector during target bundling operations, in the use of criticality bars and HBBS rack spacers and fuel blocking system during fuel bundling and storage operations, and in the replacement of blanks and cadmium plates in shipping cask after maintenance and performance of blackness tests. The consequences of an inadvertent criticality are low as discussed in Section 8.4.2.

Irradiated components stored in the K-, L-, and P-Reactor Disassembly Basins have shown evidence of corrosion as the result of extended storage of the components in basin water environments that have been determined to be conducive to pitting corrosion. A breach of the aluminum cladding of irradiated fuel stored in the basins can lead to leakage of fission products and other radiomuclides into the basin water. Also, fissile material may precipitate from fuel assemblies and collect on the basin floors and/or in the filtration system. Criticality analysis of the sludge presently in the bottom of the basins has conservatively showin that the sludge does not constitute a criticality concern, however, unless basin water quality is improved, a criticality potential could develop as fuel and target assemblies continue to corrode. A basin cleanup program presently underway is expected to reduce the initiation of new pitting corrosion and slow down the existing basin corrosion processes. 
The structure of the K-Reactor Purification Area building is not susceptible to failure during design basis earthquakes, tomadoes, and high winds. The seismic event could potentially damage the purification equipment, such as the tanks and lines releasing moderator. In addition, drums of moderator stored outside the Purification Area are susceptible to freezing during cold weather which also could release moderator. The consequences of a moderator release in the Purification Area are discussed in Section 8.3.2.19 of this BIO.

The structure of the K-Reactor Assembly Area building is susceptible to failure during design basis earthquakes, tornadoes, and high winds. The failure of the Assembly Area building structure, falling debris from the failure of a nearby structure, or tomado-induced missiles could potentially damage the borated concrete storage racks and/or strike the racks causing the fued tubes and assemblies to be fully or partially ejected from the racks onto the floor of the Assembly Area. Additionally, meteorological events could potentially topple the borated concrete storage slabs causing the fuel to be fully or partially ejected from the racks. Fuel fully or partially ejected from the racks onto the floor of the Assembly Area may be moderated by water generated by these high energy events from rain and/or exterior water and steam sources. The ability of the water to be drained from the reconfigured fuel tubes and assemblies may also be hindered by the failure of the floor drains or process sewer due to the seismic and meteorological events. The seismic event could potentially break the steam lines of the Assembly Area HVAC system, which are located in an adjacent room, and cause the steam to be blown into the Assembly Area. The possibility of these high energy events causing a criticality were, however, determined to be not credible (Ref. 9-6).

The fuel tubes and assemblies in the K-Reactor Assembly Area will be handled by personnel during initial receipt until fuel consolidation is complete, when fuel is inspected and inventoried, and when fuel is removed from the racks for boron testing and storage rack modifications. Operating procedures limit the number of fuel tubes and assemblies which are permitted to be handled at the same time outside of the borated concrete storage racks in the processing and handling room to four fuel tubes. and assemblies. Strict adherence to these operating procedures is mandatory in order to prevent conditions whereby criticality could occur. Should a moderatos be available in combination with an optimally configured array of more than four fuel tubes and assemblies, a potential for criticality exists. The likelihood of this sequence of events was, however, determined to be not credible (Ref. 9-6).

Though the Building 105-K structure is not susceptible to failure during design basis earthquakes, tomadoes, and high winds, the cranes, hoists, and storage tanks in Building 105-K, where moderator is stored, could fail during seismic events. The cranes and hoists might fall on drums and the nonseismically qualified storage tanks might rupture releasing moderator. The maximum quantity of contaminated moderator in the K-Reactor Moderator Storage Areas that is conservatively expected to be released in a DBE, including the entire site inventory of contaminated moderator which may eventually be stored there, is approximately 4650 drums (Ref. 9-7). The consequences are of low consequence (i.e., less than the medium consequence thresholds of DOE standard for BIO preparation) (Ref. 9-8). 
Drums and tanks in the K-Reactor Moderator Storage Areas could burst during freezing temperatures to produce a contaminated moderator release should the heating systems of Building $105 . \mathrm{K}$ be out of service of an extend period of time. The consequence to the maximally exposed offsite individual would not exceed 100 mrem since only a small fraction of the drums and tanks are expected to be affected if at all. However, in order to prevent a release of tritiated moderator to the environment, freeze protection and building temperature verification procedures should be strictly followed (Ref. 9-7). 


\subsection{COMPENŚATORY-MEASURES}

The measures used to compensate for the occurrence of postulated accidents are a result of the area design as well as administrative controls on the area. Compensatory measures and operator actions are detailed in Section 7.0 . 


\subsection{OPERATIONAL BISTORY}

As noted previously, K-Reactor in Cold Standby will maintain a startup capability but with no planned provision for restart while L- and P-Reactors will remain in a Cold Shutdown mode. Cold Standby operations of K-Reactor will be the continued storage and handling of unirradiated fuel and irradiated components and the storage and processing of contaminated moderator. Land P-Reactor Disassembly Basins operations will be the continued storage and handling of irradiated components. As such, the history of SRS production reactors offers examples of the history which might be expected in this continued use.

To determine the abnormal occurrences which have occurred with the storage of irradiated components, the Reactor Incident (RD) Reports and the Occurrerice Reports were examined. The reports cover the period 1957 through 1993 for the five production reactors at SRS. Of over 7600 reports, 242 were applicable to the Disassembly Basins.

Nineteen reports involved fuel or target assemblies being dropped to the basin floor, twenty-one reports involved the violation of criticality or assembly storage and handling rules, ten reports involved operational disassembly errors, twenty-seven reports involved releases of contaminated Disassembly Basin water, twenty-six reports involved improper shipment of fued and target material, ten reports involved $\mathrm{pH}$ above or below the operating limits, twenty-three reports involved the Disassembly Basin level above or below the operating limits, seventeen reports involved personnel contamination in the Disassembly Basin, two reports involved fires, and eighty-seven reports involved miscellaneous process difficulties. The compensatory measures for these occurrences were to improve attention to following procedures, correct procedures, and repair defective equipment. 


\subsection{RATIONACE BASIS FOR INTERIM SAFE OPERATION}

K-Reactor in Cold Standby consists of the Assembly Area for the storage of unirradiated fuel, the Moderator Storage Areas for the storage of contaminated moderator, the Disassembly Area for the storage and handling of irradiated components, the Purification Area for processing of contaminated moderator, and other miscellaneous areas in and around Building 105-K. In their Cold Standby state, these areas are used in the same manner as previously except for the larger quantity of fuel, larger quantities of stored moderator, and longer time irradiated components have remained in the Disassembly Basin. The current K-Reactor Technical Specifications and the additional administrative controls provided in Section 7.2 of this BIO serve as the safety requirement documents for K-Reactor in Cold Standby. The storage and handling of unirradiated fuel and irradiated components within K-Reactor while in Cold Standby are the same as previously used during reactor operations. In addition, as shown in Section 8.0 of this BIO and the BIOs for the Assembly Area and Moderator Storage Areas (Ref. 9-6, 9-7), the use of the KReactor to safely store and handle unirradiated fuel and irradiated components and to store and process contaminated moderator presents no new hazardous conditions or increased risk to the facility workers, co-located workers, public, or the environment.

L- and P-Reactor operation during Cold Shutdown consists of operating the Disassembly Areas for the storage of irradiated components. In their shutdown mission, these areas are used in the same manner as previously except for the longer time irradiated components have remained in the Disassembly Basins. The current L- and P-Reactor Technical Specifications and the additional administrative controls provided in Section 7.2 of this BIO serve as the safety requirement documents for the L- and P-Reactor Disassembly Basins. The methods of receipt, storage, and handling of irradiated components within the L- and P-Reactor Disassembly Basins are the same as previously used during reactor operations. In addition, as shown in Section 8.0 of this BIO, the use of the L- and P-Reactor Disassembly Basins to safely store and handle irradiated components presents no new hazardous conditions or increased risk to the facility workers, colocated workers, public, or the environment. 
This page intentionally left blank 


\subsection{REFERENCES, TABLES AND FIGURES}

\subsection{REFERENCES}

Note: For the purpose of this BIO the only references that apply to $L \& P$ reactors would be those references that cover information/analysis on the L \& P Disassembly Basins (unless otherwise specifically stated). In all other instances, the references listed in the BIO bound the L \& P Disassembly Basins.

1-1 Schwallie, A. L. "Improvement of Safety Documentation (U)," WSR-930178, Westinghouse Savannah River Company, Aiken, SC, December 1, 1993.

1-2 "Unreviewed Safety Question Screening and Evaluation Procedure," RDP 12.03 of WSRC Manual RD-1;. Reactor Division Administrative Manual. Westinghouse Savannah River Company, Aiken, SC.

1-3 "FY 1993 Program Execution Guidance," U.S. Department of Energy-Savannah River, Aiken, SC, April 19, 1993.

1-4 K-Reactor Cold Standby Plan, Rev. 2 (U). RRD-940039, Westinghouse Savannah River Company, Aiken, SC, March 30, 1994.

1-5 L-Reactor Cold Shutdown Plan, Revision One (C). RRD-940058, Westinghouse Savannah River Company, Aiken, SC, May 20, 1994.

1-6 Basis for Interim Operation (BIO) for the K-Reactor Assembly Area (U). WSRC-TR-93500, Rev. 2, Westinghouse Savannah River Company, Aiken, SC, March 1994.

1-7 Basis for Interim Operation (BIO) for the K-Reactor Moderator Storage Areas (U). WSRC-TR-93-611, Rev. 1, Westinghouse Savannah River Company, Aiken, SC, May 1994.

2-1 K-Reactor Cold Standby Plan, Rev. 2 (U). RRD-940039, Westinghouse Savannah River Company, Aiken, SC, March 30, 1994.

2-2 Basis for Interim Operation (BIO) for the K-Reactor Moderator Storage Areas (U). WSRC-TR-93-611, Rev. 1, Westinghouse Savannah River Company, Aiker, SC, May 1994.

2-3 Basis for Interim Operation (BIO) for the K-Reactor Assembly Area (U). WSRC-TR-93500, Rey. 2, Westinghouse Savannah River Company, Aiken, SC, March 1994.

2-4 Savannah River Site Production Reactor Safety Analysis Report K Production Reactor. WSRC-SA-10003, Amendment 4, Westinghouse Savannah River Company, Aiken, SC, November 8, 1992. 
2-5 Andes, T. C. "Disassembly Area Reference Manual, 105-K (U)," WSRC-TR-94-0137, Rev. 0, Weotinghouse Savannah River Company, Aiken, SC, May 1994.

2-6 Buczek, J. A. "Preliminary Hazards Analysis (PHA) for K-Reactor in Cold Standby (U)," WSRC-TR-94-067, Rev. 0, Westinghouse Savannah River Company, Aiken, SC, August 1994.

2-7 K-L- and P-Disassembly Basin Heat Loads from the Decay of Irradiated SRS Fuel Assemblies (U). WSRC-TR-93-600, Westinghouse Savannah River Company, Aiken, SC, November 1993.

2-8 Guy, J. C. "Reactor Irradiated Material Inventory Stored in the Disassembly Basin (U)," RRD-RSE-93-0080, Westinghouse Savannah River Company, Aiken, SC, December 15, 1993.

2-9 1993 SARA Tier II Inventory. Westinghouse Savannah River Company, Aiken, SC.

2-10 L-Reactor Cold Shutdown Plan, Revision One (U). RRD-940058, Westinghouse Savannah River Company, Aiken, SC, May 20, 1994.

2-11 Rice, P. D. P-Area Standby Plan (UD. RRD-910107, Westinghouse Savannah River Company, Aiken, SC, September 9, 1991.

2-12 Moderator Manggement Plan (U). RRD-ENG-930143, Rev. 1, Westinghouse Savannah River Company, Aiken, SC, December 17, 1993.

2-13 Reactor Division Disassembly Basin Management Plan (U). RRD-RSE-93-0075, Westinghouse Savannah River Company, Aiken, SC, November 30, 1993.

2-14 Spent Fuel Working Group Report on Inventery and Storage of the Department's Spent Nuclear Fuel and Other Reactor Irradiated Nuclear Materials and Their Environmental Safety and Health Vulnerabilities. U. S. Department of Energy, Washington, DC, November 1993.

2-15 "FY 1993 Program Execution Guidance," U. S. Department of Energy-Savannah River, Aiken, SC, April 19, 1993.

2-16 Adams, R. A. "Cadmium Control and Safety Rod Disposal Plan," WSRC-TR-93-42-062, Rev. 1, Westinghouse Savannah River Company, Aiken, SC, February 1994.

2-17 Chemistry Control For The New Disassembly Basin Mission (U). WSRC-TR-93-42-063, Rev. 0, Westinghouse Savannah River Company, Aiken, SC, September 29, 1993.

2-18 "Sample Analysis Schedule and Control - Routine," DPSOL 105-6101A, Westinghouse Savannah River Company, Aiken, SC, February 1, 1994. 
2-19 "Disassembly Basin Deionizer Sampling Requirements," DPSOL 105-3729A, Westinghouse Savannah River Company, Aiken, SC.

2-20 "pH Control of Disassembly Basin Vertical Tube Storage (VTS) Basin Water," DPSOL 105-3729D, Westinghouse Savannah River Company, Aiken, SC.

2-21 "pH Control of Disassembly Basin Machine Basin Water," DPSOL 105-3729E, Westinghouse Savannah River Company, Aiken, SC.

2-22 "pH Control of Disassembly Basin - Deionizer pH Adjustment," DPSOL 105-3729F, Westinghouse Savannah River Company, Aiken, SC.

2-23 Savannah River Site Production Reactor Safety Analysis Report I. Production Reactor. WSRC-RP-10003, Westinghouse Savannah River Company, Aiken, SC.

2-24 Savannah River Site Production Reactor Safety Analysis Report P Production Reactor. Westinghouse Savannah River Company, Aiken, SC.

2-25 Maryak, M. E. "Assessment of 105-K Disassembly Basin," 730:EPD-SE-94-0054, Westinghouse Savannah River Company, Aiken, SC, February 15, 1994.

2-26 "Criticality Rules for Fuel Assemblies in Disassembly," DPSOL 105-3695-K, Rev. 28, Westinghouse Savannah River Company, Aiken, SC, August 1993.

2-27 "Savannah River Site Reactor Training and Procedures, Disassembly Basin Deionizer System," CS-GEN-IT-SYS-09-03-SD, Rev. 0, Westinghouse Savannah River Company, Aiken, SC, November 1991.

2-28 Sayannah River Site Production Reactor Technical Specifications, K Production Reactor. WSRC-TS-10003, Rev. 16, Westinghouse Savannah River Company, Aiken, SC, November 1, 1993.

2-29 Savannah River Site Environmental Monitoring Plan (U). WSRC-3Q1-2, Volume 1, Section 1000 Addendum, Rev. 2, Westinghouse Savannah River Company, Aiken, SC, April 1993.

2-30 Savannah River Site Environmental Report for 1992. WSRC-TR-93-075, Westinghouse Savannah River Company, Aiken, SC.

2-31 Reactor Division-Fire Protection Program Manual (U). WSRC Procedure Manual RD 4.1, Rev. 0-C, Westinghouse Savannah River Company, Aiken, SC.

2-32 "Monthly Patrol," DPSOL 105-1879C, Westinghouse Savannah River Company, Aiker, SC.

2-33 "Emergency Lighting System Test," DPSOL 105-1879D, Westinghouse Savannah River Company, Aiker, SC. 
2-34 Reactor Area Emergency Plan. WSRC Procedure Manual 6Q7, Rev. 0, Westinghouse Savannah River Company, Aikem, SC, August 1, 1990.

2.35 Reactor Division Reactor Conduct of Operations Manual. WSRC Procedure Manual RD 2.1, Westinghouse Savannah River Company, Aiken, SC.

2-36 WSRC Fire Protection Program Manual. WSRC Procedure Manual 2Q, Rev. I, Westinghouse Savannah River Company, Aiken, SC, April 21, 1993.

2-37 Power Procedure Manual. SP 5.2, Westinghouse Savannah River Company, Aiken, SC, 1993.

2-38 "Life Safety Code," NFPA 101, 1993.

2-39 SRS Radiological Control. WSRC Procedure Manual 5Q, Westinghouse Savannah River Conipany, Aiken, SC. '

2-40 "Moderator Spill Carts Equipment Inventory," DPSOL 105-1843, Westinghouse Savannah River Company, Aiken, SC.

2-41 "Test of the Public Address System," DPSOL 100-4019, Westinghouse Savannah River Company, Aiken, SC.

2-42 "Safety Assessment, Horizontal Tube Storage Limits Revision," TSCR 94-0004, Westinghouse Savannah River Company, Aiken, SC, May 1994.

2-43 "Rounds Sheets, " DPSOL 105-00000-K Rev. 0 PCN-03, Westinghouse Savannah River Company, Aiken, SC.

3-1 Basis for Interim Operation (BIO) for the K-Reactor Assembly Area (U). WSRC-TR-93500, Rev. 2, Westinghouse Savannah River Company, Aiken, SC, March 1994.

3-2 Basis for Interim Operation (BIO) for the K-Reacter Moderator Storage Areas (U). WSRC-TR-93-611, Rev. 1, Westinghouse Savannah River Company, Aiken, SC, May 1994.

3-3 K-Reactor Cold Standby Plan Rev, 2 (U). RRD-940039, Westinghouse Savannah River Company, Aiken, SC, March 30, 1994.

3-4 Reacter Division Disassembly Basin Management Plan (U). RRD-RSE-93-0075, Westinghouse Savannah River Company, Aiken, SC, November 30, 1993.

3-5. Savannah River Site Production Reactor Safety Analysis Report K Production Reactor. WSRC-SA-10003, Amẹndment 4, Westinghouse Savannah River Company, Aiken, SC, November 8, 1992. 
3-6 Savannah River Site Production Reactor Technical Specifications. K Production Reactor. WSRC-TSa 10003, Rev. 16, Westinghouse Savannah River Company, Aiken, SC, November 1, 1993.

3-7 Reactor Operations Management Plan. WSRC-RP-89-368, Westinghouse Savannah River Company, Aiken, SC, 1989.

3-8 Operational Readiness Review, K-Reactor Restart Savannah River Site. U.S. Department of Energy, Washington, DC, November 12, 1991.

5-9 Update on Readiness for K-Reactor Restart (U). RRD-910127, Westinghouse Savannah River Company, Aiken, SC, November 7, 1991.

3-10 Action Plans to Address DOE-Operational Readiness Review Observations (U). RRD910139, Westinghouse Savannah River Company, Aiken, SC, December 3, 1991.

4-1 Basis for Interim Operation (BIO) for the K-Reactor Assembly Area (U). WSRC-TR-93500, Rev. 2, Westinghouse Savannah River Company, Aiken, SC, March 1994.

4-2 Basis for Interim Operation (BIO) for the K-Reactor Moderator Storage Areas (U). WSRC-TR-93-611, Rev. 1, Westinghouse Savannah River Company, Aiken, SC, May 1994.

4-3 Savannah River Site Production Reactor Safety Analysis Report. K Production Reactor. WSRC-SA-10003, Amendment 4, Westinghouse Savannah River Company, Aiken, SC, November 8, 1992.

4-4 "Safety of Department of Energy-Owned Nuclear Reactors," DOE Order 5480.6, U.S. Department of Energy, Washington, DC, September 23, 1986.

4-5 "Safety Analysis and Review System," DOE Order 5481.1B, U.S. Department of Energy, Washington, DC, May 19, 1987.

4-6 Standard Format and Content of Safety Analysis Reports for Nuclear Power Plants. Regulatory Guide 1.70, U.S. Nuclear Regulatory Commission, Washington, DC.

4-7 Standard Review Plan for the Review of Safety Analysis Reports for Nuclear. Power Plants. NUREG-0800, U.S. Nuclear Regulatory Commission, Washington, DC.

4-8 DOE Order 5480.23 Compliance Assessment and Implementation Report. WSRC-RP-93668-007, Rev, 0, Westinghouse Savannah River Company, Aiken, SC, September 15, 1993.

4-9 "Nuclear Safety Analysis Reports," DOE Order 5480.23, U.S. Department of Energy, Washington, DC, April 30, 1992. 
4-10 "FY 1993 Program Execution Guidance," U.S. Department of Energy-Savannah River, Aiken, SC,April 19, 1993.

4-11 K-Reactor Cold Standby Plan, Rev, 2 (U). RRD-940039, Westinghouse Savannah River Company, Aiken, SC, March 30, 1994.

4-12 "Description of Operation in a Changing Defense Nuclear Facility Complex," DNFSB 925, Defense Nuclear Facility Safety Board, Washington, DC, August 17, 1992.

4-13 Nuclear Safety Policy. Secretary of Energy Notice (SEN)-35-91, U.S. Department of Energy, Washington, DC, September 9, 1991.

4-14 The Final Environmental Impact Statement, "Continued Operation of K, L, and PReactors DOE/EIS-0417, Savannah River Site, Aiken, South Carolina," Westinghouse Savannah River Company, Aiken, SC, December 1990.

4-15 New, I. B. "Disposition of K-Reactor Programs (U)," RRD-930062, Westinghouse Savvannah River Company, Aiker, SC, April 13, 1993.

4-16 Savannah River Site Production Reactor Technical Specifications, K Production Reactor. WSRC-TS-10003, Revision 16, Westinghouse Savannah River Company, Aiken, SC, November 1, 1993.

4-17 "Technical Specifications," Title 10 Code of Federal Regulations Part 50, Section 50.36, U.S. Government Printing Office, Washington, DC.

4-18 Standard Technical Specifications, Westinghouse Plants. NUREG-1431, U.S. Nuclear Regulatory Commission, Washington, DC, January 1991.

4-19 "Unreviewed Safety Question Screening and Evaluation Procedure," RDP 12.03 of WSRC Manual RD-1, Reactor Division Administrative Mamual. Westinghouse Savannah River Company, Aiken, SC.

4-20 DQE Order 5480,22. Compliance Assessment and Implementation Report. WSRC-RP-93668-005, Rev. 0, Westinghouse Savannah River Company, Aiken, SC, September 15, 1993.

4-21 "Technical Safety Requirements," DOE Order 5480.22, U.S. Department of Energy, Washington, DC, February 25, 1992.

4-22 Plant Operating Specifications. RDP-2.17, Rev. 2, Westinghouse Savannah River Company, Aiken, SC, 1994.

4-23 Uniform Listing of K-Reactor Systems, Acronyms, and Functional Classifications (U). WSRC-TR-90-42-133, Rev. 5, Westinghouse Savannah River Company, Aiken, SC, April 28, 1994. 
4-24 K-Reactor Fire Hazards Analysis. WSRC-RP-92-834, Rev. 0, Westinghouse Savannah River Company, Aiken, SC, April 30, 1992.

4-25 "K-Reactor Fire Protection Cold Standby Status Report," SSD-SFP-93-0330, Rev. 1, Westinghouse Savannah River Company, Aiken, SC, November 18, 1993.

4-26 Savannah River Site Production Reactor Technical Specifications, L Production Reactor. WSRC-TS-10002, Revision 2, Westinghouse Savannah River Company, Aiken, SC, October 29, 1993.

4-27 Sayannah River Site Production Reactor Technical Specifications. P Production Reactor. WSRC-TS-10001, Revision 0, Westinghouse Savannah River Company, Aiken, SC, October 29, 1993.

4-28 L-Reactor Cold Shutdown Plan Revision One (U). RRD-940058, Westinghouse Savannah River Company, Aiken, SC, May 20, 1994.

4-29 Savannah River Site Production Reactor Safety Anatysis Report. L Production Reactor. WSRC-RP-10003, Westinghouse Savannah River Company, Aiken, SC.

4-30 Rice, P. D. "P-Area Standby Plan," RRD-910107, Westinghouse Savannah River Company, Aiken, SC, September 9, 1991.

4-31 Transfer Package for 100-L Area Facilities (U). RRD-ENG-930083, Westinghouse Savannah River Company, Aiken, SC, September 30, 1993.

4-32 Transfer Package for 100-P Area Facilities (U). RRD-ENG-930090, Westinghouse Savannah River Company, Aiken, SC, September 30, 1993.

4-33 Uniform Listing of $C, L, P$ and $R$ Reactor Systems, Acronyms and Functional Classification (U). WSRC-TR-94-01-090, Rev. 0, Westinghouse Savannah River Company, Aiken, SC, June 22, 1994.

5-1 K-Reactor Cold Standby Plan Rev. 2 (U). RRD-940039, Westinghouse Savannah River Company, Aiken, SC, March 30, 1994.

5-2 L-Reactor Cold Shutdown Plan Revision One (U) RRD-940058, Westinghouse Savannah River Company, Aiken, SC, May 20, 1994.

5-3 Transfer Package for 100-P Area Facilities (U). RRD-ENG-930090, Westinghouse Savannah River Company, Aiken, SC, September 30, 1993.

5-4 "Technical Safety Requirements," DOE Order 5480.22, U.S. Department of Energy, Washington, DC, February 25, 1992. 
5-5 DOE Order 5480,22 Compliance Assessment and Implementation Report. WSRC-RP-93668-005, Rev. 0, Westinghouse Savannah River Company, Aiken, SC, September 15, 1993.

5-6 "Nuclear Safety Analysis Reports," DOE Order 5480.23, U.S. Department of Energy, Washington, DC, April 30, 1992.

5-7 DOE Qrder 5480.23 Compliance Assessment and Implementation Report. WSRC-RP-93668-007, Rev. 0, Westinghouse Savannah River Company, Aiken, SC, September 15, 1993.

5-8 "FY 1993 Program Execution Guidance," U.S. Department of Energy-Savannah River, Aiken, SC, April 19, 1993.

6.1 Savannah River Site Environmental Monitoring Plan. WSRC-3Q1-2, Volume 1, Section 1000 Addendum, Rev. 2, Westinghouse Savannah River Company, Aiken, SC, April 1993.

6-2 Nuclear Criticality Safety Manual (U). Procedure Manual WSRC-MM-93-13, Rev. 1, Westinghouse Savannah River Company, Aiken, SC, July 1, 1993.

6-3 Savannah River Site Production Reactor Technical Specifications, K Production Reactor. WSRC-TS-10003, Revision 16, Westinghouse Savannah River Company, Aiken, SC, November 1, 1993.

6-4 Savannah River Site Production Reactor Technical Specifications, L Production Reactor. WSRC-TS-10002, Revision 2, Westinghouse Savannah River Company, Aiken, SC, October 29, 1993.

6-5 Savannah River Site Production Reactor Technical Specifications. P Production Reactor. WSRC-TS-10001, Revision 0, Westinghouse Savannah River Company, Aiken, SC, October 29, 1993.

6-6 "Criticality Rules for Fuel Assemblies in Disassembly," DPSOL 105-3695-K, Rev. 28, PCN-3, Westinghouse Savannah River Company, Aiken, SC, December 16, 1993.

6-7 DPSOL 105-0000-L, Rev. O(Round Sheets),Westinghouse Savannah River Company, Aiken, SC.

6-8 DPSOL 105-0000-P, Rev. 0 (Round Sheets),Westinghouse Savannah River Company, Aiken, SC.

6-9 Buczek, J. A. "Preliminary Hazards Analysis (PHA) for K-Reactor in Cold Standby (U)," WSRC-TR-94-067, Rev. 0, Westinghouse Savannah River Company, Aiken, SC, August 1994. 
6-10 Title 10 Code of Federal Regulations Part 100, "Reactor Site Criteris, " U.S. Government Printing Office, Washington, DC.

6-11 "Radiation Protection of the Public and Environment, "DOE Order 5400.5, Change 2, U.S. Department of Energy, Washington, DC, January 7, 1993.

6-12 Title 40 Code of Federal Regulations Part 61, "National Emission Standards for Hazardous Air Pollutants," U.S. Government Printing Office, Washington, DC.

6-13 Savannah River Site Production Reactor Safety Analysis Report K Production Reactor. WSRC-SA-10003, Amendment 4, Westinghouse Savannah River Company, Aiken, SC, November 8, 1992.

6-14 Reactor Component Assembly and HX Decontamination. DPSOP 25-2, E.I. duPont de Nemours and Company, Aiken, SC, November 1987.

6-15 East, J. M. "Revised Postulated Criticality Dose Analysis for K Reactor BIO (U)," SRTDCA-940034, Westinghouse Savannah River Company, Aiken, SC, March 1, 1994.

6-16 Cleaver, B. H. "Hazards Assessment Document for K-Reactor Moderator Storage Areas (U)," WSRC-TR-93-515, Rev. 1, Westinghouse Savannah River Company, Aiken, SC, April, 1994.

6-17 Management Policy 4.2, "Radiation Protection" WSRC Policy Manual 1-01, Westinghouse Savannah River Company, Aiken, SC, April 1, 1989.

6-18 Reduction Radiation Exposure to ALARA at the Savannah River Plant. SRS Special Hazards Bulletin 9 (SHB-9), Westinghouse Savannah River Company, Aiken, SC, December 1987.

6-19 Savannah River Site ALARA Guide. WSRC-IM-90-140, Westinghouse Savannah River Company, Aiken, SC, December 14, 1990.

6-20 "Radiation Protection for Occupational Workers," DOE Order 5480.11, Change 3, U.S. Department of Energy, Washington, DC, June 17, 1992.

6-21 SRS. Radiological Control. WSRC Procedure Manual 5Q, Westinghouse Savannah River Company, Aiken, SC.

6-22 Regulatory Guide 1.33, Rev. 2, U.S. Nuclear Regulatory Commission, Washington, DC.

6-23 Reactor Area Emergency Plan. WSRC Procedure Manual 6Q7, Rev. 0, Westinghouse Savannah River Company, Aiken, SC, August 1, 1990.

6-24 SRS, Conduct of Operations. WSRC Procedure Manual 2S, Rev. 1, Westinghouse Savannah River Company, Aiken, SC, January 28, 1994. 
6-25 Reactor Division Administrative Manual. WSRC Procedure Manual RD-1, Westinghouse Savannah River Company, Aiken, SC.

6-26 Reactor Ouality Assurance and Assessment Department Administrative Manual. WSRC Procedure Manual RD 8.1, Westinghouse Savannah River Company, Aiken, SC.

6-27 Reactor Division Maintenance Department Administrative Manual. WSRC Procedure Manual R3.2, Westinghouse Savannah River Company, Aiken, SC.

6.28 Quality Assurance Manual. WSRC Procedure Manual 1Q, Westinghouse Savannah River Company, Aiken, SC.

6-29 Reactor Engineering Department Administrative Manual. WSRC Procedure Manual R5.1, Westinghouse Savarnah River Company, Aiken, SC.

6-30 Work Control Manual. 'WSRC Procedure Manual RD 3.1, Westinghouse Savannah River Company, Aiken, SC, January 1991.

6-31 SRS, Conduct of Engineering and Technical Support, WSRC Procedure Manual ET, Westinghouse Savannah River Company, Aiken, SC.

6-32 Reactor Division Reactor Chemistry Manual WSRC Procedure Manual RD 2.2, Westinghouse Savannah River Company, Aiken, SC.

6-33 Reactor Division Fire Protection Propram Manual, WSRC Procedure Manual RD 4.1, Westinghouse Savannah River Company, Aiken, SC.

6-34 Technical Baseline Program Manual, WSRC Procedure Manual R5.3, Westinghouse Savannah River Company, Aiken, SC.

6-35 Reactor Division Administrative Manual Training WSRC Procedure Manual RD 6.1, Westinghouse Savannah River Company, Aiken, SC.

6-36 Conduct of Training WSRC Procedure Manual R6.1, Westinghouse Savannah River Company, Aiken, SC.

6-37 Pert Eyaluation Standard WSRC Procedure Manual R6.2, Westinghouse Savannah River Company, Aiken, SC.

6-38 Reactor Restart Division Administrative Manual WSRC Procedure Manual RD 7.1, Westinghouse Sayannah River Company, Aiken, SC.

6-39 Planning. Scheduling and Cost Control RRD Administrative Manual, WSRC Procedure Manual R13.1, Westinghouse Savannah River Company, Aiken, SC.

6-40 Conduct of Waste Management. WSRC Procedure Manual R14.1, Westinghouse Savannah River Company, Aiken, SC. 
6-41 "Accreditation of Performance-Based Training for Category A Reactors and Nuclear Facilities, "DOE Order 5480.18, U.S. Department of Energy, Washington, DC, November 2, 1989 . -

6-42 "Safety of Department of Energy-Owned Nuclear Reactors," DOE Order 5480.6, U.S. Department of Energy, Washington, DC, September 23, 1986.

6-43 "American National Standard for Selection, Qualification, and Training of Personnel for Nuclear Power Plants, " ANSU/ANS 3.1-1981 American Nuclear Society, La Grange Park, II.

6.44 "TMI Action Plan," NUREG-0737, U.S. Nuclear Regulatory Commission, Washington, DC.

6-45 "Personnel Selection, Qualification, Training, and Staffing Requirements at DOE Reactor and Non-Reactor Nuclear Facilities," DOE Order 5480.20, U.S. Department of Energy, Washington, DC, February 20, 1991.

6-46 Reactor Personnel Selection, Qualification, and Training, WSRC Procedure Manual RDP 6.01, Westinghouse Savannah River Company, Aiken, SC.

6-47 Safety Evaluation Report Restart of K-Reactor. Sayannah River Site. DOE/DP-0084T, U.S. Department of Energy, Washington, DC, April 1991.

6-48 K-Reactor Cold Standby Plan, Rev. 2 (U). RRD-940039, Westinghouse Savannah River Company, Aiken, SC, March 30, 1994.

6-49 L-Reactor Cold Shutdown Plan Revision One (U). RRD-940058, Westinghouse Savannah River Company, Aiken, SC, May 1994.

6-50 Plant Operating Specifications. RP-2.17, Rev. 2, Westinghouse Savannah River Company, Aiken, SC, 1994.

6-51 Reactor Division Maintenance Implementation Plan, DOE Order 5330,4A. WSRC-RP-92420, Rev. 2, Westinghouse Savannah River Company, Aiken, SC.

6-52 WSRC Employes Safety Manual. WSRC Procedure Manual 8Q, Westinghouse Savannah River Company, Aiken, SC.

6-53 "Occurrence Reporting and Processing of Operations Information," DOE Order 5000.3B, U.S. Department of Energy, Washington, DC, January 19,1993.

6-54 WSRC Manigement Requirements and Procedures. WSRC Procedure Manual IB, Westinghouse Savannah River Company, Aiken, SC.

6-55 Site Item Reportability and Issue Management (SIRIM). WSRC Procedure Manual 9B, Rev. 0, Westinghouse Savannah River Company, Aiken, SC, March 31, 1993.

10.1-11

UNCLASSTFIED CONTROLLED NUCLEAR INFORMATION 
6-56 Uniform Listing of K-Reactor Systems, Acronyms, and Functional Classification (U). WSRC-TR-90-42-133, Rev. 5, Westinghouse Savannah River Company, Aiken, SC, April 28, 1994. .

6-57 Uniform Listing of $C, L, P$ and $R$ Reactor Systems. Acronyms, and Functional Classification (U). W'SRC-TR-94-01-090, Rev. "0, Westinghouse Savannah River Company, Aiken, SC, June 22, 1994.

6-58 WSRC Quality Assurance Management Plan. WSRC-RP-92-225, Westinghouse Savannah River Company, Aiken, SC.

6-59 SRS Emergency Plan. WSRC Procedure Manual 6Q, Rev. 2, Westinghouse Savannah River Company, Aiken, SC, September 7, 1991.

6-60 WSRC Fire Protection Program Manual. WSRC Procedure Manual 2Q, Rev. 1, Westinghouse Savannah River Company, Aiken, SC, April 21, 1993.

6-61 Miscellaneous Equipment Operation. DPSOP 330-44, Volume I, E. I. duPont de Nemours and Company, Aiken, SC.

6-62 P-Area Standby Plan. RRD-SPS-910315, Westinghouse Savannah River Company, Aiken, SC, August 2, 1991.

6-63 "Rounds Sheets," DPSOL 105-00000-K Rev. 0 PCN-03, Westinghouse Savannah River Company, Aiken, SC.

6-64 "Reactor Division Fire Protection Program, " DMP 4.01, Rev. 1, Westinghouse Savannah River Company, Aiken, SC, September 30, 1993.

6-65 "Control of Transient Combustibles," DMP 4.03, Rev. 1, Westinghouse Savannah River Company, Aiken, SC, September 30, 1993.

6-66 "Fire Protection Flame/Spark Permits for Cutting, Welding, and Grinding Accidents," DMP 4.04, Rev. 1, Westinghouse Savannah River Company, Aiken, SC, September 30, 1993.

6-67 Industrial Hygiene. WSRC Procedure Manual 4Q, Westinghouse Savannah River Company, Aiken, SC.

6-68 Cardoso-Neto, J. E. "ERD Support, Installation of Additional Monitoring Wells at the L, $\mathrm{K}$, and P Reactors Disassembly Basing (U)," SWE-ERG-94-0396, Westinghouse Savannah River Company, Aiken, SC, May 25, 1994.

6-69 Chemistry Control for the New Disassembly Basin Mission (U). WSRC-TR-93-42-063, Rev. 0, Westinghouse Savannah River Company, Aiken, SC, September 1993. 
6-70 Howell, J. P. "Status Report on Corrosion of Aluminum Alloys in SRS Reactor Disassembly Basin Storage (U)," SRT-MTS-930138, Westinghouse Savannah River Company, Aiken, SC, September 27, 1993.

6-71 Howell, J. P. "Status Report on Corrosion of Aluminum Clad Fuel and Target Alloys in Reactor Basins (U)," SRT-MTS-930050, Westinghouse Savannah River Company, Aiken, SC, March 4, 1993.

6-72 WSRC Confiquration Management Control, Procedure Manual TE.

6-73 WSRC Engineering and Engineered Services Procedures Manual Procedure Manual IE (11/15/94)

6-74 244-H Facility Configuration Management Baselining Report (U)," WSRC-RP-94-459, Rev. 0, Westinghouse Savannah River Company, Aiken, SC, April 9, 1994. This report covers the K, L, \& P Disassembly Basins as well.

6-75 WSRC Administrative and Procedural Controls System for SRS Reactor and Non-reactor Nuclear Facilities Procedure Manual IIQ (7/19/94).

6-76 "Unreviewed Safety Question," DOE Order 5480.21, U. S. Department of Energy, Washington, DC, December 21, 1991.

6-77 DOE Radiological Control Manual, DOE-N5480.6

7-1 Basis For Interim Operation (BIO) for the K-Reactor Assembly Area (U). WSRC-TR-93500, Rev. 2, Westinghouse Savannah River Company, Aiken, SC, March 1994.

7-2 Basis For Interim Operation (BIO) for the K-Reactor Moderator Storage Areas (U). WSRC-TR-93-611, Rev. 1 Westinghouse Savannah River Company, Aiken, SC, May 1994.

7-3 Savannah River Site Production Reactor Technical Specifications, K Protuction Reactor. WSRC-TS-10003, Rev. 16, Westinghouse Savannah River Company, Aiken, SC, November 1, 1993.

7.4 Savannah River Site Production Reactor Technical Specifications. L Production Reactor. WSRC-TS-10002, Revision 2, Westinghouse Savannah River Company, Aiken, SC, October 29, 1993.

7-5 Savannah River Site Production Reactor Technical Specifications. P Production Reactor. WSRC-TS-10001, Revision 0, Westinghouse Savannah River Company, Aiken, SC, October 29, 1993. 
7-6 Buczek, J. A. "Preliminary Hazards Analysis (PHA) for K-Reactor in Cold Standby (U)," WSRC-TRe94-067, Rev. 0, Westinghouse Savannah River Company, Aiken, SC, August 1994.

7-7 Buczek, J. A. "Preliminary Hazards Analysis (PHA) for Fuel Storage in the K-Reactor Assembly Area (U)," WSRC-TR-93-472, Rev. "1, Westinghouse Savannah River Company, Aiken, SC, March 1994.

7-8 Buczek, J. A. "Preliminary Hazards Analysis (PHA) for the K-Area Moderator Storage Areas (U)," WSRC-TR-93-654, Rev. 1, Westinghouse Savannah River Company, Aiken, SC, June 1994.

7-9 Buczek, J. A. "Preliminary Hazards Analysis (PHA) for P- and L-Reactor Disassembly Basins (U)," WSRC-TR-94-067, Rev. 0, Westinghouse Savannah River Company, Aiken, SC, August 1994.

7-10 Technical Manual 100-Area Criticality Safety. DPSTM-100-CRIT-85, E.I. duPont de Nemours and Company, Aiken, SC, revised January 16, 1985.

7-11 Reed, R. L. "100-Area Unirradiated Fuel Consolidation Criticality Concerns (U)," SRTCMA-930062, Rev. 0, Westinghouse Savannah River Company, Aiken, SC, November 5, 1993.

7-12 Rosser, M. A. "Criticality Safety Evaluation for K-Area Disassembly VTS Cleanup (U)," RRD-RED-930306, Westinghouse Savannah River Company, Aiken, SC, August 18, 1993.

7-13 Criticality Safety Evaluation for Disassembly Basin Sand Filter (U). WSRC-TR-93-614, Rev. 0, Westinghouse Savannah River Company, Aiken, SC, May 1994.

7-14 Criticality Safety Evaluation for K Area Disassembly Basin Cleanup (U). WSRC-TR-93613, Rev. 0, Westinghouse Savannah River Company, Aiken, SC, February 1994.

7.15 Rosser, M. A "Criticality Safety Evaluation for L Area Disassembly Basin Cleanup (U)," RRD-RED-930373, Westinghouse Savannah River Company, Aiken, SC, October 6, 1993.

7-16. Rosser, M. A. "Calculations for P Area Basin Sludge Criticality Safety Evaluation (U)," N-CLC-P-00001, Westinghouse Savannah River Company, Aiken, SC, August 1994.

7-17 "Safety of Department of Energy-Owned Nuclear Reactors," DOE Order 5480.6, U.S. Department of Energy, Washington, DC, September 23, 1986.

7-18 "Technical Specifications," Title 10 Code of Federal Regulations Part 50, Section 50.36, U.S. Government Printing Office, Washington, DC. 
7-19 Standard Technical Specifications, Westinghouse Plants. NUREG-1431, U.S. Nuclear RegulatoryComimission, Washington, DC, January 1991.

7-20 "Technical Safety Requirements," DOE Order 5480.22, U.S. Department of Energy, Washington, DC, February 25, 1992.

7-21 DOE Order 5480,22 Compliance Assessment and Implementation Report. WSRC-RP-93668-005, Rev. 0, Westinghouse Savannah River Company, Aiken, SC, September 15, 1993.

7-22 Chemistry Control for the New Disassembly Basin Mission (U). WSRC-TR-93-42-063, Rev. 0, Westinghouse Savannah River Company, Aiken, SC, September 1993.

8-1 Reactor Irradiated Material Inventory Stored in the Disassembly Basins (U). RRD-RSE93-0080, Westinghouse Savannah River Company, Aiken, SC, December 15, 1993.

8-2 Cleaver, B. H. "Hazards Assessment Document for K-Reactor During Cold Standby (U)," WSRC-TR-93-665, Rev. 0, Westinghouse Savannah River Company, Aiken, SC, June 1994.

8-3 Cleaver, B. H. "Hazards Assessment Document for Fuel Storage in K-Reactor Assembly Area (U)," WSRC-TR-93-466, Rev. 1, Westinghouse Savannah River Company, Aiken, SC, April 1994.

8-4 Cleaver, B. H. "Hazards Assessment Document for the Moderator Storage Areas in KReactor (U)," WSRC-TR-93-515, Rev. 1, Westinghouse Savannah River Company, Aiken, SC, April 1994.

8-5 Cleaver, B. H. "Hazards Assessment Document for L-Reactor Disassembly Basin (U)," WSRC-TR-94-267, Rev. 0, Westinghouse Savannah River Company, Aiken, SC, August 1994.

8-6 Cleaver, B. H. "Hazards Assessment Document for P-Reactor Disassembly Basin (U)," WSRC-TR-94-268, Rev. 0, Westinghouse Savannah River Company, Aikeri, SC, August 1994.

8-7 "Nuclear Safety Analygis Reports," DOE Order 5480.23, U.S. Department of Energy, Washington, DC, April 30, 1992.

8-8 DOE, Hazard Categonization and Accident Analysis Techniques for Compliance with DOE Order 5480,23. Nuclear Safety Analysis Reports. DOE Standard DOE-STD-102792, U. S. Department of Energy, Washington, DC, October, 1992. 
8-9 Craig, D. K. et al. "Toxic Chemical Hazard Classification and Risk Acceptance Guidelines for Use in DOE Facilities, "WSRC-MS-92-206, Rev. 1 (April 1993 Recommendations of the Westinghouse M\&O Subcommittee on Nonradiological Risk Acceptance Guideline Development), Westinghouse Savannah River Company, Aiken, SC, April, 1993.

8-10 "The List of Extremely Hazardous Substances and Their Threshold Planning Quantities (Alphabetical Order)," Title 40 Code of Federal Regulations, Part 302 (Appendix 1), U.S. Environmental Protection Agency, Washington, DC, July 1, 1992.

8-11 "The List of Extremely Hazardous Substances and Their Threshold Planning Quantities (Alphabetical Order)," Title 40 Code of Federal Regulations, Part 355, U.S. Environmental Protection Agency, Washington, DC, July 1, 1992.

8-12 "Labor," Title 29 Code of Federal Regulations, Part 1910, U.S. Department of Labor, Washington, DC, July 1, 1992.

8-13 "American National Standard for Nuclear Radionuclide Release Safety in Operation with Fissionable Materials Outside Reactors", ANSI/ANS-8.1-1983, American Nuclear Society, La Grange Park, II, 1983.

8-14 Electronic Screning of Chemical Inventory Information (U). S-ESR-G-00001, Rev. 0, Westinghouse Savannah River Company, Aiken, SC, December 28, 1993.

8-15 1993 SARA Tier II Inventory. Westinghouse Savannah River Company, Aiken SC.

8-16 "Chemicals and Non-radioactive Hazardous Materials Control (U)," DPSOL 105-1845-K, Rev. 17-PCN-02, Westinghouse Savannah River Company, Aiken, SC, June 16, 1994.

8-17 Buczek J. A "Preliminary Hazards Analysis (PHA) for K-Reactor in Cold Standby (U)," WSRC-TR-94-067, Rev. 0, Westinghouse Savannah River Company, Aiken, SC, August 1994.

8-18 Buczek J. A. "Preliminary Hazards Analysis (PHA) for Fuel Storage in the K-Reactor Assembly Area (U)," WSRC-TR-93-472, Rev. 1, Westinghouse Savannah River Company, Aiken, SC, March 1994.

8-19 Buczek J. A. "Preliminary Hazards Analysis (PHA) for the K-Area Moderator Storage Areas (U)," WSRC-TR-93-654, Rev. 1, Westinghouse Savannah River Company, Aiken, SC, June 1994.

8-20 "Guidance for Preparation of DOE 5480.22 (TSR) and DOE 5480.23 Implementation Plans," Draft, DOE-STD-0019-93, U.S. Department of Energy, Washington, DC, October 26, 1993. 
8-21 Baumann, E. W., "Analysis of Water and Sludge From the K-Reactor Vertical Tube Storage Bagin (U)," WSRC-TR-92-412, Westinghouse Savannah River Company, Aiken, SC, August 18, 1992.8-22 "Savannah River Site Reactor Training and Procedures, Disassembly Basin, " CS-GEN-IT-SYS-09-01-SD, Rev. 1, Westinghouse Savannah River Company, Aiken, SC, July 1992.

8-23 T. C. Andes, "Disassembly Area Reference Manual, 105-K (U)," WSRC-TR-94-0137, Rev. 0, Westinghouse Savannah River Company, Aiker, SC, May 1994.

8-24 Rosser, M. A. "Criticality Safety Evaluation for K Area Disassembly Basin Cleanup (U)," WSRC-TR-93-613, Rev. 0, Westinghouse Savannah River Company, Aiken, SC, February 1994.

8-25 Rosser, M. A. "Criticality Safety Evaluation for L Area Disassembly Basin Cleanup (U)," RRD-RED-930373, Westinghouse Savannah River Company, Aiken, SC, October 6, 1993.

8-26 Rosser, M. A. "Calculations for P Area Basin Sludge Criticality Safety Evaluation (U)," N-CLC-P-00001, Westinghouse Savannah River Company, Aiken, SC, August 1994.

8-27 K-Reactor Cold Standby Plan Rev, 2 (U). RRD-940039, Westinghouse Savannah River Company, Aiken, SC, March 30, 1994.

8-28 Savannah River Site Production Reactor Safety Analysis Report. K Production Reactor, WSRC-SA-10003, Amendment 4, Westinghouse Savannah River Company, Aiken, SC, November 8, 1992.

8-29 Joshi, J. R. "NPH Evaluation of K Area Slug Vault (U)," 730:EPD-SE-94-0050, Westinghouse Savannah River Company, Aiken, SC, February 11, 1994.

8-30 Methodolegy Manual for Nuclear Processes Safety Analysis (U) Rev. 2. WSRC-TM-9013, Westinghouse Savannah River Company, Aiken, SC, May 1992.

8-31 Johnson, B. and Ryan, D. Tornado Hazard to Production Reactors at Savannah River Plant Final Repert DPST-86-579, E. I. duPont de Nemours Company, May, 1986.

8-32 Maryak, M. E. "Assessment of 105-K Disassembly Basin," 730:EPD-SE-94-0054, Westinghouse Savannah River Company, Aiken, SC, February 15, 1994.

8-33 "105-K Building Disassembly Basin External Events Analysis, Revision 0," N-CLC-K00157, Rev. 0, Westinghouse Savannah River Company, Aiken, SC, June 1994.

8-34 "Savannah River Site PRA of Reactor Operations Level 1 - External Events," WSRC-RP89-733, Westinghouse Savannah River Company, Aiken, SC, June 1990. 
8-35 Safety Analysis - 200-S Area Savannah River Site Defense Waste Processing Facility Operations_Westinghouse Savannah River Company, Aiken SC, August 1992.

8-36 "Consequence Analysis for Disassembly Basin Accident Analysis, "N-CLC-K-00158, Rev. 0, Westinghouse Savannah River Company, Aiken, SC, June 1994.

8-37 "K-Reactor Disassembly Basin Draindown Accident Analysis," SRT-CTG-93-9007, Rev. 0, Westinghouse Savannah River Company, Aiken, SC, November 1993.

8-38 Louthan, M. R. "The Potential for Pyrophoric Reactions on Corroded Mark 31 Slugs," SRT-MTS-94-0045, Westinghouse Savannah River Company, Aiken, SC, March 22, 1994.

8.39 Kahook, S. D. "K-, Lr, and P-Disassembly Basin Heat Loads from the Decay of Irradiated SRS Fuel Assemblies (U)," WSRC-TR-93-600, Westinghouse Savannah River Company, Aiken, SC, November,' 1993.

8-40 "Heat Transfer Calculations for Fuel in Disassembly Basin Following a Drainage Event," N-CLC-K-00159, Rev. 0, Westinghouse Savannah River Company, Aiken, SC, June 1994.

8-41 Holmes, W. "Isotopic Contents of the Discharged Mark 42 Assemblies, " ROD-88-203, E. I. duPont De Nemours and Company, Aiken, SC, October 17, 1988.

8-42 "K-Reactor Disassembly Basin Overfill Accident Analysis," SRT-CTG-93-9008, Rev. 0, Westinghouse Savannah River Company, Aiken, SC, November 1993.

8-43 "105-K Building Disassembly Basin Criticality Frequency Fault Trees, Revision 0," NCLC-K-00161, Rev. 0, Westinghouse Savannah River Company, Aiken, SC, June 1994.

8-44 Technical Mamual 100-Area Criticality Safety. DPSTM-100-CRIT-85, E. I. duPont de Nemours and Company, Aiken, SC, January 1985.

8-45 Swain, A. D., III, "Accident Sequence Evaluation Program Human Reliability Aralysis Procedure," NUREG/CR-4772, U.S. Nuclear Regulatory Commission, Washington, DC, February 1987.

8-46 Reed, R. L. "100 Area Irradiated Fuel Consolidation and Horizontal Storage Criticality Concerns (U)," SRT-CMA-930074, Rev. 0, Westinghouse Savannah River Company, Aiken, SC, January 1994.

8-47 "Safety Assessment, Horizontal Tube Storage Limits Revision," TSCR 94-0004, Westinghouse Savannah River Company, Aiken, SC, May, 1994.

8-48 "American National Standard for Nuclear Criticality Control of Special Actinide Elements," ANSI/ANS-8.15-1981, American Nuclear Society, La Grange Park, IL, 1981. 
8-49 Rosser, M. A. "Criticality Safety Evaluation for Disassembly Basin Sand Filter," WSRCTR-93-614,Rev. 0, Westinghouse Savannah River Company, Aiken, SC., May 1994.

8-50 Casey, M. "Disassembly Basin Deionizer System, System Description," CS-GEN-IT-SYS09-03-SD, Rev. 0, Westinghouse Savannah River Company, Aiken, SC, November 7, 1991.

8-51 Buczek, J. A. "Preliminary Hazards Analysis (PHA) for P- and L-Reactor Disassembly Basins (U)," WSRC-TR-94-067, Rev. 0, Westinghouse Savannah River Company, Aiken, SC, August 1994.

8-52 Gough, S. T. "Discharged Component Cooling and Criticality (U)," RRD-RTS-930083, Westinghouse Savannah River Company, Aiken, SC, April 19, 1993.

8-53 L-Reactor Cold Shutdown Plan Revision One (U). RRD-940058, Westinghouse Savannah River Company, Aiken, SC, May 20, 1994.

8-54 Rice, P. D. "P-Area Standby Plan (U)," RRD-910107, Westinghouse Savannah River Company, Aiken, SC, September 9, 1991.

8-55 K-Reactor Fire Hazards Analysis Report. WSRC-RP-92-834, Rev. 0, Westinghouse Savannah River Company, Aiken, SC, April 30, 1992.

8-56 "Freeze Protection," DPSOL 105-2310B-K, Rev. 1-PCN-04, Wertinghouse Savannah River Company, Aiken, SC, October 1, 1993.

8-57 "105-K Lay-up Rounds," DPSOL 105-0000-K, Rev. 0-PCN-02, Westinghouse Savannah River Company, Aiken, SC, Jamuary 28, 1994.

8-58 East, J. M. "Revised Postulated Moderator Spill Dose Analysis for K-Reactor BIO (U)," SRT-DCA-940045, Westinghouse Savannah River Company, Aiken, SC, March 16, 1994.

8-59 Chemistry Control for the New Disassembly Basin Mission (UD. WSRC-TR-93-42-063, Rev. 0, Westinghouse Savannah River Company, Aiken, SC, September 1993.

8-60 Howell, J. P. "Status Report on Cortosion of Aluminum Alloys in SRS Reactor Disassembly Basin Storage (U)," SRT-MTS-930138, September 27, 1993.

8-61 Howell, J. P. "Status Report on Corrosion of Aluminum Clad Fuel and Target Alloys in Reactor Basins (U)," SRT-MTS-930050, March 4, 1993.

8-62 Howell, J. P. "Corrosion of Mark 31 Slugs in L-Disassembly Basin (U)," SRT-MTS940021, January 28, 1994.

8-63 Reed, R L. "100 Area Unirradiated Fuel Consolidation Criticality Concerns (U)," SRTCMA-930062, Westinghouse Savannah River Company, Aiken, SC, November 5, 1993. 
8-64 Basis For Interim Qperation for the K-Reactor Assembly Area (U). WSRC-TR-93-500, Rev. 2, Westinghouse Savannah River Company, Aiken, SC, March 1994.

8-65 Basis For Interim Operation for the K-Reactor Moderator Storage Areas (U). WSRCTR-93-611, Rev. 1, Westinghouse Savannah River Company, Aiken, SC, May 1994.

8-66 Cardoso-Neto, J. E. "ERD Support, Installation of Additional Monitoring Wells at the L, $\mathrm{K}$, and P Reactors Disassembly Basins (U)," SWE-ERG-94-0396, Westinghouse Savannah River Company, Aiken, SC, May 25, 1994.

8-67 Deible, R. W., "Reactor Basin Chemistry Trending Report- August and September 1994 (U) ${ }^{n}$, WSRC-RP-94-827-009.

9-1 Cleaver, B. H. "Hazards Assessment Document for K-Resctor During Cold Standby (U)," WSRC-TR-93-665, Rev. 0, Westinghouse Savannah River Company, Aiken, SC, June 1994.

9-2 Cleaver, B. H. "Hazards Assessment Document for Fuel Storage in K-Reactor Assembly Area (U)," WSRC-TR-93-466, Rev. 1, Westinghouse Savannah River Company, Aiken, SC, April 1994.

9-3 Cleaver, B. H. "Hazards Assessment Document for the Moderator Storage Areas in KReactor (U)," WSRC-TR-93-515, Rev. 1, Westinghouse Savannah River Company, Aiken, SC, April 1994.

9.4 Cleaver, B. H. "Hazards Assessment Document for L-Reactor Disassembly Basin (U)," WSRC-TR-94-267, Rev. 0, Westinghouse Savannah River Company, Aiken, SC, August 1994.

9-5 Cleaver, B. H. "Hazards Assessment Document for P-Reactor Disassembly Basin (U)," WSRC-TR-94-268, Rev. 0, Westinghouse Savannah River Company, Aiken, SC, August 1994.

9-6 Basis For Interim Operation (BIO) for the K-Reactor Assembly Area (U). WSRC-TR-93500, Rev. 2, Westinghouse Savannah River Company, Aiken, SC, March 1994.

9-7 Basis For Interim Operation (BIO) for the K-Reactor Moderator Storage Areas (U). WSRC-TR-93-611, Rev. 1 Westinghouse Savannah River Company, Aiken, SC, May 1994.

9-8 "Guidance for Preparation of DOE 5480.22 (TSR) and DOE 5480.23 Implementation Plans, " Draft, DOE-STD-0019-93, U.S. Department of Energy, Washington, DC, October 26, 1993: 
Table :

TATEGORIZATION OF NATURAL PHENOMENA EVENTS FOR

K-REACTOR IN COLD STANDBY AND L-AND P-REACTOR DISASSEMBLY BASINS

\begin{tabular}{|c|c|c|c|c|c|}
\hline EVENT & $\begin{array}{l}\text { DNITLATTNG } \\
\text { EVENT } \\
\text { FREQ } Y R\end{array}$ & $\begin{array}{l}\text { HAZARD } \\
\text { EVENT } \\
\text { FREQ/YR }\end{array}$ & HAZARD & CONSEQ & $\begin{array}{l}\text { SCENARIO } \\
\text { CLASS }\end{array}$ \\
\hline Straight WindeTtornado & N.C. & N.C. & Release & N.C. & N.C. \\
\hline $\begin{array}{l}\text { Straight Wind-Stack Failure } \\
\text { (Wind > } 185 \text { mph) }\end{array}$ & $1.4 \times 10^{-6}$ & N.C. & Release & N.C. & N.C. \\
\hline $\begin{array}{l}\text { Tornado Missiles } \\
\text { - }\end{array}$ & N.C. & N.C. & Relosse & N.C. & N.C. \\
\hline Floods & N.C. & N.C. & Release & N.C. & N.C. \\
\hline Eartbquake (DBE) & $2.0 \times 10^{-4}$ & Fig $1 \& 2$ & Releave & Low & III \\
\hline Lightning & N.C. & N.C. & Release & N.C. & N.C. \\
\hline Meteorites & $2 \times 10^{-10}$ & N.C. & Release & N.C. & N.C. \\
\hline Freezing Temperanure & $1.6 \times 10^{-1}$ & N.C. & Release & N.C. & N.C. \\
\hline Snow and Ice & N.C. & N.C. & Release & N.C. & N.C. \\
\hline
\end{tabular}

N.C. - not credible

N.I. - negligible impact

SCENARIO CLASS DEFINTIONS

\section{Sceparie Class}

I - Major

$I$ - Befor

II - Sarions

II - Serious

III - Marginal

III - Marginal

IV-Negligible

N.C. - Not Credible
Conseourenges

High

Medium

High

Modium

Modium

Low

Low

Not Credible
Erequency

Above $10^{-4} / \mathrm{yr}$

Above $10^{-2}$ irs

$10^{-4}$ to $10^{-6} \mathrm{hr}$

$10^{-2}$ to $10^{-4} / \mathrm{yr}$

$10^{-4}$ to $10^{-6} / \mathrm{ys}$

Above $10^{-4}$ fys

$10^{-4}$ to $10^{-6} \mathrm{hr}$

$<10^{-5} \mathrm{hr}$ 
Table 2

- CATEGORIZATION OF PROCESS PHENOMENA EVENTS FOR

K-REACTOR IN COLD STANDBY AND L- AND P-REACTOR DISASSEMBLY BASINS

\begin{tabular}{|c|c|c|c|c|c|}
\hline EVENT & $\begin{array}{l}\text { DNTTATLNG } \\
\text { EVENT } \\
\text { FREQYR }\end{array}$ & $\begin{array}{l}\text { HAZARD } \\
\text { EVENT } \\
\text { FREQYR }\end{array}$ & HAZARD & CONSEQ & $\begin{array}{l}\text { SCENARIO } \\
\text { CLASS }\end{array}$ \\
\hline Disassembly Basin Draindown & Fis $1 \geq 2$ & Fig $1 \neq 2$ & Releas, Shine & Low & III \\
\hline Disassembly Busin Overfill & Fig $1 \& 2$ & Fig $1 \propto 2$ & Releaso & Low & III \\
\hline Inadvertent Criticality & Fij $1 \& 2$ & Fig $1 \& 2$ & Criticality & Low & 뜨 \\
\hline Criticality in Basin Sludge & N.C. & N.C. & Criticality & N.C. & N.C. \\
\hline Criticality in the Setuler Tank & N.C. & N.C. & Criticality & N.C. & N.C. \\
\hline Criticality in the Sand Filters & N.C. & N.C. & Criticality & N.C. & N.C. \\
\hline Criticality in Deionizer & N.C. & N.C. & Criticality & N.C. & N.C. \\
\hline $\begin{array}{l}\text { Loss of Disasserrbly Basin } \\
\text { Cooling }\end{array}$ & 1.0 & 1.0 & $\begin{array}{l}\text { No adverse } \\
\text { consequence }\end{array}$ & $\begin{array}{l}\text { No atverse } \\
\text { conseguence }\end{array}$ & $\begin{array}{l}\text { No adverse } \\
\text { consequence }\end{array}$ \\
\hline Hazardous Chemical Spill & N.I. & N.I. & $\begin{array}{l}\text { Chemial } \\
\text { Hazand }\end{array}$ & $\begin{array}{l}\text { No stretse } \\
\text { consequedce }\end{array}$ & $\begin{array}{l}\text { No adverse } \\
\text { consequence }\end{array}$ \\
\hline Fire & $9.1 \times 10^{-4}$ & $9.1 \times 10^{4}$ & Relesso & Low & III \\
\hline Explosion & $3.0 \times 10^{-3}$ & $3.0 \times 10^{-7}$ & Relense & N.C. & N.C. \\
\hline Aircraft - Airplane & $4.8 \times 10^{-7}$ & N.C. & Release & N.C. & N.C. \\
\hline Aircraft - WSI helicopter & $<1.0 \times:$ & N.C. & Release & N.C. & N.C. \\
\hline Loss of Power & N.I. & N.I. & Relense & N.I. & N.I. \\
\hline Loss of Ventilation & N.I. & N.I. & Release & N.I. & N.I. \\
\hline Intermal Missiles & N.C. & N.C. & Release & N.C. & N.C. \\
\hline Loss of Confinement & $\begin{array}{c}\text { Bound by DBE, } \\
\text { draindown or } \\
\text { overfill }\end{array}$ & $\begin{array}{c}\text { Bound by DBE, } \\
\text { draindown, or } \\
\text { overfill }\end{array}$ & Reterse & Low & III \\
\hline Loss of Heint & N.C. & N.C. & Relerse & N.C. & N.C. \\
\hline Toxic Ges Rein & N.C. & N.C. & Toxic Ges & N.C. & N.C. \\
\hline Purifieation Even: & $2.0 \times 10^{-4}$ & $2.0 \times 10^{-4}$ & Releare & Low & III \\
\hline Corrosion & 1.0 & N.C. & Release & N.C. & N.C. \\
\hline Cask Drop & $3.0 \times 10^{-2}$ & $3.0 \times 10^{-2}$ & Release & Low & III \\
\hline
\end{tabular}

N.C. - not crodible

N.I. - negligible impact

See Table I for Soenario Class Definitions. 
TABLE 2-1 Process Systems that will be Laid Up While K-Reactor is in Cold Standby

\section{PROCESS WATER SYSTEMS}

Reactor Tank and associated piping

$\therefore$ Process Water Heat Exchangers

Moderator Recovery System

Binghan Pumps

Process Water Allis Chalmers (AC)MDirect Current (DC) Motors

Septifoil System

Expansion Joints

Reactor Overflow and Moderator Leak Collection Tanks and Lines

214 Tank and Associated Pump

208 Tank and Associated Pump

208-1 Tank and Associated Pump

Seal Head Tank

1380 Tank in Far Motor Room

Pleaum Skirt Leak Collection Chamber

Cycloxe Separator Seal Loop (Valve 70B)

Reactor Overflow Seal Leg Line PW 75

Line PW 78 (3" Line Between 214 and 208 Tanks)

Blanket Gas Room Seal Legs

Instrumentation

Purification Systern

Helium System

Annular Cavity

COOLING WATER SYSTEM (CWS) AND WATER REMOVAL SYSTEM (WRS)

Isolation of CW-1 and CW-2 headers from the 186-K Basin

Isolation of CW-39 from the 186-K Basin

Isolation of CW-50 and CW-51 from RW-1

PW Heat Exchangers (CWS Side Only)

Isolation of the Emergency Pump Room from the Disassembly Basin

Isolation of the Cooling Tower from K-Reactor Water Supplies

Water Removal Symem Sump Pumps (216 and 206.1 to remiain functional)

Confinemeor Hint Removal System

\section{SUPPLEMIANTARY SAFETY SYSTEM (SSS)}

SSS System

Removal of Explosive Valve Primers

$25 \mathrm{lb}$ and $300 \mathrm{lb}$ Nitrogen Systems 
TABLE 2-1 Process Systems that will be Laid Up While K-Reactor is in Cold Standby (Cont.)

EMERGENCY COOLING SYSTEM (ECS)

ECS System

\section{SHIELD SYSTEM}

Shield System

\section{INSTRUMENT AND CONTROL SYSTEM}

Scram System

Traveling Wire Flux Monitor (TWFM)

Axial Power Monitoring (APM) System

The following electronies associated with the APM rods will be denergized:

Axinl Power Iodicator (API) - Brown Recorder

Roof Top Ratio (RTR) Recorders 1 \& 2

Power Density Monitor (PDM)

APM Rod Power Supply

RTR and API Chassis

Relay Chassis

External Fission Counters (EFCs)

Log N-Period Monitors

High Level Flux Monitors (HIFM)

Internal Fission Counters (IFCs)

A spare Internal Fission Counter System rack has been installed to provide a second channel of IFC monitoring during charge and discharge operations. This rack will remain in place and the electronics will be decenergized. The Process Room portable components listed below will be identified and stored as determinod by RC\&HP and Electrical and Instrument (E\&I) departments:

Pre-amplifiers and cables

Calibration source and storage drum

\section{Calibration drum}

Level Aod Difierentivl Gatvenomerer (Nuclear Console)

Safety Related AC (SRAC) System (120 VAC Instrument Panels)

Laad Shodding Symien

Vibration and Aroutical Monitoring System (VAMS) - Loose Parts Monitoring System (LPMS)

Control Rod Guide Tube Level Monitos Temporary-Modification 92-020 ·

Closed Circuit Television System (CCTV)

Control Rod Drive System (CRDS)

A\&B Auxiliary Recorders/Reactor Tank Temperaure Monitor

Essential Equipment Monitoring (EEM)

Automatic Incident Action/Manual Incident Action (ALAMIA) 
TABLE 2-1 Process Systems that will be Laid Up While K-Reactor is in Cold Standby (Cont.)

\section{ENVIRONMENTAL/HABITABILITYMONITORING .}

Fuel Failure Monitors

Low Energy Gamma Monitor

10 Minute Delay

Fuel Failure Blanket Gas Analyzer

Blanket Gas Room Monitor

Stack Tritium Monitors (STM)

Total Stack Activity Monitor

Noble Gas Monitors

Cooling Water Gamma Monitor System

The following containment monitors will be decnergized:

Filter Breakthrough

Moderator Activity

Reactor Plenum Skirt

Building 105-K Floodwater

Drain to Building 105-K

Contaminated Water Storage Tank

Process Room Drain

Cooling Water Gamma Monitors

Reactor Nozzle Leak Detection

Shield Water Activity

Overflow Tank Room

Tritium Effluent Water Monitoring System

\section{PROCESS COMPUTER}

Safety Ard Control Computer Sofware Lay-Up

The master copy of the Safty Computer punched paper tape will be stored in Document Control.

\section{Hardware Lay-Up}

The Srexy and Control Computers, peripherals (including Diagmosis of Multiple Alarms System (DMA), and associnted fire suppression systems in $\mathbf{K}$ and L-Reactors will be deenergized. Computer components currently installed will remain in place with normal Central Control Room (CCR) and Computer Room babitability ventilation on line. The Safety Computer Uninterruptible Power Supply (UPS) batteries will be removed and discardod. Mercury-wetted relays will be left in place until the status is changed from Cold Standby to Cold Shutdown. 
TABLE 2-1 Brocess Systems that will be Laid Up While K-Reactor is in Cold Standby (Cont.)

The Safety Computer (Data west) Test Stand, Breakout Box (used for test signal inputs), and Automatic Backup Shutdown System (ABS) Tert Box will be stored by Dipjtal Controls and Systems Department. Magnetic tape will not be stored on the Control Computer drive $L$. :.

\section{VENTILATTON SYSTEMS}

Airbome Activity Confinement System (AACS)

902 Fans $(A, B, C)$

909 Fans (A,B,E,F,G,H,L,M)

9L1A Fan

$911 B$ Fans

1230B Fan

Filter Compartments $(4,5,6,6$, and spare $)$

Assembly Area Ventilation

$901.01 \mathrm{Fan}$

901.02 Fan

901.06 Fan

Disassembly Area Ventilation

919.01 Fan

Building 108 Ventilation System

901 Fan

907 Fan

$906 \mathrm{Fan}$

908 Fan

Emergency Breathing Air Compressor

Miscellaneous Ventilation Systern

209.07A Control computer room exhaust

Craxe Control room exhaust

904C Far Side Pipe tunnel supply

\section{VENTILATION SYSTEMS (cont'd)}

904.1 Emargency pump room unit beater

+15-foot-elevation Remole Monitoring and Control System (REMACS) computer room AC unit

+34-foot-elevation REMACS computer room AV unit

$915 \quad-20$-foot-elevation level corridor beat diffuser

917A +15-foot-levation level corridor unit heater

917B +15-foot-elevation level corridor unit beater 
TABLE 2-1 Process Systems that will be Laid. Up While K-Reactor is in Cold Standby (Cont.)

$\begin{array}{ll}936 & \text { 0-foot-elevation personnel wing exhaust } \\ 938 & \text {-20-foot-elevation near side exhaust } \\ 939 & \text { Near Side pipe tunnel supply } \\ 945.02 & \text { A motor package supply } \\ 952 & \text { Transducer room AVC unit }\end{array}$

\section{COMPRESSED AIR SYSTEM .}

Building 191-K Standby Air Compressors

903 Fan K Damper Air Compressors

\section{PROCESS ROOM SPRAY SYSTEM}

System will be drained and the pump motor deenergized.

\section{ELECTRICAL SYSTEM}

Building 107B-K Emergency Diesel Generator Set (EDG)-

Rexctor Process Room Exhaust Fan Emergency Diesel Generator Sets (EG Sets)- Booster Pump Diesel Generator

General Motors Emergency Diesel Generator Sets \#1 and \#2

Process Water Diesel Generators (PWDG)-

Rod Equipment Room

Batteries

The following is a list of batteries to be removed.

107B-K Emergency diesel generators

Booster Pump

Rod Equipment Room Batteries

IR Uninterruptible Power Supply

Negative Pulse

Floating Emergency
Emergency Generator Sets for 903 fans

Building 108-1K and 108-2K Batteries

125 V Station (108-2K only)

125 V Starting

32 V Starting

Cooling Tower

\section{Central Control Room Batteries}

Essential Equipment Monitor Program Controller

Remote Monitoring and Control System (K-Reactor Only)

Safety Computer Uninterruptible Power Supply

Supplementary Safety System (Seismic/Explosive Valve)

Automatic Incident Action (6V/28V)

Galvanometer (3)

Reactor Tank Temperature Monitor (except on -40-foot-elevation and in the CCR) 
TABLE 2-1 Process Systems that will be Laid Up While K-Reactor is in Cold Standby (Coni.)

\section{ASSEMBLY AREA}

Total Flow Station

Pure Steam Reboiler

Deionized (DI) Water Supply

Presentation Point

Tipping Table

Stacking Machine

\section{COOLING TOWER}

Tower Basin and Lines

Building 153-1K Electrical Control Room (ECR)/nstrument Control Room (ICR)

The ECRICR Building Heating, Ventilating and Air Conditioning (HVAC) system will be reduced to the equipment needed to preserve the building electrical and fire protection systems equipment.

Building 190-K electrical feed to valve 6003 (blending) and 6013 (blowdown) will be taken out of service

DDACS process controller units at the ECRICR and Building 105- $\mathrm{K}$ will be shut down.

Building 105-K Micro Multiloop Controllers, UPS, Battery Charger, and Batteries will be taken off-line and the electrical system locked out from MCC 12M in Disassembly Area

K-018 Outfall and Diverter Area

Diversion valve 6008-1 will be closed and electrically locked out at its disconnect to prevent water from being diverted to the cooling tower.

The UPS and flow transmitters will be taken out of service. 
DOE Orders and Open CSAs Relevant to K-Reactor in Cold Standby

\begin{tabular}{|c|c|c|c|c|}
\hline $\begin{array}{l}\text { DOE } \\
\text { Jrder }\end{array}$ & Order Dexcription & $\begin{array}{c}\text { CSA or } \\
\text { Implementation } \\
\text { Plan }\end{array}$ & Noncompliance & Compensatory Measures \\
\hline
\end{tabular}
10.4
Environmental
CSA-37
Protection, Safety, and Heallh
Protoction
Slandards
Radiation protection instrumentation test capability is not in compliance.

0.7A Fire Protection

STCS-93-009

CSA-25
A new instrument calibration facility is plans be constructod.
Minor omissions in WSRC-2Q Fire Protection Program Manual, in particular the requirements for a graded Fire Hazards Amalysis and a specific requirement for sprinklers in structures over 5000 sq. $\mathrm{f}$.

K-Reactor: Redundant fire protection safety class oquipment not provided. Lack of occupant life safety items-rated stairs, multipte exits, etc., lack of automatic fire suppression systems, redundant fire proloction system, liquid nun-off control in the 107- $A$ diesel dike, floor drains and storm drains, fire (contimued)
The manual will be revised to include the sta requirements.

Continuation of monthly fire inspections per 4.1, DMP 4.05, administrative controls to ves Reactor ocaupancy is less than 100 persons, continuation of egress training and improven in the accountability oystems already in place

$10.2-9$ 
DOE Orders and Open CSAs Relevant to K-Reactor in Cold Standby (continued)

\begin{tabular}{|c|c|c|c|}
\hline $\begin{array}{l}\text { JE } \\
\text { der }\end{array}$ & Order Description & $\begin{array}{c}\text { CSA or } \\
\text { Implementation } \\
\text { Plan }\end{array}$ & Noncompliance \\
\hline ) & & $\operatorname{CSA}-25$ (cont.) & 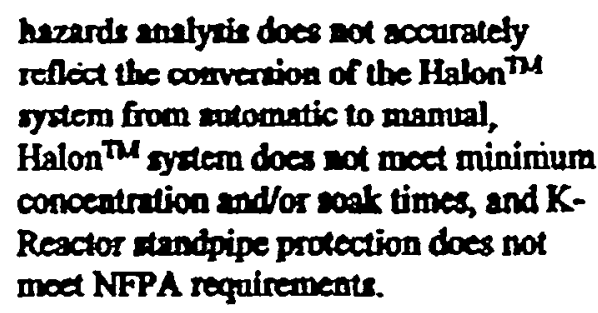 \\
\hline
\end{tabular}

8A Occupational $\cdot \operatorname{CSA}-93-028$ Medical Program

$\operatorname{CS} \Lambda-93-036$
Lack of EKG for emptoyecs who were under 30 years of age before 1991.

Lack of medical workplace visits, consistent company level procodures, and job task analyses.
Complete EKG for all employees under 30.

Develop or upgrade WSRC procedures for physician visits, medical examinations, and jok tast analyses. 
I-1 DOE Orders and Open CSAs Retevant to K-Reactor in Cold Staadby (continued)

\begin{tabular}{|c|c|c|c|c|}
\hline $\begin{array}{l}\text { DOE } \\
\text { Order }\end{array}$ & Order Description & $\begin{array}{c}\text { CSA or } \\
\text { Implementation } \\
\text { Plan }\end{array}$ & Noncompliance & Compensaloty Measures \\
\hline
\end{tabular}

5480.22 Technical Safety

Requirements

IP-93-002_Unider

DOE-HQ Review)

CSA-93-015 content has not been prepared for K-

Reactor.
5480.23 Nuclear Safety Analysis Reports
LP-93-003 Under DOE-HQ Revicw) CSA-93-016
The K-Reactor SAR has received DOE approval but does not comply with all of the scope and content provisions of the Order.
K-Reactor has a DOE approved Technica Spocifications (TS) [Rev. 16, 11/1/93] per order 5480.6. The K-Reactor IS prere de basod on the new standard TS forma for Westinghouse plants (MERTTS) which w as NUREG-1431. The current K-Reactor the intent of DOE Order 5880.22 , but doe comply with all the content and format pr TSRs will be developed.

K-Reactor has a DOE approved SAR (DO approval received 11/8/91). This B1O con Cold Standby is scheduled to be submittex No definite schodule for a consolidated 54 SAR is plannod unlil scope and funding a determined. This SAR activity for K-Rea presently unfunded.

$10.2-11$ 
1-1 DOE Orders and Open CSAs Reterant to K-Reactor in Cold Standty (continued)

\begin{tabular}{|c|c|c|c|c|}
\hline $\begin{array}{l}\text { DOE } \\
\text { Order }\end{array}$ & Order Description & $\begin{array}{c}\text { CSA or } \\
\text { Implementation } \\
\text { Plan }\end{array}$ & Noncompliance & Compensatory Measures \\
\hline
\end{tabular}

5480.24 Criticality Safdy IP-93-004 \$36 The doubte contingency basis for criticality safety is not documented.

IP-93-004 \$43 Audibility tests have nos boen performed on reactor area NIMs.

Although the Order is not yet in force, since the applicable standards have nol yet been issued, WSRC current practioes are not in full compliance.
The Reactors Nuclear Criticality Safety N schedulad to be revised.

The Assembly Area NIM bell audibility u expected to be sehoduled and performed.

For new Systerns, Strcukures, and Compo (SSCs), existing site management policie procedures will adequately ensure full $\infty$ The affected Engineering Slandards Man be revised as nocessary 6 months after the date of the last applicable standard refere the Order. compliance, WSRC is aol currently in full

Facilities

5482. IB

Environment,

Safety, and Health Appraisal Program
While there are no major arcas of nonprogrammatic compliance.

CSA-93-022

CSA-93-080

Twelve specific factors in paragraph 10 for environment safety and health appraisals should be addressed.
WSRC Manuals 6E, "Startup and Restan 12Q, "Operational Readiness Review Ma SCD-4, "Operational Readiness Function Requirements," will be reviewed and revi implement spocific Order wording.

WSRC will conduct a sitc-wide assessme Order 5482.1B including paragraph 10.

$10.2-12$ 
I-1 DOE Orders and Open CSAs Relevant to K-Reactor in Cotd Standby (continued)

\begin{tabular}{|c|c|c|c|c|}
\hline $\begin{array}{l}\text { DOR } \\
\text { Order }\end{array}$ & Order Descriplion & $\begin{array}{c}\text { CSA or } \\
\text { Implementation } \\
\text { Plan } \\
\end{array}$ & Noncompliance & Compensatory Measures \\
\hline $5483.1 \AA$ & $\begin{array}{l}\text { Occupational } \\
\text { Safety and Health } \\
\text { Program for DOE } \\
\text { Contractor } \\
\text { Employees at } \\
\text { Government- } \\
\text { Owned Contractor- } \\
\text { Operated Facilities }\end{array}$ & STCS-93-011 & $\begin{array}{l}\text { Formal policies and procedures do not } \\
\text { fully address actions required to } \\
\text { implernent and control safety and } \\
\text { occupational health activities. }\end{array}$ & $\begin{array}{l}\text { WSRC industrial safety procedures (Mam } \\
\text { will be upgraded to comply with the requi }\end{array}$ \\
\hline $5500.1 \mathrm{~B}$ & $\begin{array}{l}\text { Emergency } \\
\text { Management } \\
\text { System }\end{array}$ & STCS-93-016 & $\begin{array}{l}\text { The radiological assistance program } \\
\text { (RAP) plan and procodures are in draft } \\
\text { form and are not yed implemented. }\end{array}$ & $\begin{array}{l}\text { The RAP plan and procedures will be apl } \\
\text { and implemented. }\end{array}$ \\
\hline $5500.2 B$ & $\begin{array}{l}\text { Emergency } \\
\text { Categorization, } \\
\text { Classes, } \\
\text { Notification and } \\
\text { Reporting } \\
\text { Requirements }\end{array}$ & CSA-93-072 & $\begin{array}{l}\text { Some systems required for the SRS } \\
\text { Emergency Operation Center are not yet } \\
\text { in place. }\end{array}$ & $\begin{array}{l}\text { The project to complete the communicat } \\
\text { upgrade to the SRS Emergency Respons }\end{array}$ \\
\hline $5500.7 B$ & $\begin{array}{l}\text { Emergency } \\
\text { Operating Records } \\
\text { Protection Program }\end{array}$ & STCS-93-015 & $\begin{array}{l}\text { Training for the Operating Records } \\
\text { Program Office has not been completed. }\end{array}$ & The training will be completed. \\
\hline
\end{tabular}

$10.2-13$ 
.1-1 DOE Orders and Open CSAs Relevant to K-Reactor in Cold Standby (continued)

\begin{tabular}{|c|c|c|c|c|}
\hline $\begin{array}{l}\text { DOE } \\
\text { Order }\end{array}$ & Order Description & $\begin{array}{c}\text { CSA or } \\
\text { Implementation } \\
\text { Plan } \\
\end{array}$ & Noncompliance & Compensatory Measures \\
\hline 5500.10 & $\begin{array}{l}\text { Emergency } \\
\text { Readiness } \\
\text { Assurance } \\
\text { Program }\end{array}$ & CSA-93-025 & $\begin{array}{l}\text { The site emergency management } \\
\text { department did not receive guidance from } \\
\text { DOE on appraisals based on specific } \\
\text { standards and criteria. }\end{array}$ & $\begin{array}{l}\text { A division level procodure for emergenc] } \\
\text { management self assessment will be devi }\end{array}$ \\
\hline $5633.3 \AA$ & $\begin{array}{l}\text { Control and } \\
\text { Accountability of } \\
\text { Nuclear Materials }\end{array}$ & IP-034 & $\begin{array}{l}\text { Lack of documentation of cmergency } \\
\text { response actions for Material Control and } \\
\text { Accountability (MC\&A). }\end{array}$ & $\begin{array}{l}\text { Write an emergency response procodure } \\
\text { anomalous conditions and update DPSO } \\
\text { (chapter } 3-3 \text { and } 3-4 \text { ) by the end of } 1994\end{array}$ \\
\hline $5700.6 \mathrm{C}$ & Quality Assurance & $\begin{array}{l}5700.6 \mathrm{C} \\
\text { Implementation } \\
\text { Plan }\end{array}$ & $\begin{array}{l}\text { While the current WSRC QA program } \\
\text { addresses most of the Order requirements, } \\
\text { a QA plan upgrade to fully meet the } \\
\text { requirements has been proposed. }\end{array}$ & $\begin{array}{l}\text { DOE has approved the QA program } \\
\text { implementation plan. The upgrade calls } \\
\text { improvements in the program, personnel } \\
\text { and qualification, quality improvement, } \\
\text { processes, inspection and acoeptance tes } \\
\text { managemeat assessment, and independe } \\
\text { assessment. WSRC will be in full compl }\end{array}$ \\
\hline
\end{tabular}

10.2-14 
1-1 DOE Orders and Open CSAs Relevant to K-Reactor in Cold Standby (continued)

\begin{tabular}{|c|c|c|c|c|}
\hline $\begin{array}{l}\text { DOE } \\
\text { Order }\end{array}$ & Order Description & $\begin{array}{c}\text { CSA or } \\
\text { Implementation } \\
\text { Plan }\end{array}$ & Noncompliance & Compensatory Measures \\
\hline $5820.2 A$ & $\begin{array}{l}\text { Radioactive Waste } \\
\text { Management }\end{array}$ & CSA-93-067,R6 & $\begin{array}{l}\text { SRS production reactors do not fully } \\
\text { comply with the waste } \\
\text { characterization/manifesting requirements } \\
\text { for noncompactible and mixed waste and } \\
\text { compactible mixed waste. Complete LLW } \\
\text { certification assessments are need for } \\
\text { waste generator in SRS production } \\
\text { reactors. }\end{array}$ & $\begin{array}{l}\text { WSRC will be in full compliance with wa } \\
\text { characterization/manifesting requirement } \\
\text { have completed LLW centification assessr }\end{array}$ \\
\hline
\end{tabular}

$10.2-15$

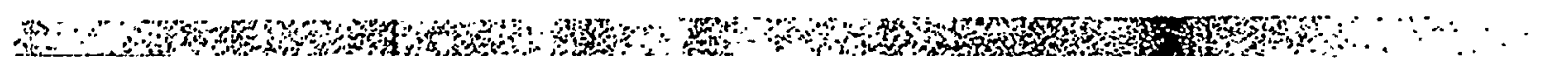


.1-2 DOE Orders, Open CSAs, and Exemption Requests Relevant to L- and P-Reactor Disassembly Basins

\begin{tabular}{|c|c|c|c|c|}
\hline $\begin{array}{l}\text { DOE } \\
\text { Order }\end{array}$ & Order Description & $\begin{array}{c}\text { CSA or } \\
\text { Implementation } \\
\text { Plan }\end{array}$ & Noncompliance & Compensatory Measures \\
\hline 5480.4 & $\begin{array}{l}\text { Environmental } \\
\text { Protection, Safety, } \\
\text { and Health } \\
\text { Protection } \\
\text { Standards. }\end{array}$ & CSA-37 & $\begin{array}{l}\text { Radiation protection instrumentation test } \\
\text { capability is not in compliance. }\end{array}$ & A new instrument calibration facility \\
\hline $5480.7 \mathrm{~A}$ & $\begin{array}{c}\text { Fire Protoction } \\
-\end{array}$ & $\begin{array}{l}\text { CSA-93-083 } \\
\text { CSA-93-084 }\end{array}$ & 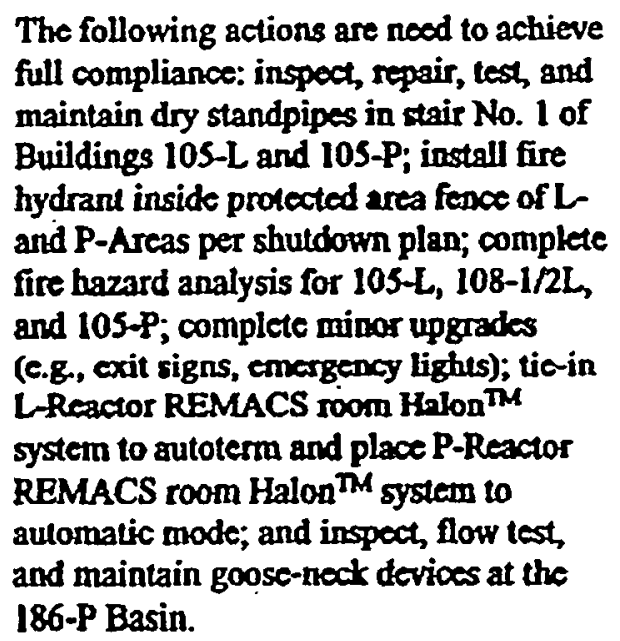 & WSRC will achieve full compliance. \\
\hline
\end{tabular}

$10.2-16$

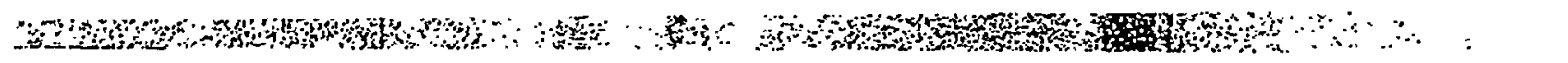


3.1-2 DOE Orders, Open CSAs, and Exemption Requests Relevant to L-and P-Reactor Disassembly Basins (continued)

\begin{tabular}{|c|c|c|c|c|}
\hline $\begin{array}{l}\text { DOE } \\
\text { Order }\end{array}$ & Order Description & $\begin{array}{c}\text { CSA or } \\
\text { Implementation } \\
\text { Plan } \\
\end{array}$ & Noncompliance & Compensatory Measures \\
\hline \multirow[t]{2}{*}{$5480.8 A$} & $\begin{array}{l}\text { Occupational } \\
\text { Medical Program }\end{array}$ & CSA-93-028 & $\begin{array}{l}\text { Lack of EKG for employees who were } \\
\text { under } 30 \text { years of age before } 1991 \text {. }\end{array}$ & Comptete EKG for all employees under: \\
\hline & & CSA-93-036 & $\begin{array}{l}\text { Lack of medical workplace visits, } \\
\text { consistent company level procedures, and } \\
\text { job task analyses. }\end{array}$ & $\begin{array}{l}\text { Develop or upgrade WSRC procedures f } \\
\text { physician visits, medical examinations, } \\
\text { task analyses. }\end{array}$ \\
\hline 5480.22 & $\begin{array}{l}\text { Technical Safety } \\
\text { Requirements }\end{array}$ & $\begin{array}{l}\text { IP-93-002 } \\
\text { CSA-93-015 }\end{array}$ & $\begin{array}{l}\text { TSRs which meet the } 5480.22 \text { format and } \\
\text { content have not been prepared for } L \text { - and } \\
\text { P-Reactors. }\end{array}$ & $\begin{array}{l}\text { Exemptions to the requirements of DOE } \\
5480.22 \text { for } L-\text { and P-Reactors have bee } \\
\text { to DOE(WSRC-EX- } 5480.22-1 \text { ). The ex } \\
\text { requests are based on the controls curret } \\
\text { place, the bounding analyses provided it } \\
\text { for K-Reactor in Cold Standoy, and the } \\
\text { decontamination and decommissioning } \\
\text { P-Reactors. }\end{array}$ \\
\hline 5480.23 & $\begin{array}{l}\text { Nuclear Safety } \\
\text { Analysis Reports }\end{array}$ & $\begin{array}{l}\text { IP-93-003 } \\
\text { CSA-93-016 }\end{array}$ & $\begin{array}{l}\text { SARs which moet the } 5480.23 \text { format and } \\
\text { content have not been prepared for } L \text { - and } \\
\text { P-Reactors. }\end{array}$ & $\begin{array}{l}\text { Exemptions to the requirements of DOE } \\
5480.23 \text { for L- and P-Reactors have bee } \\
\text { to DOE(WSRC-EX-5480.23-1). The ex } \\
\text { requests are basod on the controls curre! } \\
\text { place, the bounding anatyses provided in } \\
\text { for K-Reactor in Cold Standby, and the } \\
\text { decontamination and decommissioning } \\
\text { P-Reactors. }\end{array}$ \\
\hline
\end{tabular}

10.2-17 
1-2 DOE Orders, Open CSAs, and Exemption Requests Relevant to L- and P-Reactor Disassembly Basins (continued)

\begin{tabular}{|c|c|c|c|c|}
\hline $\begin{array}{l}\text { DOE } \\
\text { Order }\end{array}$ & Order Description & $\begin{array}{c}\text { CSA or } \\
\text { Implementation } \\
\text { Plan }\end{array}$ & Noncompliance & Comperisatory Measures \\
\hline 5480.24 & Criticality Safety & IP-93-0.04 & $\begin{array}{l}\text { The double contingency basis for } \\
\text { criticality safety is not documented. }\end{array}$ & $\begin{array}{l}\text { The Reactors Nuclear Criticality Safety } \\
\text { will be revised accordingly. }\end{array}$ \\
\hline 5480.28 & $\begin{array}{l}\text { Natural } \\
\text { Phenomena } \\
\text { Hazards Mitigation }\end{array}$ & IP-93-001 & $\begin{array}{l}\text { Although the Order is not yet in force, } \\
\text { since the applicable standards have not yet } \\
\text { been issued, WSRC current practices are } \\
\text { not in full compliance. }\end{array}$ & $\begin{array}{l}\text { For new SSCs, existing site management } \\
\text { and procedures will adequately ensure ful } \\
\text { compliance. The affected Engincering SI } \\
\text { Manual will be revised as necessary } 6 \text { mo } \\
\text { the issuance date of Une last applicable sts } \\
\text { referenced in the Order. }\end{array}$ \\
\hline 5480.31 & $\begin{array}{l}\text { Startup and Restant } \\
\text { of Nuclear } \\
\text { Facilities }\end{array}$ & CSA-93-080 & $\begin{array}{l}\text { While there are no major areas of non- } \\
\text { compliance, WSRC is not currently in full } \\
\text { programmatic compliance. }\end{array}$ & $\begin{array}{l}\text { WSRC Manuals 6E, "Startup and Restar } \\
\text { 12Q, "Operational Readiness Review Ma } \\
\text { SCD-4, "Operational Readiness Function } \\
\text { Requirements," will be reviewed and revi } \\
\text { implement specific Order wording. }\end{array}$ \\
\hline 5482.18 & $\begin{array}{l}\text { Environment, } \\
\text { Safety, and Health } \\
\text { Appraisal Program }\end{array}$ & CSA-93-022 & $\begin{array}{l}\text { Twelve specific factors in paragraph } 10 \\
\text { for environment safety and health } \\
\text { appraisals should be addressed. }\end{array}$ & $\begin{array}{l}\text { WSRC will conduct a site-wide assessme } \\
\text { Order } 5482.18 \text { including paragraph } 10 \text {. }\end{array}$ \\
\hline
\end{tabular}

$10.2-18$ 
.1-2 DOE Orders, Open CSAs, and Exemption Requests Relevant to L- and P-Reactor Disassembly Basins (continued)

\begin{tabular}{|c|c|c|c|c|}
\hline $\begin{array}{l}\text { DOE } \\
\text { Order }\end{array}$ & Order Description & $\begin{array}{c}\text { CSA or } \\
\text { Implementation } \\
\text { Plan. }\end{array}$ & Noncompliance & Compensatory Measures \\
\hline $5483.1 \mathrm{~A}$ & $\begin{array}{l}\text { Occupational } \\
\text { Safety and Health } \\
\text { Program for DOE } \\
\text { Contractor } \\
\text { Employees at } \\
\text { Government- } \\
\text { Orned Contractor- } \\
\text { Operated Facilitics }\end{array}$ & STCS-93-011 & $\begin{array}{l}\text { Formal policies and procedures do not } \\
\text { filly address actions roquired to } \\
\text { implement and control safety and } \\
\text { occupational bealth activities. }\end{array}$ & $\begin{array}{l}\text { WSRC industrial safety procedures Man } \\
\text { will be upgraded to comply with the requ }\end{array}$ \\
\hline $5500.1 \mathrm{~B}$ & $\begin{array}{l}\text { Emergency } \\
\text { Management } \\
\text { System }\end{array}$ & STCS-93-016 & $\begin{array}{l}\text { The radiological assistance program } \\
\text { (RAP) plan and procedures are in draft } \\
\text { form and are not yet implemented. }\end{array}$ & $\begin{array}{l}\text { The RAP plan and procedures will be apI } \\
\text { and implemented. }\end{array}$ \\
\hline $5500.2 B$ & $\begin{array}{l}\text { Emergency } \\
\text { Categorization, } \\
\text { Classes, } \\
\text { Notification and } \\
\text { Reporting } \\
\text { Requirements }\end{array}$ & CSA-93-072 & $\begin{array}{l}\text { Some systems required for the SRS } \\
\text { Emergency Operation Center are not yet } \\
\text { in place. }\end{array}$ & $\begin{array}{l}\text { The project to complete the communicati } \\
\text { upgrade to the SRS Emergency Response } \\
\text { will be completed. }\end{array}$ \\
\hline
\end{tabular}


1-2 DOE Orders, Open CSAs, and Exemption Requests Relevanl to L- and P-Reactor Disassembly Basins (continued)

\begin{tabular}{|c|c|c|c|c|}
\hline $\begin{array}{l}\text { DOE } \\
\text { Order }\end{array}$ & Order Description & $\begin{array}{c}\text { CSA or } \\
\text { Implementation } \\
\text { Plan } \\
\end{array}$ & Noncompliance & Compensatory Measures \\
\hline $5500.7 \mathrm{~B}$ & $\begin{array}{l}\text { Emergency } \\
\text { Operating Reconds } \\
\text { Protection Program }\end{array}$ & STCS-93-015 & $\begin{array}{l}\text { Training for the operating records } \\
\text { program office has not been complated. }\end{array}$ & The training will be completed. \\
\hline 5500.10 & $\begin{array}{l}\text { Emergency } \\
\text { Readiness } \\
\text { Assurance } \\
\text { Program }\end{array}$ & CSA-93-025 & $\begin{array}{l}\text { The site emergency management } \\
\text { Department did not receive guidance from } \\
\text { DOE on appraisals based on specific } \\
\text { standands and criteris. }\end{array}$ & $\begin{array}{l}\text { A division level procodure for emergency } \\
\text { management self assessment will be devel }\end{array}$ \\
\hline $5633.3 \mathrm{~A}$ & $\begin{array}{l}\text { Control and } \\
\text { Accountability of } \\
\text { Nuclear Materials }\end{array}$ & IP-034 & $\begin{array}{l}\text { Lack of documentation of emergency } \\
\text { response actions for Material Control and } \\
\text { Accountability (MC\&A). }\end{array}$ & $\begin{array}{l}\text { Write an emergency response procodure } f \\
\text { anomalous conditions and update DPSOP } \\
\text { (chapler 3-3 and 3-4). }\end{array}$ \\
\hline $5700.6 \mathrm{C}$ & Quality Assurance & $\begin{array}{l}5700.6 \mathrm{C} \\
\text { Implementation } \\
\text { Plan }\end{array}$ & $\begin{array}{l}\text { While the aurrent WSRC QA program } \\
\text { addresses most of the Order requirements, } \\
\text { a QA plan upgrade to fully meet the } \\
\text { requirements has been proposed. }\end{array}$ & $\begin{array}{l}\text { DOE has approved the QA program } \\
\text { implementation plan. The upgrade calls f } \\
\text { improvements in the program, personnel } \\
\text { and qualification, quality improvement, } \\
\text { processes, inspection and acoptance testi } \\
\text { management assessmenl, and independen } \\
\text { assessment. WSRC will be in full compli }\end{array}$ \\
\hline
\end{tabular}

$10.2-20$ 
1-2 DOE Orders, Open CSAs, and Exemption Requests Relevant to L- and P-Reactor Disassembly Basins (continued)

\begin{tabular}{ccc}
\hline $\begin{array}{c}\text { DOE } \\
\text { Order }\end{array}$ & Order Description & $\begin{array}{c}\text { CSA or } \\
\text { Implementation } \\
\text { Plan }\end{array}$ \\
\hline i820.2A & $\begin{array}{l}\text { Radioactive Waste } \\
\text { Management }\end{array}$ & CSA-93-067,R6 \\
\hline
\end{tabular}

SRS production reactors do not fully comply with the waste characterization/manifesting roquirements for noncompactible and mixed waste and compactible mixed waste. Complete LLW certification assessments are nood for waste generalor in SRS production reactors.
WSRC will be in full compliance with was characterization/manifesting requirements complete LLW certification assessments.

\section{Compensatory Measures}

Noncompliance 
Table 8.3-1

Categorization Of Naturet Pheromens Events For K-Reactor In Cold Standby And L-And P-Reactor Disassembly Basins

\begin{tabular}{|c|c|c|c|c|c|}
\hline EVENT & $\begin{array}{l}\text { PITIATING } \\
\text { EVENT } \\
\text { FREQNR }\end{array}$ & $\begin{array}{l}\text { HAZARD } \\
\text { EVENT } \\
\text { FREQYR }\end{array}$ & JLAZARD & CONSEQ & $\begin{array}{l}\text { SCENARIO } \\
\text { CLASS }\end{array}$ \\
\hline Straight Winda Torado & N.C. & N.C. & Release & N.C. & N.C. \\
\hline $\begin{array}{l}\text { Straight Wind Stack } \\
\text { Failure (Wind > } 185 \mathrm{mph} \text { ) }\end{array}$ & $1.4 \times 10^{-6}$ & N.C. & Release & N.C. & N.C. \\
\hline Tomado Missiles & N.C. & N.C. & Release & N.C. & N.C. \\
\hline Floods & N.C. & N.C. & Release & N.C. & N.C. \\
\hline Earthquake (DBE) & $2.0 \times 10^{-4}$ & $\begin{array}{c}\text { Fig } 8.4-1 * 8.4 \\
2\end{array}$ & Release & Low & III \\
\hline Lightning & N.C. & N.C. & Releave & N.C. & N.C. \\
\hline Metearites & $2 \times 10^{-10}$ & N.C. & Release & N.C. & N.C. \\
\hline Freecing Temperature & $1.6 \times 10^{-1}$ & N.C. & Releave & N.C. & N.C. \\
\hline Snow and Ice & N.C. & N.C. & Relenve & N.C. & N.C. \\
\hline
\end{tabular}

N.C. - not credible

N.L - negligible impact

SCENARIO CLASS DEFINITIONS (RET. 8-20)

\section{Scenerie Class}

I - Major

I- Minjar

II - Surion

II - Surions

III - Merginal

III - Marginal

IV - Negligible

N.C. - Not Credible
Consequense

High

Medium

High

Medium

Medium

Low

Low

Not Credible
Erequericy

Above $10^{-4} / y x$

Above $10^{-2} / y t$

$10^{-4}$ to $10^{-6} / \mathrm{yr}$

$10^{-2}$ to $10^{-4} / y x$

$10^{-4}$ to $10^{-6} \mathrm{hr}$

Above $10^{-4} / y x$

$10^{-4}$ to $10^{-6} / \mathrm{yr}$

$<10^{-6}$ /yr 
Table 8.3-2

Eategorization Of Process Phenomena Events For K.Reactor In Cold Standby And L-And - P-Reactor Disassembly Basins

\begin{tabular}{|c|c|c|c|c|c|}
\hline EVENT & $\begin{array}{l}\text { NNTLATING } \\
\text { EVENT } \\
\text { FREQ/YR }\end{array}$ & $\begin{array}{l}\text { HAZARD } \\
\text { EVENT } \\
\text { EREQ/YR }\end{array}$ & GAZARD & CONSEQ & $\begin{array}{l}\text { SCENARIO } \\
\text { CLASS }\end{array}$ \\
\hline Disassembly Basin Draindown & Fig 8.4-1 \& -2 & Fig 8.4-1 \& -2 & Release, Shine & Low & III \\
\hline Disassembly Basin Overfill & Fig 8.4-1 \& -2 & Fig 8.4-1\&-2 & Release & Low & III \\
\hline Inadvertent Criticality & Fig 8.4-1 \& -2 & Fig 8.4-1\& -2 & Criticality & Low & III \\
\hline Criticality in Basin Sludge & N.C. & N.C. & Criticality & N.C. & N.C. \\
\hline Criticality in the Settler Tank & N.C. & N.C: & Criticality & N.C. & N.C. \\
\hline Criticality in the Sand Filters & N.C. & N.C. & Criticality & N.C. & N.C. \\
\hline Criticality in Deionizers & N.C. & N.C. & Criticality & N.C. & N.C. \\
\hline $\begin{array}{l}\text { Loss of Disassembly Basin } \\
\text { Cooling }\end{array}$ & 1.0 & 1.0 & $\begin{array}{c}\text { No adverse } \\
\text { consequence }\end{array}$ & $\begin{array}{l}\text { No adverse } \\
\text { consequence }\end{array}$ & $\begin{array}{l}\text { No adverse } \\
\text { consequence }\end{array}$ \\
\hline Hazardous Chemical Spill & N.I. & N.I. & $\begin{array}{l}\text { Chemical } \\
\text { Hazard }\end{array}$ & $\begin{array}{l}\text { No adverse } \\
\text { consequence }\end{array}$ & $\begin{array}{l}\text { No adverse } \\
\text { consequence }\end{array}$ \\
\hline Fire & $9.1 \times 10^{-4}$ & $9.1 \times 10^{-4}$ & Release & Low & III \\
\hline Explosion & $3.0 \times 10^{-3}$ & $3.0 \times 10^{-7}$ & Release & N.C. & N.C. \\
\hline Aircraft - Airplane & $4.8 \times 10^{-7}$ & N.C. & Release & N.C. & N.C. \\
\hline Aircraft - WSI helicopter & $<1.0 \times 10^{-6}$ & N.C. & Release & N.C. & N.C. \\
\hline Loss of Power & N.I. & N.I. & Release & N.I. & N.I. \\
\hline Loss of Ventilation & N.I. & N.I. & Release & N.I. & N.I. \\
\hline Internal Missiles & N.C. & N.C. & Release & N.C. & N.C. \\
\hline Loss of Confinement & $\begin{array}{l}\text { Bound by DBE, } \\
\text { draindown, or } \\
\text { overfill }\end{array}$ & $\begin{array}{c}\text { Bound by } \\
\text { DBE, } \\
\text { draindown, or } \\
\text { overfill }\end{array}$ & Release & Low & III \\
\hline Loss of Heatin: & N.C. & N.C. & Release & N.C. & N.C. \\
\hline Toxic Gas Relem & N.C. & N.C. & Toxic Gas & N.C. & N.C. \\
\hline Purification Events & $2.0 \times 10^{-4}$ & $2.0 \times 10^{-4}$ & Release & Low & III \\
\hline Corrosion & 1.0 & N.C. & Release & N.C. & N.C. \\
\hline Cask Drop & $3.0 \times 10^{-2}$ & $3.0 \times 10^{-2}$ & Release & Low & III \\
\hline
\end{tabular}

N.C. - not credible

N.L. - negligible impact

Sec Table 8.3-1 for Scenario Class Definitions. 
Table 8.3-3

- $\quad$ Individual Event Probabilities (Ref. 8-33)

\begin{tabular}{|c|c|}
\hline EVENT & Probability (lyr) \\
\hline \multicolumn{2}{|l|}{ MAKEUP NOT AVARLABLE } \\
\hline $\begin{array}{l}\text { Failure of Power Dept to establish standly well water pumps upon loss of primary } \\
\text { pumps }\end{array}$ & $2.6 \times 10^{-2}$ \\
\hline Well water pump $\$ 2$ or 3 discharge isolation valve fails to open & $9.2 \times 10^{-3}$ \\
\hline Well water pump $\$ 2$ or 3 hush line isolation valve fails to close & $9.2 \times 10^{-3}$ \\
\hline Well water pump $\# 2$ or 3 fails to start & $5.3 \times 10^{-3}$ \\
\hline Well water pump $* 2$ or 3 unavailable due to maintenance & $3.65 \times 10^{-3}$ \\
\hline Well water pump 2 or 3 discharge check valve fails to open & $3.40 \times 10^{-3}$ \\
\hline Common cause failure of filtered water makeup valves & $9.20 \times 10^{-4}$ \\
\hline Well water pumps $\$ 1,2$ or 3 fail to nun & $3.84 \times 10^{-4}$ \\
\hline Manually operated valve for filtered water makeup line \#1 or 2 fails & $9.20 \times 10^{-3}$ \\
\hline Well water reservoir FCV fails to remain open & $5.28 \times 10^{-5}$ \\
\hline Common cause: all filter water pumps fail to nun & $1.92 \times 10^{-5}$ \\
\hline Well water pump $\$ 2$ or 3 start fails to close & $1.00 \times 10^{-5}$ \\
\hline Filtered water pump \#! fails to run & $3.84 \times 10^{-4}$ \\
\hline Failure of Por Dept to est. stndby FW pump upon loss of primary pump & $2.60 \times 10^{-2}$ \\
\hline All Building 190 compressors fail to run & $3.00 \times 10^{-6}$ \\
\hline \multicolumn{2}{|l|}{ BASIN LEVA, RSTRUINTNTS FAIL } \\
\hline Common canes billure of low hevel alarm & $1.01 \times 10^{-3}$ \\
\hline Common cause failure of basin level indicalor low pressure switches & $4.23 \times 10^{-4}$ \\
\hline Common cause failure of basin level indicator very low pressure switches & $4.23 \times 10^{-4}$ \\
\hline
\end{tabular}


Table 8.34

Fiesile Material Inventories for K-, L-, and P-Reactor Disassembly Basins

\begin{tabular}{|c|c|c|c|c|}
\hline Radionuclide & $\begin{array}{c}\text { K-Reactor } \\
\text { Disassembly } \\
\text { Basin Mass } \\
\text { (grams) }\end{array}$ & $\begin{array}{c}\text { L-Reactor } \\
\text { Disassembly } \\
\text { Basin Mass } \\
\text { (grams) }\end{array}$ & $\begin{array}{c}\text { P-Reactor } \\
\text { Disassembly } \\
\text { Basin Mass } \\
\text { (grams) }\end{array}$ & $\begin{array}{c}\text { Subcritical } \\
\text { Mass Limit } \\
\text { (grams) }\end{array}$ \\
\hline U-235 & $3,159,000$ & $2,172,000$ & $1,584,000$ & 700 \\
\hline Pul-239 & 17,170 & $1,212,000$ & 9,050 & 450 \\
\hline
\end{tabular}

** ANSU/ANS-8.1-1983, "American National Standard for Nuclear Radionuclide Release Safety in Operation with Fissionable Materials Outside Reactors" 
Table 8.3-5

Fissile Tsotopes Present in the Sludge of K., L-, and P-Reactor Disassembly Basins

\begin{tabular}{|c|c|c|c|c|c|}
\hline Isotope & $\begin{array}{c}\text { K Basid } \\
\text { Mass (8) }\end{array}$ & $\begin{array}{c}\text { L Basin } \\
\text { Mass (g) }\end{array}$ & $\begin{array}{c}\text { P Busin } \\
\text { Mass (g) }\end{array}$ & $\begin{array}{c}\text { Subcritical Muss } \\
\text { Limit (grams) }\end{array}$ & $\begin{array}{c}\text { Reference } \\
\text { for Subcritical } \\
\text { Mass Limit }\end{array}$ \\
\hline U-233 & 0.7 & 1.6 & - & 500 & 8.13 \\
\hline$U-235$ & 906.9 & 125.5 & 179.7 & 700 & $8-13$ \\
\hline Pu-239 & 191.3 & 17.8 & 61.7 & 450 & $8-13$ \\
\hline Pu-241 & 3.8 & 0.3 & - & 200 & $8-48$ \\
\hline Am-242m & 3.3 & 0.6 & - & 13 & $8-48$ \\
\hline Cm-243 & 1.9 & 0.5 & - & 90 & $8-48$ \\
\hline
\end{tabular}




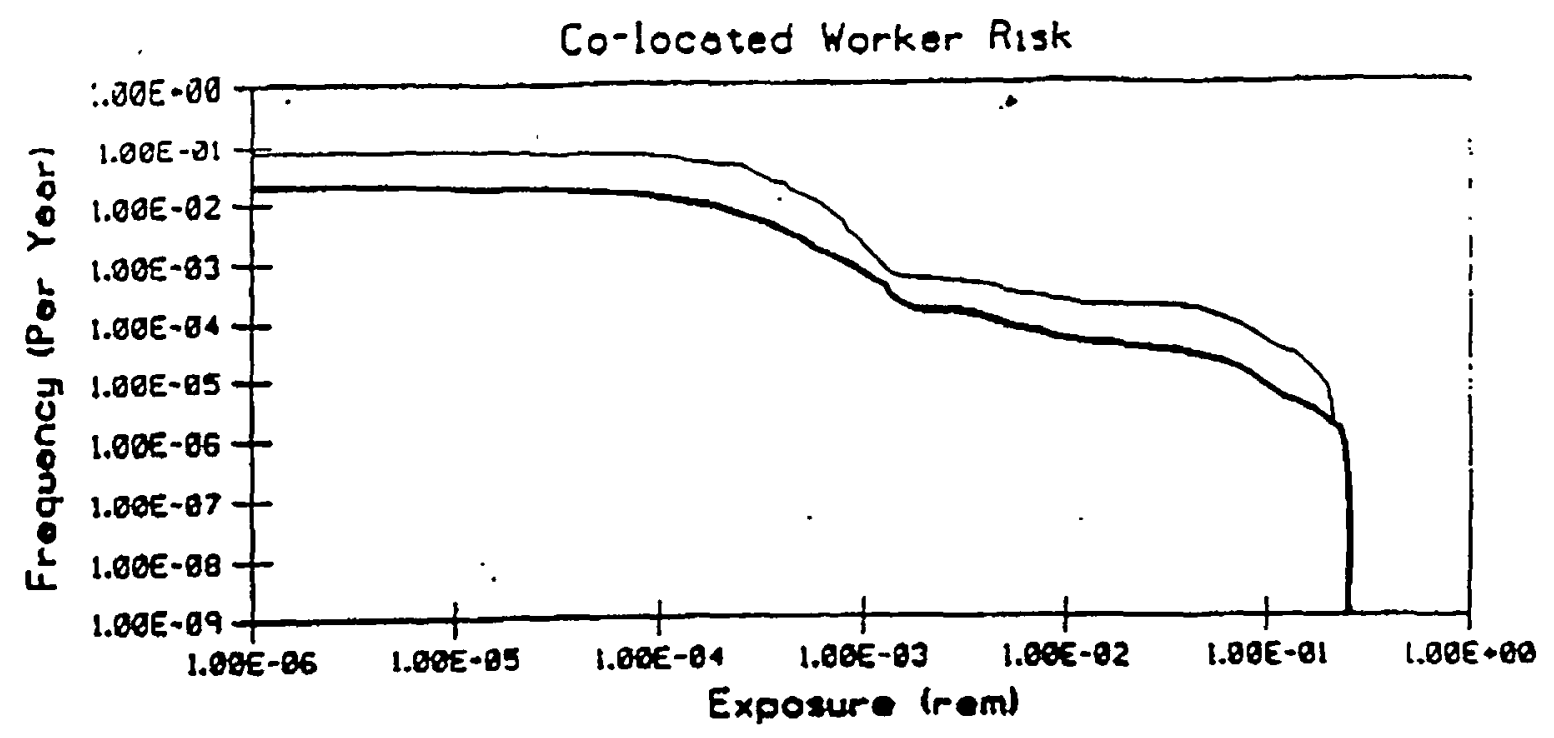

Meon Risk

95\% Confidance

Figure 1. Co-Located Worker Risk

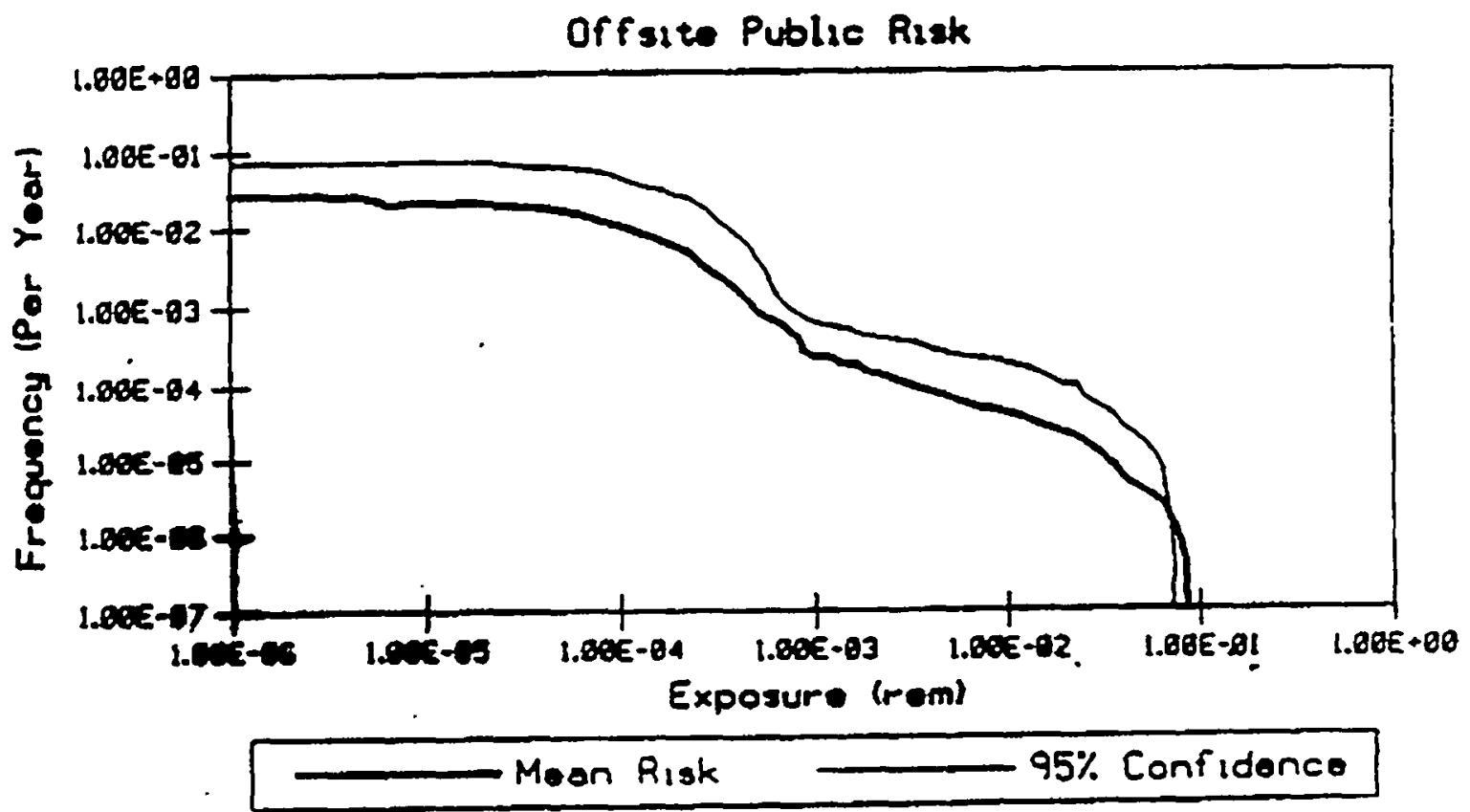

Figure 2. Offsite Public Risk 

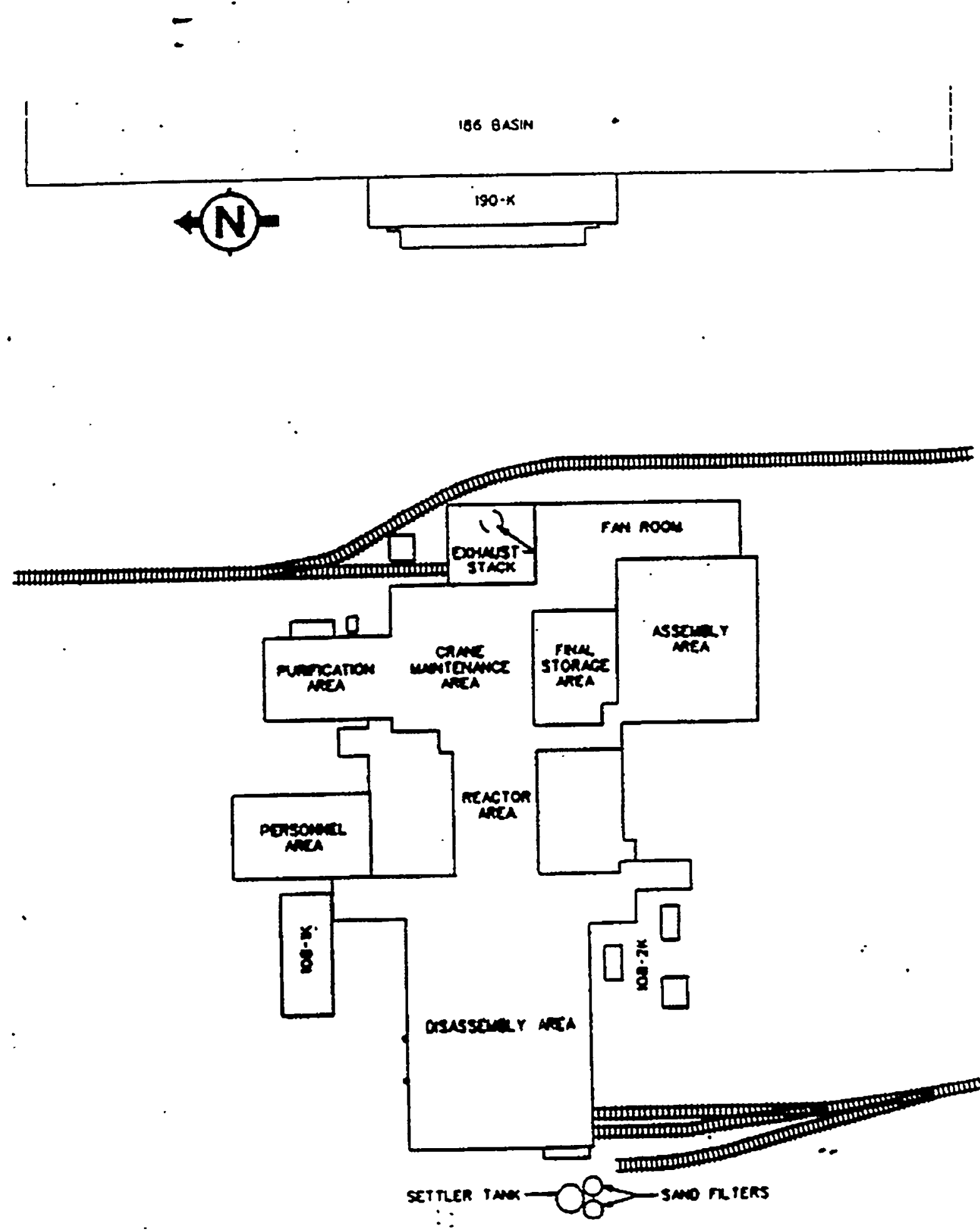

Figure 2.1

General Layout of Building 105.K 

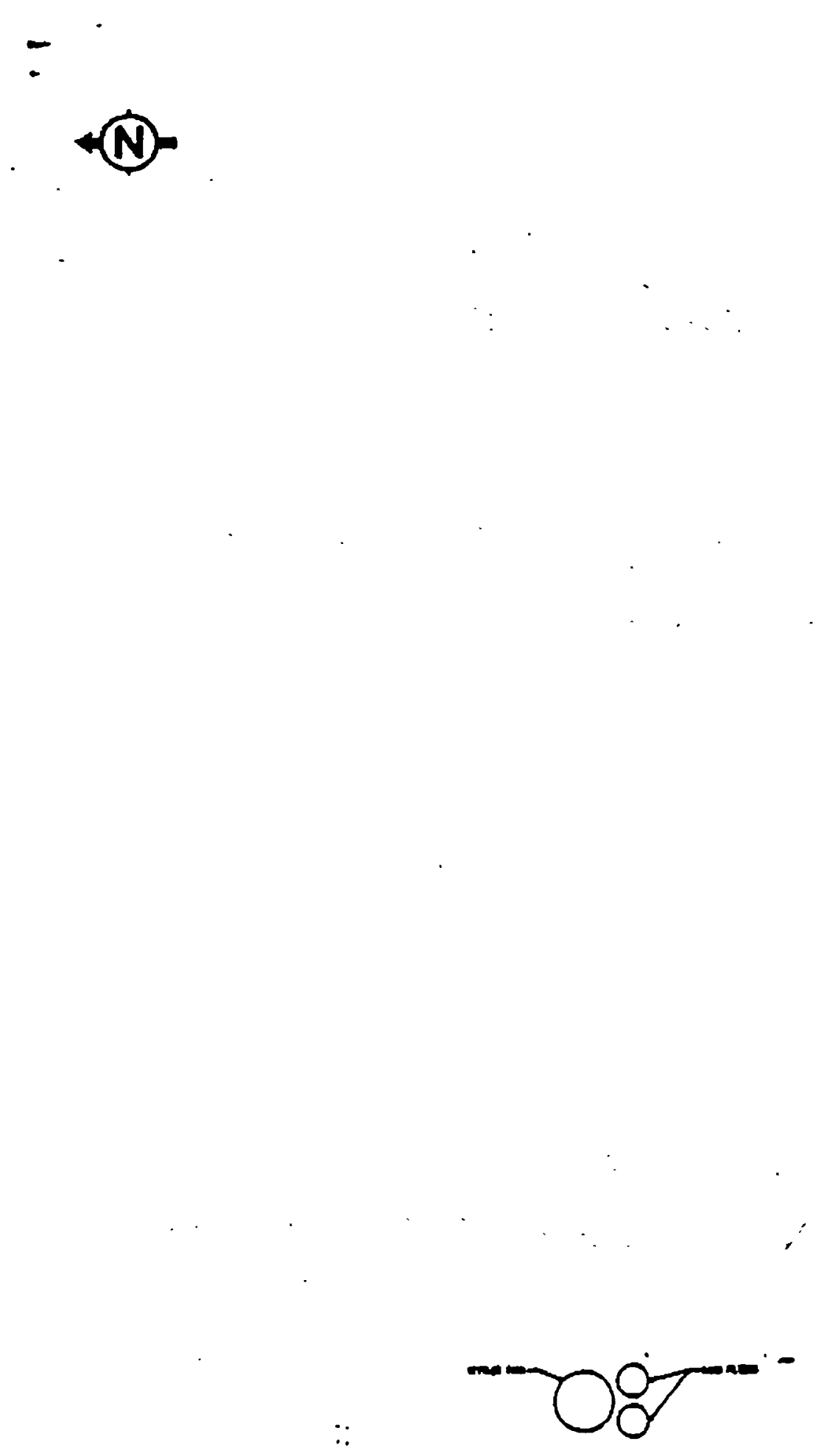

Figure 2-2

Major K-Area Layout in Relation to Disassembly Area 
WSRC-TR-94-207 - DV

Revision 0
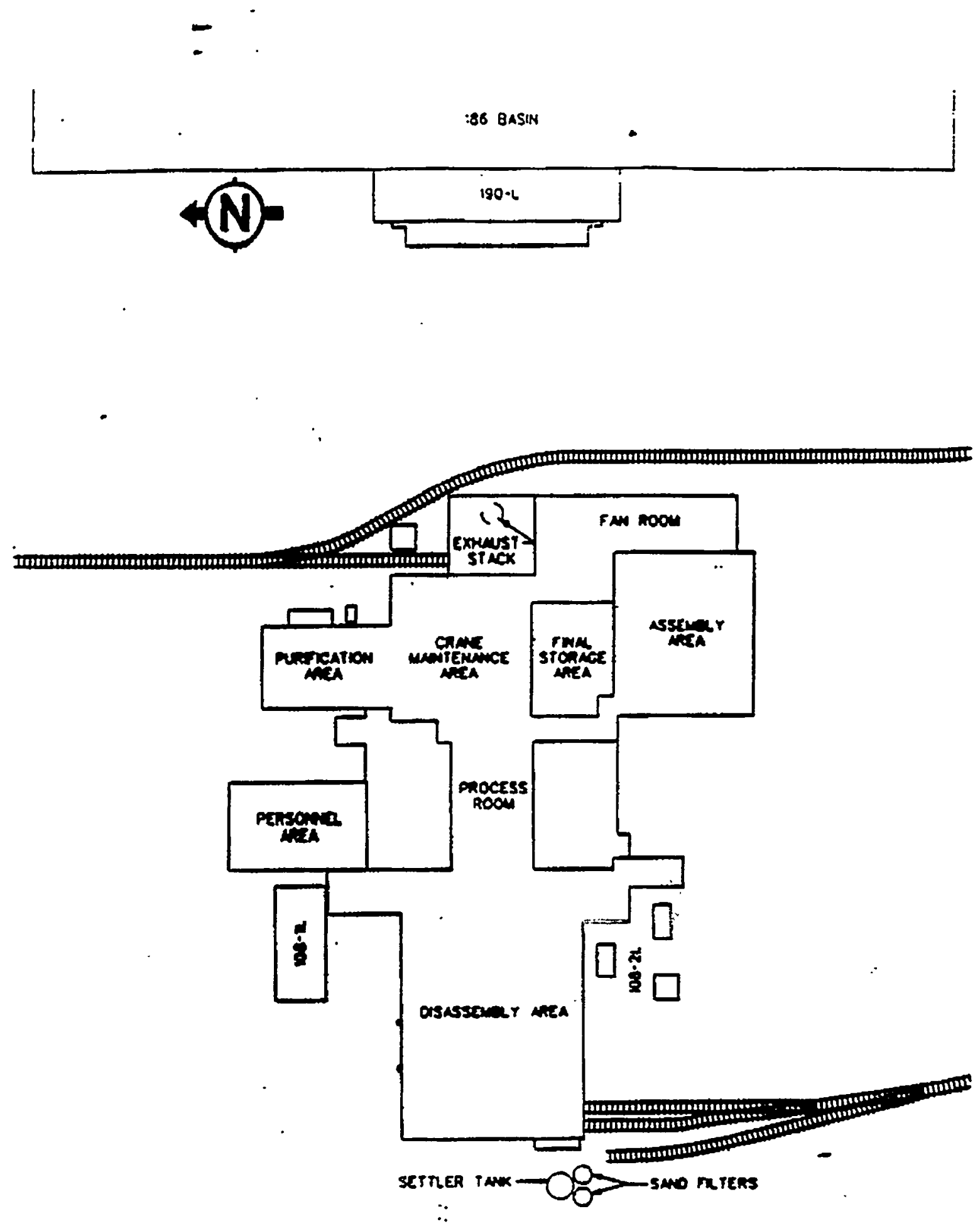

Figure 2.3

General Layout of Building 10S-L 


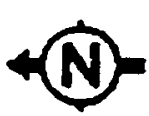



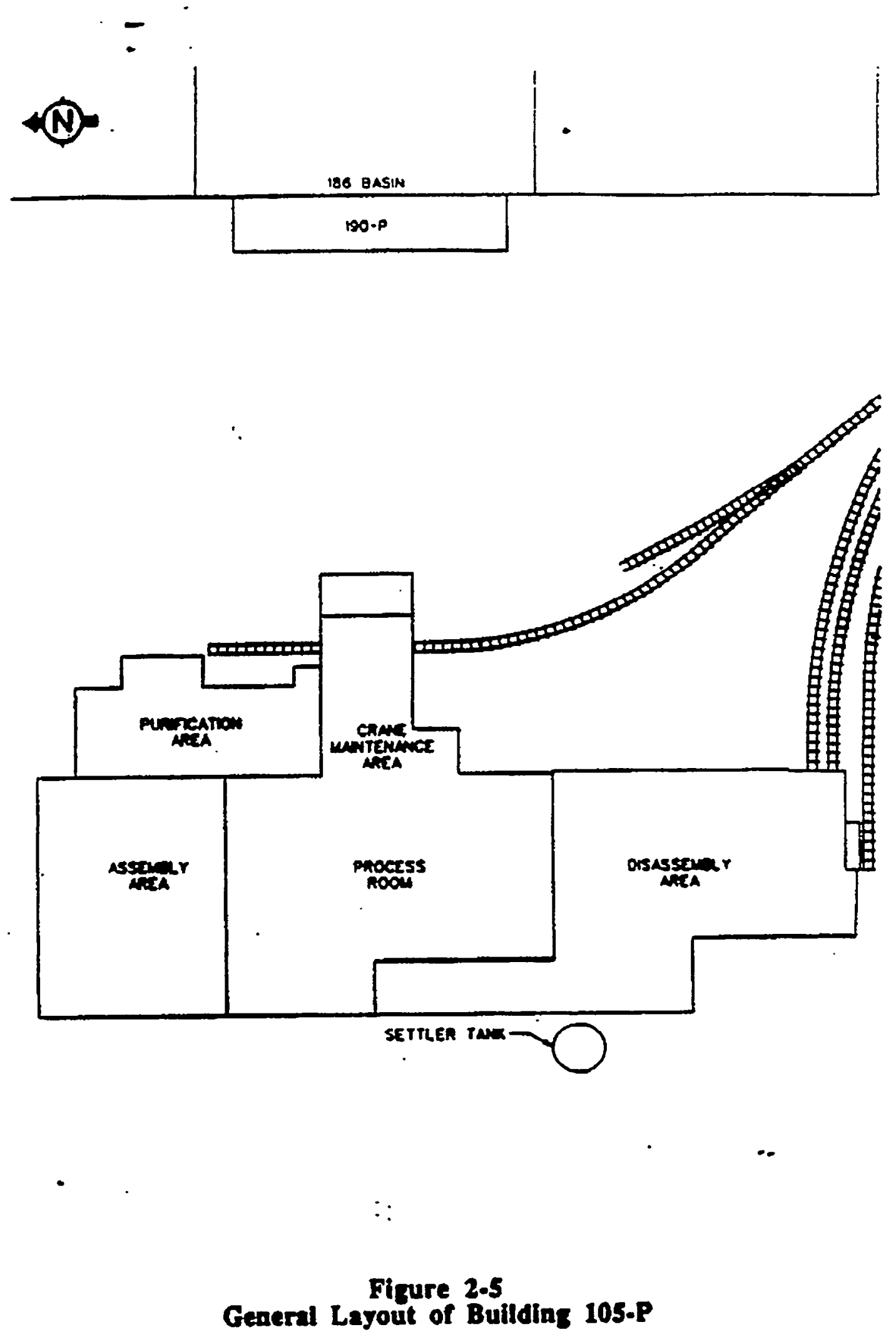

UNCLASSTFIED CONTROLLED NUCLEAR INFORMATION 


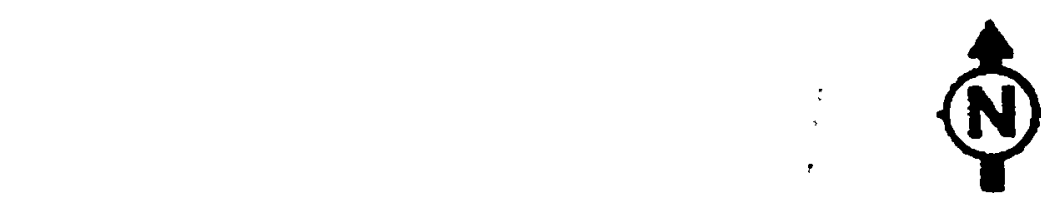

Figure 2.6

Major P-Area Layout in Relation to Disasuembly Area

UNCLASSIFIED CONTROLLED NUCLEAR INFORMATION 

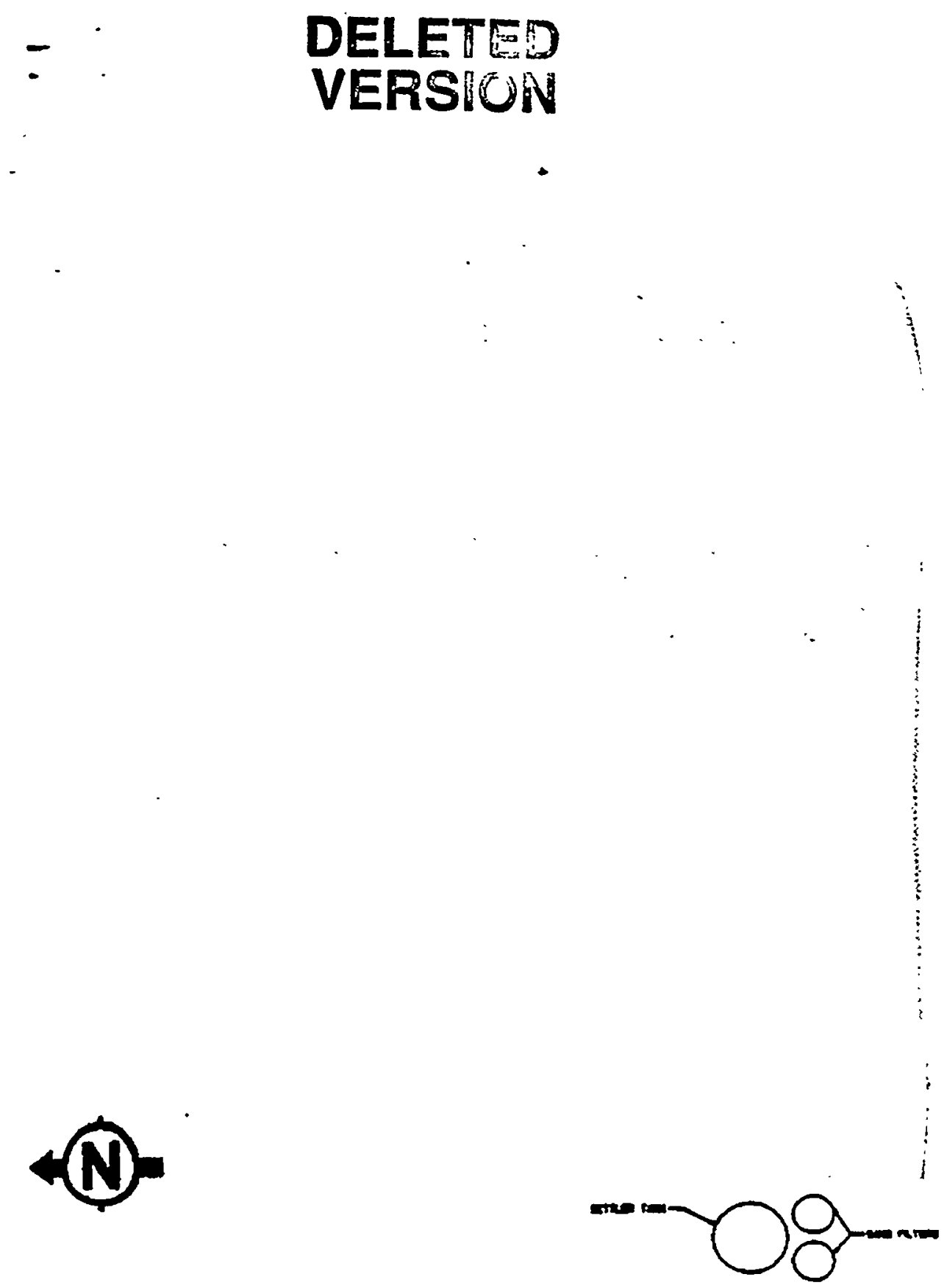

$\because$

Fizure $2-7$

Disasembly Area - Bullding 105.K 
$-$

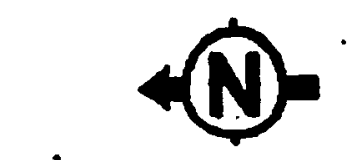

$\because$

Figure 2-8

Disassembly Area - Buildins 105-L 


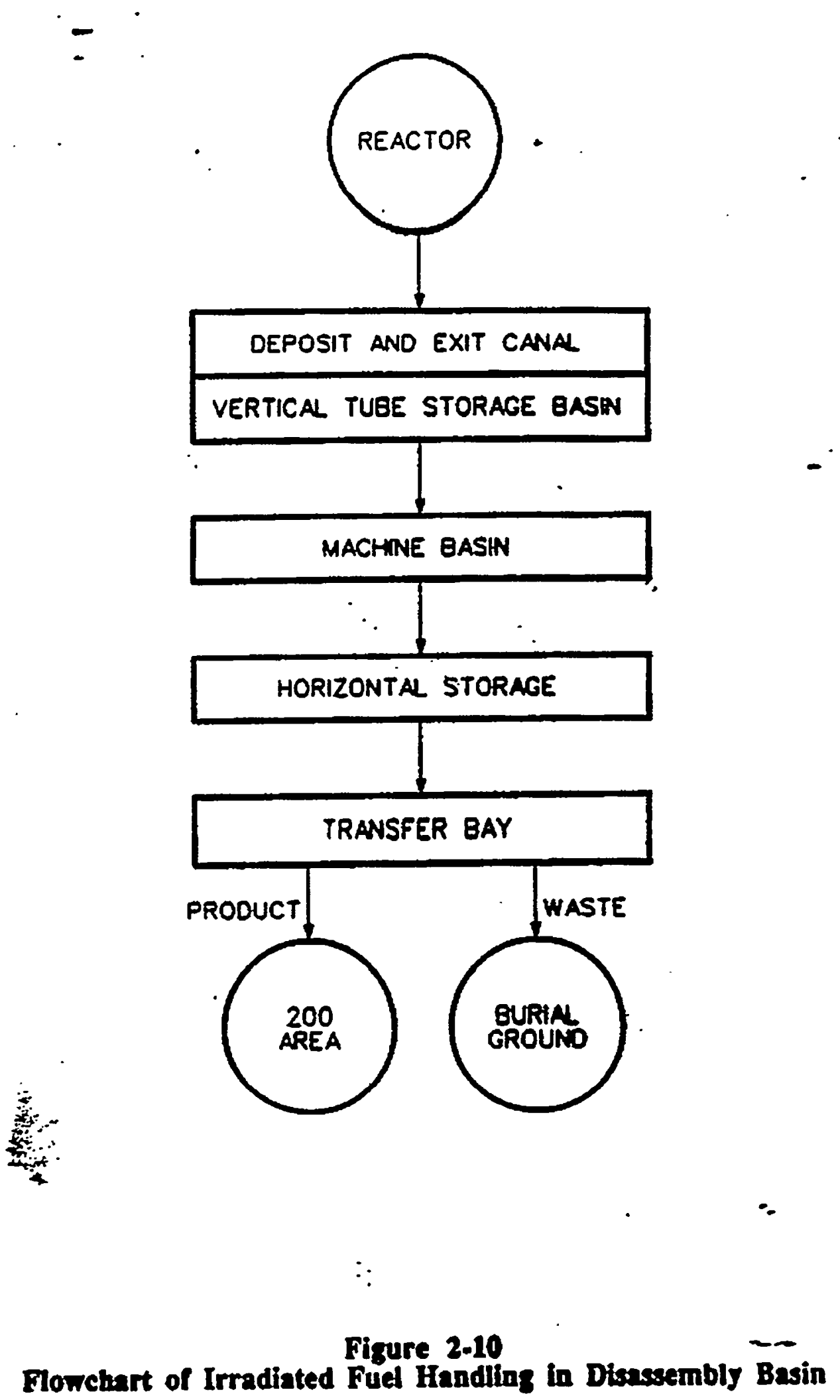




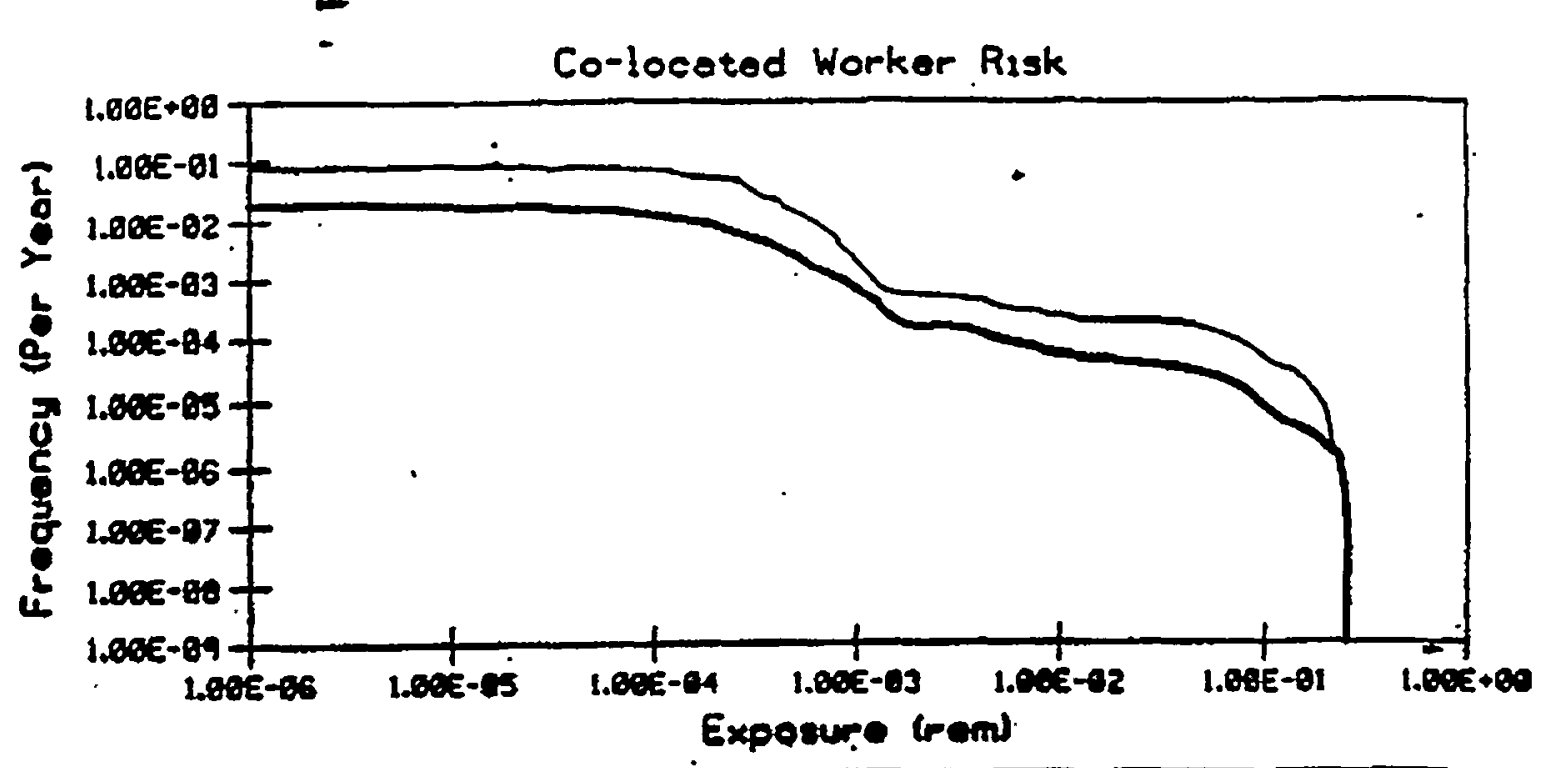

\section{Mean Risk - $95 \%$ Confidence}

Figure 8.4-1. Co-Locind Woiter Rith

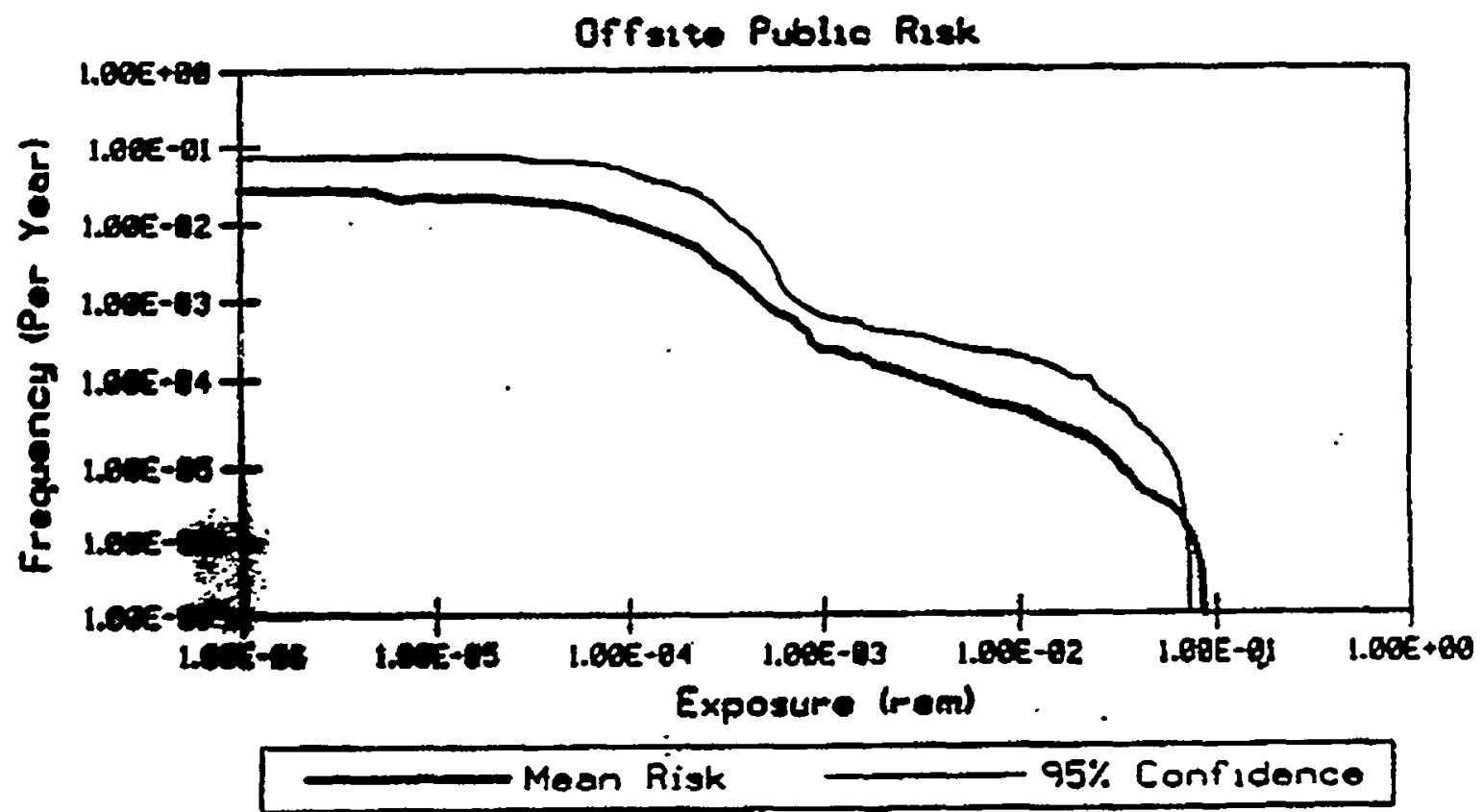

Figure 8.4-2. Offsite Public Risk

UNCLASSIFED CONTROLLED NUCLEAR INFORMATION 


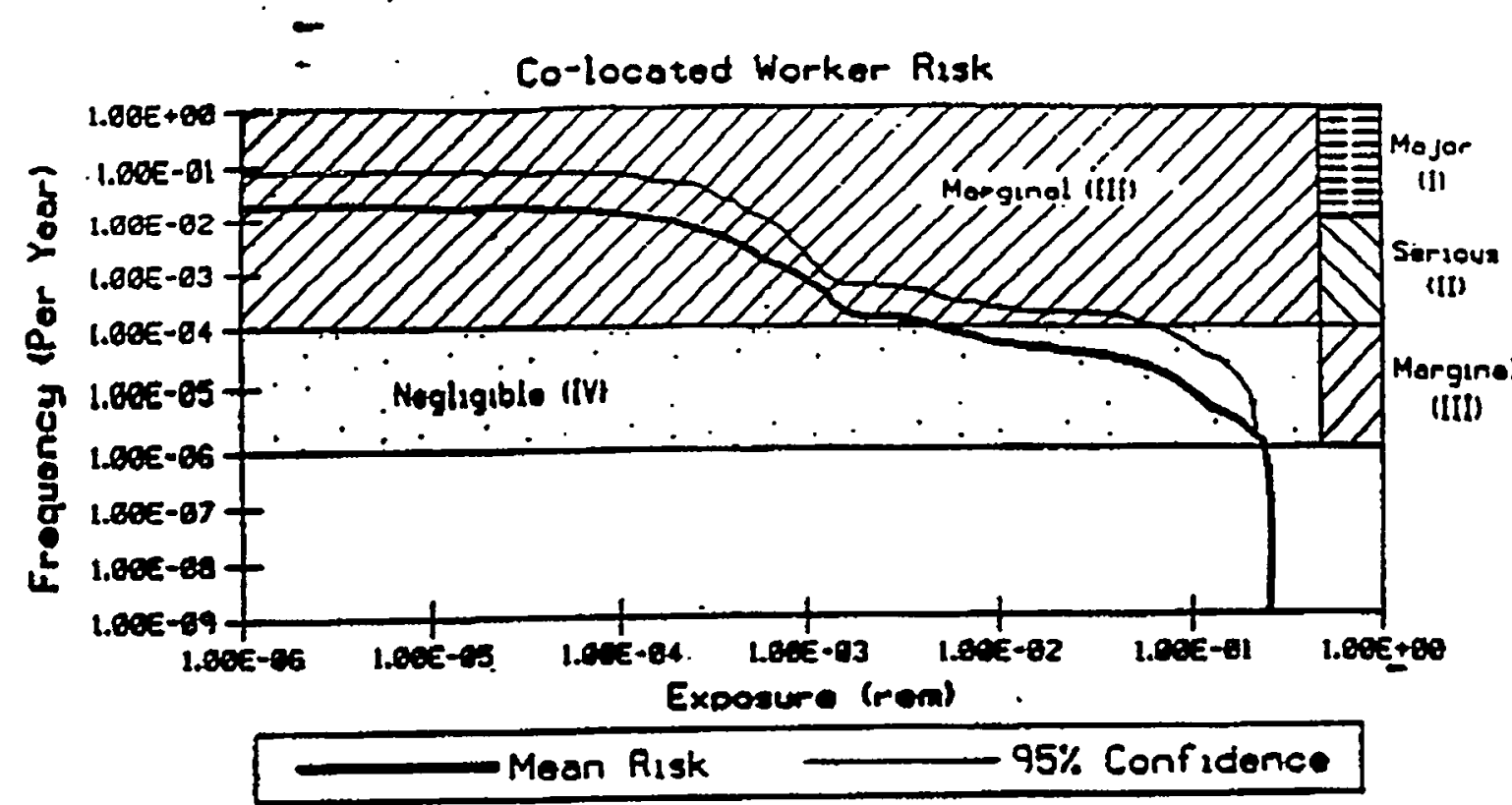

Figure 8.4-3. Co-Locmed Watker Riste with Consequence Definitions Diplayed

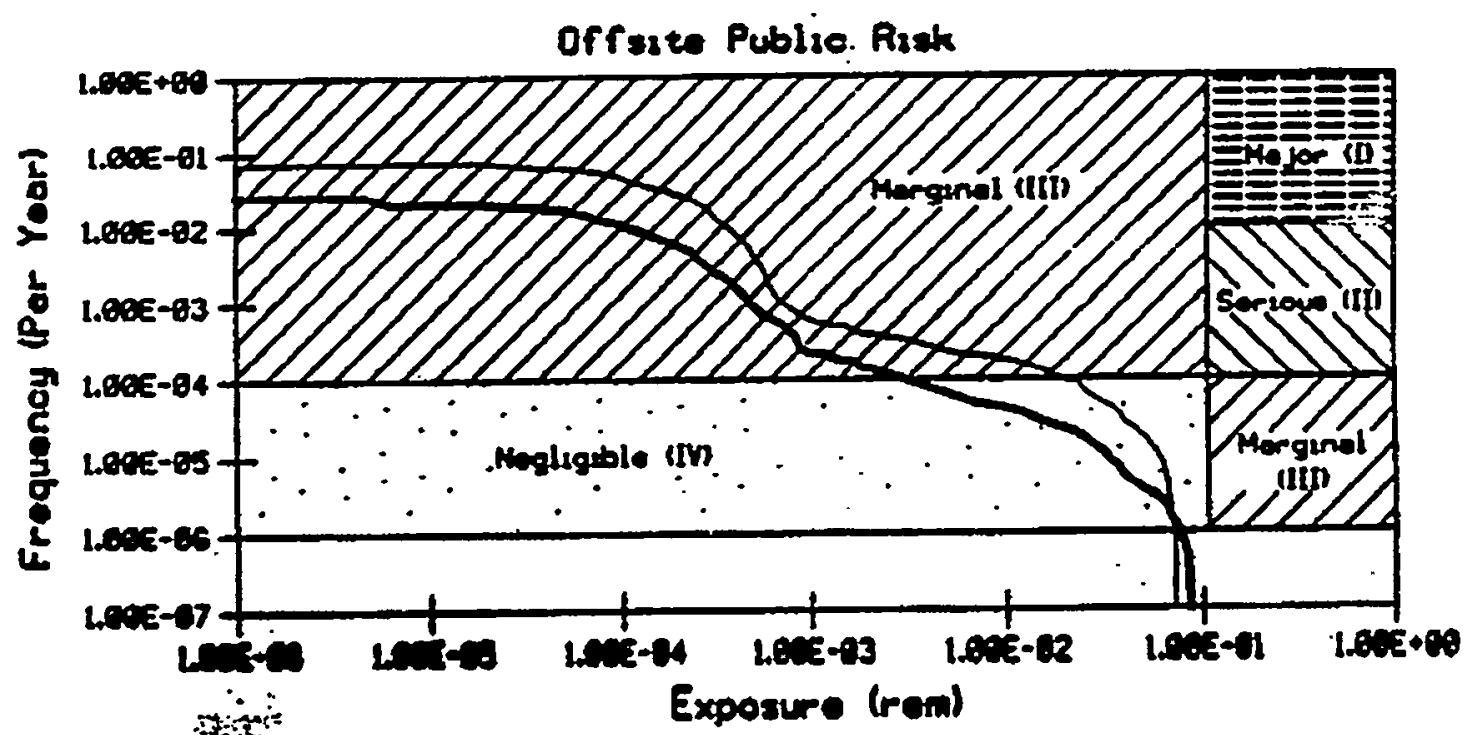
is:

Mean Risk

$95 \%$ Conf idence

\begin{tabular}{|c|c|c|}
\hline $\begin{array}{l}\text { Conseourenee } \\
\text { High } \\
\text { Modium } \\
\text { Low }\end{array}$ & $\begin{array}{c}\text { Public } \\
>5 \text { rem } \\
55 \times 88.1 \mathrm{rem} \\
\text { SMedium }\end{array}$ & $\begin{array}{c}\text { Co-Locoted Worker } \\
>25 \text { rom } \\
255 \times<0.5 \mathrm{rem} \\
\text { <Medium }\end{array}$ \\
\hline
\end{tabular}

Figure 8.4-4. Offsite Public Risk with Consequence Definitions Displayed 
Transmittal No.

\begin{tabular}{|c|c|c|c|}
\hline \multicolumn{4}{|c|}{ PenA-Trinsondte } \\
\hline To Document and Records Administration & $\begin{array}{l}\text { Location } \\
773-524\end{array}$ & Dain & 175 \\
\hline From Sohn Soares & $\begin{array}{l}\text { Location } \\
707-\mathrm{C}\end{array}$ & Reat Engor Eng. & Phone \\
\hline
\end{tabular}

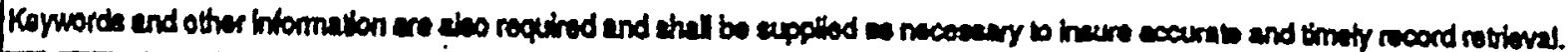

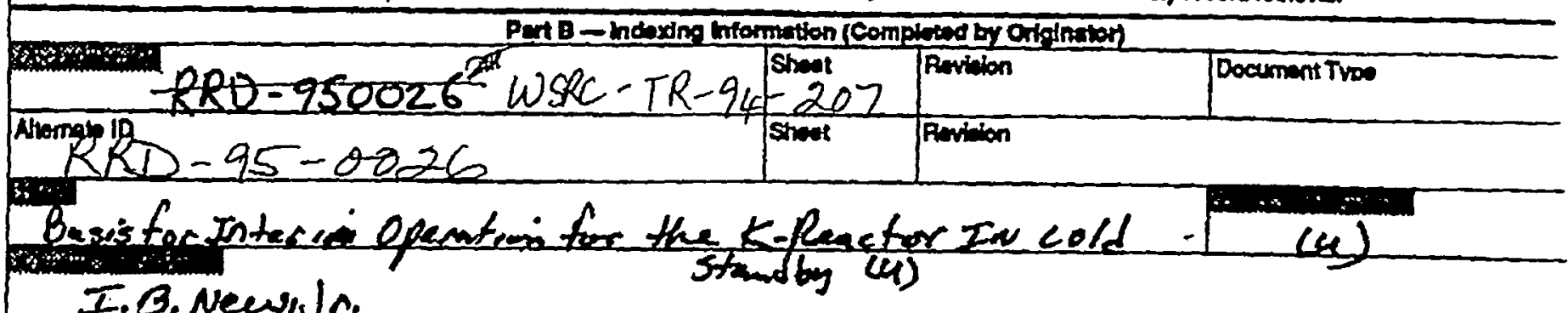

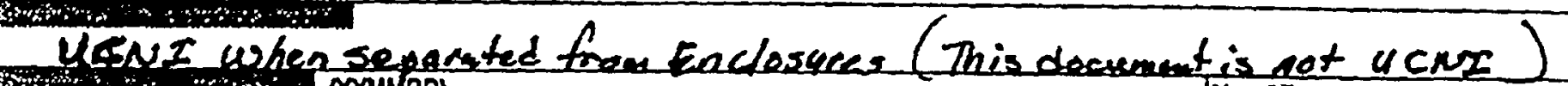

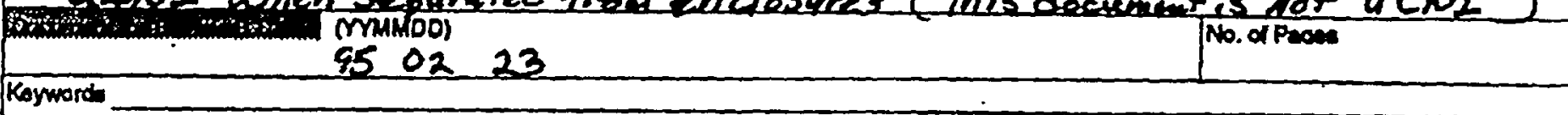

\begin{tabular}{|c|c|c|c|}
\hline Supanodes & Sheet & Fucioion & Sur-DTD \\
\hline Prokrinces Document & Stront & Rinilian & Sux-DTo \\
\hline
\end{tabular}

Sratem

Punctiane Order Akmber

Building

Froioct Number

Exration

Ares

Destan Function

Prolact Fin Nurriber

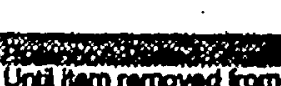

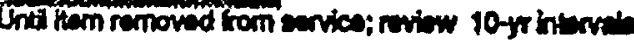

Camoory

Dreion Ares

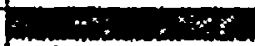

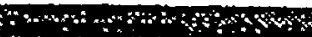

Panc-For Dera Use only

Procord Location

Transmitted By

Procalved By

Vorifiad By

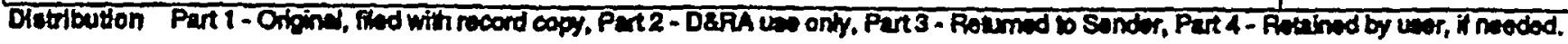

